Distribuição de carga flexível e dinâmica para provedores de web services

\author{
Jonathan de Matos
}



Data de Depósito:

Assinatura:

\title{
Distribuição de carga flexível e dinâmica para provedores de web services
}

\author{
Jonathan de Matos \\ Orientador: Prof. Dr. Paulo Sérgio Lopes de Souza \\ Dissertação apresentada ao Instituto de Ciências Matemáticas e \\ de Computação - ICMC-USP, como parte dos requisitos para \\ obtenção do título de Mestre em Ciências - Ciências de \\ Computação e Matemática Computacional.
}

USP - São Carlos

Março/2009 



\section{Agradecimentos}

Aos meus pais Alcir e Terezinha por todo apoio durante a minha vida e principalmente nos momentos difíceis durante o mestrado, me incentivando sempre. A sua preocupação com meus estudos e bem estar demandou muito da vida e trabalho de ambos, a quem serei eternamente grato. Espero um dia ser pelo menos metade do que ambos são.

À minha esposa Nésly, que suportou toda a distância e me apoiou durante o mestrado, compreendendo as minhas ausências e me alegrando sempre com suas palavras e atos.

Ao meu orientador, Prof. Paulo Sérgio e sua esposa, Prof. Simone, que representaram para mim segundos pais nos momentos em que estive longe da minha família, contribuindo muito para minha formação pessoal. Agradeço também pela formação técnica provida pelo Prof. Paulo, enriquecendo-me muito com seus conhecimentos e experiências.

Aos companheiros de república, Bruno e Thiago, pelo companheirismo, conversas e boas experiências vividas juntos.

Aos amigos de laboratório Júlio e Maycon pela convivência, conselhos e conversas.

Ao CNPq e FAPESP pelo apoio financeiro. 



\section{Sumário}

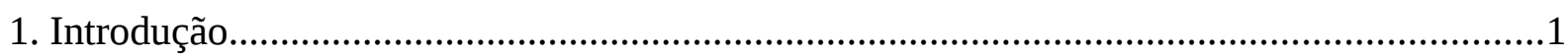

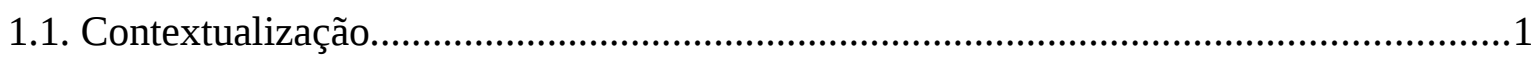

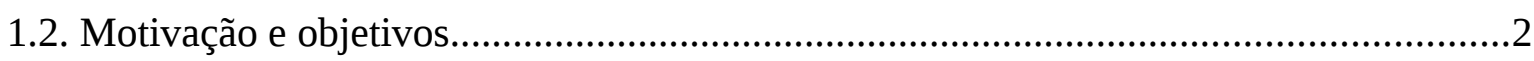

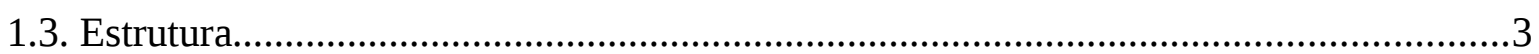

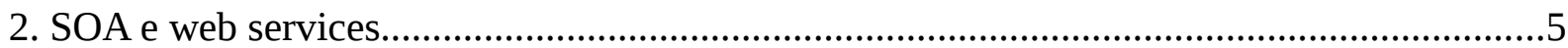

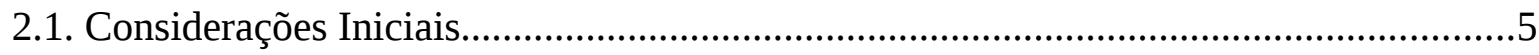

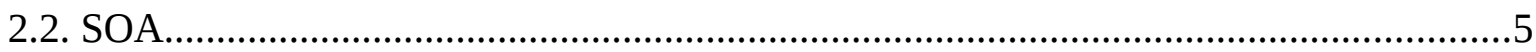

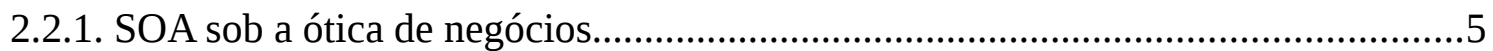

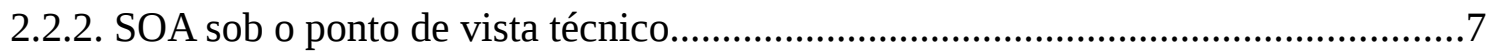

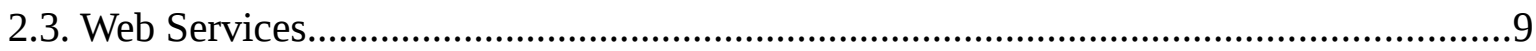

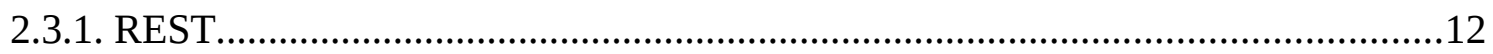

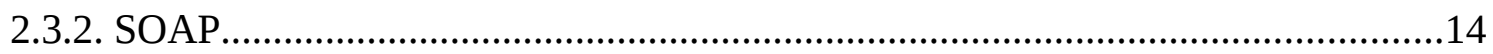

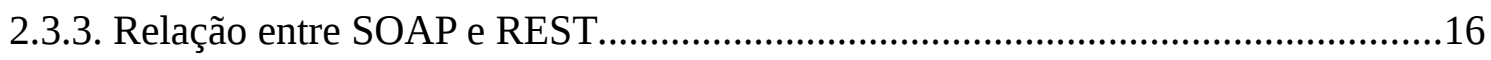

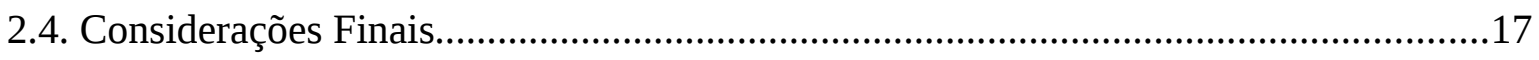

3. Suporte computacional para web services................................................................19

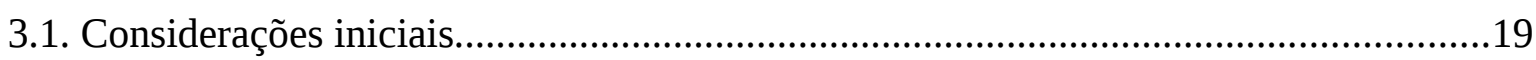

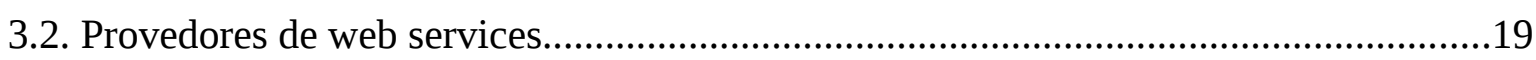

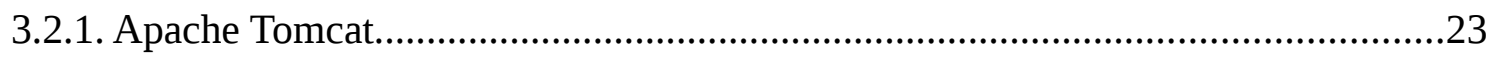

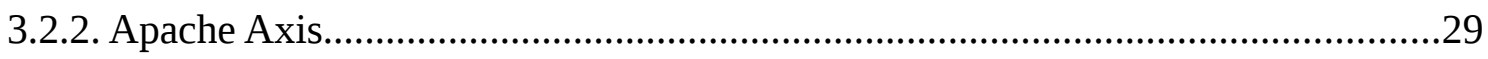

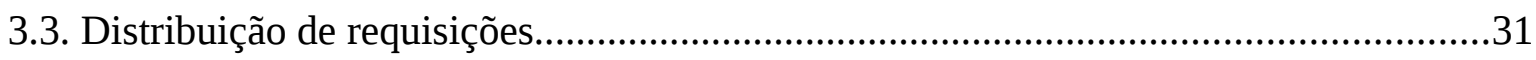

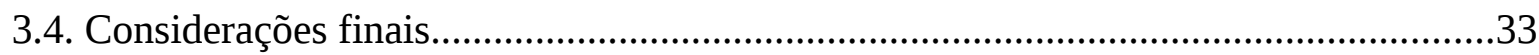

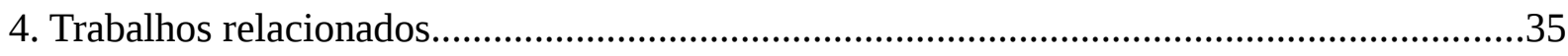

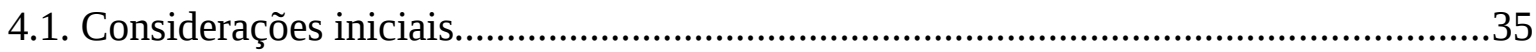

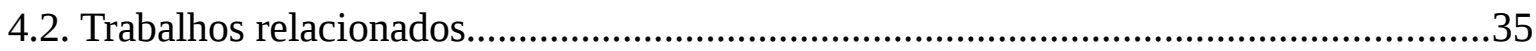

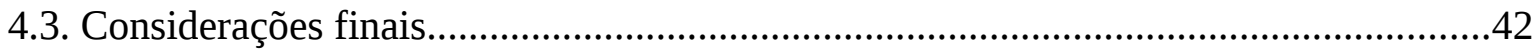

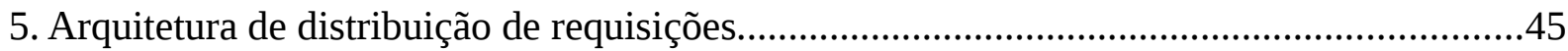

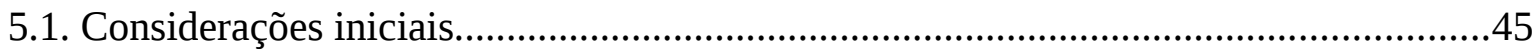





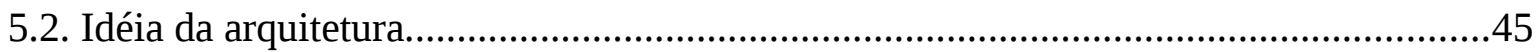

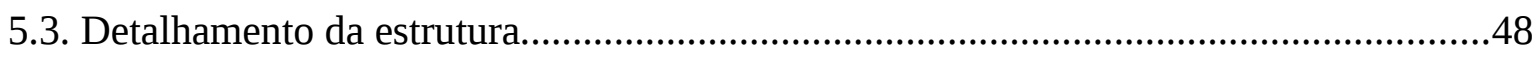

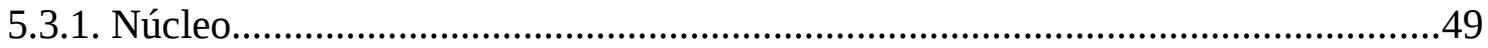

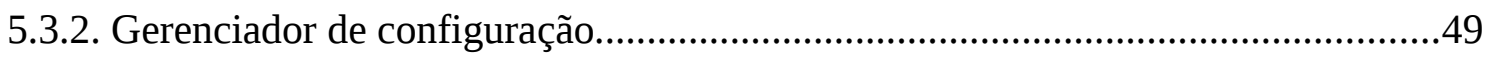

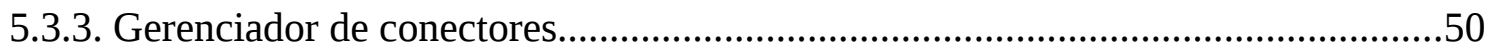

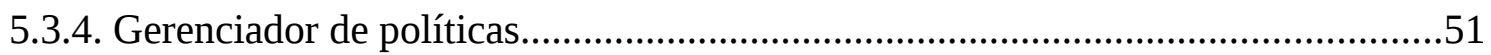

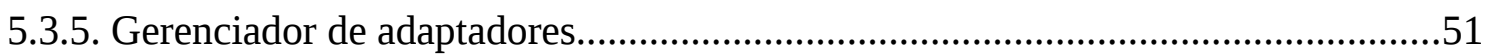

5.4. Implementação do protótipo....................................................................................52

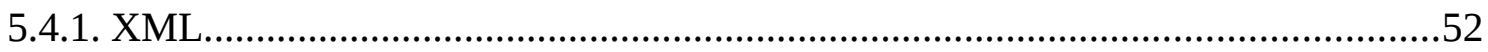

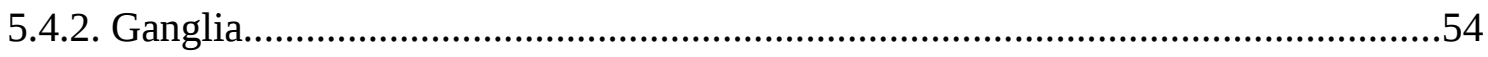

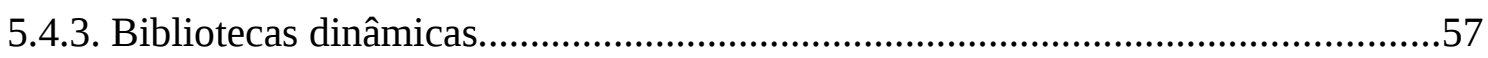

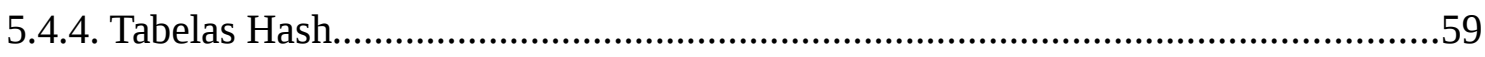

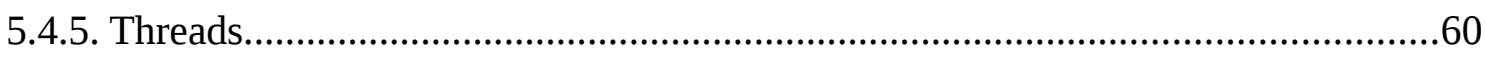

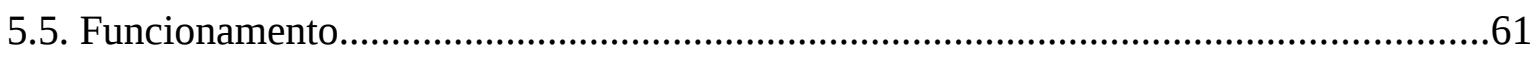

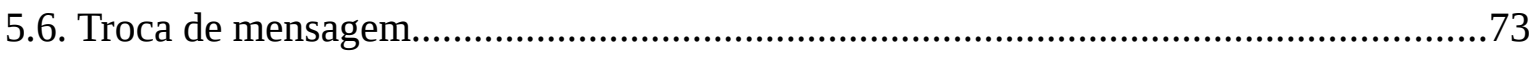

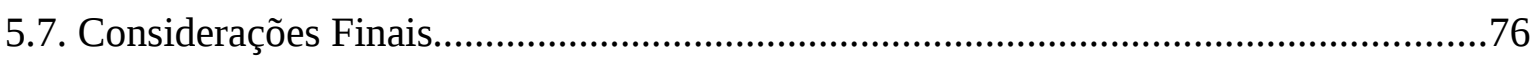

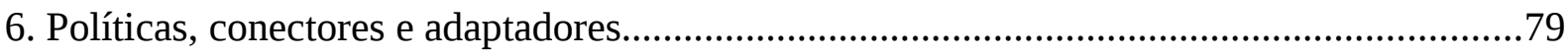

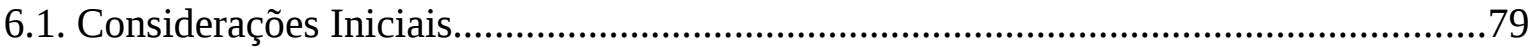

6.2.Desenvolvimento de políticas, monitores e conectores.................................................79

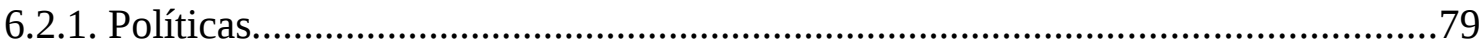

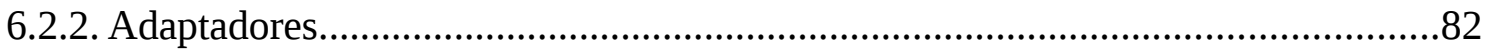

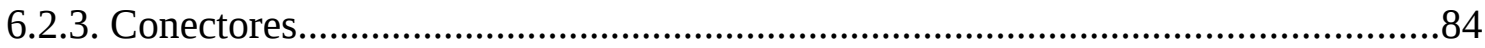

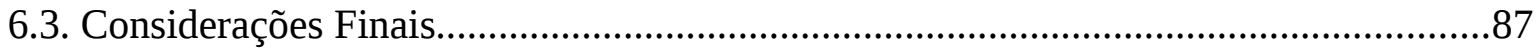

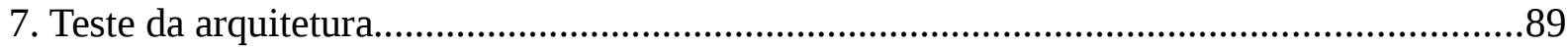

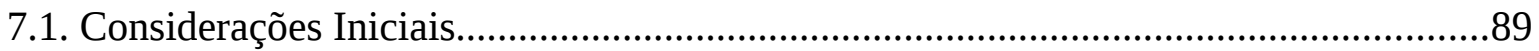

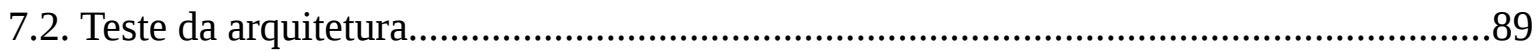

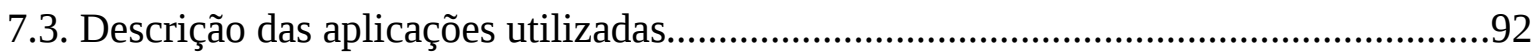

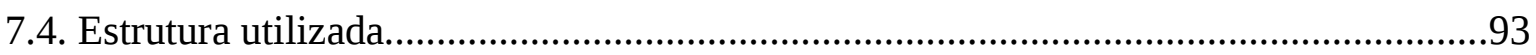

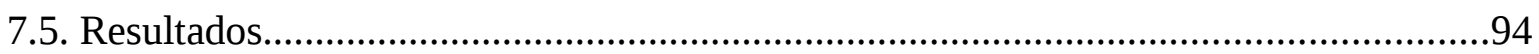

7.5.1. Teste utilizando serviço baseado em operação financeira....................................94

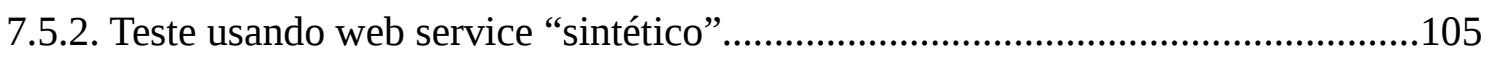

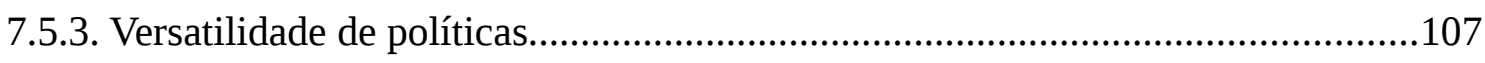

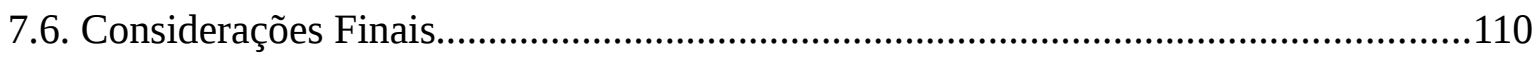





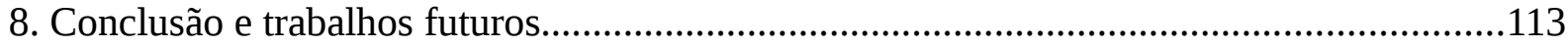

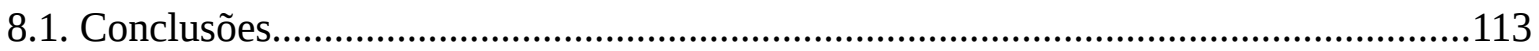

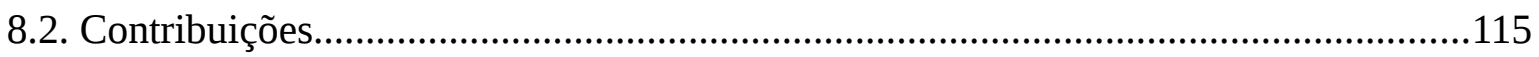

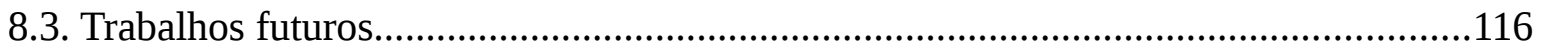

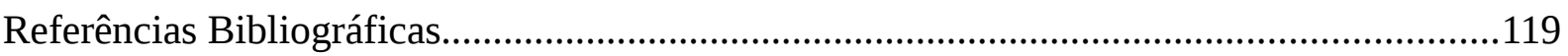

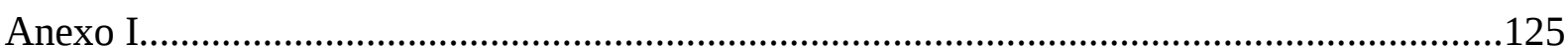

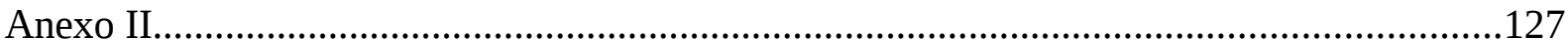

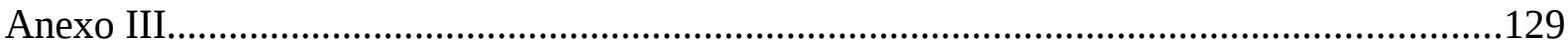

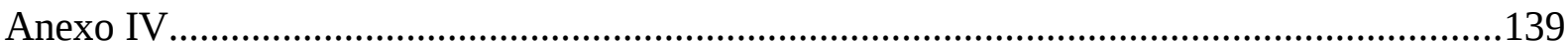





\section{Lista de Figuras}

Fig. 2.1: Composição de serviços.

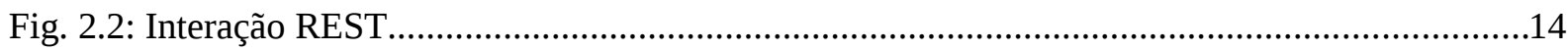

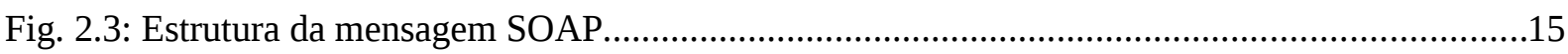

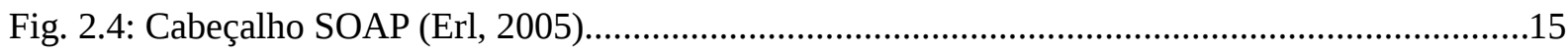

Fig. 2.5: Corpo da mensagem SOAP..............................................................................................

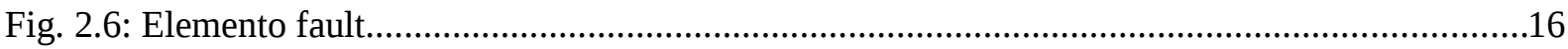

Fig. 3.1: Estrutura do Apache Tomcat (Moodie, 2008).........................................................................25

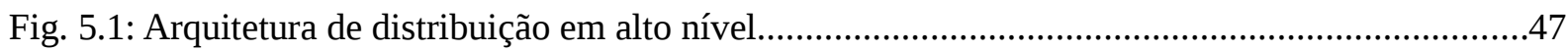

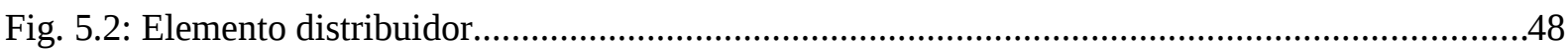

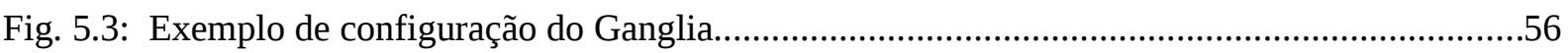

Fig. 5.4: Estruturas de dados presentes no protótipo.................................................................................62

Fig. 5.5: Declarações de tipos de dados do modelo...............................................................................66

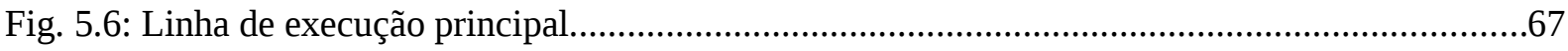

Fig. 5.7: Modelo do Gerenciador de Configuração (GC)........................................................................68

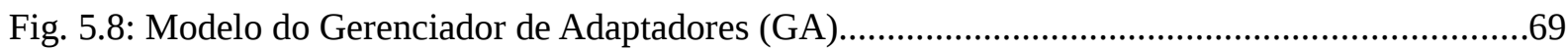

Fig. 5.9: Modelo do Gerenciador de Políticas (GP)................................................................................70

Fig. 5.10: Modelo do Gerenciador de Conectores (GCn).....................................................................71

Fig. 5.11: Modelo do Gerenciador de Webservices (GW) ....................................................................72

Fig. 6.1: Exemplos de uso da função ObterMetricas()..........................................................................81

Fig. 6.2: Estrutura de passagem de parâmetros.........................................................................................

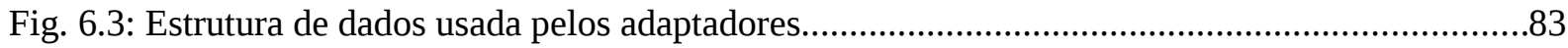

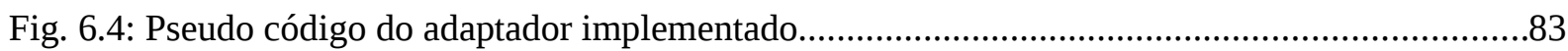

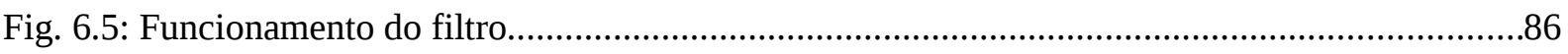

Fig. 7.1: Estrutura usando mod_jk(a) e a arquitetura proposta(b)....................................................90

Fig. 7.2: Configuração homogênea (a) e heterogênea (b).....................................................................93

Fig. 7.3: RR (distribuidor) x RR (mod_jk)(3 clientes - homogêneo)...................................................98

Fig. 7.4: MME (distribuidor) x busy (mod_jk)(3 clientes - homogêneo).............................................100

Fig. 7.5: RR (distribuidor) x RR (mod_jk) (2 clientes - heterogêneo)................................................101

Fig. 7.6: RR (distribuidor) x RR (mod_jk) (3 clientes - heterogêneo)...............................................101 

Fig. 7.7: MME (distribuidor) x busy (mod_jk)(3 clientes - heterogêneo)...........................................103

Fig. 7.8: RR ponderada (distribuidor) x RR ponderada (mod_jk)(3 clientes - heterogêneo)...............104

Fig. 7.9: Tempo de resposta de requisições com gerenciamento de energia.........................................108

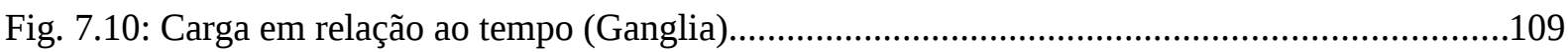

Fig. 7.11: Comparação 1 nó x 2 nós com gerenciamento de energia.....................................................109

Fig. A1.1: Modelo em RdPC detalhado sem hierarquia do protótipo...................................................125

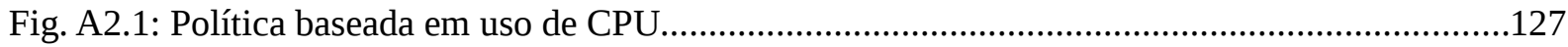

Fig. A4.1: RR (distribuidor) x RR (mod_jk) (1 cliente - homogêneo)................................................139

Fig. A4. 2: RR (distribuidor) x RR (mod_jk) (2 clientes - homogêneo)...............................................140

Fig. A4.3: RR (distribuidor) x RR (mod_jk) (3 clientes - homogêneo)..............................................140

Fig. A4.4: MME (distribuidor) x busy (mod_jk) (1 cliente - homogêneo)...........................................141

Fig. A4.5: MME (distribuidor) x busy (mod_jk) (2 clientes - homogêneo)..........................................141

Fig. A4.6: MME (distribuidor) x busy (mod_jk) (3 clientes - homogêneo).........................................142

Fig. A4.7: RR (distribuidor) x RR (mod_jk) (1 cliente - heterogêneo)..............................................142

Fig. A4.8: RR (distribuidor) x RR (mod_jk) (2 clientes - heterogêneo)..............................................143

Fig. A4.9: RR (distribuidor) x RR (mod_jk) (3 clientes - heterogêneo).............................................143

Fig. A4.10: MME (distribuidor) x busy (mod_jk) (1 cliente - heterogêneo).......................................144

Fig. A4.11: MME (distribuidor) x busy (mod_jk) (2 clientes - heterogêneo).......................................144

Fig. A4.12: MME (distribuidor) x busy (mod_jk) (3 clientes - heterogêneo).......................................145

Fig. A4.13: RR ponderada (distribuidor) x RR ponderada (mod_jk) (1 cliente - heterogêneo)...........145

Fig. A4.14: RR ponderada (distribuidor) x RR ponderada (mod_jk) (2 clientes - heterogêneo).........146

Fig. A4.15: RR ponderada (distribuidor) x RR ponderada (mod_jk) (3 clientes - heterogêneo).........146 



\section{Lista de Tabelas}

Tab. 7.1: Valores - RR (distribuidor) e RR (mod_jk)(3 clientes - homogêneo). .99

Tab. 7.2: Valores - MME (distribuidor) x busy (mod_jk)(3 clientes - homogêneo). .99

Tab. 7.3: Valores - RR (distribuidor) x RR (mod_jk) (2 clientes - heterogêneo). 100

Tab. 7.4: Valores - RR (distribuidor) x RR (mod_jk) (3 clientes - heterogêneo) 102

Tab. 7.5: Valores - MME (distribuidor) x busy (mod_jk)(3 clientes - heterogêneo). 103

Tab. 7.6: Valores - RR pond. (distribuidor) x RR pond. (mod_jk)(3 clientes - heterogêneo)...... .104

Tab. 7.7: Valores - MME (distribuidor) e RR (distribuidor)(3 clientes e heterogêneo)... 105

Tab. 7.8: Resultados dos testes com a aplicação sintética na estrutura homogênea. 106

Tab. 7.9: Hipóteses para a comparação entre mod_jk e distribuidor (aplicação sintética)..... 106

Tab. 7.10: Resultado do teste de hipótese para a aplicação sintética. 106

Tab. A3.1: Comparação - MME(distribuidor) x busy(mod_jk)(1cliente - homogêneo) 130

Tab. A3.2: Comparação - MME(distribuidor) x busy(mod_jk)(2 clientes - homogêneo)...... 130

Tab. A3.3: Comparação - MME(distribuidor) x busy(mod_jk)(3 clientes - homogêneo). .131

Tab. A3.4: Comparação - RR(distribuidor) x RR(mod_jk)(1 cliente - homogêneo). 131

Tab. A3.5: Comparação - RR(distribuidor) x RR(mod_jk)(2 clientes - homogêneo) 132

Tab. A3.6: Comparação - RR(distribuidor) x RR(mod_jk)(3 clientes - homogêneo) 132

Tab. A3.7: Comparação - RR(distribuidor) x RR(mod_jk)(1 clientes - heterogêneo). 133

Tab. A3.8: Comparação - RR(distribuidor) x RR(mod_jk)(2 clientes - heterogêneo). 133

Tab. A3.9: Comparação - RR(distribuidor) x RR(mod_jk)(3 clientes - heterogêneo). .134

Tab. A3.10: Comparação - MME(distribuidor) x busy(mod_jk) (1 cliente - heterogêneo). .134

Tab. A3.11: Comparação - MME(distribuidor) x busy(mod_jk) (2 clientes - heterogêneo). 135

Tab. A3.12: Comparação - MME(distribuidor) x busy(mod_jk) (3 clientes - heterogêneo). 135

Tab. A3.13: Comparação - RR pond.(distribuidor) x RR pond.(mod_jk) (1 cliente - heterogêneo)....136 Tab. A3.14: Comparação - RR pond. (distribuidor) x RR pond.(mod_jk) (2 clientes - heterogêneo). 136 Tab. A3.15: Comparação - RR pond.(distribuidor) x RR pond.(mod_jk)(3 clientes - heterogêneo)...137 Tab. A3.16: Comparação - MME(distribuidor) x RR(distribuidor)(3 clientes - heterogêneo). 137 



\section{Lista de Símbolos}

\begin{tabular}{|c|c|}
\hline AJP & Apache JServ Protocol \\
\hline API & Application Programming Interface \\
\hline ASF & Apache Software Foundation \\
\hline AXIOM & Axis Object Model \\
\hline CGI & Common Gateway Interface \\
\hline CMI & Clustered Method Invocation \\
\hline CORBA & Common Object Request Broker Architecture \\
\hline CPU & Central Processing Unit \\
\hline DCOM & Distributed Component Object Model \\
\hline DNS & Domain Naming System \\
\hline DTD & Document Type Definition \\
\hline EJB & Enterprise Java Beans \\
\hline EPA & Environment Protection Agency \\
\hline$E S B$ & Enterprise Service Bus \\
\hline FTP & File Transfer Protocol \\
\hline GA & Gerenciador de Adaptadores \\
\hline GC & Gerenciador de Configuração \\
\hline$G C n$ & Gerenciador de Conectores \\
\hline GNOME & GNU Object Model Environment \\
\hline GP & Gerenciador de Políticas \\
\hline GTK & Gimp Tool Kit \\
\hline$G W$ & Gerenciador de Web Services \\
\hline HTML & HyperText Markup Language \\
\hline НTTP & HyperText Transfer Protocol \\
\hline IIOP & Internet Inter-Orb Protocol \\
\hline IIS & Internet Information Services \\
\hline IP & Internet Protocol \\
\hline ISO & International Organization for Standardization \\
\hline$J 2 S E$ & Java 2 Standard Edition \\
\hline$J M S$ & Java Message Service \\
\hline$J M X$ & Java Management Extensions \\
\hline
\end{tabular}





\begin{tabular}{|c|c|}
\hline JNDI & Java Naming and Directory Interface \\
\hline$J S P$ & Java Server Pages \\
\hline$J V M$ & Java Virtual Machine \\
\hline$L A N$ & Local Area Network \\
\hline MME & Média Móvel Exponencial \\
\hline MVC & Model-View-Controller \\
\hline NAT & Network Address Translation \\
\hline NTP & Networ Time Protocol \\
\hline OASIS & Organization for the Advancement of Structured Information Standards \\
\hline OSI & Open Systems Interconnection \\
\hline PHP & PHP Hypertext Preprocessor \\
\hline QoS & Quality of Service \\
\hline$R A M$ & Random Access Memory \\
\hline$R d P$ & Redes de Petri \\
\hline RdPC & Redes de Petri Coloridas \\
\hline REST & Representational State Transfer \\
\hline $\boldsymbol{R M I}$ & Remote Method Invocation \\
\hline$R R D$ & Round Robin Database \\
\hline SMTP & Simple Mail Transfer Protocol \\
\hline SOA & Service Oriented Architecture \\
\hline SOAP & Simple Object Access Protocol \\
\hline$S S L$ & Secure Socket Layer \\
\hline StAX & Streaming API for XML \\
\hline TCP & Transmission Control Protocol \\
\hline TI & Tecnologia da Informação \\
\hline UDP & User Datagram Protocol \\
\hline URI & Uniform Resource Identifier \\
\hline$U R L$ & Uniform Resource Locator \\
\hline$W A N$ & Wide Area Network \\
\hline WSDL & Web Service Descrition Language \\
\hline$X D R$ & External Data Representation \\
\hline XHTML & Extensible HyperText Markup Language \\
\hline$X M L$ & Extensible Markup Language \\
\hline XMPP & Extensible Messaging and Presence Protocol \\
\hline
\end{tabular}





\section{Resumo}

A SOA está se tornando uma abordagem difundida no desenvolvimento de sistemas. Em sistemas maiores onde se utiliza SOA pode ocorrer problemas de alta demanda, que podem ser resolvidos com arquiteturas distribuídas como clusters. Esta dissertação apresenta a proposta de uma nova arquitetura para distribuição de requisições em clusters de web services. A arquitetura proposta tem foco na distribuição flexível de requisições, possibilitando o emprego de políticas diversificadas, estas voltadas a diferentes objetivos, aplicações e plataformas. A arquitetura também propõe trabalhar de forma dinâmica, possibilitando decisões baseadas na coleta de estado dos elementos que compõem a estrutura de atendimento. A transparência, do ponto de vista do cliente, também é tratada na arquitetura. Os testes da arquitetura foram realizados através de um protótipo que a implementa. O protótipo instancia os objetivos propostos na arquitetura, apresentando ganhos de desempenho em relação à solução existente atualmente. A flexibilidade das políticas de distribuição é destacada através da construção de uma política, cujo objetivo é melhorar a eficiência no consumo de energia de clusters. Dentre as contribuições do trabalho está a criação de uma nova arquitetura de software que atua como facilitadora para a criação de políticas de distribuição de requisições mais eficiente para web services. 



\begin{abstract}
SOA is becoming a widespread approach to develop systems. High demand problems may appear in huge systems where SOA and web services are used. This problems can be solved by means of distributed architectures like clusters. This work presents the proposal of a new architecture for request distribution in web service clusters. The proposed architecture provides flexible request distribution. It allows the use of several policies, these related to different objectives, applications and platforms. The architecture's dynamic feature enables decisions based on states of the cluster's elements, in a transparent way, under clients' point of view. The architecture was tested using a prototype that implements the proposed ideas in this work. The objectives of the proposal were reached by the prototype and still shown performance improving in many cases, when comparing to an existing solution. The use of a novel policy, related to energetic efficiency for clusters, is also shown on the experiments related to flexibility. Among architecture's contributions is a novel software architecture that acts as a facility to create and to test more efficient web services policies.
\end{abstract}





\section{Capítulo 1}

\section{Introdução}

\subsection{Contextualização}

Nos últimos anos o setor de tecnologia da informação de empresas recebeu pesados investimentos para disponibilizar seus negócios pela internet aos clientes. Durante o fim da década de noventa, esse foi o um dos focos das empresas para reduzir os custos e manter o crescimento (Carter, 2007). Um exemplo desse fenômeno são as instituições financeiras, que passaram a estimular seus clientes a utilizarem sistemas pela internet e reduziram a quantidade de funcionários para o atendimento ao público.

Atualmente, uma das frentes da computação para auxiliar as empresas a manter o crescimento é por meio da possibilidade de decomposição dos sistemas e a sua integração de diversas formas, desenvolvendo softwares diferentes do paradigma de grandes softwares isolados em seus vários setores. A decomposição e a interligação possibilita que os setores utilizem partes de softwares de outros setores sem precisar reescrever e duplicar programas. Além disso, as informações podem ser acessadas de uma única forma por todos através de um único serviço que as acesse. Segundo Carter (2007) a flexibilidade é o principal combustível para o crescimento dos negócios no cenário atual e ela é proporcionada no setor de tecnologia da informação com a decomposição e interligação dos sistemas. Os sistemas são decompostos em pequenos serviços, por isso o nome dessa nova maneira de criar sistemas é $\boldsymbol{S O A}$ (Service Oriented Architecture). Para garantir uma melhor interligação entre os serviços, criou-se o conceito de web services, que consiste em serviços os quais podem ser executados de maneira remota pela Internet usando linguagens e padrões baseados principalmente na portabilidade.

A característica de execução remota de serviços faz com que possa ser dado ao usuário um aspecto de transparência da aplicação, podendo ele mesmo acessar serviços que estejam em diferentes computadores de forma imperceptível. O acesso aos serviços é dado por uma URI (Universal Resource Identifier) que, por exemplo, pode utilizar um sistema de DNS para fornecer aos usuários diferentes endereços de acesso (Brittain; Darwin, 2003). Baseado em 
uma mesma URI, cada vez que é feito um acesso a um serviço, diferentes computadores podem recebê-lo e gerar uma resposta.

Os web services, segundo (Tanenbaum; Van Steen, 2002), classificam-se como sistemas distribuídos. Eles podem aparentar para o usuário que são parte de apenas um sistema hospedado em um único computador, mas podem estar em diversos computadores independentes.

A área de computação distribuída já possui estudos e propostas para diversos problemas que surgem em sistemas como web services. Uma das situações que podem estar presentes nos web services é a alta demanda gerada por servidores que experimentam diariamente um alto número de requisições dos usuários. Sistemas distribuídos apresentam soluções eficientes para altas demandas, seja através do uso de processamento massivamente paralelo, sistemas de estação de trabalho/servidor, clusters, entre outros. Um outro importante aspecto estudado em sistemas distribuídos é o escalonamento de processos, ou seja, como os processos executados em um sistema distribuído devem ser alocados para cada recurso do sistema. A distribuição de requisições, de maneira análoga ao escalonamento de processos, também trata como escalonar requisições para diferentes recursos de maneira eficiente. Estudar maneiras de realizar a distribuição de requisições é importante para que web services sejam executados de maneira eficiente em clusters. Assim, eles podem fornecer o devido suporte para que $\boldsymbol{S O A}$ apresente o suporte vital no atual crescimento das empresas.

\subsection{Motivação e objetivos}

A popularização de $\boldsymbol{S O A}$ e dos web services faz com que as empresas passem a gerar mais demanda sobre esse tipo de aplicação devido ao seu uso extensivo. Para suportar a alta demanda gerada, devem ser aplicados recursos computacionais de alto desempenho, esses recursos podem ser disponibilizados de maneira centralizada ou distribuída. Na primeira, é necessário o uso de servidores de grande porte que em geral têm alto custo e grande confiabilidade. A segunda pode ser implementada por um cluster de estações de trabalho, apresentando um custo relativamente baixo e alta escalabilidade.

Com a competitividade do mercado atual, poupar gastos leva ao uso de soluções de baixo custo. Para o uso de clusters, é necessário que seja feita a distribuição das requisições aos servidores de web services no cluster de alguma maneira. A distribuição eficiente, sob diferentes pontos de vista de eficiência, é o fator motivante deste trabalho. Baseado na motivação, o objetivo do trabalho é propor uma arquitetura de distribuição de requisições para softwares provedores de web services, a qual apresente as características de ser flexível, 
dinâmica e transparente. Flexível para permitir o uso de diferentes políticas de distribuição. Dinâmico para que se adapte e tome decisões em tempo de execução sobre a maneira como será realizada a distribuição baseado também no estado atual dos elementos que compõem a estrutura de atendimento. Transparente porque a distribuição não deve ser perceptível às aplicações clientes. A proposta apresentada foi testada através da implementação de um protótipo que coloca em prática os conceitos da arquitetura. A flexibilidade conseguida com a implementação se estendeu além do uso de políticas, englobando também a forma como os softwares envolvidos na arquitetura podem ser dispostos. Os resultados do trabalho mostram que o aparato necessário para o cumprimento dos objetivos da arquitetura não causam demasiada sobrecarga, resultando em bom desempenho da proposta frente à implementação usada como referência. Os resultados mostram também a flexibilidade nos objetivos das políticas de distribuição de requisições, através da construção de uma política voltada à redução da quantidade de nós ligados no cluster, melhorando a eficiência no consumo de energia.

\subsection{Estrutura}

Este documento está dividido em oito capítulos. No segundo capítulo é apresentado um texto para introduzir o leitor aos conceitos e nomenclaturas na área de $\boldsymbol{S O A}$ e web services. O terceiro capítulo é composto por um levantamento breve das ferramentas utilizadas para a criação e publicação de web services, assim como uma fundamentação sobre o tema de distribuição de requisições e monitoração. O quarto capítulo contém alguns trabalhos relacionados ao assunto abordado pelo trabalho, destacando seus pontos importantes e ressaltando vantagens e desvantagens das soluções propostas. O quinto capítulo apresenta a arquitetura de distribuição de requisições proposta por este trabalho, abordando-a em um nível mais alto e suas idéias principais. Também no quarto capítulo são apresentados o modelo, os recursos e detalhes da implementação do protótipo criado com o intuito de possibilitar uma análise pormenorizada da arquitetura. O sexto capítulo aborda o funcionamento e as técnicas de construção dos elementos modulares da arquitetura. No sétimo capítulo são apresentados os testes da arquitetura e é realizada uma breve análise de seus resultados. No oitavo capítulo são apresentadas as principais conclusões obtidas com o trabalho, relacionando suas vantagens e resultados. Nesse capitulo também é apresentado uma relação de possíveis trabalhos futuros a partir da arquitetura criada. Finalmente são relacionadas as referências bibliográficas utilizadas neste documento. 



\section{SOA e web services}

\subsection{Considerações Iniciais}

Este capítulo apresenta o conceito de $\boldsymbol{S O A}$ e web services. SOA é apresentada sob dois pontos de vista, primeiramente observando qual a sua importância para as empresas, quais as vantagens de sua adoção e os resultados que uma empresa pode esperar ao adotá-la. O outro ponto de vista de $\boldsymbol{S O A}$ refere-se sobre sua utilização frente aos outros paradigmas de desenvolvimento de softwares, principalmente no ambiente empresarial. Este último ponto de vista é voltado para a análise de $\boldsymbol{S O A}$ como uma ferramenta e como ela pode ser implementada. A parte deste capítulo que trata sobre web services tem o objetivo mostrar o que são eles, como surgiram e a quais abordagens de software eles podem ser comparados. Também é apresentada uma comparação entre as maneiras de implementação de web services.

\subsection{SOA}

\subsubsection{SOA sob a ótica de negócios}

SOA pode ser analisada por dois pontos de vista. No primeiro analisa-se o contexto da tecnologia, observando todas as possibilidades de aplicações de ferramentas existentes atualmente e no passado, para dividir as aplicações e seus modelos em serviços, disponibilizando-os para acesso de alguma forma.

Outro contexto em que $\boldsymbol{S O A}$ pode ser analisada é da visão de administradores e projetistas de software. Neste último contexto, SOA é uma abordagem para a tecnologia de informações voltada para os negócios, transformando um processo que deve ser realizado pelos administradores ou funcionários de diversos níveis em uma composição de diversas tarefas menores. Segundo Carter (2007), a definição de SOA é: 
"SOA é uma abordagem arquitetural de TI dirigida a negócio que suporta a integração de sistemas como tarefas de negócio ou serviços conectáveis e repetitivos. SOA ajuda hoje as empresas a inovar graças a garantia de que os sistemas de $\boldsymbol{T I}$ podem se adaptar rápida, fácil e economicamente para permitir rápidas mudanças nas necessidades da empresa. Ela aumenta a flexibilidade dos processos de negócio, fortalecendo a infraestrutura presente e reusando os investimentos já feitos na área de $\boldsymbol{T I}$ criando conexões entre aplicações e fontes de informação que apresentam muita diferença entre si.”

No mundo dos negócios, o uso de serviços pode auxiliar os departamentos de tecnologia de informação a se adaptarem de maneira rápida, fácil e diminuindo os custos com mudanças no decorrer do tempo. Além desses fatores, com o amparo do uso de serviços, as empresas podem aumentar a flexibilidade dos seus processos de negócio, já que podem unir pequenos pedaços de aplicações para gerar outras mais personalizadas para cada departamento, sem a necessidade de desenvolver uma aplicação totalmente nova. Com o auxílio de algumas ferramentas criadas para este fim, a construção do novo software pode ser simplificada demandando menor tempo para o desenvolvimento.

Serviços menores, que realizam operações mais pontuais trazem as empresas para o mundo de desenvolvimento usando componentes. Isso torna o setor de tecnologia de informação mais produtivo e reforça cada vez mais a infra-estrutura responsável por fornecer os dados para as aplicações. A forma como os dados são coletados dá-se de uma maneira padrão para todas as aplicações, evitando a criação de novos métodos que podem trazer restrições e possíveis falhas.

Sob o ponto de vista da empresa um serviço pode ser, por exemplo, uma tarefa exercida diversas vezes por um funcionário como a consulta de crédito de um cliente. Ele pode também ser parte de mais de um processo que o funcionário executa. Não se deve olhar para este serviço como um programa que realizará uma consulta em uma base de dados ou entrará em contato com outra empresa de crédito através de alguma tecnologia de comunicação. Para enxergar serviços em uma empresa deve-se olhar para o seu dia-a-dia e verificar as tarefas de negócio repetitivas que os funcionários fazem, nos passos que são necessários para realizar um negócio.

As relações que ocorrem entre empresas têm seguido a tendência de se tornarem cada vez mais complexas com o passar do tempo. Fatores como fusões e parcerias, aumento da competitividade, sistemas de produção just-in-time e terceirização de serviços resultam no aumento das aplicações existentes. Como exemplos de fusões e parcerias podem ser consideradas grandes instituições financeiras e fábricas de bebidas internacionais que se uniram nos últimos anos. Cada uma das empresas que participou das fusões já possuía uma 
estrutura de tecnologia de informação (aplicações, redes, servidores) bem estabelecida e funcional, que em alguns casos não poderia se comunicar com outras empresas diretamente, devido a barreiras tecnológicas. Em tais situações fica difícil escolher qual o sistema que permanecerá e qual será extinto tendo seus dados migrados. Outra possibilidade é a perda de dados durante a migração, cujo impacto não é difícil de imaginar no caso de uma instituição financeira. O abandono de um parque tecnológico desenvolvido envolve a desativação de sistemas que podem ter custado milhões de dólares.

O setor de $\boldsymbol{T I}$ dentro de uma empresa tem por objetivo agilizar os negócios por ela realizados. Ele não pode ser o responsável por manter a empresa estagnada por dificuldade integração, obtenção de dados e também não pode consumir uma fatia considerável do faturamento da empresa para o seu funcionamento.

Um recente artigo da IBM prevê que até o ano de 2010 boa parte das empresas exercerá apenas trabalhos especializados, sendo assim, cada empresa terá seu próprio sistema de informações especializado, necessitando de interação business-to-business (Carter, 2007). Devido a esses fatores, o mundo dos negócios está apostando muito na SOA. Os números apontam que no ano de 2006 a aplicação de $\boldsymbol{S O A}$ dentro das empresas gerou oportunidade de negócio de sessenta bilhões de dólares, um crescimento de $75 \%$ em relação ao ano anterior. É esperado para o ano de 2008 um crescimento nesta área de investimento próximo a 54\%, alcançando 143 bilhões de dólares (Carter, 2007).

\subsubsection{SOA sob o ponto de vista técnico}

O termo “orientado a serviços” é usado há algum tempo e já foi empregado em diversos contextos e para diferentes propósitos. O uso desse termo sempre esteve ligado ao paradigma de que a lógica necessária para resolver um problema com computação é mais simples de se construir, executar e gerenciar se o problema inicial for decomposto em um conjunto de peças menores (Erl, 2005).

A idéia de separar um problema em partes menores ou a conhecida técnica de dividir para conquistar é empregada na computação em algoritmos bem difundidos. SOA emprega esta idéia, mas em um nível mais alto e abrangente, englobando desde a camada dos processos de negócio até a implementação. O que difere $\boldsymbol{S O A}$ das outras propostas de divisão é a maneira como ela faz a separação e o objetivo que se pretende atingir com ela. No decorrer do trabalho as idéias principais serão expostas.

Os serviços, que compõem as partes na qual um processo é dividido dentro da $\boldsymbol{S O A}$, encapsulam lógicas de diferentes contextos para manter sua independência. O contexto pode 
ser uma tarefa de negócios, uma entidade de um negócio ou algum outro agrupamento lógico. A quantidade de funções executadas por um serviço pode ser grande ou pequena, assim o escopo que a lógica representa varia. Além disso, a lógica de um serviço pode utilizar a lógica de outro serviço, isso é chamado de composição de serviços. A Fig. 2.1 exemplifica possíveis relações entre serviços e suas composições, tomando como exemplo o processo de compra de um produto por uma empresa A de uma empresa B (por exemplo uma fábrica) e também a compra de matéria prima para fabricação e a contratação de seguro de transporte.

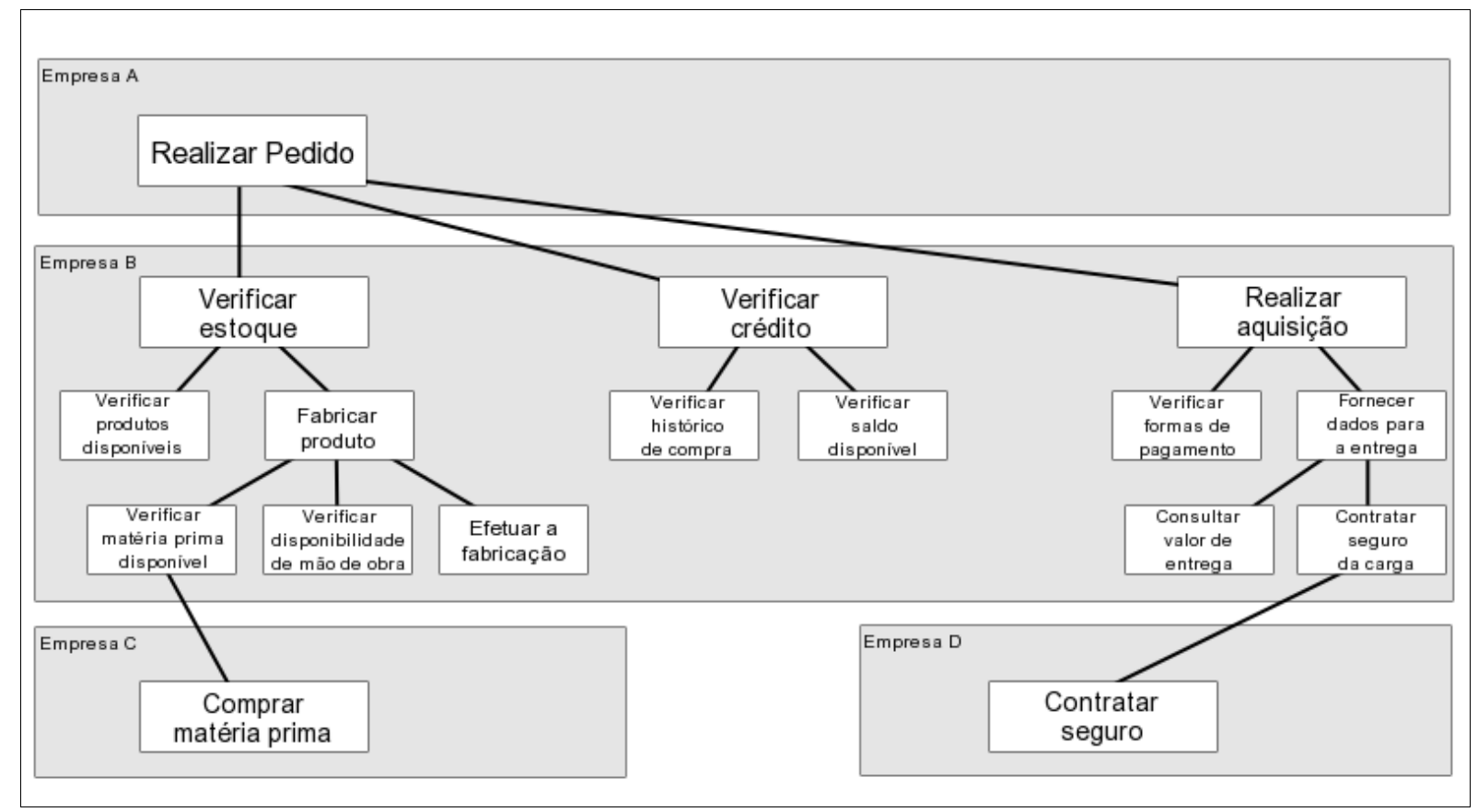

Fig. 2.1: Composição de serviços

Para que os serviços ou outras aplicações possam usar outros serviços é necessário que haja alguma forma de se relacionar com eles. A forma encontrada para se relacionar com serviços dentro de $\boldsymbol{S O A}$ é por meio de descrições de serviços. Na maneira mais básica de se observar, a descrição deve conter o nome do serviço e os dados esperados na sua entrada e na sua saída. Para que um serviço faça algum trabalho útil, deve haver uma forma de troca de informação. Para este fim, é utilizada alguma técnica de troca de mensagens, com o intuito de manter o seu fraco acoplamento.

Quando um serviço envia uma mensagem, ele perde o controle do que acontecerá com ela, portanto, as mensagens devem ser compostas por unidades independentes de comunicação, sendo disponibilizadas para o envio de uma só vez. Para que a mensagem seja independente do serviço que a originou, ela deve conter informação suficiente para trafegar por todo o caminho e chegar ao seu destino podendo descrever exatamente qual é a sua intenção.

Assim como na orientação a objetos, a orientação a serviços é uma abordagem de 
projeto que introduz princípios aceitos comumente e que dizem como os componentes da arquitetura devem estar dispostos e ligados. O princípio básico da orientação a serviços é processar e dispor a lógica dos serviços de uma maneira padronizada. Outros princípios encontrados nessa arquitetura são: fraco acoplamento, para minimizar a dependência entre os serviços; deve haver um contrato para reger a comunicação com serviços, contratos estes baseados nas descrições do serviço; os serviços devem ter autonomia sobre a lógica encapsulada dentro deles; uma camada que traga abstração sobre a lógica contida no serviço; os serviços devem ser divididos de uma forma que promova o reuso; deve haver uma forma de compor e coordenar as composições de serviços; quanto menos informações sobre o estado de uma atividade um serviço mantiver, melhor; os serviços devem ser auto descritivos e ter informações suficientes para que possam ser descobertos e acessados por elementos externos.

Com estes princípios torna-se mais intuitiva a implementação de $\boldsymbol{S O A}$. Uma solução que se encaixa bem para suprir os princípios de $\boldsymbol{S O A}$ são os web services, os quais serão detalhados no decorrer do trabalho.

\subsection{Web Services}

O uso de uma arquitetura orientada a serviços implica no particionamento das aplicações que antes eram responsáveis por fornecer dados, por exemplo, para todo um departamento em aplicações menores com funções limitadas. De alguma forma as aplicações menores resultantes desta decomposição devem comunicar-se entre si para gerar o mesmo resultado obtido pela aplicação única. Este conceito de divisão e acesso de aplicações através de um protocolo de comunicação caminha ao encontro dos conceitos há tempo difundidos na área da computação distribuída.

Uma gama de protocolos de programação distribuída existem para conectar aplicações por meio de LANs e/ou WANs. Três protocolos comumente utilizados são: CORBA (Common Object Request Broker Architecture), DCOM (Distributed Component Object Model) e RMI (Remote Method Invocation). Cada um desses protocolos apresenta pelo menos um dos seguintes problemas: incompatibilidade com outros protocolos, dependência de linguagem ou de sistema operacional, modelo de objeto e de passagem de mensagem dependente de fabricante (Brooks, 2002). Além desses problemas, há algumas barreiras que limitam o seu uso apenas a ambientes com maior acoplamento. Isso dificulta acessos remotos que necessitem passar por diversas redes ou ainda que possam ser utilizados em uma grande variedade de dispositivos.

A web possibilita que com uma quantidade pequena de recursos, um dispositivo possa 
acessar de qualquer parte do mundo um conteúdo nela disponibilizado. No seu princípio a web era uma grande fornecedora de conteúdos estáticos, não havendo formas complexas de interação entre os usuários e os servidores: os usuários apenas requisitavam os dados e dificilmente enviavam dados para o servidor. Com o passar do tempo e o surgimento de tecnologias como o CGI (Common Gateway Interface) (Mccool, 2008) tornou-se mais popular a criação de páginas de internet que possibilitavam uma melhor personalização da interação dos usuários com o conteúdo fornecido. O que tornou isso possível foi a possibilidade dos servidores coletarem dados dos usuários por meio de CGI e enviarem os dados para linguagens mais elaboradas dentro dos servidores, os quais podem fazer o processamento de diversas maneiras (Hunter, 1998). Desse ponto em diante, passou-se a observar o grande crescimento dos tipos de aplicações que executavam na web, sendo o limite muitas vezes apenas a criatividade dos programadores.

O elemento básico para que o usuário interaja com a web é o navegador, que possui a capacidade de interpretar pelo menos uma linguagem simples (HTML) vinda das mensagens do servidor e exibir elementos gráficos padrão para o usuário. Apesar de haver um padrão na linguagem usada na web (HTML 4.0 ou nos dias atuais o XHTML 1.1) (W3C, 2008), os elementos exibidos para os usuários costumam variar entre os navegadores. Além disso, tornou-se popular o uso de scripts para tornar a interface do usuário mais amigável com as páginas, causando incompatibilidade na maneira como páginas web são exibidas. Além dos fatores envolvidos no lado do usuário, entre os servidores não há uma padronização que oriente como as informações são captadas, ocorrendo problemas de codificação de dados e uma grande variedade de formas de aquisição de informações. Por exemplo, duas páginas que vendem determinado produto podem receber o pedido do usuário de maneira diferente.

A integração de aplicações que antes encontrava empecilhos na acessibilidade remota tem na web uma grande aliada. Com a comunicação em ambos os sentidos podendo ser feita sobre o protocolo HTTP, sobre o qual a web é baseada (Comer, 1995), é possível que as aplicações troquem os dados necessários para a sua interação, tal como os usuários fazem em seus navegadores. A união da web e da integração de aplicações permite uma forma de acessos mais simples e com maior alcançabilidade que as outras maneiras citadas anteriormente (CORBA, DCOM e RMI).

Há dois pontos fracos do uso de mensagens HTTP para integrar os serviços. O primeiro é a pouca flexibilidade encontrada para coletar os dados em um servidor. O segundo é como um servidor pode ser exposto para que um usuário se conecte ou escreva uma aplicação que se comunique de maneira adequada com ele sem ter acesso ao código fonte ou uma especificação mais detalhada da codificação dos dados. No caso de páginas web com 
conteúdo dinâmico, o servidor envia um formulário padrão que ele reconhece para o preenchimento e o posterior envio por parte do usuário, diminuindo a possibilidade de incompatibilidade de envio. Quando se trata de uma aplicação, esta deve coletar as informações do usuário com o seu próprio formulário e codificá-las de alguma forma para enviar para o servidor. O problema de codificação e envio torna-se mais grave com o crescimento da quantidade e a diversidade de informação que deve ser enviada.

O padrão $\mathbf{X M L}$ (Extensible Markup Language) foi criado para sanar os problemas com interoperabilidade, portabilidade e padronização. A aplicação do padrão $\boldsymbol{X} \boldsymbol{M L}$ com os servidores presentes na web facilitou uma interação mais robusta entre as aplicações e os servidores. Ela possibilitou não só o uso de mensagens simples entre cliente e servidor, mas também a disponibilização de serviços mais complexos por parte dos últimos, com transferência de informação mais complexa e em maior quantidade. Com $\boldsymbol{X M L}$ os dados podem ser codificados com tipos de dados padrão, colocados em um arquivo $\mathbf{X M L}$ e enviados para o servidor diminuindo os problemas de compatibilidade.

A exposição na web de servidores que disponibilizam parte de uma aplicação decomposta, que no contexto de $\boldsymbol{S O A}$ são os serviços, caracteriza o início dos web services. Os web services são muito mais que apenas um servidor que aceita uma requisição para uma aplicação pela web. Eles são constituídos principalmente pelos padrões que tornaram a interação entre aplicações pela web possível. O padrão que fez emergir toda a capacidade dos web services foi o $\mathbf{X M L}$.

Na essência de sua criação, web services são o elo de integração entre computadores pessoais, outros tipos de dispositivos, bancos de dados e redes, formando uma ligação na qual os usuários podem interagir através de navegadores. Os web services executam em servidores de aplicações para web e movem as funções dos computadores pessoais para a internet, tornando acessíveis as aplicações a partir de qualquer dispositivo conectado com a web, incluindo dispositivos móveis. Sob esse ponto de vista a web passa a ser uma plataforma de computação e não só um meio pelo qual o usuário tem acesso a conteúdo (Vaughan-Nichols, 2002).

Alguns especialistas dizem que os web services são basicamente chamadas remotas de procedimento com um fraco acoplamento que surgiram como uma alternativa para os métodos com forte acoplamento que requerem aplicações e protocolos específicos (VaughanNichols, 2002).

A alma dos web services são os padrões abertos, que possibilitam que qualquer um desenvolva soluções sem a necessidade de licenças de produtos. A presença de padrões abertos é o que difere os web services de outros padrões como o IIOP do CORBA (Vaughan- 
Nichols, 2002). Alguns dos padrões sobre os quais os web services são construídos são o SOAP (Simple Object Access Protocol), que é o protocolo utilizado para o transporte de dados das requisições e respostas; e o WSDL (Web Service Description Language), que é a linguagem pela qual um web service é descrito.

Em relação ao uso do protocolo $\mathbf{S O A P}$ em web services, ele não é a única maneira sobre a qual estes podem ser construídos. Uma outra abordagem que pode ser seguida é o uso de REST. Apesar de REST e SOAP não serem opostos, pois a primeira é um estilo arquitetural e o segundo um protocolo que pode ser usado em diversas arquiteturas, ainda existem muitos debates sobre esse assunto entre os defensores de cada uma das abordagens (Zur Muehlen et al., 2005).

\subsubsection{REST}

No início da web, quando seus criadores estavam definindo os protocolos e padrões sobre os quais ela seria construída, surgiu a necessidade de um modelo que descrevesse como a web deveria funcionar. Neste momento foi idealizado um estilo arquitetural denominado REST (Representational State Transfer)(Fielding, 2000).

A arquitetura de software é uma abstração dos elementos que compõe o software durante uma fase de sua execução. Um software pode ser composto de vários níveis de abstrações, cada um formando uma arquitetura. Uma arquitetura define como os elementos do sistema são identificados e alocados, como eles interagem entre si e os protocolos usados na comunicação. Um estilo arquitetural é um conjunto de restrições da arquitetura de software que limita o papel de cada elemento e as relações dentro de um sistema (Zur Muehlen et al., 2005)

$\boldsymbol{R E S T}$ é um conjunto de restrições da arquitetura que minimiza a latência e a comunicação pela rede, ao mesmo tempo que maximiza a independência e a escalabilidade dos componentes. O principal artifício utilizado no $\boldsymbol{R E S T}$ é a restrição semântica na forma como os objetos ou aplicações são acessados. O nome Representational State Transfer tem por objetivo expressar que um conjunto de páginas ou locais na web com uma semântica de localização (links) bem definidos podem representar o estado de uma aplicação, permitindo que o usuário navegue através destes links como se estivesse passando pelos estágios de interação com uma aplicação.

Usando $\boldsymbol{R E S T}$, cada requisição enviada para um recurso que representa um objeto resulta na transferência de seu estado, geralmente em forma de um documento $\boldsymbol{X M L}$. Este último fornece, além dos dados referentes ao estado do objeto, URIs (Universal Resource 
Identifiers) que permitem que o cliente navegue para os próximos estados ou então envie dados para modificar o estado do objeto. O processo de navegação entre URIs faz com que objetos sejam criados e modificados dentro do servidor como se este estivesse executando uma aplicação.

Os métodos usados para interagir com o servidor são os do protocolo HTTP, e os mais comumente utilizados são o GET e POST. Para que um cliente acesse um processo remoto em um servidor, ele realiza uma requisição utilizando o método GET para o servidor através de um URI conhecido que, na maioria dos casos, é composto por: endereço do servidor, tipo do objeto a ser acessado e finalmente o seu identificador.

A Fig. 2.2 ilustra uma interação básica utilizando REST. A interação inicia-se com o acesso do cliente à aplicação exemplo no servidor por meio de uma URI (http://www.exemplo.br/exemplo). Então o servidor retorna para o cliente um documento $\boldsymbol{X M L}$ com uma lista dos recursos ou objetos que podem nele ser acessados. Através das URIs retornadas no documento $X M L$ o cliente faz uma nova requisição usando o método GET para obter informações sobre um dos objetos (001). Novamente o servidor retorna um documento $\boldsymbol{X} \boldsymbol{M L}$, mas desta vez com informações específicas do objeto requisitado. O cliente finalmente faz uma requisição usando o método POST e envia um documento $\boldsymbol{X} \boldsymbol{M L}$ para o servidor com os dados a serem alterados no Objeto 001 (Costello, 2008).

O ponto chave é que o cliente não precisa de maneira alguma saber detalhes sobre como o processo no servidor é implementado. Ele deve se preocupar apenas com o formato das informações que são trocadas dentro dos arquivos $\boldsymbol{X} \boldsymbol{M L}$ entre ambas as partes. Essa característica faz com que a mesma interface do cliente possa ser usada para acessar qualquer processo no servidor, pois sempre o retorno será um arquivo $X \boldsymbol{M L}$ que será processado por uma camada mais abstrata da aplicação cliente. O mesmo vale para os dados enviados, a interface sempre enviará um arquivo $\boldsymbol{X M L}$ para o servidor.

Além da facilidade de troca de dados usando $\boldsymbol{R E S T}$, ele pode tornar mais eficiente a troca das informações, pois pode haver entre o cliente e o servidor um sistema de cache que reaproveite requisições já realizadas por outros clientes e que ainda podem ser válidas em requisições subseqüentes. 


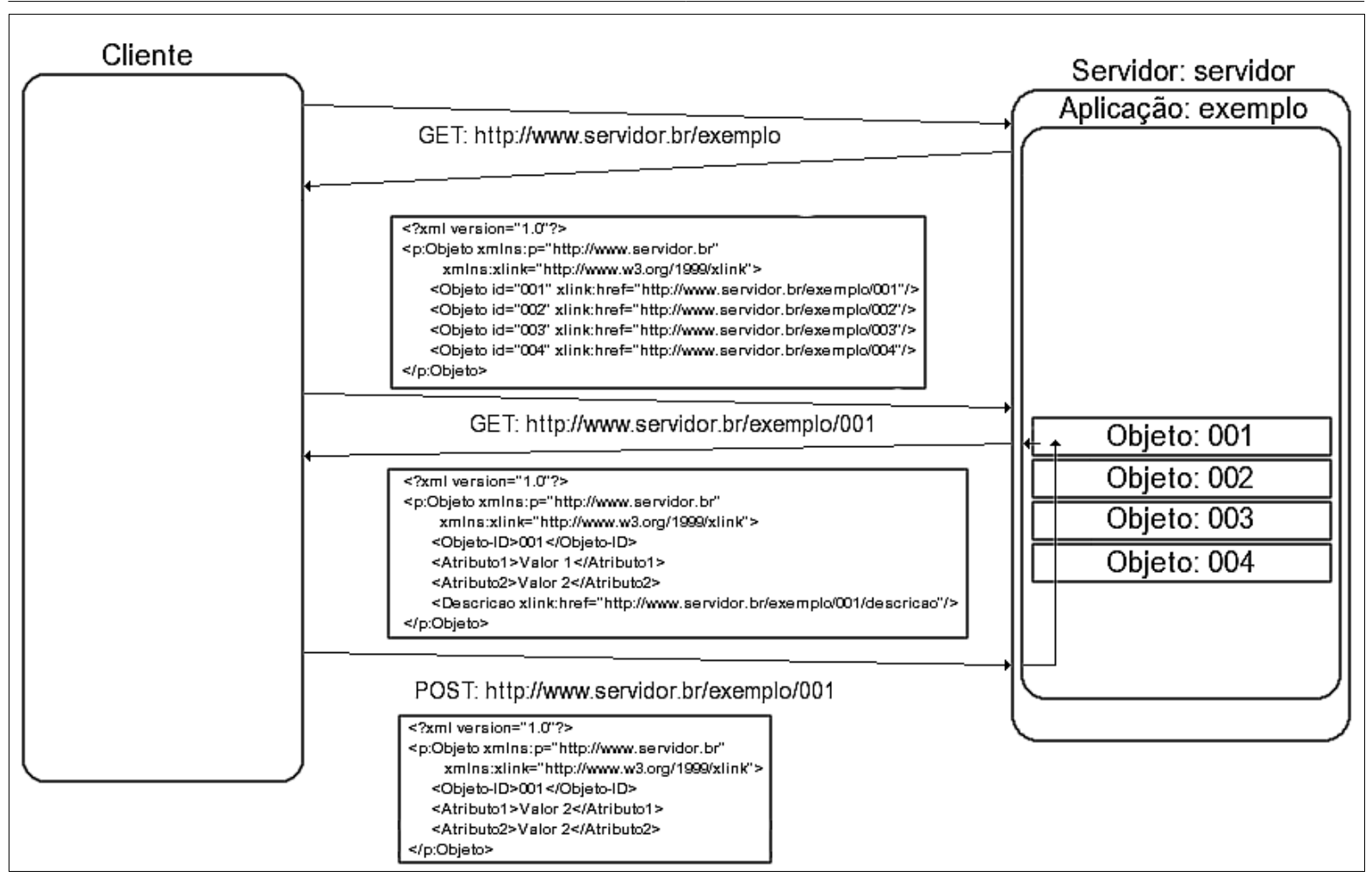

Fig. 2.2: Interação REST

\subsubsection{SOAP}

Um dos desafios quando se utiliza a computação distribuída é garantir a interoperabilidade de sistemas. Nos últimos anos, o surgimento de um protocolo chamado SOAP (Simple Object Access Protocol) apresentou-se como uma boa arma para atacar o problema de interoperabilidade. O protocolo SOAP é relativamente leve, baseado em $\boldsymbol{X M L}$, projetado para que aplicações possam trocar informações e realizar pedidos de execução de procedimentos em aplicações remotas.

SOAP é constituído por algumas partes. A primeira é o envelope, que engloba todo o conteúdo da mensagem e diz ao receptor como processar os dados contidos na mensagem através de um documento de descrição. A segunda garante a extensibilidade do SOAP, podendo nela serem configurados alguns parâmetros sobre o tráfego da mensagem e como ela deve ser interpretada por onde passa. A terceira parte de uma mensagem SOAP descreve como as informações enviadas devem ser usadas, ou seja, qual o procedimento deve ser disparado, os tipos de dados passados e os tipos de retorno para o procedimento. Também são enviadas algumas regras de como o protocolo HTTP será utilizado (no caso do uso de HTTP). Além do uso de HTTP, SOAP pode ser transportado por outros protocolos como SMTP (Simple Mail Transfer Protocol), FTP (File Transfer Protocol), JMS (Java Message Service). 
O protocolo SOAP se diferencia de RMI, CORBA ou DCOM uma vez que ele se concentra no conteúdo, desacoplado da implementação e das camadas de transporte. Ele não existe por si só além da abstração da especificação (Tidwell, 2005).

A Fig. 2.3 apresenta a estrutura básica de uma mensagem SOAP. Nela é possível ver as três partes que compõe a mensagem: o envelope, o cabeçalho e o corpo.

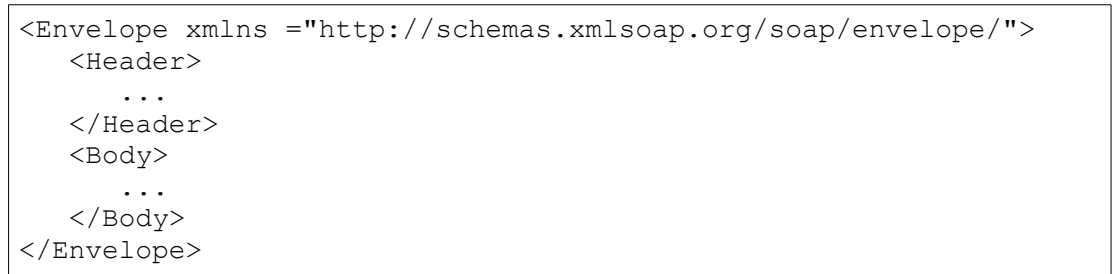

Fig. 2.3: Estrutura da mensagem SOAP

A Fig. 2.4 mostra o cabeçalho SOAP contendo um parâmetro chamado mustUnderstand, que nesse caso possui o valor 1, dizendo que por todos os lugares onde a mensagem passar, todos os campos contidos no cabeçalho devem ser compreendidos. Além desse tipo de informação, no cabeçalho podem ser adicionadas informações sobre as extensões que podem ser utilizadas nos web services como a WS-Addressing, WSReliableMessaging entre outras. Na Fig. 2.4 os rótulos marcados com ws rm, dão informações sobre a extensão WS-ReliableMessaging (Erl, 2005).

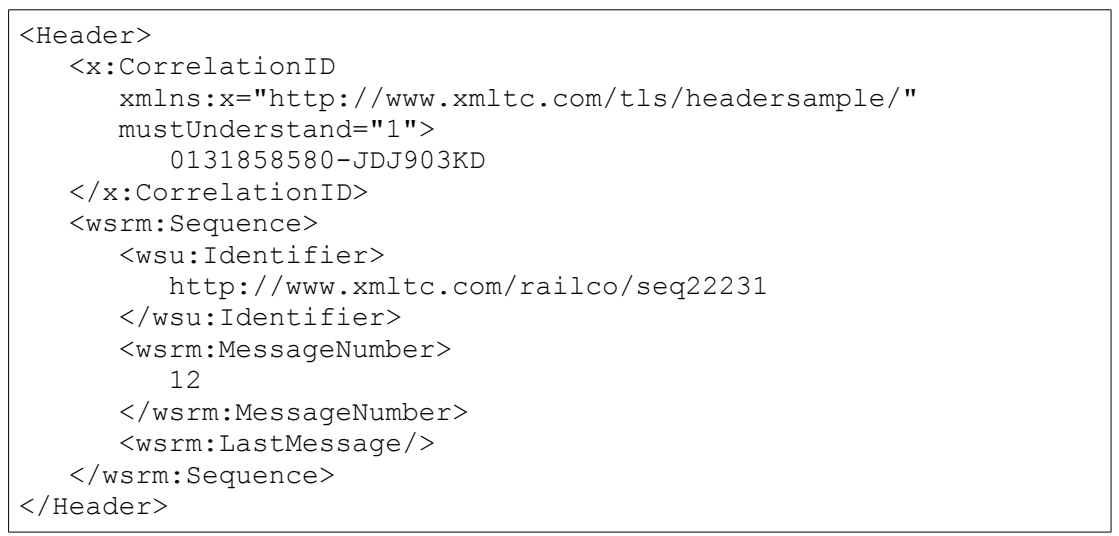

Fig. 2.4: Cabeçalho SOAP (Erl, 2005)

Um exemplo de corpo de mensagem SOAP pode ser encontrado na Fig. 2.5. O conteúdo do corpo pode ser diferente para o acesso a diferentes web services. A WSDL é quem define o seu conteúdo, descrevendo como o web service deve ser utilizado, os tipos de dados e os métodos disponíveis. A WSDL do serviço é obtida durante o processo de descoberta realizado pelo cliente. O corpo é um elemento obrigatório dentro do elemento envelope, diferentemente do cabeçalho. Ele carrega toda a informação (payload) que realmente representa a interação entre as partes envolvidas na comunicação formatada em $\boldsymbol{X M L}$. Os namespaces ${ }^{1}$ do $\boldsymbol{X M L}$ são amplamente utilizados para descrever o conteúdo do 
pacote.

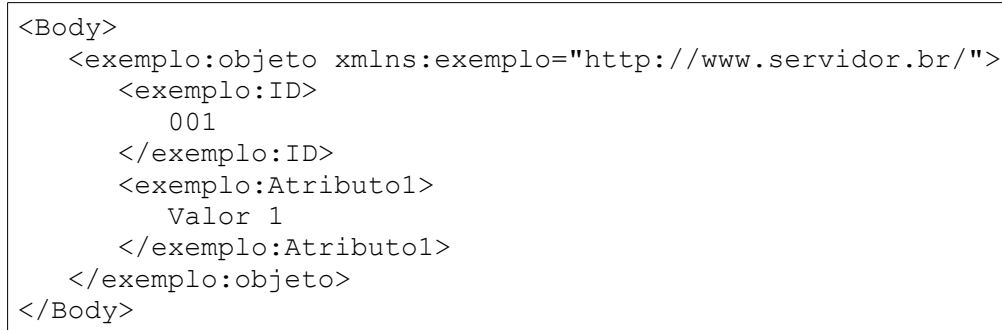

Fig. 2.5: Corpo da mensagem SOAP

Ainda dentro do corpo de uma mensagem SOAP pode haver mais um elemento que descreve estados de falha na comunicação. A Fig. 2.6 contém um corpo de mensagem SOAP com um elemento de falha que descreve um problema no campo mustUnderstand exemplificado na Fig. 2.4. O elemento de falha apresenta um código de erro no campo faultcode que é definido entre muitos outros na especificação do SOAP. Os outros campos faultstring e detail fornecem uma descrição para ser compreendida por seres humanos para amparar a correção de possíveis falhas.

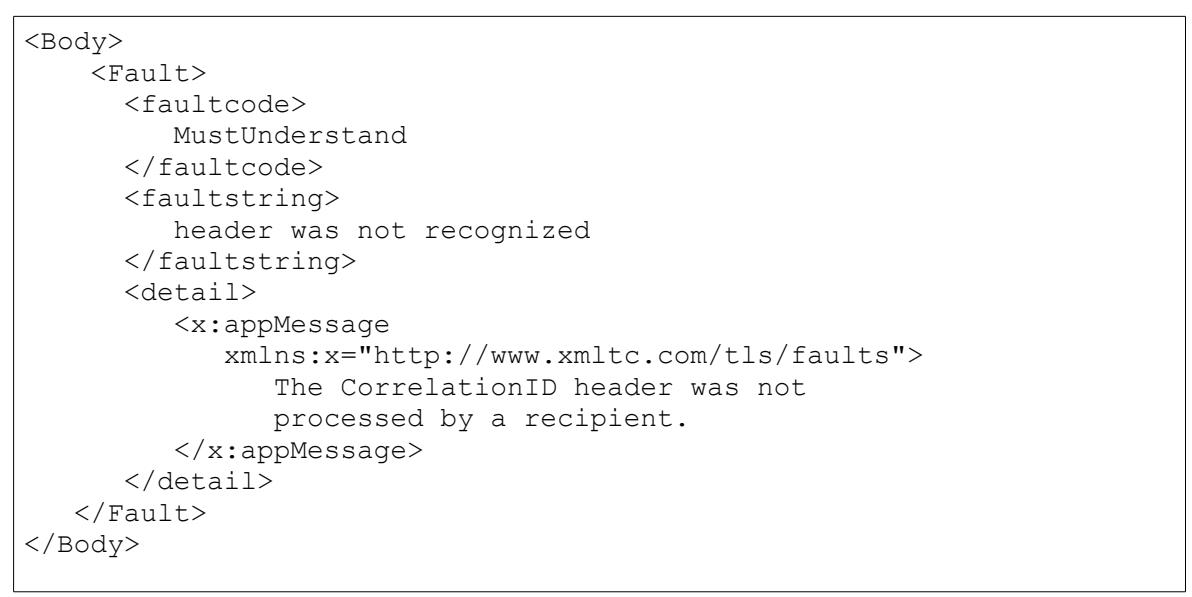

Fig. 2.6: Elemento fault

\subsubsection{Relação entre SOAP e REST}

A comparação sobre o uso de web services baseados em SOAP ou em REST baseia-se na maneira como os serviços são vistos. O uso de $\boldsymbol{R E S T}$ segue uma abordagem orientada a recursos, ou seja, existem diversos recursos e as interações com eles são realizadas através de poucas operações básicas. A abordagem de $\boldsymbol{S O A P}$ é orientada à atividade: os recursos são manipulados diretamente por várias operações descritas na WSDL do web service (Snell, 2008).

Os principais benefícios de SOAP fundamentam-se no fraco acoplamento das operações. Estas podem ser testadas e depuradas antes que uma aplicação seja colocada em ambigüidade que pode existir no caso de existirem dois rótulos iguais no documento inteiro. Namespaces podem apontar para outros documentos que dão informações sobre o rótulo aos quais eles se referem. 
operação. Para o programador, SOAP consegue trazer uma semelhança do modelo de chamadas remota a procedimentos existentes em outras tecnologias. Este fato é ainda mais acentuado com as diversas interfaces de programação de aplicações existentes atualmente. A vantagem no uso de $\boldsymbol{R E S T}$ é seu potencial para aumento gradativo da arquitetura e a reduzida necessidade de recursos para o acesso às operações devido à sua quantidade limitada.

Uma desvantagem na aplicação de $\boldsymbol{R E S T}$ é que sua capacidade de aumento da arquitetura pode levar à existência de muitos objetos, o que torna o difícil o gerenciamento do URI de onde o serviço é provido. No uso de SOAP, um revés pode ser a necessidade do cliente obter, durante o processo de desenvolvimento da aplicação, a descrição do serviço e de alguma forma interpretá-la. Isso é necessário para gerar a mensagem SOAP adequada, embora este processo seja automatizado com as ferramentas de desenvolvimento atuais.

Pode-se notar que o uso de $\boldsymbol{R E S T}$ e SOAP não é mutualmente exclusivo por completo, pois o primeiro pode ser considerado, de maneira simplista, um conjunto de regras para o acesso a recursos e o segundo uma maneira de trafegar informações que permite carregar chamadas de procedimentos internamente. Usando-se uma forma de adaptação é possível até mesmo fundir o uso das duas abordagens em um mesmo web service.

Sob o ponto de vista de alguns desenvolvedores, as extensões para web services que são trafegadas no cabeçalho SOAP podem ser mais um fator de sobrecarga e gerador de complicações em seu uso. Porém, a falta dessas extensões no REST pode levar alguns a argumentarem que este último não fornece recursos suficientes para a geração de aplicações mais complexas.

O uso de SOAP vem se tornando cada vez mais popular e ganhando amparo de grandes fornecedores comerciais e de software livre pelo mundo (Vaughan-Nichols, 2002).

\subsection{Considerações Finais}

Este capítulo apresentou uma introdução sobre $\boldsymbol{S O A}$, destacando a flexibilidade e interoperabilidade conseguidas com tal arquitetura e que fazem com que ela se torne uma interessante abordagem para desenvolvimento de aplicações empresariais. Foram tratados também os web services, mostrando seu surgimento baseado na evolução das técnicas de interação entre usuário e servidor através da web, mostrando que web services podem ser implementados usando-se REST ou SOAP e quais suas vantagens.

Considerando o que foi apresentado neste capítulo, este trabalho utilizará o conceito de web services baseados em SOAP por meio da ferramenta Axis2 para aplicar a distribuição de requisições. 



\section{Suporte computacional para web services}

\subsection{Considerações iniciais}

Neste capítulo serão abordados os softwares que podem ser utilizados para amparar o uso de web services, seja no seu desenvolvimento ou publicação. Serão apresentados alguns softwares que tem mais expressividade em relação ao seu uso na comunidade e suas características principais, destacando pontos fortes e fracos em suas implementações. Na parte seguinte do texto serão abordados os softwares que tem mais importância para o trabalho com um maior detalhamento de suas características. Finalizando este capítulo, será tratado o tema de distribuição de requisições, contextualizando o assunto e o relacionando com sistemas distribuídos. Nessa parte também será apresentado um resumo sobre o uso de técnicas ferramentas de monitoração e sua importância dentro da parte de distribuição de requisições.

\subsection{Provedores de web services}

Os web services são basicamente pequenas aplicações que depois de implementadas precisam ser publicadas na web para que outras aplicações possam acessá-las. Para tornar a tarefa de publicar web services mais simples, existem softwares que encapsulam todo o tratamento de conexões através de protocolos e direcionam apenas as informações relevantes para a aplicação que implementa o serviço. Se não existissem os software provedores, todos os web services deveriam implementar um pequeno servidor para a recepção de requisições. Além disso, seriam necessários métodos para que vários web services pudessem coexistir e diferenciar para qual deles as requisições se destinariam.

Os softwares que agrupam os web services e os tornam públicos são os provedores de web services. Atualmente, existem muitas implementações destes provedores, cada um com suas características particulares, o que torna difícil a escolha de um deles e também eleger o melhor entre todos. Assim como na discussão sobre SOAP e REST, a escolha entre um 
provedor deve levar em conta qual é a abordagem desejada na implementação e publicação dos serviços.

Entre os softwares provedores mais conhecidos para web services estão o XFire (Codehaus, 2008), Celtix (Object Web, 2008), JBoss (jboss.org, 2008)(Red Hat, 2008a), WebSphere (IBM, 2008), Jetty (Webtide, 2008), Apache Tomcat (The Apache Software Foundation, 2008a) e Apache Axis2 (The Apache Software Foundation, 2008b). A área de web services está em ascensão, por isso estão surgindo vários outros provedores e adaptações de provedores web que podem fornecer suporte à publicação de web services. Os softwares citados estão em desenvolvimento por mais tempo e possuem grupos de usuários relativamente amplos, cada grupo defendendo o seu software e apontando seus pontos fortes.

Os softwares que fornecem suporte aos web services podem atuar em duas frentes, disponibilizando uma interface de programação para aplicações que auxilia os desenvolvedores a realizarem o envio, recebimento e publicação dos web services encapsulando esses detalhes, e também atuando como provedores que expõem os serviços na web. Alguns dos softwares realizam ambas as tarefas. Outros apenas fornecem as APIs e utilizam outros softwares para a publicação.

Entre os softwares que apenas expõe os web services estão o Jetty e o Apache Tomcat. O WebSphere e o JBoss possuem todas as funções para fornecer e implementar web services. Celtix, XFire e Apache Axis2 fornecem uma API para desenvolvimento e necessitam de outros softwares para fazer a publicação dos serviços. Como pode-se perceber, existem diversas combinações que podem ser feitas entre eles além de que, existem outras iniciativas menos conhecidas ou em processo de desenvolvimento para amparar o uso de web services.

O WebSphere é uma plataforma de integração da IBM. Ele é composto por um conjunto de servidores, serviços e ferramentas necessárias para amparar o uso em larga escala de aplicações web fornecendo interoperabilidade. O seu conceito é garantir que a integração de softwares seja robusta, flexível e confiável. Sua base é o servidor de aplicação baseado em EJB (Enterprise Java Beans), sobre o qual todas as outras funcionalidades trabalham. Com o intuito de integração, um dos principais focos do WebSphere é $\boldsymbol{S O A}$, mas ele também fornece subsídios para desenvolvimento sem SOA. Ele possui algumas versões proprietárias, divididas pelo tamanho do ambiente onde ele será usado, que acarretam custos de licença. Também existe uma versão baseada em software livre, chamada Community Edition que funciona sobre a estrutura do Apache Geronimo (The Apache Software Foundation, 2008b). O Apache Geronimo é um conjunto de softwares do grupo Apache que forma um ambiente de integração. Por isso seu uso na versão aberta do WebSphere, pois os dois tem o mesmo 
propósito. Web services são utilizados no Apache Geronimo através do Apache Axis 2. Ele também inclui um servidor que suporta servlets baseado no Apache Tomcat.

O WebSphere possui extensiva documentação, mas seu uso é relativamente complexo. Isso ocorre porque ele agrega muitas funcionalidades de diversas tecnologias. Para o fim deste trabalho, o WebSphere não se adequa, pois nas suas versões não abertas não é possível realizar modificações. Outro ponto é o preço elevado da licença. A versão Community Edition é baseada em softwares do grupo Apache, como o Apache Tomcat e Axis2 (que serão tratados a seguir). Então, uma modificação nestes dois softwares pode refletir-se no Apache Geronimo. Outra característica que torna este software inapto para o trabalho é a alta complexidade e a grande quantidade de documentação a ser estudada para colocá-lo em funcionamento e para analisar sua estrutura, tornando-se inviável devido a relação tempo x recurso humano..

O servidor de aplicação JBoss surgiu em 1999 e com o seu crescimento e popularização houve a criação do JBoss Group em 2001, para fornecer suporte especializado. Em 2004, o JBoss Group transformou-se em uma empresa (Fleury et al., 2005). Com apenas sete anos de existência, o JBoss, que sempre foi baseado em software livre, passou a estar entre os líderes no ambiente empresarial como solução para servidores de aplicação. O seu sucesso chamou a atenção da Red Hat, também uma das líderes em soluções empresariais mundial, que adquiriu o JBoss em maio de 2006 por aproximadamente 400 milhões de dólares. O crescente interesse por SOA foi o propulsor de ambos os lados, JBoss e Red Hat (Red Hat, 2008b).

Atualmente o JBoss continua sendo fornecido sob licença livre seguindo os padrões da Red Hat, apresentando versões gratuitas e versões empresariais. Ambas as versões são iguais, sendo a diferença entre elas o suporte prestado. Assim como o WebSphere, o JBoss apresenta uma solução completa para integração de aplicações empresariais atuando sobre a maioria das tecnologias Java voltadas para este fim. Uma das frentes de atuação do JBoss é em relação a web services, fornecendo todo o ambiente para a publicação dos serviços e a interface de programação de aplicação, atualmente baseada em anotações. O JBoss também possui o Apache Tomcat embarcado podendo haver a execução de web services através deste último, em conjunto com o Apache Axis2 ou a sua própria interface interna.

A documentação do JBoss, assim como do WebSphere, também é extensa, fornecendo detalhes sobre todas as suas funcionalidades. Para este trabalho, a aplicação do JBoss não é adequada em primeira instância, pois ele engloba mais funcionalidades do que apenas o tratamento de web services. Devido a sua característica de ser uma solução para integração completa, o seu código é grande, fato que dificulta a sua compreensão e utilização 
no projeto. Este é um problema de ambos WebSphere Community Edition e do JBoss. O JBoss porém devido a característica de conter o Apache Tomcat pode ser adaptado para trabalhar com a solução proposta no trabalho, fato que será tratado na seção 7.2.

Os softwares mencionados anteriormente também agregam sobrecarga a mais em relação a softwares mais simples para prover apenas web services, devido às camadas a mais necessárias para dividir e identificar requisições de outros tipos (requisições HTTP para conteúdo web e invocação remota de métodos). Como o objetivo deste trabalho é a criação de uma nova arquitetura e a sua aplicação prática visando, principalmente, desempenho, não é vantajoso utilizar softwares que agreguem camadas de sobrecarga desnecessárias e, com isso, tenham menor desempenho em relação a outros no atendimento a web services.

Outros dois softwares que estão relacionados com web services são o XFire e Celtix. Ambos não são propriamente provedores de web services em si. Eles são interfaces de programação de aplicação que fornecem um conjunto de bibliotecas e funções para tornar a implementação de web services mais simples.

O software XFire apresenta suporte à transferência de mensagens SOAP via HTTP, JMS (Java Message Service) e XMPP (Extensible Message and Presence Protocol). Ele é baseado no método de manipulação de arquivos chamado StAX (Streaming API for $\boldsymbol{X M L}$ ) que é baseado em pull, isto é, a aplicação não passa o controle do parsing de dados $\boldsymbol{X M L}$ para o parser, mas sim comanda o parser para que ele atue apenas nos elementos $\boldsymbol{X} \boldsymbol{M L}$ desejados. Esta abordagem faz com que não haja necessidade da aplicação manter arquivos $\boldsymbol{X M L}$ muito grandes inteiros na memória, além disso, pode ser usado um parsing retardado, onde o caminhamento pela árvore $\boldsymbol{X} \boldsymbol{M L}$ é realizado apenas sob demanda, não carregando o documento inteiro (Sun Microsystems, 2008). O XFire clama por ter desempenho superior à versão 1 do Apache Axis, porém não há comparações com a versão 2. A publicação dos serviços através do XFire é realizada através de qualquer container de servlets como Apache Tomcat ou Jetty.

O software Celtix se baseia em um $\boldsymbol{E S B}$ (Enterprise Service Bus) ${ }^{2}$ e também fornece uma $\boldsymbol{A P I}$ para a criação de serviços. Ele foi desenvolvido por uma empresa chamada Object Web e apresenta basicamente duas versões, uma gratuita e outra empresarial. A versão gratuita deixou de ser desenvolvida dentro da Object Web e passou para o grupo Apache. A versão empresarial também saiu das mãos da companhia que o criou e passou para um grupo chamado Open.IONA (IONA, 2008) onde o software acabou mudando de nome. A

2 ESB é uma arquitetura ou software, embora existam discussões sobre essa definição na literatura, que fornece um conjunto de primitivas para tornar a conexão de serviços padronizada, além de conectar todos os serviços. Uma analogia a sua função podem ser os ambientes de passagem de mensagem (Carter, 2007). 
publicação de serviços com o Celtix ainda pode ser feita através do Apache Tomcat. Ele também oferece ligações para outras ferramentas como Spring (Spring Source, 2008) e ActiveBPEL (Active Endpoints, 2008).

Ambos os software mencionados anteriormente (Celtix e XFire) estão em processo de fusão e passando para o controle do grupo Apache em sua incubadora de projetos. O produto gerado pela fusão possui o nome $\mathbf{C X F}$ e está em processo de desenvolvimento, não possuindo ainda uma API bem estabelecida e estável. Este é um dos fatores que os torna inapropriados para este trabalho. Além disso, eles encaixam-se no mesmo tipo de software que o Apache Axis2, que também pode ter os serviços criados publicados por um container de servlets, mais especificamente o Apache Tomcat. Comparados ao Apache Axis2 eles perdem em relação à estabilidade da API, documentação disponível e maturidade do código.

Em uma outra categoria de software está o Jetty, um servidor web completo escrito inteiramente em Java e que possibilita o uso de extensões para fornecer conteúdo dinâmico. Ele possui características semelhantes ao Apache Tomcat como a configuração através de arquivos $\boldsymbol{X} \boldsymbol{M L}$, a capacidade de ser um container para servlets e a ligação com outros software como o JBoss, Geronimo e JOnAS (Ow2, 2008). Além da ligação com estes softwares, que possuem uma função mais ampla, o Jetty e Apache Tomcat também podem ter inseridos dentro deles APIs para web services como XFire, Celtix e Apache Axis. Um fator que faz o Apache Tomcat se destacar em relação ao Jetty é que o primeiro é a implementação de referência de servlets (Moodie, 2008) e, como muitas das APIs para web services que usam como base servlets, o Apache Tomcat oferece maior compatibilidade.

\subsubsection{Apache Tomcat}

Para se chegar ao desenvolvimento do Apache Tomcat deve-se iniciar com a transição da web de conteúdos estáticos para dinâmicos. Após o aparecimento de CGI (Common Gateway Interface), surgiram outras maneiras de se coletar e processar conteúdo web. As tecnologias que receberam atenção considerável foram as derivadas da linguagem Java, linguagem esta que se destaca pelo apelo à portabilidade. Java proporcionava aos desenvolvedores web criar applets como aplicações executadas no navegador de qualquer plataforma, desde que o mesmo possuísse uma máquina virtual Java. Com o passar do tempo os applets foram perdendo espaço para outras aplicações como Adobe Flash nas aplicações executadas no lado do cliente.

Uma outra tecnologia derivada de Java e que possibilitava a criação de conteúdo dinâmico executado no lado do servidor eram os servlets. Estes últimos estão presentes até 
hoje no desenvolvimento de conteúdo dinâmico para a web. Seu funcionamento é simples: eles necessitam de um container de servlets e um servidor HTTP. O servidor HTTP recebe as requisições vindas de usuários remotos pelo protocolo HTTP, através de métodos post e get (o primeiro comumente utilizado para enviar dados do cliente para o servidor e o segundo no caminho inverso). Dentro dele existem regras que mapeiam os endereços das páginas para conteúdos estáticos e dinâmicos muitas vezes os relacionando com a própria extensão do arquivo a ser acessado no servidor.

Uma vez que o servidor HTTP consiga descobrir qual o objetivo/tipo da requisição, ele a encaminha para o container de servlets, se for o caso, ou então fornece um documento estático para o usuário diretamente. Quando as requisições chegam ao container de servlets, outro processo de mapeamento ocorre para descobrir qual é o servlet que corresponde àquela requisição. Encontrado o servlet, que na prática, nada mais é que uma classe Java, o container executa um processo carregador de classes (class loader) e inicia a classe do servlet em uma nova thread do seu próprio código, passando como parâmetros os dados da requisição, os quais podem ser retirados do método GET Ou POST.

Além dos servlets, existe a possibilidade de inserção de chamadas a classes Java dentro de um documento HTML, construindo um documento híbrido Java/HTML. O processo de execução desse documento se dá praticamente da mesma maneira que nos servlets, com a diferença que podem existir diversas chamadas a classes Java por todo o documento. Esse método de construção de documentos é chamado de JSP (Java Server Pages) e, assim como os servlets, se tornou popular. Atualmente ele é um concorrente expressivo em relação a linguagens como ASP (Active Server Pages) e PHP (PHP Hypertext Preprocessor).

O Apache Tomcat é um container de servlets que tem a característica de ser a implementação de referência de servlets, ou seja, o seu intuito é ser completamente compatível com a especificação de servlets definida pela Sun Microsystems. Isto faz com que ele seja, na maioria das vezes, o primeiro software a refletir alterações na especificação citada.

Na origem do Apache Tomcat estão dois softwares, o Java Web Server desenvolvido pela Sun Microsystems e o JServ criado pela ASF (Apache Software Foundation). Ambos criados com o intuito de serem containers de servlets. O primeiro software não era suficientemente robusto para os padrões de seus criadores, o que fez com que seu código fosse doado para a ASF. Neste momento (por volta de 1999) houve a fusão do JServ e Java Web Server. A primeira versão do Apache Tomcat, derivada dessa fusão, foi a versão 3.0. Desde 2001 foram lançadas as versões 4, 5 e 6 sendo que nas versões 4 e 5 houve 
reconstruções completas da arquitetura do software.

O Apache Tomcat possui uma estrutura modular, na qual os seus elementos podem ser classificados dentro de 4 categorias: elementos de alto nível, conectores, containers e elementos aninhados. Os elementos de alto nível estão no topo da configuração e possuem uma estreita relação de configuração com elementos da mesma categoria. Os elementos da categoria conector ligam o Apache Tomcat às requisições, sejam elas vindas de navegadores ou de outros servidores. Os elementos da categoria container contém uma coleção de outros elementos. Os elementos do tipo aninhados podem ser inseridos dentro de containers, mas não podem conter outros elementos. A Fig. 3.1 contém a estrutura do software englobando os elementos de todas as categorias. Os elementos apresentados são configurados através de um documento $\boldsymbol{X M L}$ que contém a configuração do software, especificando cada elemento como uma sub-árvore do documento $\mathbf{X M L}$.

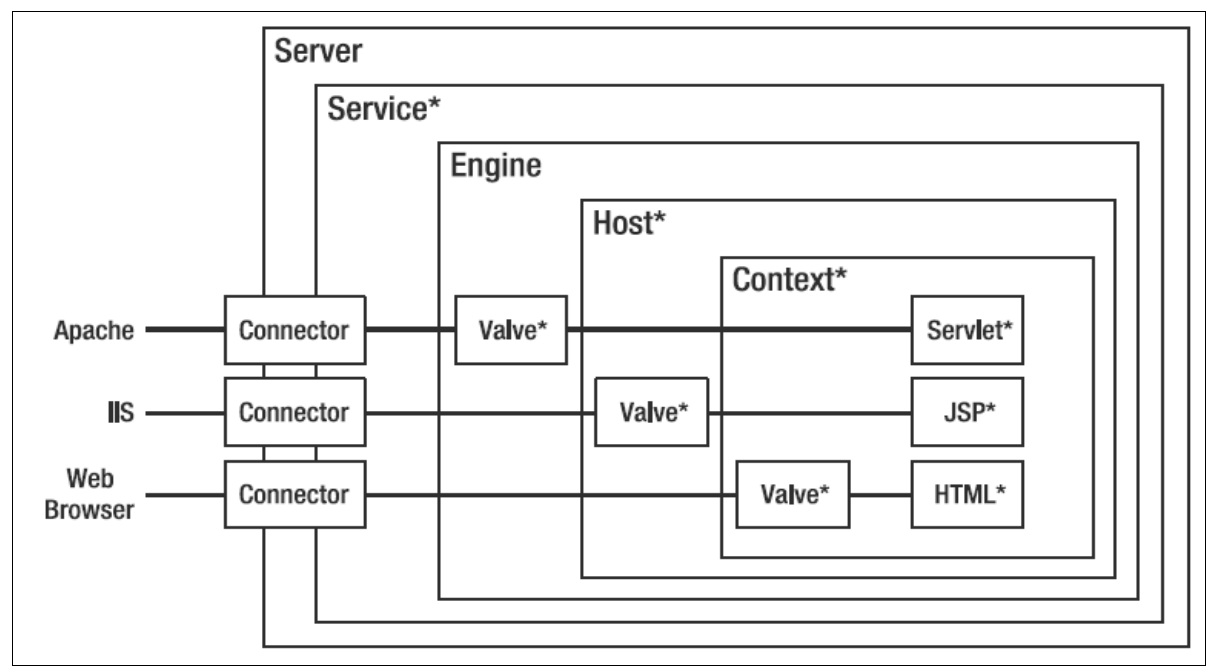

Fig. 3.1: Estrutura do Apache Tomcat (Moodie, 2008)

O primeiro elemento e mais básico da estrutura é o Server, que é um elemento do tipo alto nível. Ele representa uma instância do Apache Tomcat em uma máquina virtual Java. Somente um Server pode executar em uma máquina virtual, com o intuito de evitar que falhas em uma instância do Apache Tomcat em uma determinada máquina virtual pare outras instâncias. Essa abordagem é útil em ambientes onde o servidor no qual o Apache Tomcat está instalado atende a mais de uma empresa, cada uma em uma instância do software. Se por algum motivo uma aplicação de determinada empresa causa um problema em uma máquina virtual, o atendimento às outras não é afetado.

O elemento Server contém todos os outros elementos. Essa característica pode ser vista também no próprio arquivo de configuração, que coloca a configuração do software em hierarquia assim como a sua estrutura.

O segundo elemento da hierarquia é o Service, ele é a união entre os elementos 
conectores e o elemento Engine. O elemento Engine é quem recebe as requisições vindas do protocolo HTTP e identifica para qual aplicação Java uma requisição deve ser enviada.

Os elementos conectores ligam os clientes com o Engine, eles são a porta de entrada das requisições para as aplicações. Através do uso de um conector o Apache Tomcat pode ser ligado diretamente a um servidor HTTP básico ou ainda conectado com servidores web, como o Apache HTTP Server (popularmente conhecido apenas por Apache) e o IIS (Internet Information Service).

Na categoria de elementos container estão três elementos: o Engine, Host e Context. O elemento Engine é o container de mais alto nível. Ele deve estar dentro do elemento Service, sendo que este último pode ter apenas um elemento Engine dentro de si. O Engine padrão do Apache Tomcat é o processador de servlets denominado Catalina. É ele que de acordo com a requisição recebida redireciona-a para o elemento Host e context que é responsável por processá-la.

O elemento Host é semelhante à configuração de hosts virtuais dentro do servidor web Apache (Moodie, 2008). Dentro de um pacote HTTP há a identificação do host (como p.ex. o nome www.icmc.usp.br), para qual há a intenção de enviar o pacote. Essa informação é utilizada pelo elemento Engine para identificar qual o Host que receberá a requisição. Podem haver vários elementos Host dentro de um Engine para receber diferentes requisições, permitindo que um mesmo endereço $\boldsymbol{I P}$ receba requisições para hosts diferentes.

O último dos elementos do tipo container é o Context. Ele é o servlet ou aplicação em si. Na sua configuração é indicado o caminho onde o processador de servlets deve procurar as classes que podem atender às requisições. No elemento Context também podem ser especificadas as regras de autenticação e autorização de acesso.

Existem diversos elementos na categoria de elementos aninhados, o Global é um deles e só pode ser colocado dentro de um elemento Server. Ele fornece fontes JNDI (Java Naming and Directory Interface) como conexões para bancos de dados e variáveis globais do servidor. Outro elemento do tipo aninhado é o Loader, que é colocado dentro do elemento Context e, cuja função é carregar as classes dos servlets. O elemento Manager, assim como o Loader, só pode ser colocado dentro de um Context e é responsável por gerenciar sessões entre os clientes e os servlets. O elemento Realm é colocado dentro de um elemento Engine e fornece suporte para a autenticação de usuários e regras de acesso. Os elementos Valve podem ser adicionados em qualquer container e têm a função de interceptar requisições antes que elas entrem no container. Eles podem ser usados para gerar logs de tráfego de requisições dentro do Apache Tomcat e não são perceptíveis para os clientes que acessam um recurso do 
servidor. O elemento Valve é uma adição às funcionalidades do Apache Tomcat e não é descrito na especificação de servlets. Um elemento de função semelhante ao Valve é o elemento Filter (definido na especificação).

O Apache Tomcat fornece suporte a implementações em clusters. O suporte é focado em replicação de sessões e publicação automática entre os nós formadores do cluster. A replicação de sessões é responsável por continuar a mesma interação que um outro nó estava fazendo com um cliente mesmo que o nó pare. As interações entre cliente e servidor no Apache Tomcat geram alguns dados, como variáveis ou conexões com banco de dados feitas pelo servlet, as quais podem ser armazenadas e recuperadas à medida que o cliente navega entre as páginas dinâmicas. Os dados gerados são armazenados em sessões. Para que mantenha-se o funcionamento de uma sessão, mesmo que ocorra interrupção de funcionamento em um nó, os outros nós precisam também ter as sessões armazenadas. Surge então o conceito de replicação, pois as sessões iniciadas em um nó são replicadas em outros nós. Além do suporte a sessões em clusters, o Apache Tomcat fornece também a publicação automática, ou seja, uma vez que uma aplicação seja publicada em um nó, a publicação é repassada aos outros que também fazem a publicação da aplicação.

O suporte para clusters dentro do Apache Tomcat não contempla a distribuição das requisições ou balanceamento de carga. Para implementar essas características podem ser usadas as seguintes abordagens: distribuição por DNS, distribuição por NAT (Network Address Translation), ligação entre Apache HTTP Server e Apache Tomcat, acesso à base de dados e através de uso de $\boldsymbol{E} \boldsymbol{J B}$.

A distribuição por $\boldsymbol{D N S}$ é a mais simples, implementada com alguns produtos como o Eddie (Eddie, 2007), Foundry Network ServerIron (Foundry Network, 2007) e Cisco DistributedDirector (Cisco, 2007). Os problemas oriundos dessa abordagem são: a carga das máquinas não é considerada; a maioria dos pacotes utiliza apenas round-robin; não há tolerância a falhas (como recuperação de sessões); as soluções não levam em conta servidores que param de responder e continuam submetendo cargas a eles; vários servidores intermediários entre o cliente e o servidor podem usar cache para os nomes, fazendo com que um cliente receba sempre o mesmo endereço de acesso baseado na $\boldsymbol{U} \boldsymbol{R} \boldsymbol{L}$ que ele deseja, não aplicando a distribuição corretamente (Cardellini, 1999).

A segunda abordagem é a utilização de distribuição por NAT (Network Address Translation). Ela apresenta maior flexibilidade quando são considerados servidores "fora do ar", isto é, tolerância a falhas e alta disponibilidade. Porém, como na abordagem anterior, elas trabalham em um nível mais baixo do modelo ISO OSI, dificultando ao balanceador obter informações referentes à requisição de algum serviço. 
A distribuição de requisições também pode ser aplicada na camada de banco de dados. Quando algum serviço estiver sendo executado e necessitar de dados, a requisição irá ser direcionada para o cluster de banco de dados e o balanceamento decidirá qual o melhor nó do cluster para fornecer o dado. Esse tipo de distribuição apresenta algumas soluções como MySQL Cluster (Mysql AB, 2007), PG Cluster (Pgcluster, 2007), Slony (Slony-l, 2007), Sequoia (Continuent.org, 2007), além de outras soluções proprietárias como Oracle e Microsoft. Este modelo de utilização de clusters com balanceamento não trabalha diretamente no web service, mas nos dados que eles necessitarão. No caso de serviços que precisam de mais processamento do que obtenção de dados, a estrutura do cluster não será muito utilizada, pois o gargalo será o processamento dentro do provedor de serviços.

Em (Sicard et al., 2006) é apresentada a abordagem de distribuição de requisições através de $\boldsymbol{E} \boldsymbol{J} \boldsymbol{B}$. Para a implementação é usado um método de invocação remota de procedimentos chamada CMI (Clustered Method Invocation). Essa abordagem permite que o próprio web service realize a chamada a um outro método para que este então faça a distribuição de cargas. Desse modo, o provedor de web service continua recebendo todas as requisições e não há distribuição no seu nível. Usando esse método, o gargalo continua sendo o provedor de web services, embora o problema seja de fato reduzido, pois boa parte do processamento é encaminhado ao cluster. No entanto, o trabalho de desempacotamento e invocação de métodos remotos é realizado pelo provedor de web services. Além disso, a invocação remota de métodos não possui a portabilidade que o protocolo $\mathbf{S O A P}$ e os web services apresentam, dificultando o gerenciamento de políticas que operam com todas as aplicações e, conseqüentemente, trabalham com informações mais detalhadas das requisições.

O Apache Tomcat oferece um método de distribuição de requisições através da sua ligação com o Apache HTTP Server pelo AJP (Apache Jserv Protocol). Essa ligação está presente em estruturas cujo intuito é fornecer páginas de internet com conteúdo estático e dinâmico. Em estruturas como essa, o Apache HTTP Server desempenha o papel de atender às requisições por páginas estáticas e o Apache Tomcat é usado para processar servlets ou $\boldsymbol{J S P}$. Além de servlets e $\boldsymbol{J S P}$, essa estrutura também pode atender requisições para conteúdo dinâmico processados por um interpretador $\boldsymbol{P H P}$.

Quando o Apache HTTP Server recebe uma requisição para uma página dinâmica (servlet ou JSP) e identifica que deve enviar para o Apache Tomcat, ele o faz pelo módulo mod_jk, um conector agregado a seu código através de uma biblioteca de ligação dinâmica. O mod_jk recebe a requisição repassada pelo servidor HTTP e de acordo com algumas configurações realiza o encaminhamento para o Apache Tomcat. O módulo pode ser configurado para trabalhar em clusters com distribuição de requisições e balanceamento de 
carga. Seu comportamento de distribuição se baseia no princípio de fila circular, tentando atribuir uma requisição para cada instância do Apache Tomcat presente nos nós do cluster. A distribuição de requisições através do mod_jk é a melhor abordagem que se pode contar atualmente para realizar a distribuição. Porém existem alguns problemas, como não considerar as cargas dos nós. Informações como uso de processador, memória ou outros recursos computacionais não são considerados. Dessa forma, influências externas aos nós, como processos com execução em segundo plano ou processos agendados, podem concorrer com o Apache Tomcat no nó, eventualmente causando retardo no processamento.

O módulo mod_jk não é dinâmico, ou seja, não toma decisões em tempo de execução para direcionar o fluxo de requisições para o nó mais adequado para aquele momento. A heurística a ser usada para distribuir as requisições é determinada antes da sua execução. Outro fator negativo envolvido no mod_jk é que ele trabalha com o protocolo HTTP diretamente, assim ele não tem informações referentes ao web service que está sendo requisitado. Esse tipo de informação está dentro do envelope SOAP. O módulo mod_jk nem mesmo toma ciência se ele está executando um web service ou apenas um servlet. Não há também implementado no módulo uma diversidade de políticas de distribuição, há apenas a round-robin seguindo alguns critérios como o número de requisições enviadas ou o número de requisições ativas.

A estrutura descrita composta por Apache HTTP Server e Apache Tomcat aplica-se a um cenário de atendimento de requisições a conteúdo web em geral. Em situações onde é necessário apenas o uso de web services, não é necessário o uso do Apache HTTP Server, fazendo com que as aplicações façam as requisições diretamente ao Apache Tomcat. Isso diminui o número de camadas de software que a requisição terá que passar até ser processada, implicando em diminuição da sobrecarga e aumento de desempenho.

\subsubsection{Apache Axis}

O Apache Axis ou Axis (Apache eXtensible Interaction System) é um framework para construir clientes, servidores e gateways para SOAP. Ele possui implementações voltadas para Java e para $\mathbf{C + +}$ e inclui, além do suporte ao desenvolvimento, as seguintes características: um servidor simples para receber as requisições, ligação através de servlets com o Apache Tomcat, suporte atualizado a WSDL, ferramentas para geração de classes baseado em $\boldsymbol{W S D L}$ e ferramentas para monitoração de pacotes.

Considera-se que a versão atual do Axis é a terceira geração de frameworks SOAP. A primeira geração foi marcada pelo SOAP4J, desenvolvido pela IBM por volta de 1996. A 
segunda geração iniciou-se com a passagem do controle do SOAP4J para o grupo Apache, criando o Apache SOAP, que foi seguido pelo desenvolvimento do Axis.

A motivação para sua criação caracterizou-se pelas diversas propostas existentes para a sua implementação que convergiam para um ponto em comum: a criação de um conjunto de funcionalidades pequenas que poderiam ser compostas para cumprir funções maiores aumentando a sua flexibilidade. O conceito envolvido nas propostas era o de criar uma cadeia de mensagens que pudessem ser repassadas para cada pequena função exercer sua tarefa sobre ela.

Em agosto de 2004 foi introduzida a versão 2 do Axis, ou simplesmente Axis2. Ela apresenta uma nova arquitetura em relação à versão 1 (criada apenas como prova de conceito (Jayasinghe, 2008)) e possui maior flexibilidade, eficiência e possibilidade de configuração em relação à anterior. A última versão suporta não só o uso do protocolo SOAP (versões 1.1 e 1.2), mas também o desenvolvimento de web services baseados em REST. Ela clama por apresentar modularidade e dar melhor suporte para $\boldsymbol{X M L}$, não só o utilizando em sua configuração, mas também nas bibliotecas para o usuário (The Apache Software Foundation, 2008d).

As extensões para web services WS-ReliableMessaging, WS-Coordination, WSAtomicTransaction, WS-Security e WS-Addressing possuem implementações através de módulos que podem ser adicionados ao Axis2 (The Apache Software Foundation, 2008d).

O Axis2 possui um modelo de objetos chamado AXIOM (Axis Object Model) que possibilita um melhor desempenho usando processamento de $\boldsymbol{X} \boldsymbol{M L}$ baseado no método pull. O uso do AXIOM faz com que não seja necessária a criação de stubs para a comunicação com web services. Como o $\mathbf{A X I O M}$ trabalha em contato mais direto com $\mathbf{X M L}$, sendo seu desempenho superior ao dos stubs (The Apache Software Foundation, 2008d).

O uso do Axis2 para este trabalho apresenta-se como uma boa escolha, uma vez que ele apresenta documentação acessível e organizada. Devido ao seu suporte a muitos avanços na área de web services, ele desperta interesse da comunidade de desenvolvimento envolvida no tema. Ele é liberado sob a licença do grupo Apache, o que o faz um software livre, contribuindo ainda mais para seu uso. Sua API também é mais estável em comparação com as outras ferramentas analisadas.

Comparando as ferramentas analisadas, o Apache Tomcat e o Axis2 demonstram características positivas ao trabalho sendo, por isso, utilizados extensivamente. 


\subsection{Distribuição de requisições}

O escalonamento de processos é um tema muito pesquisado na computação distribuída onde, de maneira simplista, vários processadores distribuídos recebem programas para serem executados. Quando se trata do contexto de $\boldsymbol{S O A}$, que pode ser implementada por meio de sistemas distribuídos, ao invés de apenas processos, podem ser consideradas requisições a diversos serviços como objeto da divisão. A analogia aos processos pode ser considerada pelo fato de requisições, no momento em que chegam a um servidor, fazem com que este último execute certo processamento (podendo executar um processo ou uma thread).

Por ser um problema comum no dia-a-dia da computação distribuída, o problema de escalonamento possui vasta literatura, surgindo várias nomenclaturas e taxonomias (Souza et al., 2000). Apesar das várias definições e discussões na área, existe um ponto de partida no estudo sobre escalonamento. Casavant e Kuhl (1998) diferenciam o escalonamento como local e global. O primeiro é relacionado à situação onde há a atribuição de processos a um único processador, cenário encontrado em um sistema operacional , por exemplo. O segundo é definido como um recurso para a gerência de recursos. Os elementos para o escalonamento global são os consumidores, o escalonador e os recursos. Os consumidores são os usuários e suas aplicações. Os recursos podem ser processadores, memórias, dispositivos de comunicação, entre outros. O escalonador é quem realiza a alocação dos recursos aos consumidores e é composto por uma política que dita como serão as regras para a alocação.

Com o uso crescente de clusters para atender requisições a web services, faz-se necessário o uso de algum instrumento que faça o escalonamento, nesse caso o escalonamento global, das requisições para cada um dos nós do cluster. O escalonamento ou distribuição das requisições pode ter diversos fatores motivantes. Se for considerado um cluster onde todos os nós tenham o mesmo poder de processamento (ambiente homogêneo) e que todos eles possam atender a um certa requisição no mesmo intervalo de tempo, pode ser que o envio de uma requisição para cada nó (round-robin) seja uma boa abordagem. Essa solução pode ser implementada de maneira estática sempre com a mesma regra de distribuição. Nesse mesmo ambiente, pode ser que haja além das requisições, outros processos em execução nos nós, tornando o mesmo inapto à execução. Para solucionar esse problema, segue-se uma abordagem dinâmica, que reaja ao estado atual do sistema.

A tarefa de otimizar o uso de um sistema distribuído, ou seja, encontrar a melhor solução possível para o atendimento de uma requisição é uma tarefa complexa. Na maioria dos casos ela é um problema NP-completo, podendo ter solução viável apenas em casos específicos como, por exemplo, um número fixo de processos com tempo de processamento 
conhecido e dois processadores (Shirazi et al., 1995). Assim, torna-se mais interessante realizar a distribuição baseada em heurísticas, com parâmetros que afetam a plataforma de maneira indireta (Souza et al., 2000).

Neste trabalho, a distribuição das requisições pode ter diversos fins, seja melhorar a utilização dos processadores, melhorar o tráfego de informações pela rede do cluster, melhorar o acesso à base de dados, entre outros.

Nos softwares como o JBoss ou Apache Tomcat a distribuição das requisições é feita de maneira simples, sem conhecimento do estado dos nós do cluster. A política usada neles é round-robin, enviando as requisições à medida em que chegam para cada nó. Quando já foram atribuídas requisições para todos os nós, a distribuição recomeça pelo que recebeu a primeira requisição e continua da mesma maneira. Um esquema semelhante ao round-robin também é usado nas outras abordagens como distribuição por DNS e por NAT.

Há uma lacuna a preencher no atendimento a web services levando em consideração as informações do próprio serviço, como sua demanda por comunicação, por acesso a unidades de armazenamento ou processamento. Também não há softwares que realizem a distribuição relacionando o serviço com o estado das máquinas, como a sua carga de processamento atual, tráfego de rede, tráfego em dispositivos de armazenamento, número de processos em execução, entre outros. Outra característica que torna interessante uma distribuição mais eficiente de requisições, não encontrada nos softwares estudados, é a flexibilidade referente ao uso de várias políticas ou a criação e incorporação de novas políticas aos softwares.

Para que a distribuição seja realizada levando em conta a carga de trabalho dos nós do cluster é necessário que de alguma forma eles sejam monitorados e que essas informações sejam disponibilizadas para o escalonador. A ferramenta Ganglia (Massie et al., 2004) é um monitor de sistemas escalável para computação de alto desempenho. Ela foi projetada para ser utilizada com clusters e em estruturas de clusters trabalhando como federações ${ }^{3}$. Ela usa comunicação multicast para a publicação dos nós do cluster na rede. Para a comunicação entre federações ela usa uma comunicação ponto-a-ponto em forma de árvore, tornando-a apta a passar pela maioria das estruturas de rede. Ela usa a linguagem $\boldsymbol{X M L}$ para a publicação dos dados dos nós pela rede e usa $\boldsymbol{X D R}$ no protocolo de transporte. Sua implementação é robusta e provou ser eficaz na prática, sendo usada por mais de 500 clusters pelo mundo, tendo muitos usuários de grande porte e bem conhecidos (Massie et al., 2004). A ferramenta Ganglia se mostrou interessante para o projeto, pois sua proposta permite a fácil coleta de dados dos nós do cluster por outros softwares por meio de comunicação TCP/IP.

Com o grande interesse em Java na comunidade que desenvolve não só web services,

3 conjuntos de clusters 
mas também aplicações empresarias, JMX (Java Management Extension) mostra-se como um apoio para a monitoração de aplicações Java. $\boldsymbol{J} \boldsymbol{M} \boldsymbol{X}$ é uma tecnologia que faz parte da máquina virtual Java em sua versão padrão (J2SE), adicionada a partir da versão 5.0. Ela fornece uma maneira simples e padronizada para gerenciar recursos Java, inclusive a própria máquina virtual. A especificação $\boldsymbol{J M X}$ define a arquitetura, os padrões de projeto, $\boldsymbol{A P I}$ s e serviços na linguagem Java para gerenciar e monitorar aplicações e redes (Sun Microsystems, 2008b). Como pretende-se usar a linguagem Java no projeto e levando em consideração que o Apache Tomcat e Axis2 são desenvolvidos nessa linguagem, a aplicação de $\boldsymbol{J} \boldsymbol{M} \boldsymbol{X}$ torna-se atrativa. Sua capacidade de monitorar elementos Java pode ser útil para fornecer informações sobre o estado dos softwares utilizados. As informações obtidas podem até mesmo ser disponibilizadas através da ferramenta Ganglia por meio da sua capacidade de adição de novas métricas.

\subsection{Considerações finais}

Foram abordadas neste capítulo algumas ferramentas que auxiliam no desenvolvimento e publicação de web services. As ferramentas apresentadas que suportam a publicação de web services são Apache Tomcat e Jetty. As ferramentas que auxiliam no desenvolvimento são: o Apache Axis2, Celtix e XFire. Foram também apresentadas ferramentas que realizam ambas as tarefas, sendo elas IBM WebSphere e JBoss. Além do suporte a web services, foi destacada a distribuição de requisições, mostrando sua classificação em analogia ao escalonamento de processos. Em virtude da maneira como a distribuição pode ser realizada, também foram apresentadas formas de monitoração para o uso em políticas dinâmicas de distribuição. As ferramentas citadas em relação à monitoração foram Ganglia e $\boldsymbol{J} \boldsymbol{M}$.

Baseado no texto apresentado, este trabalho utiliza as ferramentas Apache Tomcat e Apache Axis2 para efetuar o desenvolvimento e publicação dos web services. Também é utilizado o JBoss devido a sua compatibilidade com o Apache Tomcat. A arquitetura é implementada em um protótipo e ligada, para o fim de teste, na ferramenta Apache Tomcat. Recursos como a criação de clientes e servidores dentro do trabalho utilizam principalmente o Apache Axis2. Além das ferramentas diretamente relacionadas com web services, a arquitetura encaixa-se na categoria de distribuição de requisições dinâmica e heurística. Por isso, é importante para o trabalho a ferramenta Ganglia, para efetuar a monitoração necessária. Dependendo das necessidades, $\boldsymbol{J} \boldsymbol{M} \boldsymbol{X}$ pode ser útil na monitoração de aplicações Java, auxiliando a construção de políticas. 



\section{Trabalhos relacionados}

\subsection{Considerações iniciais}

Este capítulo mostra o levantamento de alguns trabalhos relacionados com o tema de web services, mais especificamente na área de distribuição de requisições para web services. São apresentados inicialmente três artigos relacionados entre si, que tratam da distribuição de requisições com uma abordagem descentralizada voltada para $\boldsymbol{Q o S}$. A seguir é apresentado um trabalho relativo à distribuição de carga adaptativa e auto configurável. Outro trabalho apresentado diz respeito ao desempenho de funções para distribuição de requisições mostrando uma maneira aproximada para uma melhor distribuição de requisições diminuindo sua complexidade. Em seqüência é apresentado um trabalho sobre a distribuição de requisições para aplicações distribuídas em várias camadas. O último trabalho trata da reconfiguração de parâmetros em servidores para o melhor atendimento de requisições.

\subsection{Trabalhos relacionados}

O trabalho apresentado em (Adam; Stadler, 2006) propõe um sistema de distribuição de requisições com arquitetura distribuída em clusters para prover web services. O principal argumento para o uso dessa arquitetura é que um sistema centralizado não fornece escalabilidade, apresenta dificuldade de configuração e pouca robustez. A proposta leva em consideração um ambiente onde todos os nós do cluster são iguais, ou seja, um cluster homogêneo, por isso há facilidade de configuração. Para diminuir a sobrecarga e aumentar a escalabilidade, cada nó armazena apenas informações de alguns nós a sua volta.

Outra característica é que o sistema se auto organiza, ou seja, em caso de falha de algum nó, ele é automaticamente excluído das listas dos outros nós. O sistema também leva em conta a carga de trabalho sobre o processador, através do uso de um parâmetro que apenas diz se o processamento, ou utilização, atual do nó é elevado ou baixo em relação a um limite 
estabelecido.

Um dos objetivos desse trabalho é possibilitar o uso de diretivas de $\boldsymbol{Q o S}$ no atendimento à diferentes classes. A propagação das informações sobre o estado do sistema e sobre as decisões de distribuição é realizada por um protocolo epidêmico (Tanenbaum; Van Steen, 2002).

Esse trabalho é a concretização do projeto proposto em (Adam, 2006) e implementa um protótipo chamado Chamaleon. O cenário sob o qual o protótipo atua é em uma arquitetura onde há vários clientes conectados através da internet fazendo acesso ao provedor de serviço. $\mathrm{O}$ acesso do cliente é primeiro recebido por uma entidade denominada como ponto de entrada, e que atua como um switch na camada 7 do modelo OSI. Este ponto de entrada seleciona um entre vários clusters de servidores e redireciona a requisição para o cluster escolhido. A requisição é encaminhada para um nó do cluster, que pode ser qualquer um que esteja na lista do ponto de entrada. Uma vez que o nó escolhido recebe a requisição, uma análise é realizada dentro dele sobre uma função que tenta minimizar o tempo de resposta e o número de descarte de requisições.

O protótipo foi implementado e ligado ao Apache Tomcat sob a argumentação de que este software é amplamente divulgado como um software de código aberto e apresenta uma implementação simples. No trabalho também é citado que o protótipo pode ser ligado a qualquer provedor de web services que dê suporte a filtros de aplicações e como exemplo é mencionado o software IBM Websphere.

O processo de tratamento da requisição inicia-se quando o Tomcat recebe a requisição e a redireciona, dentro dele mesmo, para o contexto de tratamento. Dentro do contexto, é aplicado um filtro à mensagem, este realiza as tarefas de monitoração da utilização de $\boldsymbol{C P U}$ do nó e o cálculo da função de decisão de atendimento.

Podem existir três decisões, o atendimento da requisição por este nó, o descarte da requisição ou o seu redirecionamento para outro nó. $\mathrm{O}$ atendimento é feito quando a utilização de $\boldsymbol{C P U}$ está abaixo de um limite máximo, estabelecido através da análise do comportamento do sistema para que ele reaja melhor a situações de influências externas e sobrecargas. $\mathrm{O}$ descarte ocorre quando o tempo em que a mensagem está sendo redirecionada entre nós é muito alto. Este tempo é determinado pela diferença calculada usando um campo no cabeçalho HTTP que marca tempo de entrada da requisição e o tempo local da máquina. Para que as máquinas possam realizar esse cálculo, elas devem estar sincronizadas usando o protocolo NTP (Network Time Protocol). O redirecionamento de uma requisição ocorre quando o uso de $\boldsymbol{C P U}$ local está acima do limite. O nó para onde é realizado o redirecionamento é determinado por uma lista local que contém alguns dos nós do cluster que 
estão mais próximos do nó que está tomando a decisão. Quando há o redirecionamento, o processo de decisão ocorre novamente na outra máquina, e se outro redirecionamento for necessário ele também se dará da mesma forma até que o tempo máximo de atendimento da requisição esgote-se. O redirecionamento da requisição usa um método de "request chaining" onde a resposta deve viajar por todos os servidores por onde ela foi redirecionada. O sistema de monitoramento utilizado possibilita a aquisição de dados sobre a taxa de requisições, média do tempo de resposta e média de uso de processador.

Os testes realizados nesse trabalho utilizaram o benchmarck TPC- $\boldsymbol{W}$, que é voltado para a simulação de cargas de serviços semelhantes aos encontrados em empresas, usando consultas à base de dados e transações. Os resultados apresentados mostraram que a proposta conseguiu cumprir os objetivos de QoS propostos, diferenciando as classes de serviço utilizadas no teste, quando a carga excedeu o limite de 1000 clientes conectados. A escalabilidade não pode ser comprovada, pois foram utilizados apenas doze nós no cluster. O trabalho deixa algumas questões em aberto como a afinidade de aplicação e servidor ${ }^{4}$. O escalonamento das requisições através do seu perfil também não é coberto pelo trabalho e são citados trabalhos sobre determinação de perfil de aplicações.

Outro fator relacionado ao desempenho é quanto ao redirecionamento das requisições entre os nós do cluster, pois quando houver muitos redirecionamentos, a quantidade de conexões abertas pode afetar o desempenho. Os testes realizados não relacionam um crescimento gradativo do cluster, o que pode apontar para uma melhor conclusão sobre escalabilidade e para a sobrecarga gerada pela distribuição das requisições. O uso de $\mathbf{N T P}$ para manter a sincronia entre os nós pode trazer mais complexidade à configuração.

Em (Adam, 2006) é proposto e validado um modelo de distribuição de requisições para clusters de provedores de web services com foco em QoS através de simulação. A implementação desse trabalho foi citada anteriormente em (Adam; Stadler, 2006) e apresenta algumas limitações em relação ao modelo proposto neste último. A simulação utilizou uma ferramenta denominada JavaSim que possibilita simulações orientadas a evento. Os principais pontos destacados no trabalho são: o uso de um mecanismo peer-to-peer para a conexão entre os provedores de serviço dentro do cluster; as características apresentadas pela função de utilização do sistema; a eficiência do protocolo de propagação baseado em protocolo epidêmico. Para alcançar os objetivos na distribuição das requisições, é utilizada a função de utilização. Ela é associada a dois parâmetros de desempenho, o máximo tempo de resposta e a taxa máxima de rejeições.

4 Capacidade do cliente continuar executando uma aplicação que havia aberto uma sessão em um servidor continuar acessando o mesmo servidor. 
Na simulação, os servidores executam apenas um tipo de serviço por vez, apesar do sistema todo poder utilizar mais de um serviço. Este é um avanço frente ao trabalho apresentado anteriormente em (Adam; Stadler, 2005). O ponto vital para essa proposta foi o uso do protocolo de disseminação de Newcastle que possui a característica de manter os nós do cluster agrupados segundo um fator de conectividade $\boldsymbol{c}^{5}$, facilitando a troca de informações entre eles e a configuração do sistema.

Devido à característica do sistema ser distribuído, podendo todos os nós serem distribuidores de requisições, espera-se que o modelo de software proposto adapte-se automaticamente a falhas no sistema, como a queda ou a sobrecarga de um nó. Além disso, a distribuição elimina um ponto central de falha.

Outro ponto que chama a atenção é o mecanismo de seleção de serviço apresentado. Ele é necessário, pois os servidores executam apenas um serviço por vez. Ele atua em um servidor fazendo com que este selecione para si o serviço que melhora a função de utilização dos vizinhos. Se os seus vizinhos estão sobrecarregados para atender um determinado serviço ele pode começar a atendê-lo para reduzir o acesso aos outros nós.

Os resultados apresentados nesse trabalho mostram que é possível manter os contratos de $\boldsymbol{Q o S}$ estipulados com o uso da função de utilização apresentada. As simulações levaram em consideração quatro cenários: média carga de entrada com pouca flutuação, média carga seguida por sobrecarga, mudança de prioridade de um serviço durante a execução e falhas em servidores. Três serviços foram considerados na simulação apresentando diferentes contratos entre eles com $\mathbf{Q o S}$ relativa.

Não são avaliados nesse trabalho servidores que possam atender múltiplos serviços ao mesmo tempo, ou seja, para um servidor atender um outro serviço diferente do que ele executava, ele deve deixar de executá-lo para atender outro. Outra questão importante é que as decisões de distribuição tentam melhorar o uso de apenas um recurso, neste caso a $\boldsymbol{C P U}$. O trabalho deseja manter destaque na função de utilização, mas ela é influenciada diretamente por qual recurso deseja-se basear a decisão. Não fica clara qual é a relação da função de utilização com outras métricas ou mesmo métricas compostas. A característica de prover facilidade de configuração durante o funcionamento é relativa, pois o que é alterado durante os testes são os parâmetros de contrato de um determinado serviço. Apesar disso o sistema se reconfigura automaticamente e continua funcionando com a queda de servidores. É considerado na simulação que todos os servidores possuem a mesma potência computacional, caracterizando um cluster homogêneo. Como os servidores apenas executam um serviço e há homogeneidade, não é mencionado nada sobre a variação da distribuição da carga em relação 
à mudança de fatores externos ao provedor de serviço.

Embora a transparência de configuração apresentada pelo protocolo epidêmico seja um fator muito positivo para a proposta, ele tira das mãos do usuário totalmente o controle de configuração da função de cada nó no cluster. Não é exposto pelos autores também nenhuma maneira pela qual possam ser criadas políticas de distribuição diferentes para um determinado serviço ou cliente, podendo implicar na falta de controle sobre as demandas de cada serviço frente ao seu conteúdo.

Chess (2005) propõe um sistema de distribuição de carga e gerenciamento de clusters para web services com a visão de computação autônoma, ou seja, fazendo com que os nós do cluster encontrem uma maneira de se distribuir automaticamente para fornecer um melhor aproveitamento de seus recursos.

O sistema proposto é representado por dois elementos básicos, um gerenciador de grupo de nós $(\boldsymbol{G} \boldsymbol{G})$ e um gerenciador de fornecimento de recursos $(\boldsymbol{G R})$. O primeiro elemento tem contato direto com os nós do cluster e os agrupa sob alguns parâmetros em comum, por exemplo, arquitetura ou tipos de serviços disponibilizados. O segundo tem a capacidade de comunicar-se com os gerenciadores de grupos de nós e obter seu estado. Quando um grupo de nós atinge seu limite, o $\boldsymbol{G} \boldsymbol{R}$ pode escolher algum nó que esteja ocioso e que não pertença a nenhum grupo para uni-lo naquele grupo sobrecarregado.

A inclusão de um nó a um grupo se dá através da notificação do $\boldsymbol{G} \boldsymbol{R}$ ao $\boldsymbol{G} \boldsymbol{G}$, adicionando o novo nó à lista daquele. Se em alguma situação não houver nós sem grupo definido, o gerenciador pode optar por retirar de outro grupo um nó que seja compatível com o grupo de que esteja precisando de recursos. O objetivo é tornar esta decisão o mais transparente possível para o usuário ou administrador do sistema. As requisições que chegam até o cluster são recebidas por um outro elemento do sistema chamado de controlador de distribuição, que determina para qual nó a requisição pode ser enviada.

O ponto interessante desse trabalho é que todas as configurações e a identificação de qual grupo ou nó deve receber qual tipo de requisição, de que nó pertence a qual grupo e de que migrações de nós entre grupos devem ocorrer são determinadas automaticamente pelo sistema, por isso o uso de computação autônoma.

O processo todo de funcionamento e auto configuração se dá inicialmente sem a existência de grupos, assim os nós não pertencem a nenhum grupo. À medida que as requisições chegam, elas são enviadas para os nós através de um gerenciador de carga simples. Com o passar do tempo, o controlador de distribuição passa a determinar qual aplicação deve executar em qual servidor baseado na maneira como as requisições estão sendo distribuídas pelo gerenciador de carga e o estado do sistema. Em um prazo mais longo, 
o $\boldsymbol{G} \boldsymbol{G}$ e o $\boldsymbol{G} \boldsymbol{R}$ passam a atuar, e o $\boldsymbol{G} \boldsymbol{R}$ começa a criar os grupos e passá-los para o $\boldsymbol{G} \boldsymbol{G}$ para o gerenciamento. A decisão de criação dos grupos leva em conta as informações obtidas por um analisador de objetos presente em cada nó.

Esse trabalho apresenta uma maneira interessante para a organização de clusters, apresentando a característica de ser auto configurável possibilitando o balanceamento de carga e requisições entre nós separando-os por grupos. Estes grupos podem conter aplicações específicas e características que os tornam diferentes de outros grupos, caracterizando um ambiente heterogêneo e possibilitando ao sistema obter as vantagens que cada grupo pode oferecer. Os aspectos mostrados no trabalho não englobam a maneira como as requisições são distribuídas, ou seja, as decisões que norteiam o seu destino dentro do cluster. O trabalho também é aplicado ao servidor de aplicação WebSphere, que além de web services, pode prover aplicações mais complexas. O provedor WebSphere é um produto proprietário da IBM, dificultando seu acesso a usuários sem recursos financeiros suficientes.

Em (Tang, 2007) é apresentado um trabalho que visa à distribuição de aplicações em um cluster para atendimento de web services e também clusters de servidores de aplicação. Este trabalho destaca a dificuldade de encontrar uma distribuição ótima de requisições em um conjunto de nós com recursos limitados. Neste trabalho, é comparada a distribuição de cargas ao problema da mochila (Martello; Toth, 1990), onde é necessário otimizar o uso de um recurso, no caso a mochila, com o maior número de itens, sendo estes itens ponderados, maximizando o valor colocado na mochila. Este problema é um conhecido problema NP difícil, ou seja, que possui apenas soluções aproximadas e baseadas em heurísticas.

O problema de distribuição de aplicações, e conseqüentemente a distribuição de requisições, engloba outros problemas como a maximização de satisfação de uma determinada aplicação; a execução mais estável sem a necessidade de migração e de paradas e inícios de aplicações durante o uso do sistema; e finalmente o balanceamento das cargas às quais as máquinas são submetidas.

A proposta apresentada neste trabalho utiliza métodos de determinação de aplicações on-line e regressão de dados para estimar as necessidades das aplicações e realizar a distribuição. Também é utilizado um sistema de coleta de dados do estado das máquinas para usar em conjunto com o algoritmo, a fim de predizer a distribuição mais adequada dentro das limitações computacionais.

No decorrer do artigo é apresentado o algoritmo usado em detalhes, explicando o seu funcionamento. $\mathrm{O}$ algoritmo criado apresenta forte fundamentação matemática e teoria de grafos. Por fim é demonstrada a sua complexidade de execução que no caso é de $\mathbf{O}\left(\mathbf{n}^{2,5}\right)$ frente à complexidade de $\mathbf{O}\left(\mathbf{n}^{3,5}\right)$ presente nos algoritmos de distribuição aos quais ele é comparado. 
A complexidade do algoritmo é a chave para a sua escalabilidade e para a possibilidade de executar a distribuição on-line das aplicações.

A solução proposta foi testada em relação a diversas outras propostas semelhantes e a problemas de distribuição aplicando-se o problema da mochila. Os testes foram realizados de maneira experimental usando o software WebSphere. Os resultados comprovam que o algoritmo criado apresenta bom desempenho em relação aos existentes. Este algoritmo já se encontra implementado em produtos comerciais que podem ser executados em clusters. Durante todo o artigo destaca-se a importância de um bom algoritmo de distribuição de aplicações nos provedores de serviços web ou servidores de aplicação.

Em (Sicard, et al., 2005) é apresentada uma solução para os problemas de escalabilidade e de alta disponibilidade envolvendo servidores de aplicação baseados na web. Na proposta é considerado um cenário que, segundo o artigo, é muito encontrado em ambientes empresariais usando Java e servidores de aplicação. O cenário é composto por quatro camadas de software, sendo que a primeira consiste em um servidor HTTP, instanciado como o Apache HTTP Server, cuja função é servir conteúdo estático. A segunda é baseada em um servidor de conteúdo dinâmico, no caso o Apache Tomcat. A terceira é responsável por realizar o processamento em si, como a conexão com banco de dados e implementar a lógica de negócio usando $\boldsymbol{E} \boldsymbol{J B}$ e podendo ser implementada usando JOnAS. A quarta e última camada é o gerenciador de banco de dados que fornece os dados para as outras camadas. Este cenário é muito semelhante ao qual pode ser encontrado em ambientes que explorem web services. Web services podem ser empregados nesse cenário com o uso de um software que forneça o seu suporte dentro da segunda camada e se necessário mantendo ainda o uso de $\boldsymbol{E} \boldsymbol{J B}$. Os $\boldsymbol{E} \boldsymbol{J B}$ s podem ser abandonados no caso de web services, pois seu trabalho pode ser movido para dentro de diferentes web services explorando o conceito de arquitetura orientada a serviços.

A questão de escalabilidade, definida no artigo como a capacidade de manter um tempo de atendimento aceitável com o aumento de requisições dos clientes, é resolvida com o uso de replicação e particionamento. A replicação é obtida com o uso de mais de um servidor em uma das camadas. No caso da avaliação apresentada a replicação foi aplicada na terceira e quarta camada. O particionamento é implementado dividindo-se a função de uma única aplicação em mais de uma, para que uma tarefa como um todo possa ser dividida em mais de um servidor. Neste artigo não foi aplicada a replicação na segunda camada nos testes. Apenas foi mencionada que ela pode ser realizada utilizando-se o mod_jk. A replicação aplicada na terceira camada utilizou CMI (Cluster Method Invocation) na interação entre a segunda e terceira camada. Assim, quando uma aplicação da segunda camada necessitava de um $\boldsymbol{E} \boldsymbol{J B}$, a 
invocação é direcionada para uma das réplicas da terceira camada utilizando um escalonamento round-robin. É possível observar com esse trabalho que há preocupação com a alta demanda em servidores de aplicação e $\boldsymbol{E} \boldsymbol{J B}$ que podem, por sua vez, ter como alternativa o uso de $\mathbf{S O A}$ e web services seguindo uma tendência atual.

O trabalho apresentado em (Chung; Hollingsworth, 2004) tem como objetivo a reconfiguração de parâmetros de provedores para requisições web em geral sendo estendido até o uso em clusters de servidores. A reconfiguração em clusters se dá de duas maneiras diferentes. Na primeira os servidores são separados de acordo com sua função inicial, formando grupos e os parâmetros são configurados para o grupo todo de maneira uniforme. Na segunda maneira a reconfiguração é feita através da migração de servidores entre grupos, ou seja, à medida que um grupo se torna sobrecarregado, um servidor é retirado de um grupo e colocado em outro para suprir as necessidades do sistema. Este trabalho é voltado para os softwares provedores de conteúdo para web e não para o conceito de distribuição de cargas. Supõe-se neste trabalho que de alguma forma as requisições já estão balanceadas e que o software proposto realiza otimizações na configuração para tornar o tempo de atendimento menor. Porém este trabalho mostra também a importância do uso de clusters para prover conteúdo. O conteúdo considerado neste trabalho é composto por cargas semelhantes às encontradas em sistemas de e-commerce e necessita de um provedor de conteúdo dinâmico, que no caso foi obtido com o uso do Apache HTTP Server na primeira camada e na segunda camada foram utilizados o Tomcat e Jetty. No decorrer do trabalho, são apresentados testes de desempenho comparando algumas versões desses softwares, mostrando que o Tomcat tem desempenho superior ao Jetty em um ambiente de cluster. Apesar de não estar diretamente relacionado com o conceito de web services, esse trabalho demonstra a utilização de softwares sobre os quais pode ser adicionada uma camada para o atendimento de web services, como Axis ou ainda Spring. O desempenho desses softwares é crucial para o desempenho final no uso de web services.

\subsection{Considerações finais}

Foi apresentado neste capítulo um levantamento de alguns trabalhos que possuem relação com o trabalho desenvolvido. Os trabalhos que mais se relacionam com o projeto são os de Adam (2006), Adam e Stadler (2006) e Adam e Stadler (2005). Apesar de estarem relacionados, o trabalho apresentado neste documento não envolve a questão de $\boldsymbol{Q o S}$, nem um modelo de distribuição baseado em peer-to-peer. O trabalho desenvolvido por Sicard et al. 
(2005) mostra a necessidade da distribuição de requisições para aplicações executadas em clusters, apesar de abordar esse tema em um nível diferente deste trabalho. O trabalho proposto por Chung e Hollingsworth (2004) mostra como o tema de atendimento de requisições por clusters é um assunto explorado de diversas formas. O trabalho desenvolvido por Chess (2005) aborda o tema de distribuição de requisições pelo ponto de vista da auto configuração, diferentemente deste trabalho, mas ele mostra uma arquitetura para a distribuição interessante, e que pode ser implementado dentro de políticas no protótipo implementado. Tang (2007) dá enfase à política de distribuição e como melhorar o seu tempo de execução para chegar a um melhor resultado. Esse trabalho pode ser interessante pois mostra a importância do desenvolvimento de políticas eficientes e a necessidade criá-las de maneira a possibilitar testes em diversas situações, recaindo na questão de flexibilidade da arquitetura. 



\section{Arquitetura de distribuição de requisições}

\subsection{Considerações iniciais}

Este capítulo apresenta as idéias nas quais a nova arquitetura de distribuição é baseada. A descrição de alto nível apresentada primeiramente mostra a disposição dos componentes da arquitetura em uma estrutura para atendimento de requisições. Em seguida é feito o detalhamento do elemento de distribuição, principal elemento da arquitetura. São apresentados neste capítulo também as tecnologias usadas na implementação do protótipo utilizado para testar a arquitetura. O funcionamento do protótipo é detalhado no texto por meio de modelos usando Redes de Petri Coloridas.

\subsection{Idéia da arquitetura}

A arquitetura proposta neste trabalho visa a distribuição de requisições em clusters de maneira flexível e dinâmica. Para isso, o projeto foi desenvolvido para que um administrador de sistema ${ }^{6}$, ou até mesmo o desenvolvedor de web services, pudesse ver a estrutura distribuída criada com o propósito de atender requisições a web services. A proposta é centrada em uma arquitetura que que possibilite fácil configuração, adaptação e confiabilidade, fatores necessários para atingir com sucesso a distribuição flexível e dinâmica.

A estrutura básica para esta distribuição de requisições é composta pelo componente de distribuição, front-end, provedores de serviço e monitores, como apresentado na Fig. 5.1. As requisições devem entrar na arquitetura por algum meio de conexão de mais baixo nível no modelo OSI. Nesse nível pode ser utilizado algum meio de balanceamento de rede para evitar sobrecargas de link de conexão. Algumas das soluções foram apresentadas na seção 3.2.1 e

6 O termo administrador será usado desse ponto em diante para designar desde o responsável por administrar a estrutura distribuída (o cluster) até o desenvolvedor de web services que se preocupa com a maneira mais eficiente de atender requisições. O termo cliente será utilizado para designar desde os programas que consomem web services até pessoas que realizam requisições para os serviços da mais variadas formas. 
incluem DNS e NAT. Essas soluções são representadas na Fig. 5.1 no passo 1. Uma vez que uma requisição passa pelo passo 1, ela é encaminhada para um front-end que implementa um servidor web e a processa para então tomar uma decisão de distribuição. Pode haver mais de um front-end, de acordo com as necessidades em relação à carga do sistema. O encaminhamento da requisição para um outro nó depende da política dentro do distribuidor. Mediante consulta ao distribuidor, passo 2, este retorna um endereço IP para onde enviar a requisição. A consulta pode envolver uma política desenvolvida pelo administrador ou então uma política padrão caso o serviço não tenha uma política específica para ele. Além da possibilidade de haver mais de um front-end, pode haver mais de um distribuidor. O pedido pela decisão, no caso de mais de um distribuidor, pode ser feito a qualquer distribuidor presente na estrutura. Os distribuidores existentes devem ter um canal de comunicação para manter consistente as configurações entre eles. Se uma alteração for efetuada em um distribuidor em relação a uma política para um determinado serviço, os outros distribuidores devem estar cientes da alteração. Assim, a decisão para um serviço será consistente onde quer que ela seja tomada. Levando em consideração a proposta de distribuição dinâmica, outro elemento envolvido no processo de escolha de um destino é o monitor. O monitor deve estar presente nos nós de destino para avaliar sua condição atual e publicá-la para que as políticas possam ter acesso às informações. A flexibilidade deve ser algo também presente no monitor para contribuir para a flexibilidade da distribuição.

Quando o front-end obtém o endereço para o qual deve enviar a requisição (passo 3) ele a redireciona para o destino (passo 4). O reenvio da requisição pode envolver vários níveis de complexidade. Ele pode ser feito com uma reconstrução da requisição, porém, em nome do front-end; e quando este receber a resposta a reencaminha para o cliente que fez a requisição. Um outro método mais complexo que pode ser utilizado é a migração de conexões. Este é um tema conhecido e apresenta algumas soluções (Maltz e Bhagwat, 1998)(Kuntz e Rajan, 2002) (Sultan et. al., 2002), muitas delas envolvendo até mesmo alterações nos clientes. Isto se torna muito intrusivo em uma arquitetura como a apresentada. Finalizando, o passo 5 é o atendimento pelo provedor de web services.

Como pode ser visto na Fig. 5.1, o intuito é que o hardware possua o menor acoplamento possível com o software, permitindo as mais variadas configurações possíveis (um dos itens relacionados à flexibilidade). A configuração permite explicitar que os nós do cluster podem conter todos os componentes ou apenas um deles. Um dos objetivos de se colocar o distribuidor de requisições dentro do mesmo nó do provedor de serviços que atua como front-end pode ser a diminuição da sobrecarga de comunicação. O acoplamento do distribuidor com o provedor de serviços deve usar poucas informações, também com o intuito 
de diminuir a sobrecarga. A comunicação entre esses dois componentes é realizada de maneira flexível, possibilitando as mais diversas configurações. Dentro da arquitetura é necessário buscar soluções e atentar para cada detalhe onde possa aparecer um gargalo piorando o desempenho.

Na Fig. 5.1 pode ser observado um cluster com 4 nós. Dois desses nós (nós 3 e 4) possuem basicamente um provedor de serviço e um elemento de monitoração. Esses provedores de serviços podem estar configurados como se eles fossem os únicos elementos que respondem às requisições aos web services existentes. Eles implementam um servidor web e, internamente a este, um framework que captura e atende a requisição ao serviço implementado. Em relação ao provedor de serviços, a arquitetura deve diminuir ao máximo a intrusão da aplicação do distribuidor nesse componente. Para tanto, as alterações nestes elementos de software já existentes foram minimizadas durante o projeto desta arquitetura de distribuição. A concepção de uma arquitetura que permita flexibilidade e dinamicidade no contexto desta proposta inicial, atendendo os requisitos de desempenho impostos, é considerada uma tarefa não trivial, a qual exige cuidados.

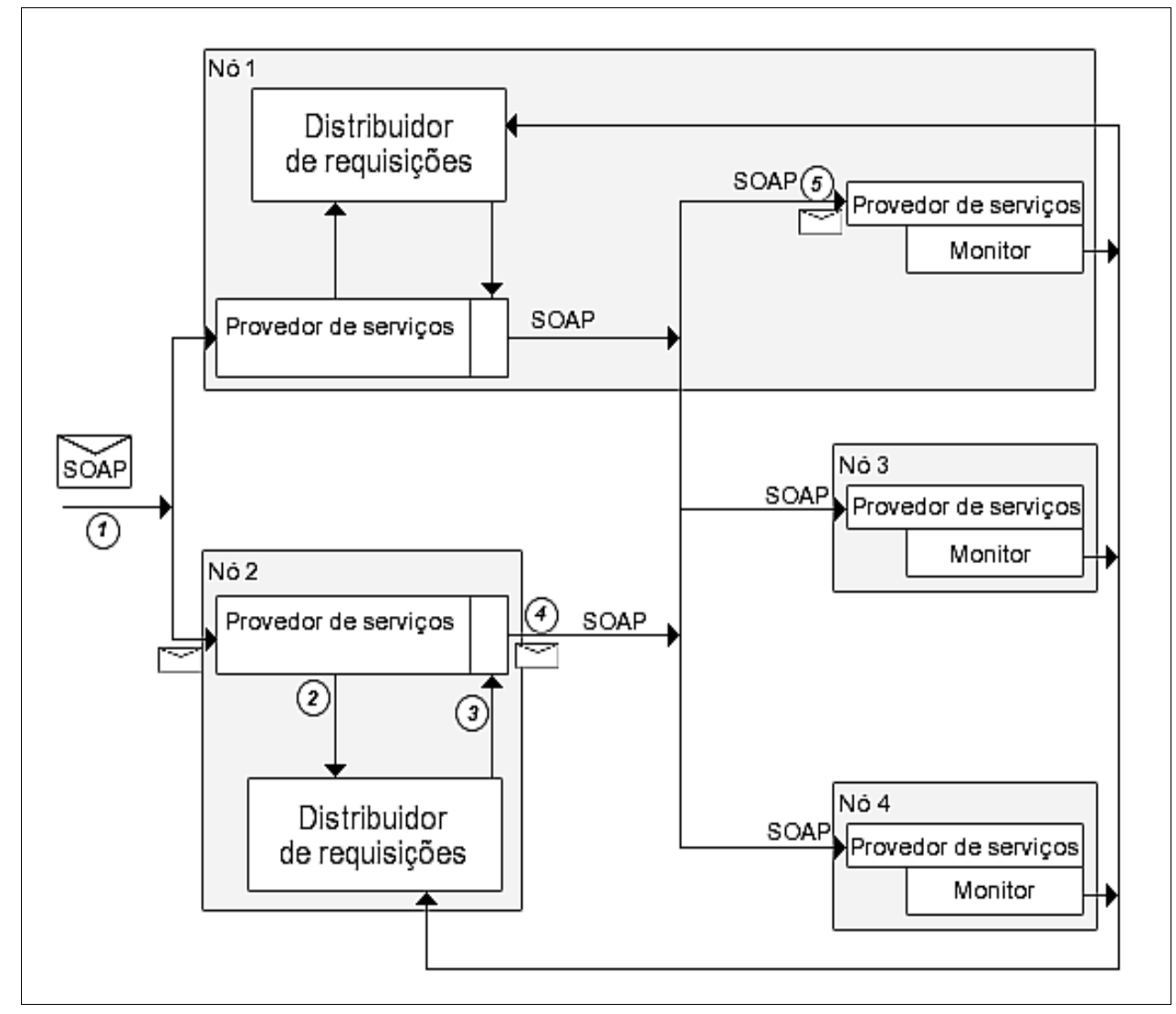

Fig. 5.1: Arquitetura de distribuição em alto nível

O elemento de monitoração deve estar presente nos nós que atendam os web services. As informações, sejam elas de carga ou atividade, do nó de destino devem de alguma forma 
ser propagadas para o(os) distribuidor(es) dentro da arquitetura. A flexibilidade pretendida pela arquitetura deve permitir conectar quantos monitores forem necessários aos distribuidores.

A Fig. 5.1 é uma representação mais genérica de como pode ser a configuração de um ambiente distribuído para o atendimento a requisições. O principal objetivo dessa representação é mostrar o baixo acoplamento com o hardware e os passos necessários desde a entrada da requisição no sistema até o seu atendimento.

Para o desenvolvimento deste trabalho, foram utilizadas algumas ferramentas que atuam como cada componente da Fig. 5.1. O provedor de web services utilizado foi o Apache Tomcat. Sua utilização foi justificada na seção 3.2.1. O monitor utilizado foi o Ganglia, também mencionado na seção 3.3 e que será detalhado mais adiante na seção 5.4.2. A Fig. 5.1 instancia a maneira como a arquitetura foi desenvolvida, não se preocupando em abordar a ligação entre o software e hardware. Ela apresenta os elementos de ligação entre os componentes do sistema e os tipos de dados que trafegam entre eles.

\subsection{Detalhamento da estrutura}

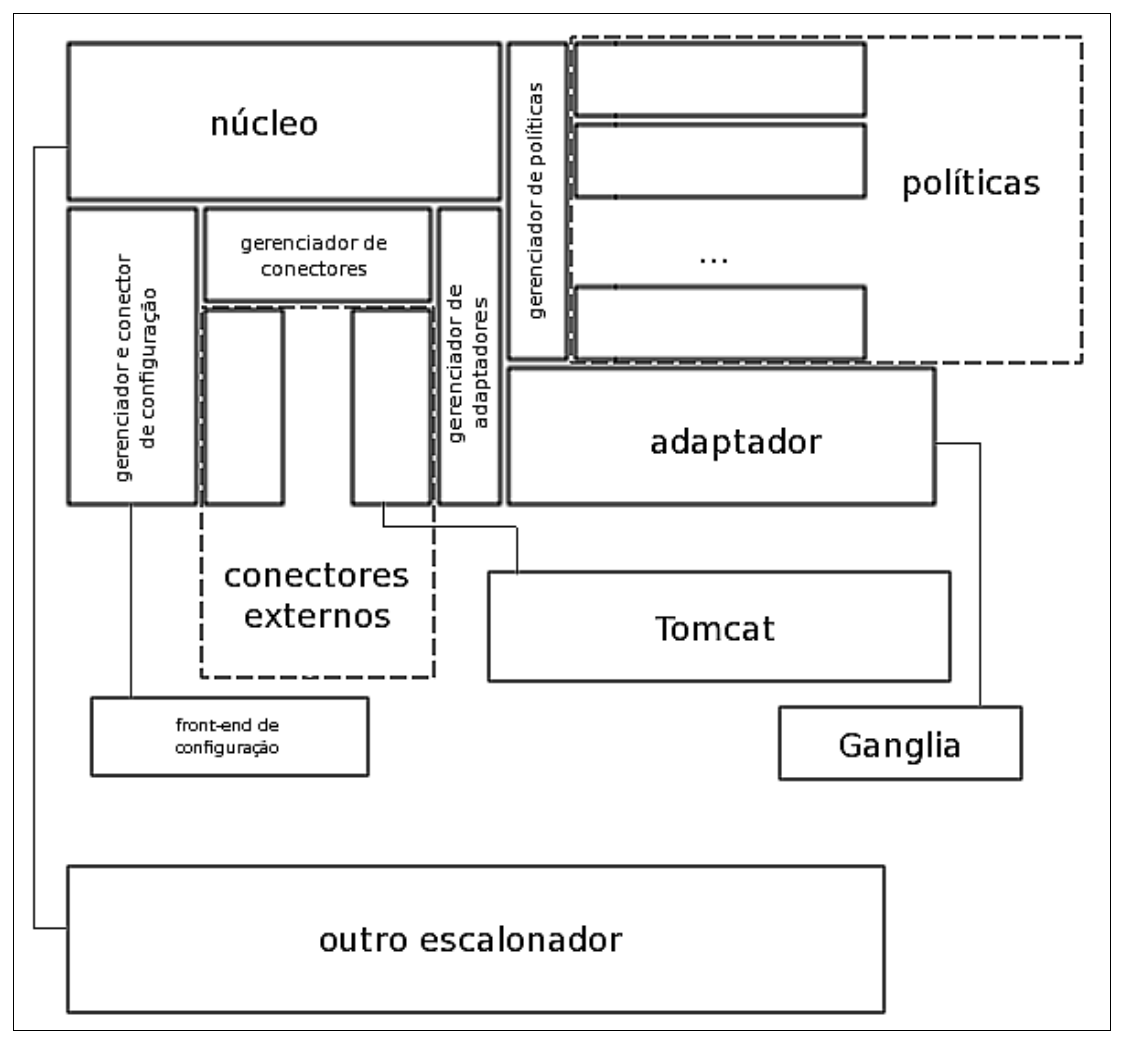

Fig. 5.2: Elemento distribuidor

O distribuidor de requisições é o elemento de maior interesse neste trabalho. Ele foi 
projetado dentro da arquitetura para ser ligado aos outros componentes, já existentes, e fornecer as características pretendidas na proposta da arquitetura. A Fig. 5.2 apresenta a estrutura do elemento de distribuição com todos os seus elementos que fornecem as funcionalidades de flexibilidade e dinamicidade.

Os seus elementos são: núcleo, gerenciador de configuração, gerenciador de conectores, gerenciador de adaptadores e gerenciador de políticas.

\subsubsection{Núcleo}

O núcleo é o elemento central do componente de distribuição (distribuidor). Ele é primeiro elemento a ser executado pelo distribuidor e fica responsável pelo gerenciamento dos demais componentes. O núcleo é a ponte de ligação entre os conectores (descritos adiante) e as políticas. No início do distribuidor, o núcleo realiza o processo de carga das configurações. A partir das configurações, são seguidos os passos de carga dos gerenciadores. Os gerenciadores funcionam de maneira paralela ao núcleo. Assim, com os gerenciadores iniciados, o núcleo permanecerá ativo até que eles finalizem, retornando a linha de execução para o núcleo. O processo de tomada de decisões passa pelo núcleo usando-o como uma ponte de referência para os dados gerais do programa que contém as referências para as políticas.

\subsubsection{Gerenciador de configuração}

O gerenciador de configuração atua como um conversor das configurações para que todos os componentes do distribuidor possam acessá-las de maneira universal. A função inicial dele é carregar o arquivo que contém toda a configuração do sistema, esta descrita em $\boldsymbol{X M L}$. A linguagem $\boldsymbol{X M L}$ foi escolhida por criar um meio simples de interação entre o administrador e o distribuidor, além de tornar o arquivo de configuração legível para humanos e facilmente interpretável pela máquina. O processo de carga da configuração é baseado em recursos de validação que $\boldsymbol{X M L}$ traz, como o XML Schema e o DTD. Dessa forma, qualquer erro na maneira como o usuário configura o distribuidor pode ser detectado antes de sua execução, diminuindo a possibilidade de erros posteriores no seu funcionamento. Uma vez que a configuração é validada, o próximo passo realiza o parsing, transformando as informações obtidas em uma representação binária que pode ser lida e navegada pelos componentes.

Uma função muito importante para a arquitetura e onde atua o gerenciador de configuração é a configuração do sistema durante a sua execução. Quando o gerenciador de 
configuração termina seus passos iniciais, ele permanece ativo e retorna a linha de execução para o núcleo. A sua atividade consiste em esperar por alguma interação entre o administrador e o distribuidor ou mesmo uma interação distribuidor-distribuidor. O primeiro tipo de interação garante que de maneira dinâmica, sem a necessidade de paradas, o administrador realize variadas alterações na configuração do distribuidor. Ele pode atuar alterando o estado dos conectores (entre ativo e inativo), políticas e monitores. Além de alterar os estados dos anteriormente mencionados componentes, o administrador pode também exclui-los ou adicioná-los. Esse processo requer alguns cuidados, pois o restante do distribuidor permanece ativo, recebendo principalmente pedidos de decisão. Estes detalhes serão explicados na seção 5.4.5, que trata da implementação do protótipo do distribuidor.

Além de alterar alguns componentes do distribuidor, o gerenciador de configuração tem a função de propagar atualizações em sua configuração para outros distribuidores. A propagação é realizada de maneira universal, ou seja, usa o mesmo canal de interação que o administrador. De maneira simplificada, o mesmo canal que permanece ativo esperando que o administrador envie comandos é utilizado por outros distribuidores para realizar alterações na configuração.

Para fins de gerenciamento por parte do administrador, o gerenciador de configuração durante o processo de carga da configuração realiza a abertura de um elemento de log. O elemento de log basicamente, assim como na maioria dos sistemas, é um arquivo no qual as atividades realizadas pelo distribuidor são impressas. O nível de $\log$ (o quanto e o detalhamento da informação que será impressa) pode ser configurado no arquivo de configuração. O administrador pode mandar o gerenciador de configuração imprimir sua configuração no arquivo de log de maneira legível para verificação do seu estado atual. Tendo a configuração como um elemento muito importante, antes de finalizar o distribuidor (função também disponibilizada pelo gerenciador de configuração) o administrador pode requisitar que a mesma seja gravada para que em uma futura execução o sistema reinicie da mesma maneira que o seu último estado.

Este elemento possui ligação com todos os demais gerenciadores, devido à abertura de possibilidade de configuração de vários elementos da arquitetura. A maneira como sua ligação com os demais gerenciadores é realizada será detalhada na seção 5.6.

\subsubsection{Gerenciador de conectores}

O distribuidor é projetado para não possuir uma ligação rígida com nenhum provedor de web services. Dessa forma, o mesmo possui uma interface de interação com o provedor de 
web services. Essa interface são os conectores. O distribuidor, mais especificamente o seu núcleo, possui uma forma única de acesso para realizar chamadas às políticas. Os conectores (abordados na seção 6.2.3) podem receber conexões de diferentes provedores. Esse detalhe fica encapsulado (escondido) do distribuidor e seu núcleo. A única preocupação é como o gerenciador de conectores executará o conector. Para isso todos os conectores desenvolvidos devem ter uma única assinatura e obedecer o modo como é feito o casamento entre políticas e web services. O gerenciador de conectores é o elemento que, executado a partir do núcleo, lê as configurações sobre os conectores já convertidas pelo gerenciador de configuração e instancia os conectores. Ele inicialmente coloca em execução os conectores que ficam então em funcionamento paralelamente a ele, esperando por conexões externas. Como o ambiente é dinâmico, o gerenciador de conectores precisa manter uma referência para todos os conectores ativos. Quando uma mensagem chega a este gerenciador, partindo do gerenciador de configuração, ele se encarrega de notificar o conector. Os conectores podem ser ativados, desativados (permanecendo na memória), adicionados ou então removidos. A comunicação entre o gerenciador de conectores e os conectores será tratada na seção 5.6.

\subsubsection{Gerenciador de políticas}

A políticas são os meios para fornecer a maior parte da flexibilidade da arquitetura. O objetivo é que existam diversas políticas para reger o redirecionamento das requisições dentro do cluster. Para que seja possível a existência dessas diversas políticas, deve haver um componente que gerencie sua “vida” durante a execução do distribuidor. Essa é a função do gerenciador de políticas. Assim como o gerenciador de conectores, este gerenciador de politicas recebe notificações vindas do administrador e entregues a ele pelo gerenciador de configuração. Quando o gerenciador de políticas é iniciado, ele utiliza os dados presentes na memória do distribuidor para buscar e carregar as políticas. As políticas, diferentemente dos conectores não permanecem ativas. Elas são executadas apenas quando uma decisão é requisitada ao distribuidor. As políticas podem ser ativadas, desativadas, adicionadas e removidas por meio desse gerenciador.

\subsubsection{Gerenciador de adaptadores}

Os monitores possibilitam a implementação de políticas dinâmicas baseadas na situação atual de cada nó. O gerenciador de adaptadores carrega os adaptadores que serão ligados aos monitores presentes no sistema. Ele pode ativar, desativar, adicionar e remover os 
adaptadores do distribuidor. Além da função de gerenciamento, ele funciona como a ponte de ligação entre a política e os adaptadores. Os adaptadores são iniciados por esse gerenciador e permanecem ativos paralelamente até que uma notificação de fechamento seja realizada. $\mathrm{O}$ elemento que envia os sinais de término para os adaptadores é o gerenciador de adaptadores. Ele só é finalizado quando os adaptadores terminam sua execução. Quando ele finaliza, juntamente com os outros gerenciadores, todo o distribuidor deve retornar para apenas uma linha de execução no núcleo.

O processo de consulta de métricas parte internamente das políticas a partir de uma função específica que então utiliza-se dos dados do gerenciador de adaptadores para consultar os adaptadores ativos sobre a informação necessária. Todos os adaptadores são consultados até que uma informação seja retornada. Deve-se atentar para a estrutura interna dos adaptadores para evitar que haja bloqueios referentes à espera por retorno de informações. Outra preocupação é referente à complexidade interna dos adaptadores, já que todos são consultados. A complexidade é um fator preocupante em relação a um sistema como esse para garantir escalabilidade. Na seção 6.2.2 serão apresentados detalhes dos métodos utilizados no protótipo para tentar contornar problemas nesse sentido.

\subsection{Implementação do protótipo}

O funcionamento da arquitetura proposta é apresentado através da implementação de um protótipo do distribuidor de requisições que englobe os conceitos desta arquitetura. Para a implementação foram necessárias várias tecnologias bem conhecidas na computação e a aplicação de alguns recursos de maneira criativa para garantir a flexibilidade e dinamicidade sem prejudicar o desempenho. Também foi necessário para o projeto a compreensão de algumas ferramentas utilizadas no atendimento a web services dentro de clusters. Muitos dos conceitos de web services, devido a sua natureza de ter como principal protocolo de base o HTTP, vem dos servidores web para conteúdo dinâmico. As soluções existentes até hoje em meio comercial para distribuir requisições a web services baseiam-se nas propostas existentes para web services. Como tratado anteriormente, o perfil de páginas web dinâmicas pode ser muito diferente de web services e ainda, estes últimos podem ter uma necessidades de recurso muito variada.

\subsection{1. $X M L$}

Muitas partes do protótipo baseiam-se na linguagem $\mathbf{X M L}$, tal como a configuração 
carregada pelo gerenciador de configuração. Essa escolha deve-se principalmente a sua legibilidade e à disponibilidade de frameworks para sua interpretação em praticamente todas as linguagens de programação atuais. Quase que a integridade do protótipo foi desenvolvido utilizando-se a linguagem $\mathbf{C}$. Entre muitas bibliotecas para o processamento de $\boldsymbol{X} \boldsymbol{M L}$ dentro da linguagem C, destacam-se a libxml2 e a expat. A biblioteca expat é orientada a fluxo, então deve haver o registro de funções de callback para que, à medida que o documento $\boldsymbol{X M L}$ seja lido, as funções de callback sejam executadas. Para o objetivo do projeto, essa biblioteca não se mostrou interessante, pois era necessária uma biblioteca que garantisse grande flexibilidade em termos de função e modos de processamento do $\boldsymbol{X} \boldsymbol{M L}$. Outro ponto necessário dentro do projeto é a criação de documentos $\boldsymbol{X} \boldsymbol{M L}$, principalmente devido à comunicação em alguns pontos (por exemplo entre distribuidores) ser realizada utilizando-se $\boldsymbol{X M L}$. Na seção 5.6 serão tratadas as comunicações (trocas de mensagens) dentro do distribuidor. A biblioteca libxml2 é formada por uma biblioteca para processamento de $\boldsymbol{X M L}$ e por um conjunto de ferramentas desenvolvido dentro do projeto GNOME, porém não restrita a ele. Ela é liberada sob a licença MIT (MIT, 1988), ou seja, mais liberal em relação à distribuição e abertura de código em relação à licença $\boldsymbol{G P L}$. Existem ligações dessa biblioteca para diversas linguagens e também ela é portátil para diversos sistemas operacionais. A libxml2 possui compatibilidade com os testes especificados pelo consórcio OASIS (Organization for the Advancement of Structured Information Standards)(Veillard, 2009) (OASIS, 2009), um importante grupo de desenvolvedores de padrões voltados à $\boldsymbol{X M L}$ e web services. Graças a essas características e outras mais, a libxml2 foi escolhida para ser utilizada dentro do protótipo.

A validação da configuração inicial é feita usando-se DTD e XML Schema, o que proporciona qualidade dos dados de entrada. Toda a validação é realizada de maneira automática pela libxml2 passando-se o schema e o DTD. O processamento do arquivo de configuração e transformação dos seus dados em um tipo de dado facilmente manipulável pelos elementos do protótipo é feito sobre a libxml2 também. Outro ponto interessante onde foi utilizado o processamento de $\boldsymbol{X} \boldsymbol{M L}$ foi dentro do adaptador de monitoração criado. Como tratado na seção 3.3 (e 6.4 .2 mais detalhadamente), o monitor utilizado publica as informações sobre o estado das máquinas em forma de um documento $\boldsymbol{X M L}$. Assim também foi utilizada a libxml2 para tornar os dados acessíveis pelas políticas. Este processamento é o ponto mais crítico em relação à arquitetura no que diz respeito à escalabilidade e será tratado na seção 5.6. O desempenho apresentado pela biblioteca utilizada mostrou-se satisfatório.

A funcionalidade de gerar documentos $X \boldsymbol{M L}$ pela libxml2 foi de grande valia no processo de armazenamento da configuração atual do distribuidor. O documento gerado 
possibilita manter a legibilidade da configuração por parte do administrador, mantendo identações e espaçamentos. A geração de $\boldsymbol{X} \boldsymbol{M L}$ também foi útil dentro do front-end de configuração, já que todas as informações para configuração durante a execução também trafegam codificadas em $\mathbf{X M L}$. Durante todo o desenvolvimento do projeto, a linguagem $\boldsymbol{X M L}$ mostrou-se uma ótima escolha trazendo facilidades e diminuindo o tempo dedicado à implementação da parte central do protótipo.

\subsubsection{Ganglia}

A monitoração, com seu papel importante dentro do projeto, teve grande foco voltado para a facilitação de seu uso. A implementação de políticas que usem a monitoração não deve se preocupar com o modo como a monitoração é realizada. Os dados obtidos através da monitoração devem ser acessados de forma transparente pelo criador da política. Optou-se por inicialmente prover o protótipo com uma ferramenta que permitisse a monitoração de muitas informações dos nós de maneira simplificada. Uma ferramenta que se mostrou interessante para esse fim foi o monitor chamado Ganglia (Massie et al., 2004). O Ganglia apresenta as características necessárias para o trabalho, visto que proporciona uma grande flexibilidade. Ele foi criado na universidade de Berkeley e seu projeto tem como base a distribuição hierárquica de clusters formando federações. Seus desenvolvedores argumentam que ele pode ser usando em clusters com até 2000 nós, graças às estruturas de dados e algoritmos utilizados, que causam baixa sobrecarga. Hoje existe uma lista de grandes players de mercado que utilizam o Ganglia para monitoração (Ganglia Monitoring System, 2009). Apesar de todo o seu poder para monitoração de grandes estruturas, ele é de simples instalação e configuração, funcionando bem também em pequenas estruturas.

O Ganglia é composto por um núcleo e algumas ferramentas auxiliares que o tornam poderoso para o fim pretendido neste trabalho. O núcleo do Ganglia é constituído pela ferramenta gmond. Este é um daemon que deve estar presente em todos os nós do cluster, coletando as informações sobre sua carga. Esse daemon possui por padrão métricas sobre a configuração do nó, seu uso de processador, memória, rede e disco. Além desses ele também obtém os dados de carga do nó (métricas referentes à quantidade de processos ativos, esperando E/S, etc.). A configuração do daemon engloba também a maneira como as métricas serão coletadas. Uma função importante da configuração é o tempo de atualização e propagação dos dados coletados. Os dados são coletados da máquina com uma periodicidade definida na configuração. Isso auxilia muito o administrador a criar um elemento de monitoração que não cause demasiado impacto na função à qual o nó é destinado. A 
configuração é facilitada com o agrupamento das informações, diminuindo a quantidade de parâmetros necessários. A partir dos dados coletados, baseado também em suas configurações, o gmond decide se deve ou não propagar as informações. A propagação de informação em um cluster deve ser feita de maneira cuidadosa, já que afeta diretamente a escalabilidade. A propagação no caso do Ganglia obedece alguns parâmetros e pode ser considerada um forma híbrida de monitoração, encaixando-se ora em monitoração por mudança de estado e ora em periódica. Podem ser configurados intervalos dentro dos quais a informação será propagada ou ainda um valor de limite de mudança. Se dentro de um intervalo um valor mudar mais que o valor determinado pelo administrador, a informação é propagada, se isso não acontecer, o valor só será enviado quando terminar o intervalo de tempo definido.

A propagação das informações coletadas é realizada através de multicast. Isso torna possível que todos os nós do cluster que contém um gmond possam ter informações de todos os outros. Os gmonds possuem capacidade de coletar informações de outros nós e publicar as suas, por isso o cuidado referente a propagação das informações. A consulta das informações conhecidas por um gmond pode ser realizada mediante uma conexão em uma porta configurada. Quando ele recebe uma conexão, ele envia todas as informações codificadas dentro de um documento $\boldsymbol{X M L}$. Isso simplifica a interface entre outros programas e o gmond, tornando possível que programas externos utilizem diretamente as informações somente com uma conexão $\mathbf{T C P}$ e um processador de $\boldsymbol{X M L}$.

Uma outra ferramenta interessante dentro do Gangia é o gmetric. Este último permite que sejam adicionadas mais métricas on-the-fly. O gmetric é um comando que pode ser disparado manualmente dentro de qualquer um dos nós. Para sua execução ele requer que sejam informados o nome de um dado a ser propagado, seu valor e o tipo de dado (string, inteiro, etc). O gmetric então conecta-se ao gmond e passa esse novo dado. Este é então propagado através do gmond tornando-se acessível para todos os gmonds e programas que dele coletam informações. Esse é um grande trunfo do Ganglia, e torna seu uso um facilitador dentro do trabalho. A execução do gmetric pode ser agregada a um script qualquer que juntamente com as conhecidas ferramentas UNIX podem coletar variadas informações. Além disso, dentro do site dos desenvolvedores da ferramenta existem repositórios de scripts em Bash, Perl, Python, etc, que coletam informações úteis que não estão presentes nativamente nos módulos do Ganglia.

O Ganglia ainda contém uma ferramenta chamada gmetad. Este também é um daemon com a capacidade de consultar o gmond e armazenar as informações coletadas. Com isso é possível obter um histórico sobre a situação dos nós monitorados. Partindo das características do próprio gmond, somente é necessário que o gmetad conecte-se em um 
único gmond para obter informações de diversos nós. O armazenamento das informações é realizado utilizando-se um banco de dados chamado $\boldsymbol{R} \boldsymbol{R D}$ (round-robin database). Os gmetads podem conectar-se a outros gmetads para buscar informações, ou seja, não necessariamente gmonds. Essa característica explicita a funcionalidade do Ganglia ser baseado em estruturas hierárquicas. A Fig. 5.3 mostra uma estrutura de configuração do Ganglia.

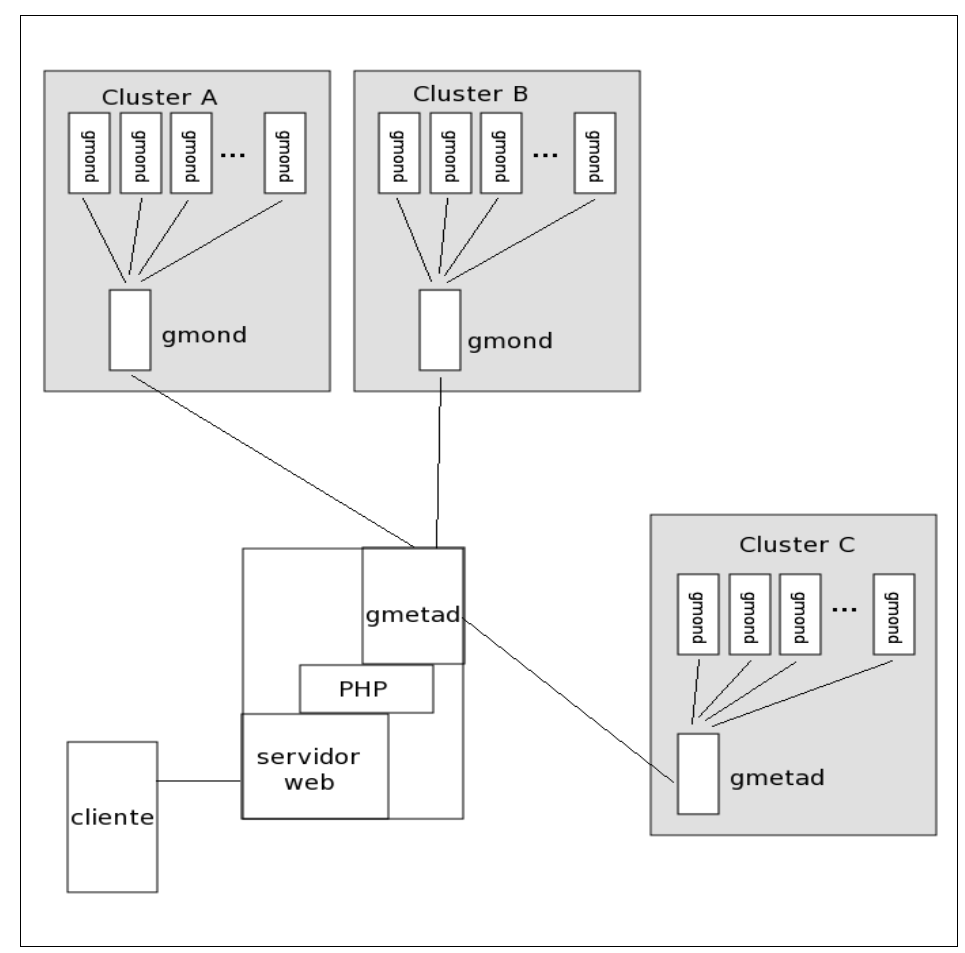

Fig. 5.3: Exemplo de configuração do Ganglia

Nela pode ser vista a comunicação entre gmonds e ainda a comunicação gmetadgmond e gmetad-gmetad. Outro ponto interessante é a interface web disponibilizada pelo Ganglia. Nela é possível ver em forma de gráficos o estado dos nós do cluster. Os gráficos são construídos a partir dos dados do $\boldsymbol{R} \boldsymbol{R D}$ através do gmetad. Esse acompanhamento do estado pelo navegador se torna útil durante os testes da arquitetura, pois mostra a carga à qual os nós estão expostos. Através dele pode ser constatada a distribuição das requisições sendo realizada.

A monitoração utilizada no trabalho, dentro do distribuidor pelas políticas, é realizada pelo Ganglia, mostrando-se efetiva e de simples instalação e configuração. Através do uso do gmetric é possível publicar dados como o estado do provedor de web services.

O uso do gmetric também apontou ser interessante juntamente com a $\boldsymbol{J} \boldsymbol{M} \boldsymbol{X}$. A $\boldsymbol{J} \boldsymbol{M} \boldsymbol{X}$ permite coletar dados diretamente da máquina Java onde o provedor de serviços está executando. Esses dados podem ser coletados pelo distribuidor e disponibilizados para as 
políticas usando o Ganglia. Os dados fornecidos pela $\boldsymbol{J} \boldsymbol{M} \boldsymbol{X}$ podem ser os dados padrão da $\boldsymbol{J V M}$, como tamanho de heap, número de classes carregadas, threads ativas, etc. Outros dados podem ser gerados usando-se MBeans (Kodali, Wetherbee e Zadrozny, 2006). Os provedores de web services como o Apache Tomcat e JBoss (que no seu interior acaba por usar o Apache Tomcat) possuem MBeans já ativos para que seu estado seja monitorado. Essa característica/ferramenta da máquina virtual Java e conseqüentemente da própria linguagem Java a tornam interessante, disponibilizando dados úteis para as políticas. Aliando-se o poder da $\boldsymbol{J} \boldsymbol{M} \boldsymbol{X}$ juntamente com o Ganglia tem-se um bom método para monitorar o estado dos nós e mais especificamente dos provedores de web services.

\subsubsection{Bibliotecas dinâmicas}

Um recurso interessante de algumas linguagens de programação e sistemas operacionais é a possibilidade de carregar códigos para a execução de maneira dinâmica. Em Java, por exemplo, existe o processo de “class loading” usado largamente dentro dos próprios provedores de web services e dentro dos frameworks para o mesmo fim. O processo de class loading é relativamente simples na linguagem Java, visto que as suas classes são unicamente enraizadas herdando características básicas da classe object. O Apache Tomcat utiliza esse recurso, pois ele já se encontra “compilado” e não é viável que a cada novo servlet ou $\boldsymbol{J S P}$ adicionado o seu código seja inteiramente compilado novamente. Assim, os novos códigos são carregados na memória e executados como se já estivessem sido compilados com o Tomcat.

Usando-se a linguagem $\mathbf{C}$, também é possível realizar a execução por parte de um programa de códigos já compilados. Esse recurso é chamado de compartilhamento de componentes ou bibliotecas. Sua função e utilidade é ampla. Pode-se utilizar esse recurso para gerar APIs, assim os novos programas construídos não precisarão conter todo o código para uma funcionalidade comum entre vários programas. A funcionalidade necessária já estará codificada e residente no sistema. Além de diminuir a quantidade de código necessário para um programa, por exemplo, as bibliotecas podem ser compartilhadas entre vários programas em execução. Assim não há a necessidade de se carregar na memória do computador várias vezes o mesmo código para diversas aplicações. Isso pode ser notado quando é requisitado ao Linux, por exemplo, a quantidade de memória ocupada por um programa. O número retornado pode ser grande frente ao tamanho do programa, porém, muita da memória utilizada é compartilhada com outros programas. Um exemplo claro pode ser a quantidade de memória utilizada por um programa em modo gráfico que se baseia em Qt (Nokia Corporation, 2009) 
ou GTK (The GTK Team, 2009). Muitos outros programas que baseiam-se nesses toolkits gráficos não chegam a carregar códigos para o seu funcionamento, pois os códigos já estão residentes na memória devido a outro programa já o estar usando. Um pequeno programa que apenas possui um botão pode aparentar usar uma quantidade grande de memória frente a sua funcionalidade, porém ele pode estar usando bibliotecas compartilhadas com outros programas gráficos em execução.

Além das vantagens citadas anteriormente, o uso de bibliotecas pode-se dar de forma dinâmica, com o carregamento de códigos especificados pelo usuário em um arquivo qualquer (dentro de certos padrões do sistema operacional e compilador). Esse uso é freqüente em programas que utilizam plugins (o Mozilla Firefox é um exemplo muito comum). Os plugins tornam os programas flexíveis, adicionando funcionalidades extras em relação às quais eles foram projetados. A flexibilidade é justamente um dos focos deste trabalho, sendo assim esse recurso foi utilizado.

O uso de bibliotecas dinâmicas se deu nas políticas, adaptadores e conectores. Todos esses elementos são desenvolvidos usando essa metodologia, possibilitando ao distribuidor inserir e retirar códigos de maneira dinâmica ao distribuidor. Os gerenciadores presentes na arquitetura são os responsáveis por buscar, carregar e descarregar esses elementos. O que possibilita o uso de bibliotecas dinâmicas em $\mathbf{C}$ é uma biblioteca chamada libdl cujas funções básicas são: dlopen, dlclose e dlsym. A primeira função permite a abertura de um arquivo contendo os códigos das funções que se deseja carregar de maneira dinâmica. Quando o arquivo é aberto cria-se um identificador, que posteriormente será utilizado para localizar a função necessária. $\mathrm{O}$ arquivo pode ser fechado usando a função dlclose, analogamente ao fechamento de um arquivo, liberando memória. O identificador é utilizado dentro da função dlsym, que procura por símbolos dentro do arquivo apontado pelo identificador. O símbolo pode ser a função que se deseja carregar. Se a função for encontrada, é retornado um ponteiro para a função carregada na memória. No caso deste trabalho, as políticas, os conectores e adaptadores tem funções de entrada com nome e parâmetros sempre iguais, facilitando a sua chamada. A partir da carga, as funções podem ser usadas de maneira normal dentro do distribuidor, apenas usando-se os ponteiros criados. O uso de ponteiros para funções facilitou o registro das funções dentro das estruturas de dados internamente no distribuidor. Além disso, o acesso se tornou rápido e direto, diminuindo possíveis sobrecargas.

Com o uso das bibliotecas dinâmicas através da biblioteca libdl alcançou-se a flexibilidade, possibilitando o uso de diversos elementos construídos pelo administrador, sem a necessidade de alteração no código do distribuidor. A dinamicidade do protótipo foi também reforçada com o uso dessa biblioteca permitindo a leitura de novos “módulos” durante sua 

execução.

\subsubsection{Tabelas Hash}

As tabelas hash são estruturas de dados clássicas e bem conhecidas, tratadas no início de qualquer curso de computação. Sua principal vantagem é a ordem de busca $\mathrm{O}(1)$. O preço a ser pago por esse ganho é o espaço extra necessário para evitar colisões nos dados inseridos. Neste trabalho essas estruturas foram úteis para diminuir a complexidade em dois pontos. O primeiro deles é na associação entre um web service e uma política. Observou-se que a quantidade de web services utilizados não deveria causar grande impacto na complexidade de armazenamento (revés da tabela hash). Considerando que para armazenar cada par de web service e política sejam necessários 256 e 4 Bytes respectivamente, em um cenário com 1000 serviços com uma taxa de ocupação na tabela de 0,5, o uso total seria de 320 KBytes, uma quantidade não preocupante frente as máquinas atuais. O cenário de 1000 serviços cadastrados é um pouco exagerado tomando-se por base o estudo realizado em (Tavares et. al., 2008). O ganho no uso de uma tabela hash nesse caso é bom em relação ao espaço desperdiçado. Dentro da tabela hash utilizada, foram armazenados uma cadeia de caracteres (chave), que representa o serviço a ser tratado, e um ponteiro para a função da política associada aquele serviço. A execução da política se dá de maneira direta tendo-se o identificador do serviço, que pode ser o recurso vindo da própria requisição HTTP. Nesse ponto vê-se a utilidade clara do uso de ponteiros para função derivada das bibliotecas dinâmicas e do uso da tabela hash.

Um outro local no protótipo onde foi utilizada a tabela hash foi dentro do adaptador para o Ganglia. O uso da tabela permitiu uma busca rápida das informações de monitoração. Nessa parte da implementação foram utilizados dois níveis de tabela hash. Um primeiro nível forma uma tabela com um par chave/valor constituído pelo endereço dos nós monitorados e um ponteiro para outra tabela hash respectivamente. Isso permite que em um ambiente com muitos nós a localização das métricas de um nó específico se torne eficiente $(\mathrm{O}(1))$. A segunda tabela hash faz com que a métrica seja localizada de maneira eficiente da mesma maneira. A segunda tabela hash pode ser dispensada no caso de um cluster onde haja métricas bem determinadas para as decisões de distribuição. Nesse caso, podem existir poucas métricas, o que pode tornar viável o uso de estruturas menos complexas (como listas ou até mesmo vetores estáticos), principalmente em termos de espaço, porém com ordem de busca $\mathrm{O}(\mathrm{n})$. A abordagem adotada demonstrou-se eficiente e sem complexidade de implementação, fazendo com que seu uso fosse adequado para os testes. A opção por usar tabelas para 
armazenar as métricas evita bloqueios na requisição por informação ao monitor. No adaptador criado, é possível ajustar o tempo de atualização das métricas na sua configuração, evitando ajustes fixos no código que necessitem de recompilação. Além disso, as configurações do adaptador podem ser alteradas durante seu funcionamento, bastando apenas remover e inserilo novamente. Outra vantagem do uso de tabelas temporárias no adaptador é a redução do tráfego de informações por canais de comunicação, neste caso sockets. A implementação do adaptador e do método de associação entre web service e política usando tabelas hash se deu através de uma biblioteca genérica. A biblioteca utilizada foi a glib. Nos testes realizados durante a implementação seu desempenho foi satisfatório, apresentando um ganho considerável em tempo de implementação. O uso de suas funções é simplificado pela grande documentação existente sobre sua API. Além disso, sua API é genérica o suficiente para que suas funções possam ser usadas em diversos códigos. O tempo ganho na implementação com o uso dessa biblioteca foi considerável, visto que não foi necessário perder tempo em depuração de códigos e testes extras. A biblioteca glib é bem difundida é utilizada hoje em softwares baseados em $\boldsymbol{G T K}$, pois o próprio $\boldsymbol{G T K}$ a usa como base, e GNOME. Seu nascimento se deu juntamente com o software de manipulação de imagem Gimp. Considerando seu tempo de existência, versão, licença, portabilidade e penetração no desenvolvimento de software livre ela é adequada para os fins do projeto.

\subsubsection{Threads}

A característica dinâmica da arquitetura, principalmente no que diz respeito a sua configuração on-the-fly, deve em muito ser atribuída ao uso de múltiplas linhas de execução. O desenvolvimento do protótipo teve como base a larga exploração do recurso de threads. O gerenciador de configuração é um dos componentes que faz uso dessa característica. Enquanto o restante do programa está voltado para a tarefa de atendimento de requisições, esse gerenciador permanece esperando alterações na configuração. $O$ adaptador implementado também utiliza threads. Ele mantém a atualização das tabelas hash dedicadas à recuperação de informações. Periodicamente ele realiza uma conexão com o monitor e atualiza seus valores. Para o uso de diversos conectores também é necessário o uso de threads, visto que eles devem permanecer na espera por conexões dos provedores. Os diversos provedores poderiam conectar em uma mesma porta, ou mesmo o conector poderia fazer uso da função select para esperar e atender conexões. Porém isso tiraria a liberdade de parar e iniciar conectores para diferentes provedores. Outro fator negativo dessa opção seria a dependência de um único padrão de comunicação entre conector e provedor, fazendo com que 
o provedor tivesse que se adaptar às formas como outros provedores realizam as requisições por decisões.

Os gerenciadores de conectores, adaptadores e políticas são extensões do gerenciador de configuração e também executam em threads separadas. Sua existência como threads separadas não é de vital importância, pois o próprio gerenciador de configuração poderia ser encarregado da tarefa dos mesmos. Eles foram utilizados para modularização e manter a independência entre os componentes.

O uso de diversas threads requer uma preocupação extra com a consistência dos dados da aplicação. Portanto, devem ser utilizados os recursos existentes na manipulação de memória compartilhada dos componentes. Grande parte desses recursos são baseados em exclusão mútua de acesso às regiões compartilhadas. O uso da memória compartilhada é útil também na comunicação entre os componentes (tratada na seção 5.6). Na implementação do protótipo foram usados mutex, semáforos e variáveis de condição. Semáforos foram aplicados a locais críticos para evitar perda se sinais. Os mutex em alguns casos foram usados por serem requisitos para o uso de variáveis de condição, estas usadas em comunicações. Outros usos de mutex foram em regiões onde havia conflito de escrita e leitura de informações. Esse caso se dá principalmente no processo de decisão concomitante a uma alteração de configuração. Outra situação onde o mutex se fez necessário é no adaptador, durante a atualização das tabelas, pois se houver requisições por métricas no momento em que elas estão sendo atualizadas, pode ocorrer a leitura de uma região de memória inconsistente.

O acesso às variáveis de controle dos recursos citados é feito através das estruturas internas do protótipo, que permitem o acesso por todos os componentes do mesmo. Quando o travamento de uma informação é necessário e o componente não é intrínseco ao protótipo, como no caso de conectores, adaptadores e políticas, as variáveis de controle são passadas como parâmetros a esses. Isso será abordado na seção 5.6. Na implementação, o objetivo foi usar ao máximo primitivas relacionadas a threads que possibilitem a portabilidade, por isso o extensivo uso de primitivas derivadas da biblioteca pthread. Semáforos foram utilizados em locais pontuais de comunicação devido a sua natureza de evitar perda de sinais. Semáforos são primitivas fornecidas pelo sistema operacional e em alguns casos dificultam a portabilidade, por isso a decisão de reduzir o seu uso.

\subsection{Funcionamento}

O funcionamento do protótipo obedece o previsto para a arquitetura e apresentado em mais alto nível na seção 5.2. Em resumo, a seqüência de eventos do funcionamento da 
arquitetura é composto pela recepção da requisição pelo front-end e, na seqüência, por um pedido ao distribuidor pela decisão de distribuição por parte do provedor de web services. Em seguida, o distribuidor baseado nos dados de monitoração e na política adotada retorna ao provedor o nós de destino. O provedor então remonta a requisição e a envia para o nó de destino. Depois dela ser recebia e processada no destino, o nó que a processou retorna o resultado ao front-end que finalmente retorna o resultado ao cliente.

Para entender a maneira como todo o processo é realizado no protótipo é necessário um detalhamento que possua uma ligação mais forte com a implementação realizada. Na Fig. 5.4 é apresentado um esquema das estruturas de dados contidas internamente no protótipo.

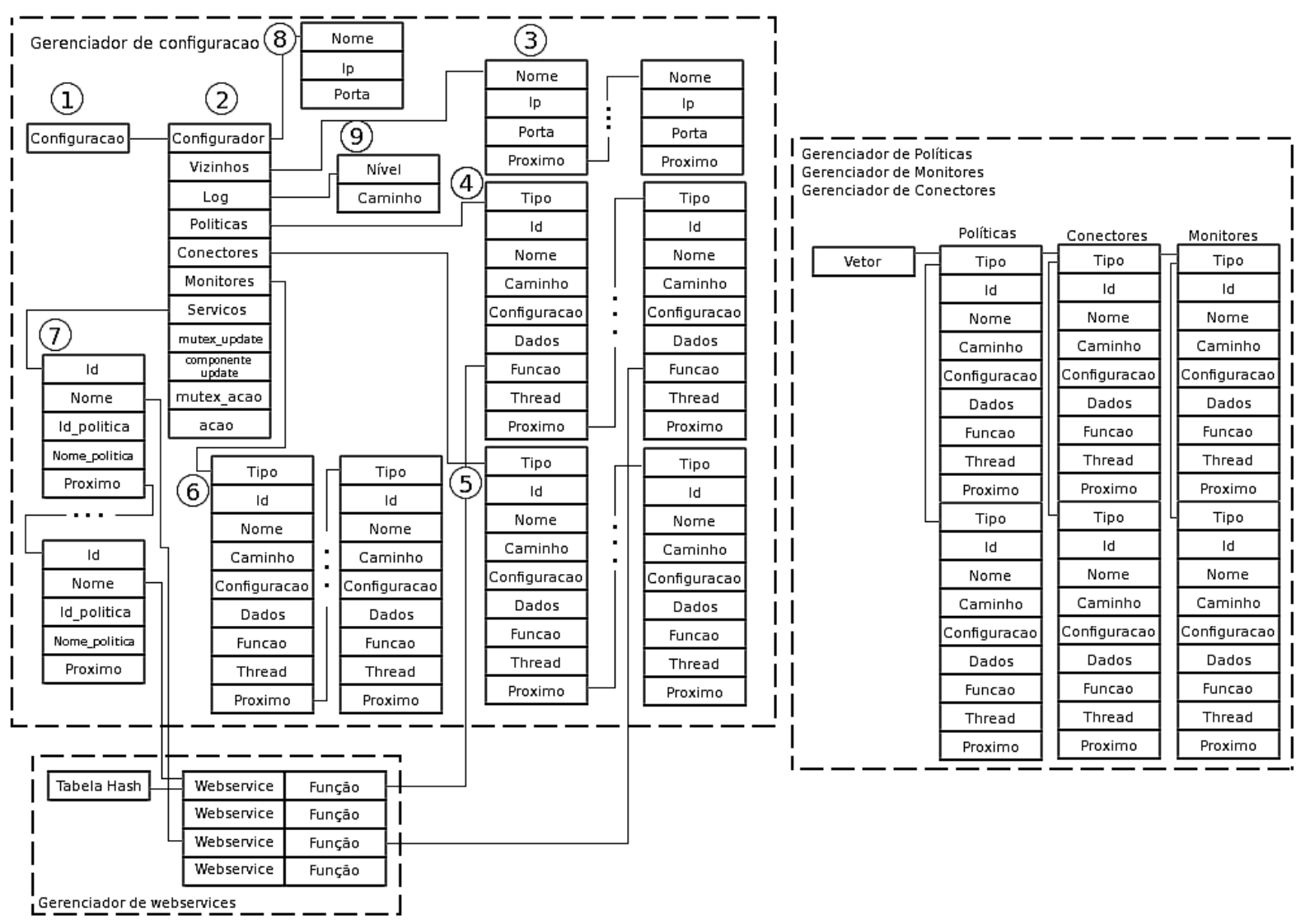

Fig. 5.4: Estruturas de dados presentes no protótipo

A Fig. 5.4 destaca as estruturas existentes no protótipo e sua ligação. Como pode ser visto, toda a configuração (dentro do Gerenciador de configuração) possui um único ponto de entrada (1). Isso torna possível o acesso por todos os componentes internos do protótipo às configurações usando apenas um único ponteiro. Derivado desse ponteiro de configuração existe uma estrutura que centraliza toda a configuração (2). Essa estrutura contém um conjunto de ponteiros para listas ligadas que descrevem os componentes do sistema. A escolha por listas nesse local do protótipo tem o intuito de possibilitar a variação da quantidade de elementos presentes no sistema de maneira mais simplificada. As listas que podem ser 
acessadas por essa estrutura são as listas de: vizinhos (3), políticas (4), conectores (5), monitores (6) e serviços (7). Além das ligações para as listas, existem outros dados na estrutura. Um deles é o dado de configuração do gerenciador de configuração (8). Esse dado diz ao distribuidor em que par endereço/porta ele deve permanecer esperando conexões para interações com a configuração. Os dados referentes ao log (9) descrevem qual o nível de detalhamento (expresso numericamente) de log que deverá ser usado pelo distribuidor (de depuração com valor 5 até informação com valor 1). Esse parâmetro se torna útil para o administrador quando é necessário observar o comportamento do distribuidor com mais ou menos detalhes, tendo acesso às decisões e às interações entre os componentes. Também nessa configuração é possível informar qual será o arquivo de saída no qual o log deve ser gravado.

Existem ainda dentro da estrutura de configuração 4 dados referentes à memória compartilhada pelos componentes. Um desses dados (mutex_update) é utilizado em conjunto com o dado componente_update, este último uma variável de condição que permite sinalizar às threads dos gerenciadores de componentes dinâmicos. Esses dados são vetores com um número definido de posições, cada uma referente a um componente. Essa sinalização ocorre em conjunto com a mudança de valor da variável compartilhada acao. A seção 5.6, sobre trocas de mensagens, detalha melhor essa interação.

A lista ligada referente aos vizinhos (3) é utilizada para que o gerenciador tenha informações sobre os outros distribuidores presentes na arquitetura. Essa informação é utilizada quando, durante a interação do usuário, este diz ao distribuidor que ele deve repassar suas configurações para os demais distribuidores. O conteúdo dessa estrutura possui um endereço e porta no qual os outros vizinhos podem ser encontrados. Vizinhos também podem ser adicionados e removidos durante a execução sem necessitar parar o distribuidor, por isso o uso da lista ligada.

As listas de políticas (4), conectores (5) e monitores (6) possuem uma estrutura semelhante, visto que os elementos que elas representam possuem características semelhantes. A estrutura é denominada elementos e possui para cada um dos elementos as seguintes informações: id, nome, caminho, configuracao, dados, manipulador_thread, funcao, ativo, manipulador_lib e proximo. O nome e id são identificadores dos elementos atribuidor pelo administrador para que seja possível a ligação entre um serviço e uma política e ainda também facilitar a manipulação via gerenciador de configuração. O caminho informa o local onde a biblioteca dinâmica pode ser encontrada. A configuracao diz qual é o local do arquivo de configuração para esse elemento, facilitando ao administrador criar arquivos de configuração específicos para o seu elemento. Isso possibilita que o 
administrador use as bibliotecas de processamento de configurações que mais lhe convier. $\mathrm{O}$ ponteiro de tipo genérico dados é utilizado para que o administrador possa manter persistente alguma informação da execução do seu elemento, por exemplo, uma decisão de distribuição de uma política. Isso é feito através da alocação dinâmica de memória do elemento. Esse detalhe será tratado na seção 6.2.1 que aborda o desenvolvimento dos elementos (principalmente de políticas). O dado manipulador_thread permite ao distribuidor manter a ligação com as threads de adaptadores e conectores, permitindo determinar quando essas threads foram finalizadas. Como as políticas não utilizam o recurso de threads, no seu caso, esse dado permanece inutilizado. O próximo dado é um ponteiro para a função do elemento contida no arquivo da biblioteca dinâmica e obtido através da função dlsym. Nos conectores e adaptadores esse ponteiro é passado para a função de criação de threads para que os elementos sejam inicializados. Nas políticas, esse dado é armazenado na tabela hash de associação de web service/política para que esta seja executada quando uma decisão para o serviço seja necessária. O dado ativo é usado em conjunto com um outro dado do mesmo tipo em outro local (vetor) para manter a consistência de quando um elemento está ativado ou desativado e quando os gerenciadores devem realizar uma ação sobre o elemento. O manipulador_lib é utilizado quando é necessária a remoção de um elemento. Assim, usando a função dlclose é destruída a ligação do distribuidor com o arquivo da biblioteca que pode então ser fechado.

Concomitantemente com a existência das listas para os elementos é mantido um vetor que mantém os seus dados duplicados para auxiliar na busca mais eficiente por um elemento e também na informação se um elemento está ativo ou não. Esse vetor possui algumas funções para facilitar buscar e alterar alguns dados básicos de maneira mais simplificada. As alterações realizadas pelos gerenciadores também só são propagadas para ele quando ela ocorreu com êxito, fornecendo um meio de desfazer erros de configuração internos. Outra utilidade para a duplicação é manter o funcionamento do distribuidor mesmo quando uma alteração está sendo realizada. Assim ele não precisa permanecer bloqueado esperando pela completude e confirmação da operação realizada com sucesso no momento em que uma requisição por decisão é necessária, por exemplo.

Outra lista existente na implementação do protótipo é a lista que contém os web services (7) para os quais é necessária uma decisão de distribuição. Esta lista contém os seguinte campos: id, nome, id_política, nome_política. O primeiro e segundo campos têm a função de identificar os serviços para sua manipulação. O nome é o campo no qual será gravado na tabela hash para a associação à política. Os outros dois campos citados são destinados ao armazenamento de qual é a política associada ao serviço. O valor desses 
campos é passado pelo administrador no arquivo de configuração do distribuidor. No momento do carregamento das configurações do serviço, que ocorre depois da política, é procurada dentro do vetor de políticas uma política que possua nome ou id iguais ao fornecido. Quando a política é encontrada, uma nova entrada é criada na tabela hash. Se não existir a política especificada, o distribuidor assume uma política padrão.

O funcionamento do protótipo pode ser representado pelas Figs. 13 a 18. Nelas são apresentados diagramas comportamentais usando Redes de Petri Coloridas (RdPC) para ilustrar o funcionamento do protótipo. Foi escolhido o uso de $\boldsymbol{R} \boldsymbol{d P}$ para a representação devido a sua capacidade de representar o funcionamento de processos concorrentes com relativo grau de simplicidade. Além disso, o modelo gerado permite a sua simulação para verificação de corretude e ainda observar o funcionamento do protótipo durante a simulação passo-a-passo.

A ferramenta utilizada para gerar o modelo é a CPN Tools (CPN Group, 2009). Ela permite a criação de $\boldsymbol{R} \boldsymbol{d} \boldsymbol{P}$ coloridas hierárquicas. As $\boldsymbol{R} \boldsymbol{d} \boldsymbol{P}$ foram propostas em originalmente entre os anos 60 e 70. Quando elas surgiram, foram consideradas a linguagem mais adequada e representativa para descrever e analisar sincronização, comunicação e compartilhamento de recursos para processos concorrentes. Porém, no seu início, devido à falta de um tipo de representação de dados (em Redes de Petri Ordinárias, RdP) os modelos cresciam muito, tornando-os impraticáveis. Outro problema também relacionado ao tamanho era a falta de representações hierárquicas, usando composição de modelos para gerar modelos maiores. Por volta dos anos 80, o surgimento das Redes de Petri Coloridas (RdPC) teve por objetivo remover esses problemas.

A ferramenta utilizada na construção do protótipo foi desenvolvida na Universidade de Aarhus (Dinamarca) e é derivada de uma outra ferramenta, chamada Design/CPN, também desenvolvida nessa universidade entre os anos 80 e 90. Segundo dados dos criadores, hoje a ferramenta CPN Tools é usada por mais de 700 organizações em 60 diferentes países. Pode ainda ser encontrado no site da ferramenta uma extensa lista de organizações que utilizam a ferramenta para diversos fins na modelagem de sistemas e processos.

Basicamente em um modelo em $\boldsymbol{R} \boldsymbol{d} \boldsymbol{P}$ existem três conceitos importantes, lugares, transições e arcos. Arcos ligam lugares a transições e transições a lugares. As transições representam ações e podem ser disparadas mediante a presença de uma marca (token) nos lugares ligados a ela (lugares de entrada). Quando uma transição dispara, ela consome as marcas do lugar de entrada e cria marcas a serem depositados em lugares de saída. No contexto de $\boldsymbol{R} \boldsymbol{d P C}$ as marcas podem representar tipos de dados (inteiros, cadeias de caracteres, números em ponto flutuante, etc). Os tipos de dados ainda podem ser compostos 
de diferentes formas, como produtos, uniões, listas, etc. Os arcos de entrada nas transições funcionam como condicionais para o disparo das mesmas impondo a presença dos tipos de dados adequados. Os arcos de saída das transições depositam os tipos de dados especificados neles nos lugares aos quais estão ligados. Os lugares armazenam as marcas de um tipo de dado específico. As transições ainda podem apresentar condições baseadas em variáveis presentes nos arcos, que são instanciadas com os valores das marcas presentes nos arcos de ligação.

Redes de Petri Coloridas ainda podem fazer com que seus dados sejam temporizados, possibilitando criar um tempo lógico para a simulação. O uso de temporização pode ser útil tanto para avaliação de desempenho de tarefas quanto para alterar sincronização entre processos concorrentes. O uso de hierarquia também é possível usando a ferramenta CPN Tools. Isso torna o modelo mais manipulável e simplifica seu entendimento.

O modelo criado para representar o funcionamento do protótipo utiliza RdPC, com hierarquia e temporização. Ele possibilita observar como interagem as threads existentes e como se dá o processo de interação entre os componentes. A representação está em um nível mais alto, usando algumas abstrações para facilitar a compreensão do modelo. O tipo de dado que representa a estrutura de configuração no protótipo engloba apenas os web services, conectores, adaptadores e políticas. Esses dados são representados apenas como números, sem maiores significados. Apesar das abstrações é possível observar as interações do sistema. A Fig. 5.5 mostra as declarações utilizadas para os tipos de dados do modelo.

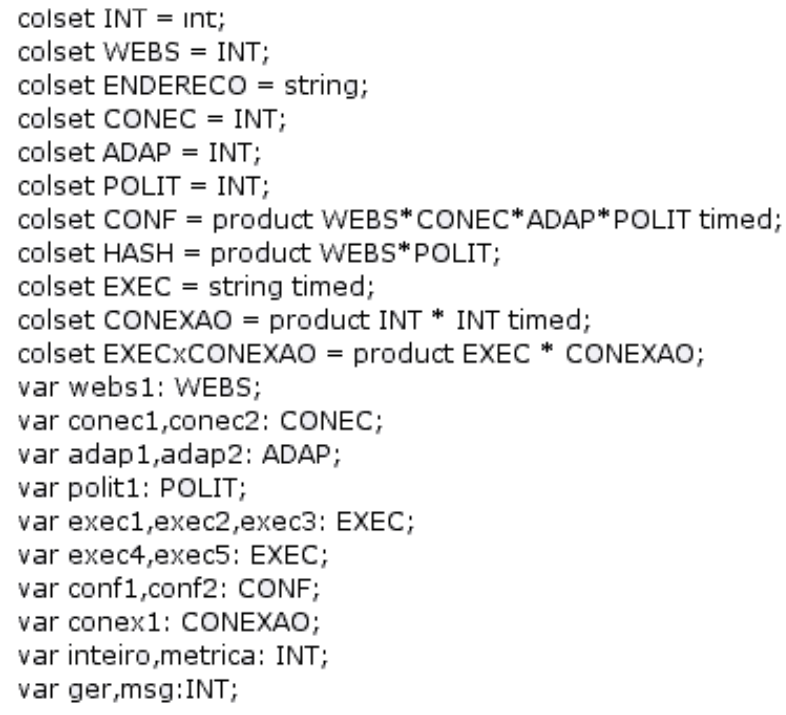

Fig. 5.5: Declarações de tipos de dados do modelo

O tipo CONF é um produto entre WEBS, CONEC, ADAP, POLIT sendo web services, conectores, adaptadores e políticas respectivamente. Este tipo é temporizado ( $t$ imed) o que 
possibilita aplicar modificações nas configurações em relação ao tempo de simulação do modelo. Outro tipo de dados importante no modelo é o EXEC. Ele representa a marca de execução, sua presença mostra as threads ativas e quais atividades elas estão realizando. Ele também é temporizado, mantendo a ordem de execução dos eventos na simulação. Além dos tipos de dados, existem as variáveis, utilizadas nos arcos para garantir a passagem de marcas variáveis de um lugar para outro lugar passando por uma transição. Variáveis também são úteis para gerar condições em arcos e transições, como pode ser visto em algumas partes do modelo.

Na Fig. 5.6 é apresentado o modelo do protótipo representando sua principal linha de execução aplicando-se o conceito de hierarquia. Nela é possível ver a execução dos carregadores dos gerenciadores como uma “caixa preta”. Um detalhe presente nos modelos apresentados são arcos que parecem ser bidirecionais, porém são apenas sobreposições de dois arcos em sentidos opostos posicionados automaticamente pela ferramenta utilizada, não quebrando as regras de $\boldsymbol{R d P C}$.

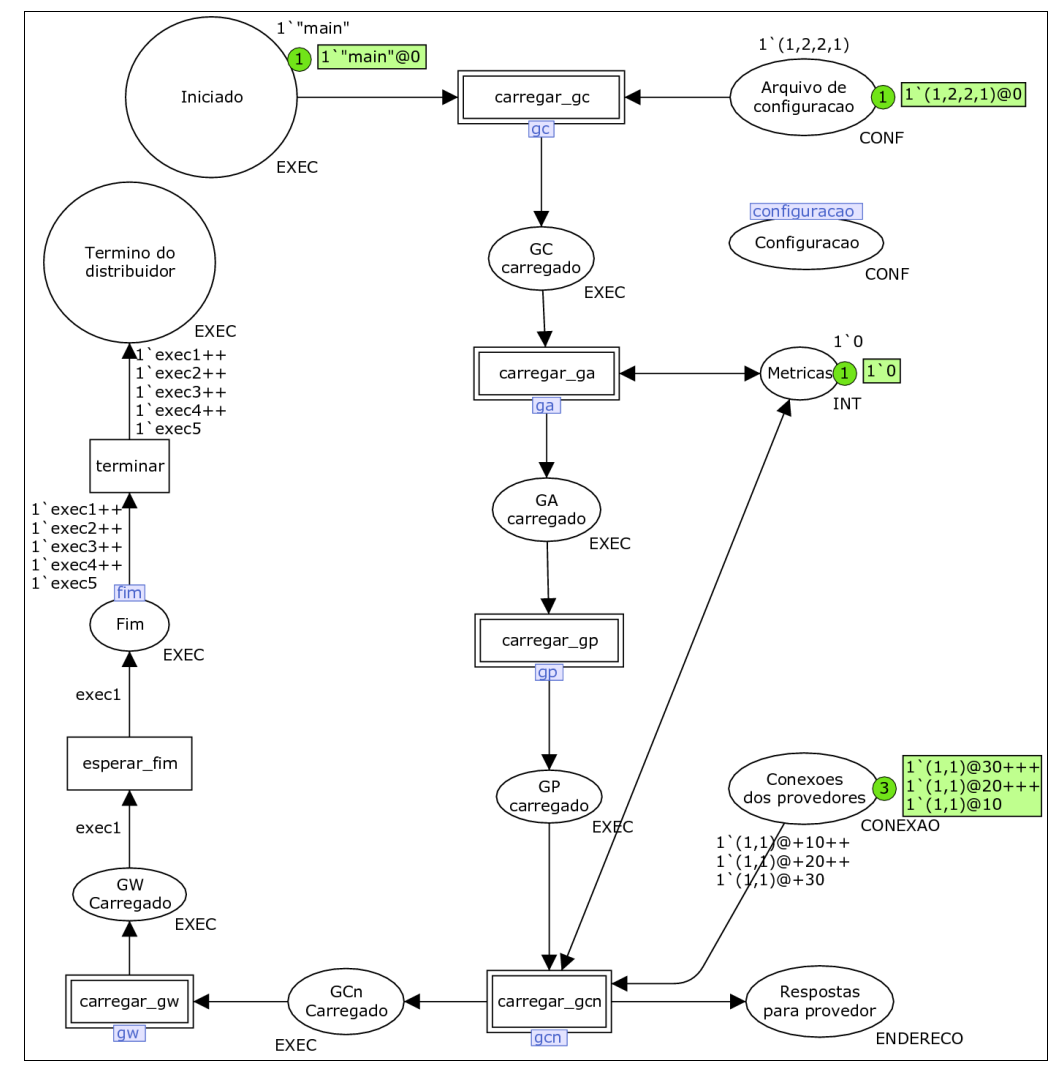

Fig. 5.6: Linha de execução principal

O fluxo de execução do modelo inicia-se na parte superior esquerda da Fig. 5.6, no lugar Iniciado. Ali está presente uma marca inicial ( 1 ' "main") do tipo EXEC. Esta marca representará o fluxo de execução da linha principal de execução do protótipo. O término da execução se dá no lugar Termino do distribuidor, quando todas as marcas do tipo 
EXEC que representam as linhas de execução do protótipo estão nele depositadas. A execução passa pelo carregamento do gerenciador de configuração $(\boldsymbol{G C})$, gerenciador de adaptadores $(\boldsymbol{G A})$, gerenciador de políticas $(\boldsymbol{G P})$, gerenciador de conectores $(\boldsymbol{G C n})$ e gerenciador de web services $(\boldsymbol{G W})$. Observando-se o modelo, podem ser vistos lugares com "pequenos quadrados” quase que internamente com inscrições. Esses elementos fazem com que os lugares se tornem "fusion places", que são representações de um único lugar com a mesma inscrição. Eles são uma espécie de link entre lugares iguais, uma vez que uma marca é depositada em um lugar com essa inscrição, essa marca estará disponível em todos os lugares com a mesma inscrição. Esse recurso foi utilizado principalmente no lugar que armazena a configuração, nos lugares que armazenam as notificações aos gerenciadores e na hash que associa serviço/política.

O processo de inicialização do protótipo inicia-se pela carga do gerenciador de configuração. Ele lê o arquivo de configuração e carrega para a estrutura de dados interna do programa (representada pelo lugar Configuracao) as especificações do arquivo. A configuração então se torna disponível para todos os outros gerenciadores.

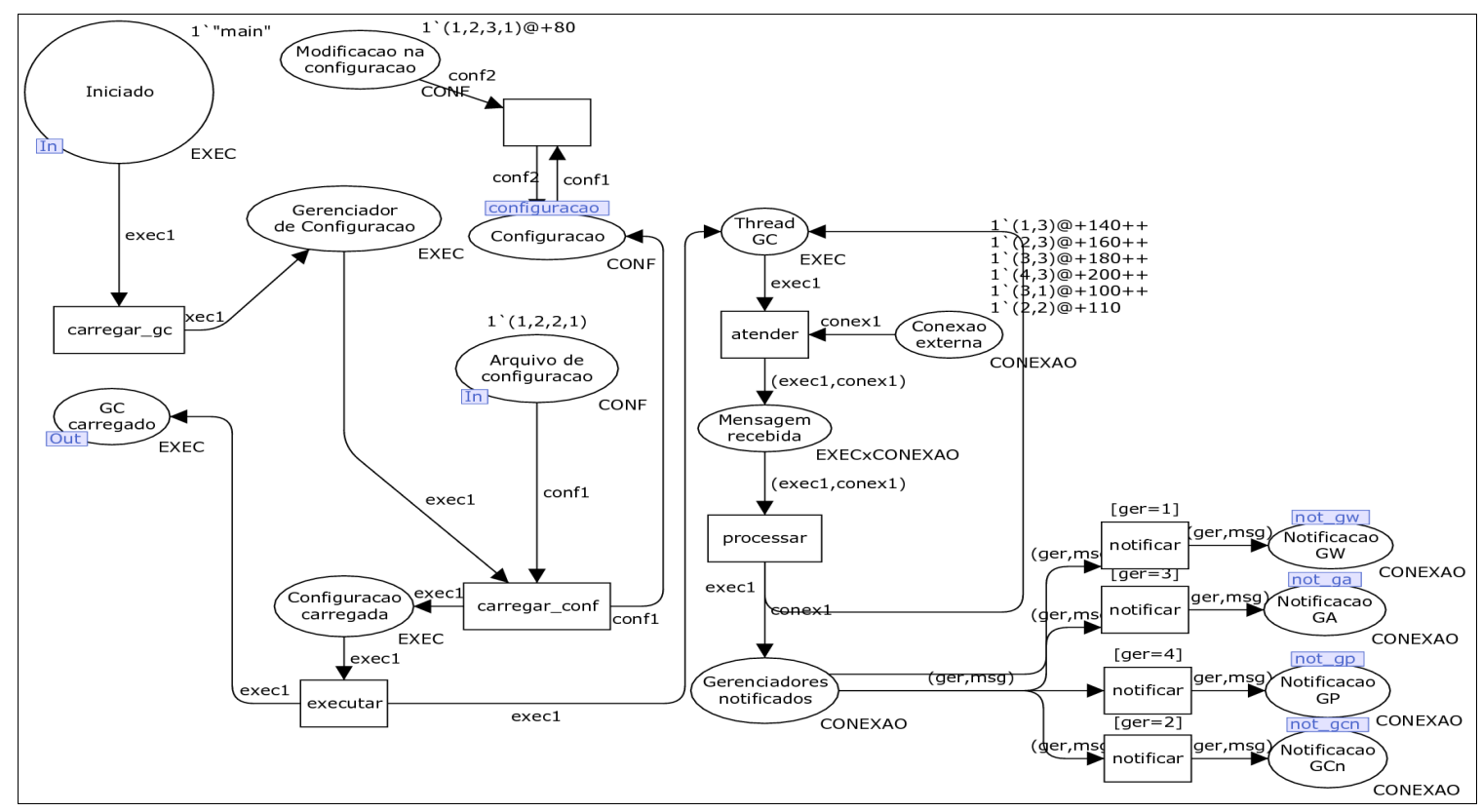

Fig. 5.7: Modelo do Gerenciador de Configuração (GC)

Na Fig. 5.7 é apresentado o funcionamento do GC. Essa figura, assim como as Figs. 5.8 a 5.11, apresentam os modelos dos gerenciadores, de maneira expandida em relação as transições apresentadas na Fig. 5.6. Esse é o recurso de hierarquia que possibilita a expansão para o detalhamento de transições, auxiliando na criação, manipulação e compreensão do modelo. Depois que é carregado o arquivo de configuração (carregar_conf) no $\boldsymbol{G C}$ ele 
executa a sua thread, que permanecerá esperando conexões externas para então processar as mensagens recebidas e notificar as ações a serem realizadas pelo outros gerenciadores. É possível ver que o lugar Conexao externa possui 6 marcas iniciais temporizadas, representando mensagens de configuração que entrarão no sistema quando o devido tempo de simulação for atingido.

Depois de executada a thread do $\boldsymbol{G C}$, existem duas threads existentes no protótipo, a do $\boldsymbol{G C}$ e a principal, que dará início a carga do $\boldsymbol{G A}$. O modelo do $\boldsymbol{G A}$ está presente na Fig. 5.8.

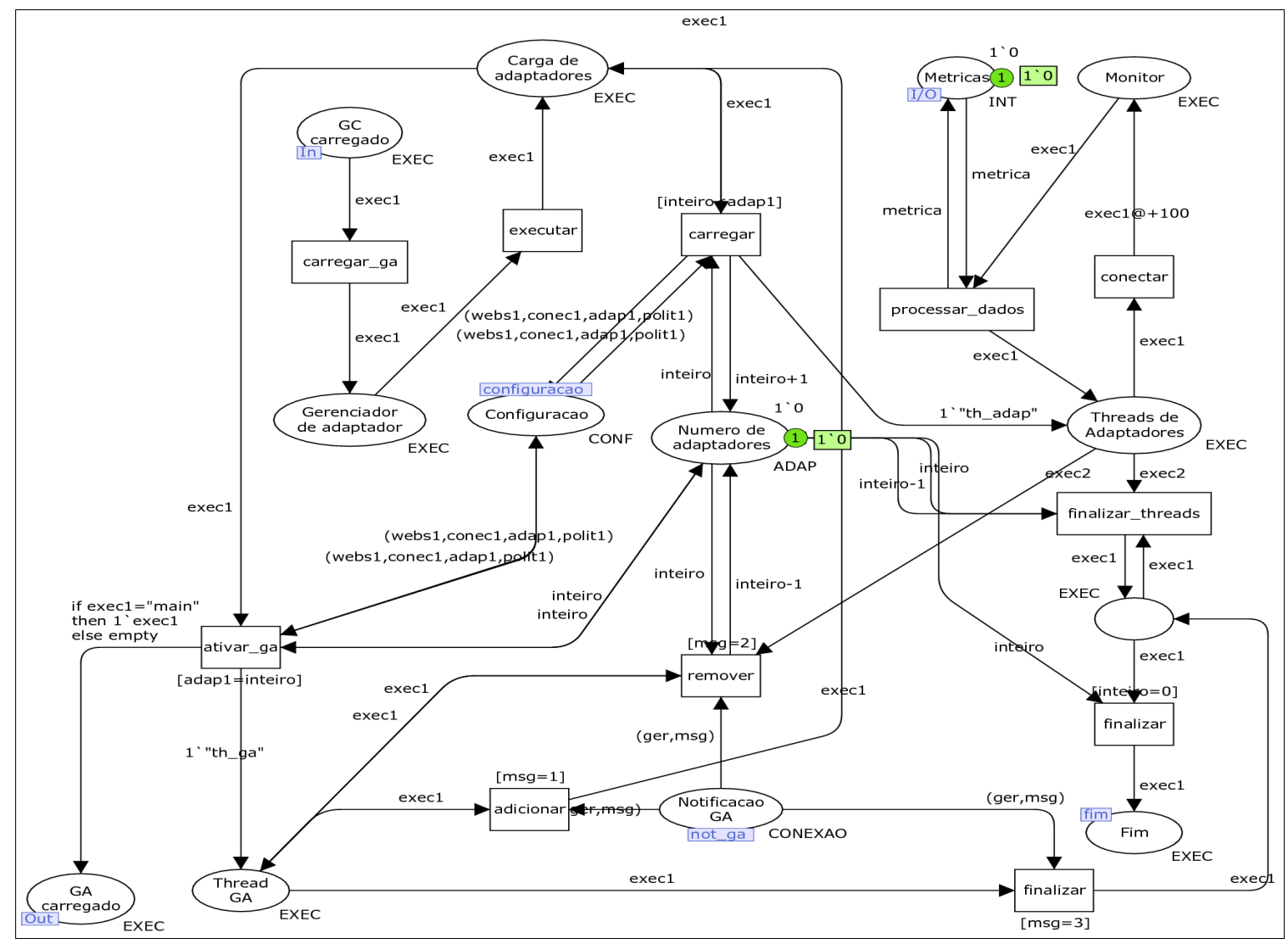

Fig. 5.8: Modelo do Gerenciador de Adaptadores (GA)

O ponto de entrada do $\boldsymbol{G A}$ é o lugar $\boldsymbol{G C}$ carregado. A partir dele é realizada a leitura do arquivo de configuração e a contagem dos adaptadores carregados (em Numero de adaptadores) como forma de controle. Cada adaptador carregado inicia uma nova thread, que será depositada Threads de Adaptadores a partir de onde permanecerão na tarefa de conectar ao monitor, processar os dados obtidos e disponibilizá-los para que as políticas possam utilizá-los. Quando todos os adaptadores são carregados, a transição ativar_ga é disparada graças ao seu guarda (condição de disparo adapl=inteiro) gerando a thread do $\boldsymbol{G A}$ e fazendo com que a linha de execução principal retorne para a carga dos próximos gerenciadores. A thread do $\boldsymbol{G A}$ permanece em espera até que uma notificação remoção, 
adição ou finalização (no caso do modelo, por efeito de simplificação foram retiradas ativação e desativação) seja recebida. A maneira como o $\boldsymbol{G A}$ trata cada uma das notificações pode ser acompanhada no próprio modelo.

O próximo gerenciador a ser carregado é o $\boldsymbol{G P}$, que pode ser observado na Fig. 5.9. O processo de carga das políticas é semelhante ao do $\boldsymbol{G A}$, porém sem a execução de uma nova thread. As políticas são depositadas em Políticas ativas, de onde adiante o $\boldsymbol{G} \boldsymbol{W}$ carregará a hash para associação de serviço/política. Depois de carregadas as políticas (preenchidas todas as estruturas de dados do protótipo referentes às políticas), é lançada uma nova thread a partir de ativar_gp. Essa nova thread permanecerá esperando notificações vindas do $\boldsymbol{G C}$. A execução é retornada à linha de execução principal, existindo nesse ponto 4 threads ativas (principal, $\boldsymbol{G C}, \boldsymbol{G A}$ e $\boldsymbol{G P}$ ).

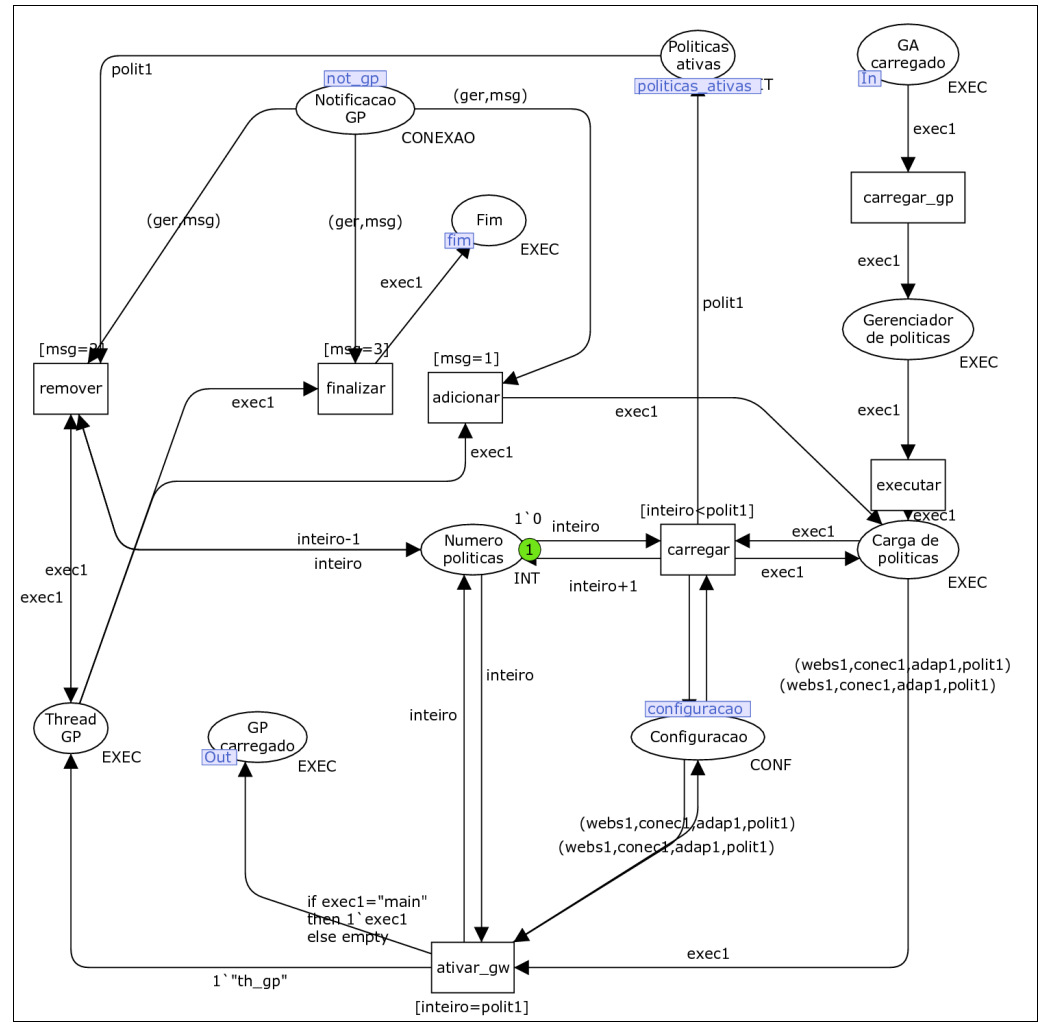

Fig. 5.9: Modelo do Gerenciador de Políticas (GP)

A Fig. 5.10 contém o modelo do próximo gerenciador o qual é executado, o $\boldsymbol{G C n}$. O ponto de entrada desse modelo é o lugar GP carregado. No protótipo ele é executado logo depois do retorno do carregamento do $\boldsymbol{G P}$. Esse gerenciador segue a mesma idéia do $\boldsymbol{G A}$, pois ambos disparam novas threads. A adição, remoção e finalização também funcionam da mesma maneira, mediante as notificações do GC. A maior diferença está no funcionamento das threads, depositadas no lugar Threads dos conectores. Elas esperam conexões dos seus 
devidos provedores para associar uma política a um serviço através da tabela hash. A tabela hash nesse caso é representada pelo lugar Hash web/pol, que é carregada no $\boldsymbol{G} \boldsymbol{W}$.

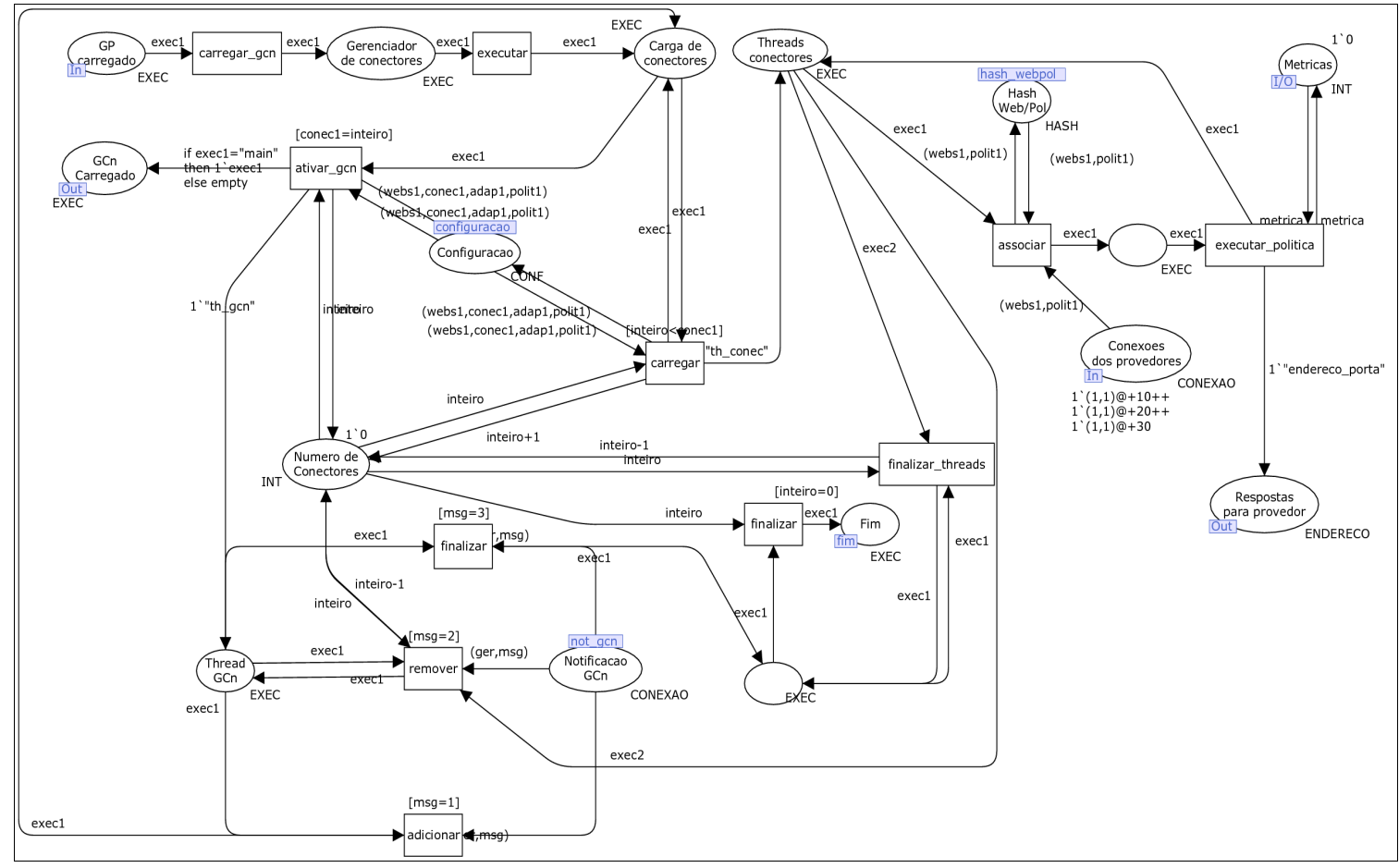

Fig. 5.10: Modelo do Gerenciador de Conectores (GCn)

Apesar de não representado no modelo, para efeito de simplificação, quando uma política não é encontrada é adotada uma decisão baseada em uma política padrão. Quando é realizada a associação, a thread passa para a execução da política (executar_política). No modelo, o disparo dessa transição acontece mediante a presença de marcas no lugar Metricas. Intrínseco ao modelo, pode ser considerado o bloqueio de escrita ou então decisão enquanto ou uma métrica é consultada por uma política ou então enquanto ela é atualizada pelo adaptador. Isto acontece graças as transições que consomem as métricas do lugar Metrica, impossibilitando outras transições de disparar. Esse comportamento é implementado no protótipo usando-se mutex. O lugar Conexoes dos provedores contém marcas iniciais que são temporizadas, fazendo com que as requisições por elas representadas somente executem no determinado tempo no modelo. As threads dos conectores permanecem nesse loop de atendimento até que a finalização seja notificada ao seu gerenciador.

O próximo passo executado dentro do protótipo e representado no modelo depois da carga dos conectores e do início do GCn é o carregamento dos serviços. Esse processo é apresentado na Fig. 5.11. 


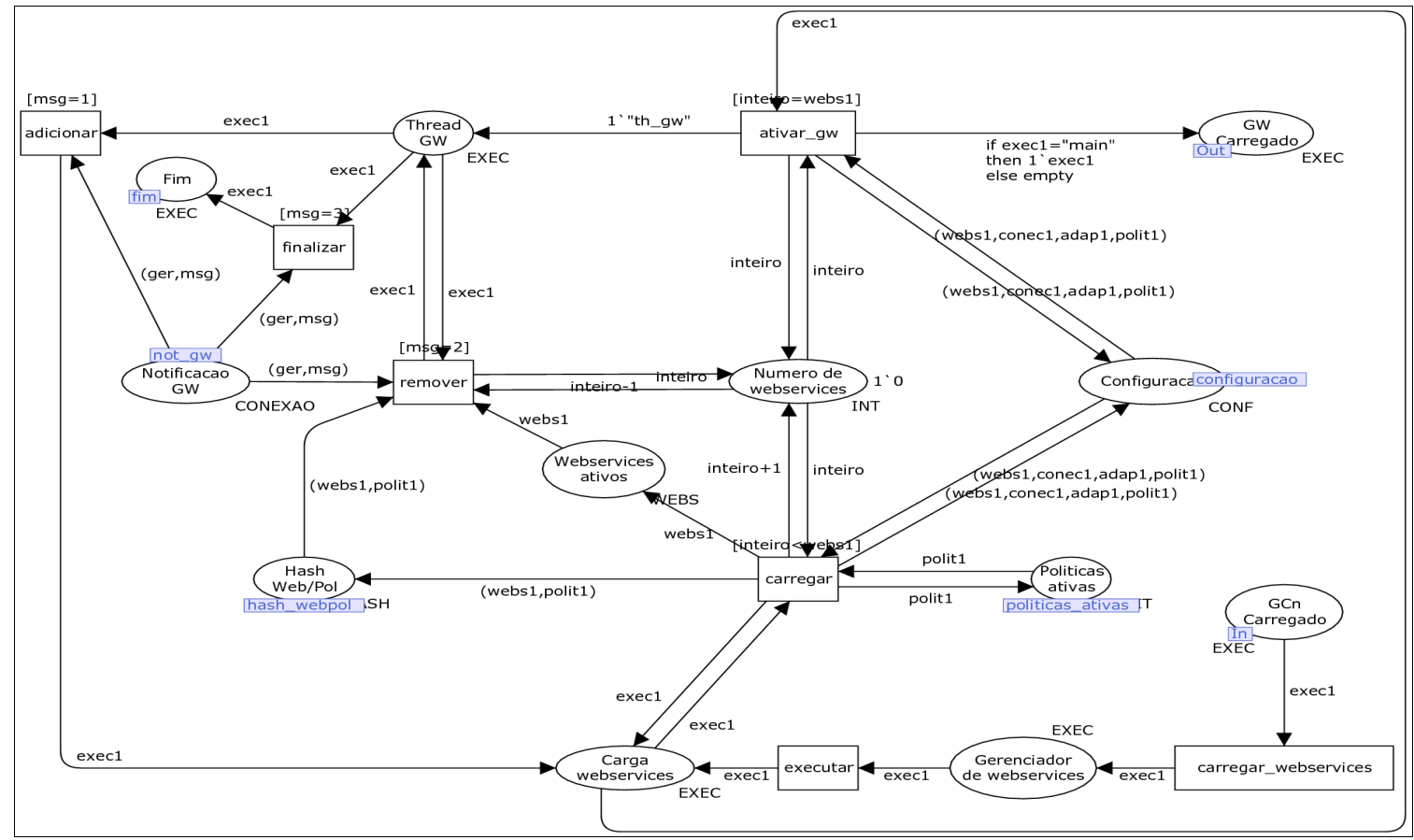

Fig. 5.11: Modelo do Gerenciador de Webservices (GW)

Os serviços são carregados pelo $\boldsymbol{G W}$, ainda pela thread principal. A carga é realizada na transição carregar e consiste, no protótipo, na leitura das configurações e criação das associações das políticas carregadas pelo $\boldsymbol{G P}$ e os serviços na tabela hash. Depois de carregada a tabela, é iniciada a thread do $\boldsymbol{G W}$, que executará as notificações do $\boldsymbol{G C}$. Concomitantemente ao início dessa thread é retomada a execução da linha principal. Depois da execução do $\boldsymbol{G W}$, a linha principal fica depositada em um lugar chamado Fim, isso pode ser visto na Fig. 5.6. Esse lugar representa a junção de todas as linhas de execução depois que uma notificação de finalização é realizada. Quando todas as threads são finalizadas, é disparada a transição terminar, que enfim faz com que a linha de execução se torne apenas uma, depositando a marca de execução única agora no lugar Termino do distribuidor.

Para uma visão mais geral do modelo, é apresentado no Anexo I o mesmo modelo detalhado neste capítulo usando $\boldsymbol{R d P C}$ sem o recurso de hierarquia, utilizado nos modelos da Fig. 5.6 a 5.11. A inserção do modelo no anexo é explicada pelo seu tamanho, podendo ser notado a contribuição da hierarquia para a compreensão do modelo que foi apresentado neste capítulo.

Durante a simulação do modelo apresentado em $\boldsymbol{R d P C}$ usando a ferramenta CPN Tools é possível observar a capacidade de representação desse modelo, apresentando as semelhanças necessárias entre o protótipo e o modelo. As características de concorrência que $\boldsymbol{R} \boldsymbol{d P C}$ possuem fazem com que seja possível observar claramente a existência de diversas linhas de execução do protótipo. 


\subsection{Troca de mensagem}

A troca de mensagens é uma questão presente na arquitetura proposta em alguns níveis. Observando-se a Fig. 5.1 vê-se que existem, ao redor do distribuidor, trocas de mensagens entre o provedor de web services e o distribuidor e entre o distribuidor e o monitor. A primeira tem a intenção de passar ao distribuidor uma referência para o serviço que se quer executar e espera de retorno uma resposta do endereço para onde encaminhar a requisição. A segunda é necessária para que o adaptador disponibilize para as políticas as informações dos nós. Ela consiste em uma requisição de informações para o monitor e uma resposta com as informações coletadas.

Observando-se a arquitetura proposta, existem outras trocas de mensagens. A monitoração consiste não só apenas da requisição do distribuidor ao monitor, mas de toda a coleta de informações do cluster. Para isso, é necessário que os outros nós enviem para o monitor as suas informações. Na implementação da arquitetura foi usada a ferramenta Ganglia, como supracitado. Ela encapsula para o distribuidor todas as mensagens necessárias à obtenção das informações dos nós. Essas mensagens são trocadas por meio de multicast, facilitando a sua obtenção e diminuindo a sobrecarga. O uso de multicast deve ser analisado cuidadosamente, pois pode inverter a situação e acabar causando sobrecarga. Nada impede que em alguma situação, caso algum outro adaptador seja implementado, de que o próprio adaptador faça a comunicação com os demais nós para obter os dados desejados. A opção pelo Ganglia deve-se à sua robustez e facilidades apresentadas.

Existe, na arquitetura, a troca de mensagem ocasionada pela reconstrução do pacote HTTP para o envio e recepção para o nó de destino. Essa comunicação foi implementada internamente no filtro ligado ao provedor de serviços. O filtro, que será detalhado na seção 6.2.3, utiliza o encapsulamento de conexão $\mathbf{T C P}$ fornecido internamente pelas bibliotecas de manipulação para o protocolo HTTP da linguagem Java para a comunicação. A recepção da requisição e a resposta por parte do front-end ao cliente foi deixado a cargo do próprio provedor, já que o filtro intercepta a mensagem internamente, não afetando essa tarefa.

A troca de informação entre o adaptador e o monitor foi implementada utilizando sockets e TCP. Essa decisão foi tomada principalmente devido à característica do monitor utilizado. Para obter as informações, é necessário que se estabeleça uma conexão com o protocolo TCP. Quando a conexão é estabelecida o Ganglia responde com uma mensagem composta em $\boldsymbol{X} \boldsymbol{M L}$ com todas as informações. Para a obtenção da mensagem não é necessário o envio de nenhuma informação por parte do adaptador. A mensagem em $\boldsymbol{X M L}$ é composta 
pelo DTD e das tags de informações. O processamento do $\boldsymbol{X} \boldsymbol{M L}$ da mensagem é trivial através do uso de bibliotecas (no caso do protótipo a libxml2). As informações em $\boldsymbol{X M L}$ ocupam aproximadamente $10 \mathrm{~KB}$ por nó monitorado. Essa quantidade de dados transporta 33 métricas, podendo-se, em casos onde realmente seja necessário, diminuir a quantidade de métricas publicadas. O uso de sockets possibilita que o monitor de onde sejam obtidos os dados esteja em qualquer máquina acessível dentro da mesma rede, apenas usando-se seu endereço IP. Com isso, é possível obter pelo menos duas configurações de disposição dos elementos analisando-se impactos de desempenho. Apesar de não ser preocupante em clusters em menor escala, é possível, para soluções maiores, deixar um nó dedicado para realizar a monitoração e responder às requisições por dados, diminuindo a concorrência com o distribuidor/protótipo. Essa solução tem o revés das informações em $\boldsymbol{X} \boldsymbol{M L}$ trafegarem na rede. Outra situação possível é manter o protótipo no mesmo nó que o monitor, assim as informações podem trafegar pela interface de loopback, não causando sobrecarga na rede e aumentando o desempenho. Nessa disposição, o nó que contém o protótipo usará recepção em multicast de sua interface de rede para que os outros nós do cluster enviem suas informações. Isso aumenta a concorrência pelo dispositivo de rede. Essa análise depende de cada configuração, quantidade de nós e métricas. Considerando as possibilidades expostas, é possível constatar a flexibilidade em relação à configuração de software/hardware da arquitetura.

A comunicação entre o provedor e o protótipo foi implementada usando-se sockets e UDP. A escolha por $\boldsymbol{U D P}$ foi devido à quantidade de informações que é trocada nesse ponto de comunicação e a menor possibilidade de perda de pacotes usando ethernet, devido a qualidade do hardware voltado para este fim nos dias atuais. Outra questão é que a perda de pacotes nesse ponto não é crítica, pois o filtro implementado possui mecanismos para tratar as perdas e ocorrendo uma falha maior, o atendimento das requisições pode ser até mesmo realizado pelo front-end em casos de necessidade de maior tolerância à falhas. A pequena, mas existente sobrecarga na realização de uma conexão $\mathbf{T C P}$ para a obtenção de tão poucos dados também foi um fator considerado. Assim como na questão da conexão adaptador e monitor, o distribuidor pode não estar necessariamente no mesmo nó onde está o provedor de serviços que atua como front-end. Estando o distribuidor/protótipo no mesmo nó, a comunicação pode ser feita pela interface loopback, diminuindo possibilidade de perdas, aumentando o desempenho e não causando tráfego extra nas interfaces de rede que podem ser usadas quase que integralmente para o encaminhamento das requisições aos serviços. A informação trafegada por esse canal de comunicação constitui-se de cadeias de caracteres puras, sem formatação $\boldsymbol{X} \boldsymbol{M L}$ nem outra qualquer. A cadeia de caracteres de entrada é um identificador, no 
caso o próprio nome do recurso que implementa o serviço no provedor, por questões de simplicidade. Essa cadeia é mapeada no arquivo de configuração do distribuidor para que tenha uma política que seja a ela relacionada. Escolheu-se usar o nome do recurso, pois para o filtro é simples obtê-lo através das bibliotecas de processamento HTTP e de servlets existentes na linguagem Java. A possibilidade do uso de outra informação para a ligação serviço/política não necessita modificações diretas no protótipo, apenas na maneira como o filtro obtém essa informação do pacote HTTP. Como retorno da mensagem da decisão é enviada uma cadeia de caracteres contendo o endereço IP e a porta do nó para onde a requisição será enviada. Essa informação também é pequena, causando pouco tráfego e diminuindo a possibilidade de perda de informação. A necessidade de controle de seqüência nessa comunicação não é de vital importância, visto o tamanho das mensagens. O conector pode implementar qualquer tipo de comunicação com o provedor, até mesmo através de memória compartilhada se for necessário. Para isso não é necessária alteração no protótipo e sim no conector e filtro, mostrando mais uma vez flexibilidade.

A comunicação entre o conector e a política é feita apenas com passagem de parâmetros para a função da política. Para a política é passado o serviço ou qualquer outro tipo de informação através de um vetor de bytes alocado pelo conector. A política lê o vetor, toma a decisão e sobrescreve seu valor, retornando o resultado para o conector, que então envia o vetor para o provedor. Esse processo torna a comunicação entre esses dois elementos eficiente e sem maiores preocupações com sincronismo.

Em relação à política, também é necessário o uso de comunicação no processo de obtenção dos dados da monitoração. Para a política esse processo é transparente, necessitando apenas a chamada a uma função do protótipo que retorna o valor da métrica pedida. A função é universal e usada da mesma forma por todas as políticas. A política nem mesmo tem a noção de qual foi o monitor que respondeu aos dados. A comunicação é realizada pela função de obtenção de métricas, dentro do gerenciador de adaptadores. É necessária a comunicação, pois os adaptadores funcionam como uma thread independente. O gerenciador de adaptadores envia mensagens para todos os adaptadores presentes, parando o processo quando o primeiro adaptador responde positivamente à requisição de uma métrica. A comunicação com os adaptadores é feita utilizando memória compartilhada. Para o controle da região de comunicação são implementados semáforos temporizados. Os adaptadores permanecem bloqueados até que o gerenciador de adaptadores realize o up no semáforo do adaptador. Uma vez que o adaptador é desbloqueado, ele busca a informação requisitada e a deposita na região de memória compartilhada. O uso de semáforos temporizados no adaptador se deve à necessidade deste atualizar as métricas periodicamente, tratado na seção 6.2.2. O semáforo e o 
vetor de comunicação são enviados para o adaptador na passagem de parâmetros para a função inicial do mesmo.

A configuração do protótipo também utiliza canais de comunicação. É utilizada comunicação por rede com sockets e $\mathbf{T C P}$ e também memória compartilhada. A parte da comunicação que envolve $\boldsymbol{T C P}$ faz a intermediação entre a interação do usuário com o distribuidor ou então distribuidor com distribuidor. Essa comunicação foi implementada utilizando-se $\boldsymbol{T C P}$ devido ao tráfego de informações em $\boldsymbol{X M L}$, sendo interessante o controle de seqüência e a conexão para o envio de dados providos por ele. Os dados de configuração são passados em $\boldsymbol{X} \boldsymbol{M L}$, aproveitando o processamento de configurações utilizado na leitura do arquivo de configuração. Outro ponto positivo em relação ao uso de $\boldsymbol{X} \boldsymbol{M L}$ é a facilidade do administrador em criar um mecanismo de configuração se necessário. $\boldsymbol{X M L}$ facilita a interoperabilidade e validação dos dados de configuração oferendo assim mais uma vantagem. A mensagem de configuração é recebida pela thread do $G C$, que a processa e decide qual gerenciador notificar. Quando a mensagem refere-se a alguma ação como adição, remoção, ativação ou desativação, quem realiza a tarefa necessária é a própria thread do $\boldsymbol{G C}$, bloqueando as tabelas de configuração. Quando o $G C$ realiza a alteração, é necessário que o administrador a efetue, enviando uma mensagem de atualização. A mensagem de atualização é recebida pelo $\boldsymbol{G C}$ e depois de identificada, uma variável compartilhada é então ajustada para o valor adequado e a comunicação é efetivada através de uma variável de condição, no sentido do $\boldsymbol{G C}$ para o outro gerenciador. A finalização também ocorre de maneira semelhante ao processo da atualização. Para fins de facilidade no envio de mensagens de configuração, foi criado juntamente com o protótipo um front-end de configuração, que apresenta as características básicas necessárias para configurar maior parte dos componentes.

\subsection{Considerações Finais}

Foi apresentada neste capítulo a nova arquitetura proposta, inicialmente posicionando os seus componentes em um cluster, com o intuito de mostrar a função de cada componente e a conectividade entre eles. Os elementos apresentado foram: o front-end, usado para receber a requisição, redirecioná-la para o cluster e retornar a resposta ao cliente; o distribuidor, responsável por consultar políticas de distribuição estabelecidas pelo administrador para o redirecionamento interno; os provedores de serviço que processam as requisições e encaminham a resposta ao front-end; e o monitor, usado para obter informação dos nós do cluster. O elemento distribuidor foi apresentado, juntamente com o detalhamento de seus componentes internos. São eles: Núcleo, Gerenciador de Configuração $(\boldsymbol{G C})$, Gerenciador de 
Conectores (GCn), Gerenciador de Adaptadores (GA), Gerenciador de Web Services (GW), Gerenciador de Políticas (GP). As tecnologias utilizadas para a implementação do protótipo da arquitetura foram: a linguagem $\boldsymbol{X} \boldsymbol{M L}$, bibliotecas dinâmicas, threads, a ferramenta Ganglia, e tabelas hash. As Redes de Petri apresentadas neste capítulo tiveram o intuito de mostrar o processo de inicialização do distribuidor e as interações entre componentes. As estruturas de dados utilizadas no protótipo também foram apresentadas para auxiliar na compreensão do mesmo. 



\section{Políticas, conectores e adaptadores}

\subsection{Considerações Iniciais}

Neste capítulo, é abordada a criação dos elementos modulares da arquitetura. Inicialmente são apresentadas as formas como são passados e retornados os dados entre o núcleo do distribuidor e as políticas. É apresentada também a forma de interação das políticas com a monitoração. Em seguida, são apresentados os cuidados em relação à implementação dos adaptadores, também abordando os métodos de comunicação núcleo-adaptador. Os conectores são os próximos elementos descritos, juntamente com os métodos de comunicação que devem ser utilizados.

\subsection{Desenvolvimento de políticas, monitores e conectores}

A criação de elementos de interação para a arquitetura proposta é o ponto chave para possibilitar a flexibilidade. Para o protótipo, foram implementados alguns elementos, são eles: adaptador, conector e políticas. O adaptador criado tem a função de coletar os dados do monitor Ganglia e disponibilizá-los para o distribuidor. O conector tem a função de ligar o provedor de web services Tomcat/Axis2 ao protótipo. As políticas implementadas tomam decisões baseadas em round-robin, round-robin ponderada e menor uso de recurso. A implementação de qualquer um dos elementos deve se encaixar em algumas regras para que o distribuidor possa carregá-los corretamente. Há também alguns recursos disponíveis para o implementador dos elementos, principalmente em relação as políticas.

\subsubsection{Políticas}

Para a implementação de políticas, o administrador dispõe do recurso da monitoração 
de maneira facilitada e universal. A monitoração diz ao implementador inicialmente quais os nós disponíveis para a distribuição. Essa informação é baseada em quais nós notificaram mais recentemente sua atividade para o monitor, o período em que uma máquina é considerada inativa é codificado dentro do adaptador e nos testes realizados, o tempo considerado foi de 3 segundos. Para que o administrador receba essa informação, a única medida é chamar a função ObterMetricas(char[]), passando como único parâmetro uma cadeia de caracteres vazia, ou seja, com um “ $\backslash 0$ ” na primeira posição. Consultados os adaptadores, essa função retornará uma lista de endereços IP dos nós ativos separados por “;”. A cadeia de caracteres retornada pelo adaptador é alocada por ele, e deve ser desalocada pela política depois do seu uso. Subseqüentemente à consulta por nós ativos, a função ObterMetricas (char[]) pode ser consultada usando-se como parâmetro o endereço de algum dos nós ativos. Quando executada dessa forma, o retorno contém uma lista das métricas disponíveis naquele nó separadas por “;”. A maneira como métricas e endereços são retornados facilita a sua interpretação através de rotinas como strtok ( ) . Da mesma maneira que com os nós, a informação com a lista de métricas também deve ser desalocada pela política. A decisão pela implementação dessa forma tem como exemplo a própria libxml2 que retorna as informações de processamento do $\boldsymbol{X} \boldsymbol{M L}$ em cadeias de caracteres que deve ser desalocados manualmente. Isso proporciona ao administrador alterar as cadeias de retorno sem precisar duplicá-las para evitar alteração no seu conteúdo. De posse do endereço do nó requerido e da métrica que se deseja obter, pode ser realizada uma nova requisição usando ObterMetricas (char[]) com essas informações separadas por “:” e o resultado será finalmente o valor da métrica desejada. Não é necessário que se executem todos esses passos para a obtenção dos valores, apenas o último passo pode ser feito caso o desenvolvedor da política saiba que o nó e a métrica requisitados existem. No caso de não ser encontrada a métrica ou nó, o valor nulo é retornado à política, ficando fácil para ela saber que houve erro e tomar as medidas necessárias. A Fig. 6.1 traz exemplos de chamadas à função ObterMetricas, com o seu retorno.

Pode ser notado que a monitoração é fornecida de maneira simplificada para as políticas, não necessitando de recursos avançados para realizar as consultas. Além disso, existe transparência na busca pelas informações da monitoração, não necessitando o desenvolvedor saber qual adaptador respondeu a qual dado monitorado. Isso torna o desenvolvimento de políticas independente do monitor de certa forma. Para um desenvolvimento mais funcional e efetivo, é aconselhável que o desenvolvedor saiba quais métricas estão disponíveis para poder realizar distribuições mais conscientes. 
Considerando:

char *retorno, chamada[256];

\begin{tabular}{|c|c|}
\hline Chamadas: & Conteúdo apontado por retorno: \\
\hline $\begin{array}{l}\text { chamada }[0]=' \backslash 0 ' \text {; } \\
\text { retorno = ObterMetricas (chamada); }\end{array}$ & $\begin{array}{l}192.168 .2 .100 ; 192.168 .2 .101 ; \\
192.168 .2 .102\end{array}$ \\
\hline $\begin{array}{l}\text { strcpy (chamada,"192.168.2.101"); } \\
\text { retorno = obterMetricas (chamada); }\end{array}$ & $\begin{array}{l}\text { cpu_user; cpu_system; load_one; } \\
\text { bytes_in; bytes_out }\end{array}$ \\
\hline $\begin{array}{l}\text { strcpy (chamada,"192.168.2.101:cpu_user") ; } \\
\text { retorno = ObterMetricas (chamada); }\end{array}$ & 72 \\
\hline $\begin{array}{l}\text { strcpy (chamada,"192.168.2.105"); } \\
\text { retorno = ObterMetricas (chamada); }\end{array}$ & nulo \\
\hline $\begin{array}{l}\text { strcpy (chamada,"192.168.2.105:metrica"); } \\
\text { retorno = obterMetricas (chamada); }\end{array}$ & nulo \\
\hline
\end{tabular}

Fig. 6.1: Exemplos de uso da função obterMetricas ()

Para trazer mais recursos e auxiliar no desenvolvimento de políticas, foram desenvolvidos alguns exemplos de políticas e algumas políticas com relativa flexibilidade. Estas últimas utilizam recursos da biblioteca glib para manipulação de estruturas de dados para facilitar ao usuário fazer buscas sobre os valores retornados pelas chamadas as funções ObterMetricas(). Essas políticas podem funcionar como "estrutura básica inicial” (ou “esqueletos”) para o desenvolvimento de outras políticas, apenas com a necessidade de alteração de alguns parâmetros. A idéia desse “esqueleto” é colocar os nós e as métricas dentro de vetores de tamanho variável com funções genéricas. Assim, apenas executando uma dessas funções é possível encapsular nas chamadas a função ObterMetricas e o processamento do seu retorno, buscando diretamente apenas o nó que tem o menor valor de uma determinada métrica. O objetivo de não colocar essas funções disponíveis para todas as políticas diretamente é possibilitar ao desenvolvedor flexibilidade para implementar suas funções de acordo com as suas necessidades e o desempenho desejado.

A assinatura da função inicial da política deve seguir o padrão estabelecido para que ela seja carregada. Esta função deve possuir o nome Decidir, não retornar valores (void) e receber como argumento de entrada um ponteiro para o tipo de dado composto Parametro. Este tipo de dado é universal para todas as funções iniciais dos elementos implementados. Devido a isso, em alguns casos ele contém alguns campos que permanecem vazios durante a operação do elemento.

\begin{tabular}{|l|l|l|l|}
\hline id & void (*funcao) () & void *dados & char *caracteres \\
\hline
\end{tabular}

Fig. 6.2: Estrutura de passagem de parâmetros

A estrutura Parametro pode ser vista na Fig. 6.2. Ela possui 4 campos: id, funcao, dados e caracteres. O campo id é usado apenas para enviar ao elemento sua 
identificação dentro do funcionamento do protótipo caso esta seja necessária dentro de alguma função do elemento. O campo funcao é um ponteiro para uma função qualquer sem valores de retorno, podendo ser passado para ela um argumento qualquer. No caso das políticas, esse valor pode ser ignorado, porém considerando algumas diretivas de compilação, pode ser necessário enviar para a política a função de obtenção de métricas. Isso se deve pelo fato da política ser uma biblioteca externa ao distribuidor, onde está localizada a função mencionada. Se a ligação do código não for realizada de maneira dinâmica, a política não encontrará uma função com a assinatura de obterMetricas(). O campo dados, como pode-se notar pelo seu tipo de dado, é um ponteiro genérico. Ele é utilizado para garantir persistência das informações dos elementos. Se uma região de memória for alocada em alguma das chamadas de uma política, como o ponteiro pertence ao distribuidor, o ponteiro não é perdido nem a região reservada. Assim a cada chamada é possível recuperar-se o estado anterior da política. Essa característica torna-se útil quando, por exemplo, deseja-se implementar uma política round-robin. Nesse campo, qualquer tipo de dado pode ser armazenado através de alocação de memória e atribuição do endereço alocado ao ponteiro. No momento em que for necessário o uso do valor é necessário apenas um cast. O campo caracteres, no caso da política, é utilizado para enviar qual o serviço está sendo acessado e também para retornar a decisão tomada pela política (endereço e porta).

No Anexo II é possível encontrar um exemplo de política implementada para escolher o nó com menor uso de $\boldsymbol{C P U}$ pela métrica cpu_user. A métrica é coletada pelo monitor Ganglia e obtida através da função obterMetricas. A política apresentada é simples e tem o intuito de demonstrar principalmente o recurso de monitoração.

\subsubsection{Adaptadores}

Os adaptadores demandam, assim como as políticas, certos padrões em sua implementação. A função buscada pelo $\boldsymbol{G A}$ é a IniciarMonitor, com retorno nulo e parâmetro do tipo Parametro. Os adaptadores devem ser implementados para atuar como uma thread que coleta as informações do monitor desejado. A própria função do monitor pode coletar informações dos nós, caso seja de interesse do desenvolvedor. Quando a função do adaptador é executada, ele deve realizar suas atividades para auto-configuração ou outras atividades necessárias (intrínsecas a cada adaptador) e então entrar em um loop para responder as requisições por métricas. Internamente a esse loop deve ser implementado um semáforo que espera a sinalização da função obterMetricas do distribuidor para 
desbloquear e preencher a área de memória compartilhada com os dados requisitados. O bloqueio para esperar a entrada de dados para que ele saiba quando fornecer o dado é implementado com um down sobre o semáforo que representa a entrada. A maneira como ele preenche essa área depende de cada implementação, mas depois de preenchida, ele deve realizar um up sobre o semáforo de saída, desbloqueando a função ObterMetricas e conseqüentemente a política. O desempenho do adaptador é um fator determinante para o desempenho da política e também da arquitetura como um todo. Na Fig. 6.3 são apresentadas as estruturas utilizadas pelo adaptador, passadas como parâmetro para a função IniciarMonitor.

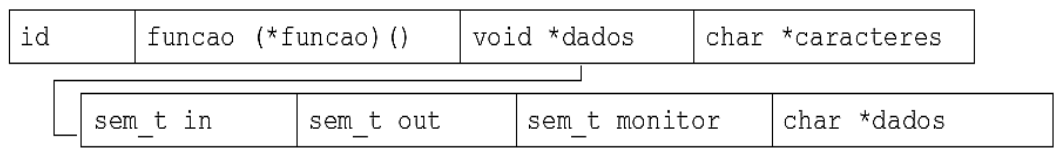

Fig. 6.3: Estrutura de dados usada pelos adaptadores

Como mencionado, o parâmetro passado é do tipo Parametro, com o formato id, funcao, dados e caracteres. O campo funcao permanece vazio, o campo dados aponta para a estrutura de comunicação entre a política e a thread do adaptador. O campo caracteres é carregado com o caminho para o arquivo que possui as suas configurações. A estrutura de comunicação possui quatro campos: in, out, monitor e dados. Os dois primeiros são responsáveis pelo controle da comunicação entre as threads. O campo monitor garante exclusão mútua, para que essa região de memória não seja sobrescrita quando diferentes política estiverem obtendo dados do adaptador. O campo dados é a região usada para comunicação.

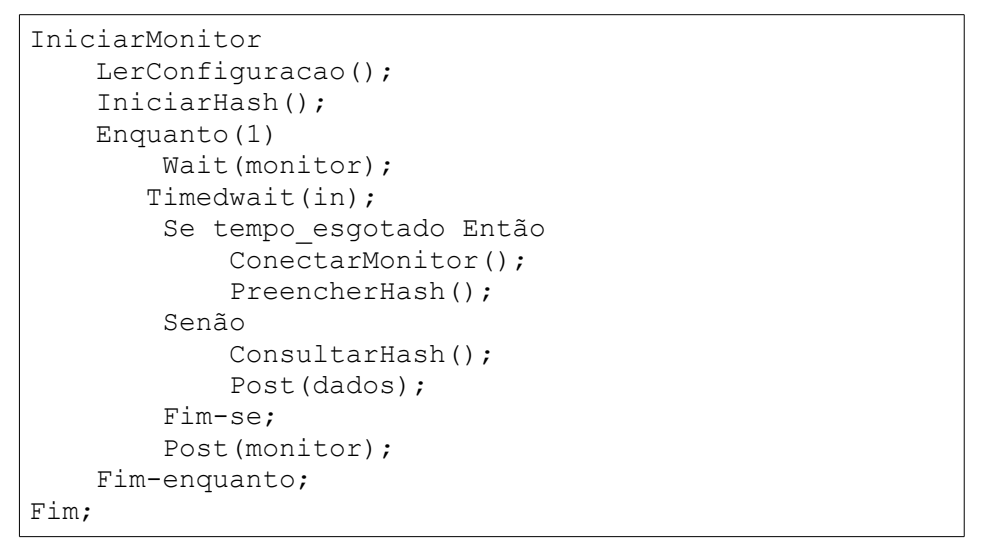

Fig. 6.4: Pseudo código do adaptador implementado

O adaptador implementado foi utilizado para comunicar-se com o Ganglia. Seu pseudo código é apresentado na Fig. 6.4. Ele utilizou o conceito de tabelas hash para armazenar as métricas com o objetivo de aumentar o desempenho das consultas aos dados da 
monitoração. Periodicamente a thread desse adaptador conecta-se ao Ganglia e processa o $\boldsymbol{X M L}$ de resposta, armazenando as informações nele contidas em uma tabela hash de dois níveis. No primeiro nível, a tabela contém chaves relacionadas ao endereço do nó monitorado e como valor um ponteiro para outra hash que contém as métricas. Cada par do segundo nível, contém como chave o nome da métrica que relaciona-se com o valor da mesma. Com isso a consulta aos dados de monitoração é realizado em $\mathrm{O}(1)$. O custo de memória pode-se tornar inviável em situações onde haja muitos nós a se monitorar. Porém nos testes realizados não houve este problema. Quando essa questão for importante, também será prudente configurar o monitor para obter um menor número de métricas para não sobrecarregar a rede. Com um menor número de métricas torna-se interessante trocar o segundo nível da hash por listas ligadas ou, em casos mais controlados, usar um vetor para acesso $\mathrm{O}(1)$. A intenção com o uso de estruturas como essas é fazer com que as políticas não permaneçam um tempo comprometedor para o desempenho bloqueadas esperando a conexão com o monitor e o processamento da mensagem. A periodicidade da atualização das métricas pode ser alterada no arquivo de configuração do adaptador. Outros valores configuráveis são o endereço e porta nos quais é possível realizar uma conexão com o Ganglia. O semáforo utilizado para esperar a entrada foi do tipo temporizado, possibilitando que dentro de um certo intervalo de tempo, caso não haja um pedido por obtenção de métricas, a thread desbloqueie independentemente para atualizar as suas tabelas.

\subsubsection{Conectores}

Os conectores são os elementos que tornam o distribuidor "útil”, pois eles recebem as requisições por decisão, que é o objetivo para o qual ele foi projetado. Os conectores, que executam em forma de threads, permanecem esperando por conexões de provedores de web services. A exigência para a construção de conectores é que eles implementem uma função chamada IniciarConector, possuindo como parâmetro o tipo de dado Parametro e retorno nulo. O conector é iniciado com a estrutura Parametro (Fig. 6.2) passada para ele. O principal campo desta estrutura é o campo funcao, que é um ponteiro para a função AssociarPolitica. Tal ponteiro realiza a associação do serviço com a política, esta necessária em caso de compilação sem a diretiva para uso de funções externas. O campo dado pode ser usado para persistência de informações e o campo caracteres contém o caminho para o seu arquivo de configuração. A função de associação tem a assinatura AssociarPolitica (Parametro *). É necessário que se passe para ela apenas a cadeia de caracteres que representa o serviço sobre o qual é necessária decisão. A cadeia deve ser 
enviada pelo campo caracteres do tipo Parametro. É importante notar que o tipo Parametro é usado duas vezes dentro do conector, para a sua inicialização (função de entrada) e para a chamada da função AssociarPolitica. O tipo parâmetro usado na função associar política possui campos subutilizados.

O conector criado para testar a arquitetura recebe conexões do provedor de serviços Tomcat. Para a sua implementação foram necessários dois tipos de código. Um para implementar o conector em si e outro para realizar a interceptação dentro do Tomcat. O conector, obviamente implementado em $\mathbf{C}$, permanece em sua thread esperando por datagramas (uso do protocolo UDP, como explicado na seção 5.6 sobre troca de mensagens) enviados pelo Tomcat contendo o identificador do web service. Dentro do conector não houve a necessidade de uso de recursos mais avançados no atendimento de conexões externas (pool de threads, por exemplo). Recebida a mensagem, é ativada a função de associação que desencadeia todo o processo de decisão dentro do distribuidor.

Dentro do Tomcat, não houve a necessidade de alteração de código para a interceptação da requisição pelo serviço para a decisão. A especificação de servlets prevê a existência de filtros (citado na seção 3.2.1), que são implementações do padrão de projeto filtro de interceptação. Como o Tomcat é uma implementação de referência de servlets (seção 3.2.1) ele dá suporte aos filtros. Os filtros são classes que são colocadas entre o provedor de serviços e o servlet. Essas classes podem ser adicionadas e retiradas do provedor de serviços apenas com a edição de um arquivo de configuração padrão da especificação. Quando uma requisição para um servlet chega ao provedor, ela passa primeiro pelos filtros, que são dispostos como uma cadeia. Quando um filtro é executado, ele deve chamar recursivamente o próximo filtro . Ao término de todos os filtros chamados, finalmente a aplicação é executada. O retorno dos filtros também é realizado de maneira encadeada de maneira inversa a como foi feita a entrada.

A requisição por uma decisão é realizada por um filtro dentro do Tomcat, sendo ele o primeiro dos filtros a ser executado. Três vantagens podem ser claramente vistas no uso do filtro. Primeiramente, não há a necessidade de alterações no código. Segundo, o filtro pode ser instalado em apenas um servlet, que no caso de web services é o Axis2. A terceira vantagem é que o filtro já obtém a requisição processada, não havendo a necessidade de se preocupar como o servidor web presente no provedor fez o atendimento. Isso torna possível o atendimento às requisições $\boldsymbol{H T T P}$ usando $\boldsymbol{S S L}$ e tira da implementação realizada a preocupação de implementar um servidor web para o front-end de maneira eficiente, ficando isso a cargo do próprio provedor de serviços. Na seção 7.5, serão apresentados testes da arquitetura. Neles foi utilizado o Tomcat embarcado no JBoss. Isso só foi possível graças à 
versatilidade do Tomcat, podendo ser integrado a esse servidor de aplicação. O uso do filtro nessa situação foi realizada da mesma forma que no Tomcat nativo.

O funcionamento do conjunto filtro e distribuidor pode ser observado na Fig. 6.5. Internamente no filtro, quando ele recebe a requisição para o serviço, ele faz a consulta ao distribuidor usando $\boldsymbol{U D P}$ e fazendo verificações de segurança em relação ao recebimento de resposta e à atividade do nó indicado. Se houver alguma falha nesse processo, a requisição é atendida localmente pelo Tomcat, ou seja, pelo próprio front-end fornecendo um subsídio de tolerância a falhas.

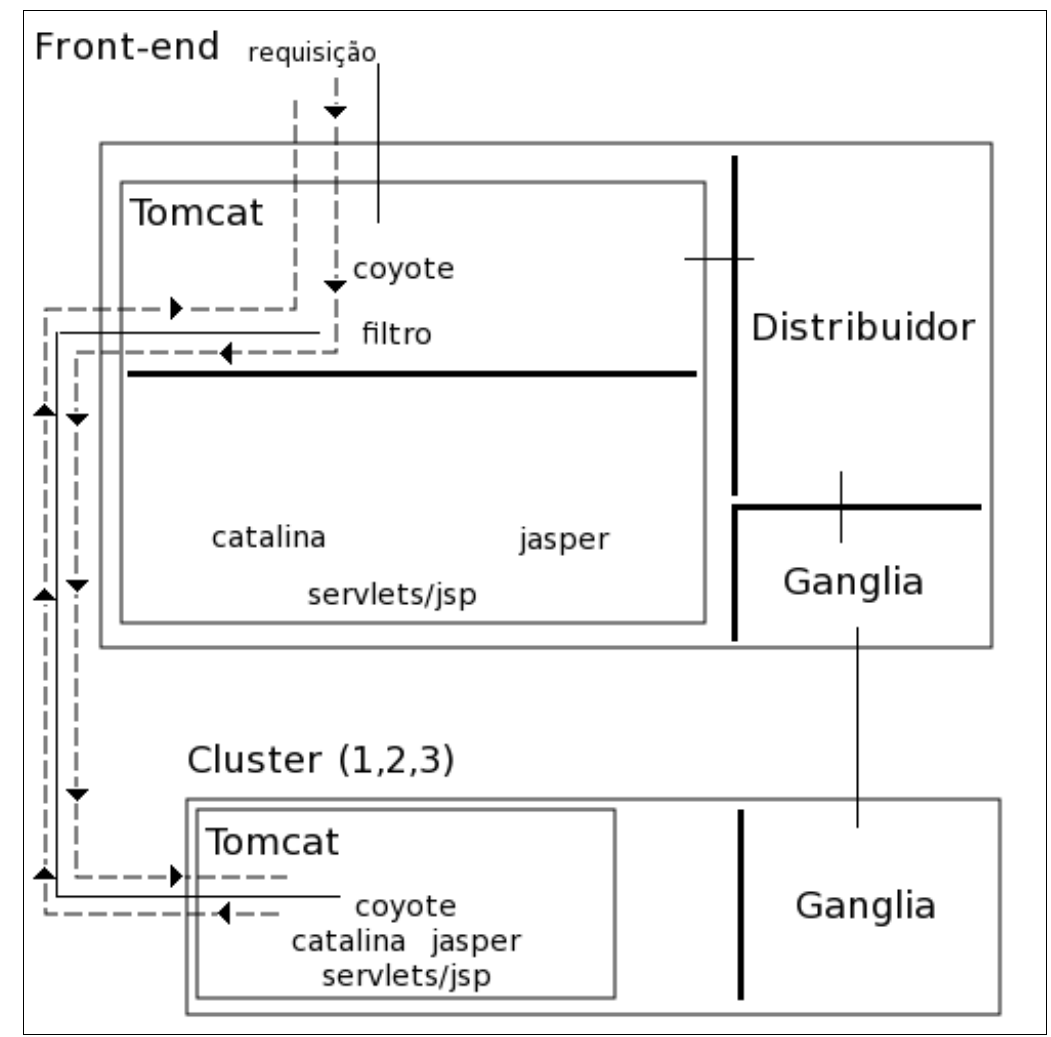

Fig. 6.5: Funcionamento do filtro

Na Fig. 6.5, Coyote é o servidor HTTP interno do Tomcat, Catalina é o container de servlets e $\boldsymbol{J S P}$, e Jasper o módulo responsável por executar o servlets e $\boldsymbol{J S P}$. Esses são apenas detalhes dos módulos do Tomcat que não sofreram modificações e têm como objetivo apenas localizar a posição dos filtros. É possível notar que depois que a requisição é interceptada pelo filtro, ela entra no coyote de outro Tomcat, pois como foi apresentado na seção 5.6, a requisição é reconstruída usando-se também HTTP. Nada impediria da requisição utilizar o protocolo AJP 1.3 do Tomcat, porém essa foi uma decisão de projeto, tentando facilitar ao máximo a portabilidade e flexibilidade do filtro e distribuidor. Esse fator, mais uma vez, mostra a flexibilidade da arquitetura. 


\subsection{Considerações Finais}

Foram abordados neste capítulo os métodos de construção dos componentes flexíveis do distribuidor. O intuito foi mostrar quais as preocupações necessárias na implementação desses elementos e as facilidades fornecidas para os desenvolvedores. As políticas foram os primeiros elementos descritos. Além das formas de implementação desse tipo de componente, foi mostrado um exemplo de implementação e as possibilidades de uso. Os adaptadores também foram abordados, apresentando a implementação que realiza a ponte entre o distribuidor e o monitor Ganglia. Foram mostradas as preocupações necessárias em relação ao desempenho e o seu impacto nas decisões das políticas. Os conectores, componentes de ligação entre o distribuidor e os provedores de web services, foram tratados em seguida. $\mathrm{O}$ exemplo apresentado foi o do conector utilizado para a interação entre o Apache Tomcat e o distribuidor, mostrando ambos os lados da interação, o conector ligado ao distribuidor e o filtro ligado ao Apache Tomcat. 



\section{Teste da arquitetura}

\subsection{Considerações Iniciais}

O intuito deste capítulo é apresentar os métodos e materiais utilizados para a realização dos testes da arquitetura. São apresentados inicialmente os objetivos dos testes e os softwares utilizados, abordando a função de cada um, seu papel nos testes e as interações realizadas. Também importantes, e abordadas neste capítulo, são as aplicações utilizadas como cenário de teste. A estrutura utilizada é brevemente descrita com o intuito de posicionar o desempenho obtido com em relação ao hardware disponível nos testes. Os resultados são apresentados e descritos. Eles são divididos em três cenários.

\subsection{Teste da arquitetura}

A arquitetura proposta foi testada através da implementação de um protótipo descrito na seção 5.5 e 5.6. O protótipo seguiu as idéias da arquitetura, tentando ao máximo garantir flexibilidade e dinamicidade sem afetar o desempenho. Duas etapas de teste foram realizadas: funcionalidade e desempenho. A primeira, essencial para mostrar que o quesito de flexibilidade funciona. A funcionalidade também é importante para verificar a existência de falhas na ferramenta desenvolvida, antes das execuções voltadas aos testes de desempenho.

O desempenho da arquitetura proposta e da ferramenta desenvolvida foi comparado com uma implementação que permite a execução de web services em cluster. Esta implementação é baseada no mod_jk descrito na seção 3.2.1, usando o Tomcat juntamente com o Apache HTTP Server (Apache). Como mencionado, ela não é uma solução específica para web services, e sim para conexões $\mathbf{H T T P}$ para aplicações $\boldsymbol{J S P}$ e servlets. De acordo com o mapeamento aplicado no Apache, os acessos são redirecionados para um provedor em outro nó. O mod_jk utiliza o protocolo AJP 1.3, que é um protocolo binário específico para comunicação entre essas aplicações. Além do mod_jk existe o mod_proxy que faz o Apache 
se comportar como um proxy, redirecionando as requisições contidas em um determinado mapeamento para nós de destino. O mod_proxy usa protocolo HTTP assim como o filtro implementado. O mod_jk possui várias configurações e um gerenciador simplificado que pode ser acessado por um browser. O mod_proxy tem menos tempo de desenvolvimento e não possui todas as características de configuração que o mod_jk. O mod_proxy possui políticas básicas de balanceamento quando aplicado juntamente com o mod_proxy_balancer. As políticas do mod_proxy e do mod_jk são semelhantes, sendo elas: por quantidade de requisições, por requisições ativas, por tráfego entre Apache e Tomcat e por sessões. O balanceamento baseado em sessões não é aplicável a web services, pois eles são stateless ${ }^{7}$. Os outros tipos de balanceamentos não possuem retorno da situação dos nós para os quais as requisições foram enviadas. Por exemplo, o balanceamento realizado baseado em tráfego, não considera o tráfego de rede total do nó, apenas a interação Apache e Tomcat. Em casos de concorrência com outras aplicações, seja por recursos de rede, disco ou processador, não há monitoração direta.

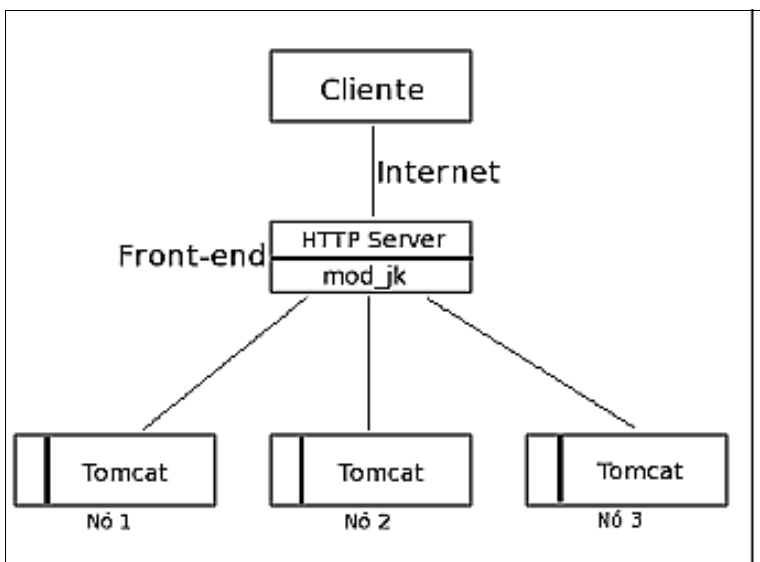

(a)

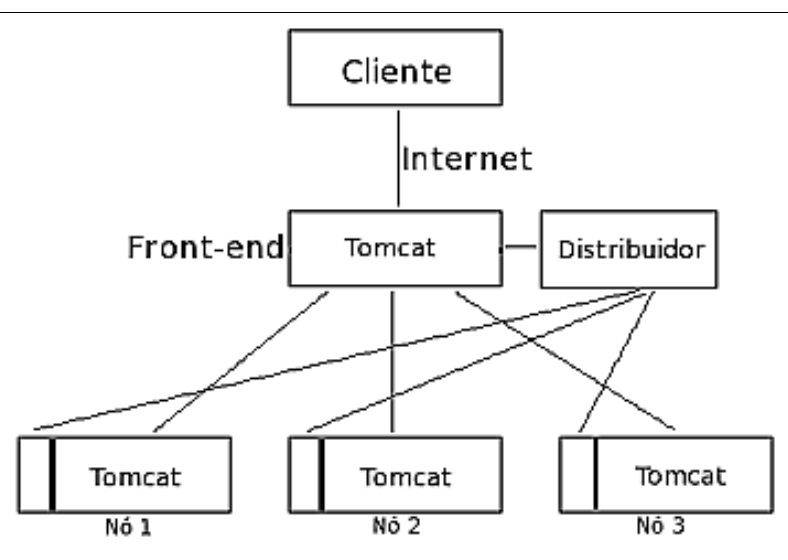

(b)

Fig. 7.1: Estrutura usando mod_jk(a) e a arquitetura proposta(b)

A Fig. 7.1 mostra a semelhança entre a abordagem e usando o mod_jk (a) e usando o filtro (b), esta última proposta neste trabalho. A estrutura da abordagem desenvolvida, usando mod_proxy, é praticamente igual à original usando mod_jk, mudando apenas as configurações e módulos utilizados. Observando-se a estrutura, as diferenças nos testes concentram-se no front-end, mais especificamente em software e protocolo. Clientes e nós do cluster permanecem iguais a cada experimento, mudando apenas de Apache para Tomcat no front-end. A mudança entre esses softwares no front-end implica em uma configuração

7 Não mantém informações (nem controle) em relação às interações entre cliente e servidor. Não são armazenadas variáveis de sessão, por exemplo, que identifiquem um cliente no servidor. 
diferente de servidor $\boldsymbol{H T T P}$ na entrada e um procolo diferente entre o front-end e o nó do cluster. As configurações de servidor HTTP, apesar do Apache ser implementado em C e o Tomcat em Java, tentaram ser mantidas as mais semelhantes possíveis. A quantidade de parâmetros de configuração do Apache é consideravelmente maior que a do Tomcat, tornando essa tarefa mais complexa.

O mod_proxy foi utilizado com o intuito de isolar problemas de configuração no Apache e mod_jk.

Foram utilizados nos experimentos o Tomcat (para a aplicação sintética, seção 7.3) e o Tomcat otimizado embarcado no JBoss (para a aplicação relacionada a mercado financeiro, seção 7.3). Em relação Tomcat embarcado no JBoss seus proponentes afirmam que esse software está em nível de competição com outros servidores web de alto desempenho existentes como IIS e Apache HTTP Server (Red Hat, 2009). O principal apelo para o uso de um servidor como o Apache ou IIS em relação ao Tomcat/JBoss é quanto à eficiência de recuperação de conteúdo estático. O conteúdo dinâmico criado utilizando Java no Apache deve, impreterivelmente, ser atendido por um software como o Tomcat através de redirecionamento e o mod_jk. O Apache não pode atender esse tipo de requisições de forma nativa. Considerando um cenário de serviços onde todas as requisições são para servlets (dinâmicas), pois o Axis2 é um servlet, o Apache nesse caso já não é a solução mais interessante.

Considerando os pontos abordados, a solução usando Apache para um cenário de web services torna-se menos indicada que o uso do Tomcat. Assim, a maneira como foram feitas as execuções é realista e fundamentada para o cenário proposto.

Os testes foram executados basicamente em duas plataformas (ou ambientes), uma homogênea e outro heterogênea. A plataforma homogênea teve o objetivo maior de mostrar o impacto da solução proposta pela arquitetura. As plataformas homogêneas são “apropriadas” a uma distribuição mais “simples”, sem a diferença de hardware, software ou carga extra. Em situações como esta, uma distribuição round-robin pode tornar-se eficiente, pois os nós recebem sempre a mesma quantidade de carga, tornando-se balanceados. Usando uma política round-robin para comparar a arquitetura proposta e o mod_jk, é possível observar o real impacto no conjunto de soluções, considerando os protocolos utilizados no redirecionamento e na monitoração. Além disso, em uma plataforma homogênea é possível inserir cargas externas vindas de outros softwares e medir a resposta da arquitetura a essa "heterogeneidade" vinda da concorrência externa à aplicação.

A plataforma heterogênea foi utilizada para mostrar que a arquitetura pode ser configurada para atender cenários onde haja diferenças entre os nós sem causar grande 
impacto. Além disso foi utilizado um método de realimentação baseado em métricas coletadas pelo monitor ligado à arquitetura para mostrar a resposta dinâmica da mesma em relação à heterogeneidade. Plataformas mais heterogêneas e específicas podem ser encontradas dentro de empresas, onde pode ser interessante a partição de clusters em "sub-clusters" com finalidades mais específicas, como o tratamento de requisições que demandem recursos diferentes (banco de dados, recursos de memória, processamento, disco, rede, etc). Exemplos disso podem ser particionamentos de clusters em nós com e sem discos rígidos, aplicações que utilizam bancos de dados que permanecem ativos em memória $\boldsymbol{R} \boldsymbol{A M}$ para otimização de consultas, etc.

\subsection{Descrição das aplicações utilizadas}

Os testes realizados para observar o desempenho da arquitetura utilizaram basicamente duas aplicações. A primeira delas envolve uma aplicação usada comercialmente no mercado de operações financeiras envolvendo transações de compras usando cartões de crédito. Esse tipo de aplicação possui uma base que se assemelha a diversas aplicações comerciais para fins variados. Ela funciona com base em um servidor de aplicações, usando $\boldsymbol{E} \boldsymbol{J B}$. O ponto de entrada da aplicação se dá por web services. Outras tecnologias envolvidas nessa aplicação e largamente utilizadas no mercado são dispositivos de persistência de dados. A persistência de dados evoluiu nos últimos tempos com o intuito de fornecer produtividade e otimizar a manipulação de dados na camada de aplicação. Um framework conhecido para este fim é o Hibernate (Red Hat Middleware, 2008). O servidor de aplicação no qual a aplicação é hospedada é o JBoss. Este possui suporte nativo para o framework em questão. A idéia por trás do framework de persistência é que o desenvolvedor da aplicação manipule somente objetos e o framework se encarregue de mapear os objetos ativos para um banco de dados relacional, cuidando de sua gravação, recuperação e atualização no banco. Ele também é responsável por garantir a consistência dos dados que estão sendo operados na memória. Existem duas demandas envolvidas com a persistência: o acesso ao banco de dados relacional e a manipulação dos objetos na memória. Além do framework de persistência, exitem conceitos de separação de funcionalidade da aplicação, como o modelo MVC (Model-ViewController)(Marrs e Davis, 2005). As validações dos atributos tratados na aplicação são realizadas por uma camada, enquanto que a lógica da aplicação é desenvolvida em outra. Não existem nessa aplicação os $\boldsymbol{E} \boldsymbol{J B}$ usados para mensagem (Message Driven EJB), mas os outros dois estão presentes (sessão e entidade). Esse conjunto de tecnologias faz com que a aplicação utilizada possua um denominador em comum com aplicações usadas no mercado. 
Considerando a representatividade dessa aplicação, ela foi extensivamente utilizada nos testes para analisar qual o comportamento da arquitetura sobre o tipo de demanda gerada por ela.

A segunda aplicação utilizada nos testes é uma aplicação sintética com o objetivo de gerar alta demanda por processamento. Esta aplicação tem o objetivo de receber uma imagem de um documento e realizar o processamento devido sobre a mesma para converter seu conteúdo em texto. A sua base é um OCR (Optical Character Recognition) e um processador de qualidade de imagem. Para realizar o OCR de maneira efetiva, é necessário que a imagem possua algumas características como alto contraste e "aspereza”, facilitando o reconhecimento de letras. Ambos os procedimentos realizados sobre a imagem geram demanda por processamento. O objetivo no uso dessa aplicação foi a criação de um ambiente com concorrência entre as aplicações que são executadas, usando-se web services e aplicações locais, por exemplo em batch. Apesar de sintética, a aplicação utilizada tem uma função real. Ela pode ser aplicada em ambientes onde servidores podem ser usados para realizar o processamento de imagens sem sobrecarregar clientes e ainda para evitar que clientes possuam o aparato de software necessário para realizar o $\boldsymbol{O C R}$.

\subsection{Estrutura utilizada}

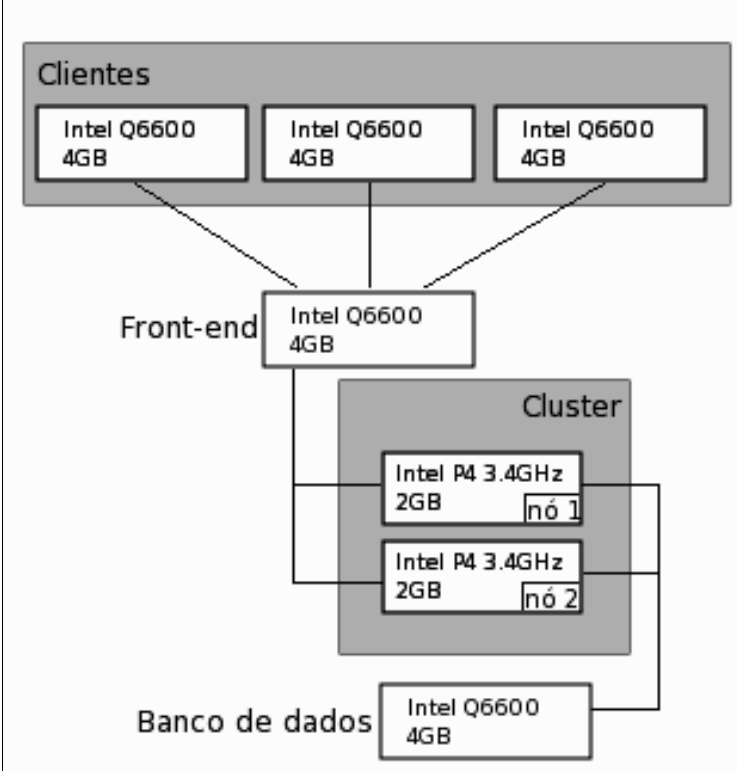

(a)
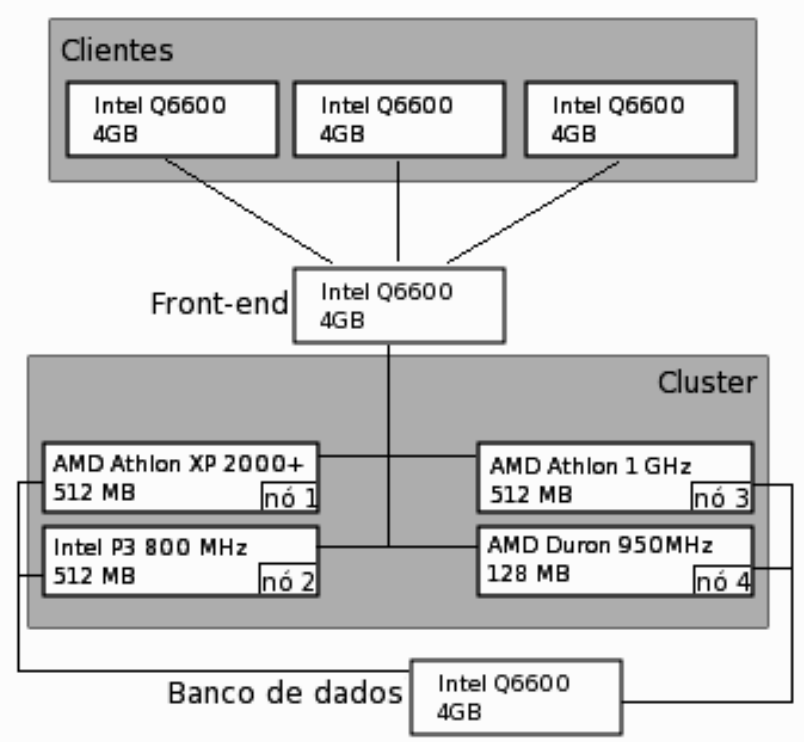

(b)

Fig. 7.2: Configuração homogênea (a) e heterogênea (b)

As duas plataformas utilizadas nos testes (a homogênea e a heterogênea) estão apresentadas na Fig. 7.2. 
A plataforma heterogênea utilizada envolveu nós de configurações diferenciadas, baixo custo e relativamente antigos. As conexões representadas pelas linhas nas Figs. 25 são conexões lógicas, ou seja, não representam o elemento de ligação entre os nós. A ligação entre nós do cluster, banco de dados, front-end e clientes se deu por meio de um switch TP-LINK TL-SL3428 usando uma rede de 100 Mbits.

\subsection{Resultados}

\subsubsection{Teste utilizando serviço baseado em operação financeira}

Para o uso da aplicação em questão foi necessária a instalação do servidor de aplicação JBoss nos nós do cluster e no front-end. Os clientes foram desenvolvidos usando o Apache Axis2. Outro software necessário à aplicação foi o Apache HTTP Server juntamente com o módulo mod_jk no front-end. Os clientes não necessitaram de nenhuma configuração extra. Para seu funcionamento é apenas necessário indicar o endereço e a porta nos quais o front-end está ouvindo. No caso do Apache, na porta 80 e no caso do JBoss na porta 8100. O Apache permanece ouvindo conexões HTTP na porta padrão desse tipo de provedor. Quando uma nova conexão é recebida, o mapeamento presente nos seus arquivos de configuração fornecem a informação necessária para que ele a redirecione para o destino adequado, no caso o mod_jk. São necessários 2 arquivos de configuração para que essa estrutura funcione. O primeiro deles é o do próprio Apache contendo o mapeamento. O segundo arquivo informa ao mod_jk das configurações referentes à conexão com os destinos que processarão os serviços. A configuração básica é relativamente simples e requer que o administrador informe endereço e portas dos nós e os agrupe em um nó virtual que representa o balanceador. A configuração do balanceador permite que seja informada a política a ser adotada. Para que o mod_jk, Apache e Tomcat/JBoss trabalhem de maneira adequada para atender serviços de alta demanda, a configuração básica não é suficiente. O já citado uso do procolo AJP 1.3 trás uma complicação em relação à forma como as conexões de redirecionamento são realizadas. O protocolo de comunicação mantém conexões permanentes entre o Tomcat e o Apache. À medida que novas requisições chegam, elas são enfileiradas para serem transmitidas por essas conexões. A configuração para atendimento de alta demanda requer um ajuste fino entre os parâmetros do Tomcat e do mod_jk. Em caso de falha de alguma das conexões ou excesso de tempo no atendimento de uma requisição, são usados tempos limites para que as conexões sejam fechadas. Estes limites devem ser previamente definidos. Em um cenário de alta demanda, foi observado empiricamente que o número de conexões falhas é grande. Isso faz 
com que sejam mantidos vários sockets abertos no sistema operacional em estado de fin_wait ${ }^{8}$. Esse sockets permanecem ocupando recursos da aplicação, fazendo com que em situação de alto tráfego seja excedido a quantidade limite de conexões permitidas. Além das conexões com fin_wait, existem, devido ao mesmo problema (estado subseqüente do estado citado), vários sockets que permanecem em estado de time_wait ${ }^{9}$, também ocupando desnecessariamente recursos. Para diminuir esse problema, é necessário ajustar corretamente os tempos de detecção de conexões inativas. Além do tempo, outros parâmetros também são necessários, como a sua quantidade e a forma de monitoração.

O servidor HTTP Apache exige uma configuração cuidadosa, assim como também ocorre no mod_jk e Tomcat. Por ser um servidor utilizado em situações das mais diversas, o Apache possui parâmetros para o seu ajuste tornando-o mais genérico possível. A configuração básica do Apache, assim como a do mod_jk responde bem a situações de baixa demanda e tráfego de páginas estáticas. Esse perfil, porém, não representa o cenário de atendimento das requisições utilizadas nesse trabalho. Durante a realização dos testes para a comparação da arquitetura desenvolvida, foram detectados empiricamente deficiências no perfil de atendimento de requisições da configuração, em relação ao cenário que foi utilizado. A constatação do problema foi uma tarefa trabalhosa e que consumiu bastante tempo, esforço e conhecimento amplo na configuração. O problema foi isolado da parte interna do ambiente de teste para a externa, ou seja, configurando o cenário de teste inicialmente pelos nós do cluster, a ligação entre os nós e o front-end, o front-end e, finalmente, o front-end e o cliente. Internamente no cliente foi necessário estabelecer números de configuração (quantidade de threads, por exemplo) condizente entre a capacidade dos nós e o Tomcat. A capacidade do nó é importante pois evita que mais conexões sejam criadas além da sua capacidade de atendimento, gerando erros por incapacidade de recepção (erro 503 do protocolo HTTP, por exemplo). A configuração da ligação entre front-end e cluster corresponde ao tempo de vida e identificação de erro das conexões. Para identificar os problemas nesse nível foi utilizado o mod_proxy, como citado anteriormente, uma solução alternativa do Apache HTTP Server para redirecionamento de requisições, usando o procolo HTTP. Quando foi utilizado o mod_proxy, foi identificado um problema na camada do atendimento HTTP do Apache, pois o mod_proxy funciona de maneira mais simples que o mod_jk, tirando sua camada de complexidade. A configuração padrão do Apache HTTP Server possui a característica de tentar otimizar o acesso de um cliente aos dados estáticos do servidor. Isso é feito mantendo a

8 A conexão foi finalizada, ou seja, o pacote FIN foi enviado pelo outro participante, e é esperado uma sinalização em relação ao pacote de ACK enviado em retorno ao FIN recebido.

9 O ACK em relação ao FIN de resposta do outro lado foi enviado mas deve-se esperar para evitar que o outro lado reenvie o FIN e outra conexão subsequente receba um FIN derivado de um processo de finalização anterior. 
conexão com o cliente aberta. Assim, quando o cliente carrega um arquivo HTML com mais elementos (figuras, por exemplo), ele não precisa abrir uma conexão para cada um. Essa característica é conhecida como keepalive. Como dito anteriormente, isso é útil para conteúdo web normal. Os web services (em especial os utilizados para os testes) não precisam obter mais elementos além da mensagem SOAP de retorno. Assim, depois do retorno, com o keepalive ativado, o servidor Apache continua com uma conexão presa (inutilmente), da mesma maneira como as conexões em fin_wait entre o mod_jk e o Tomcat. Com o limite de sockets ativos no Apache, ele não pode aceitar mais conexões, o que faz com que haja pausas no atendimento de requisições até que mais sockets sejam liberados. O parâmetro de keepalive é presente na maioria dos Apaches utilizados, pois em primeiro lugar ele é usado para o atendimento de requisições estáticas. Em um cenário de atendimento de web services de alta demanda, o Apache com a configuração padrão enfrenta problemas de falta de desempenho. Para solucionar esse problema é necessário retirar o keepalive penalizando então o conteúdo estático. Uma análise mais geral dessa situação remete que a necessidade de utilizar o Apache em relação à arquitetura proposta (usando Tomcat) pode ter como motivo o atendimento a requisições com conteúdo estático. Se para funcionar de maneira mais adequada para web services o Apache deve "prejudicar” o atendimento estático, o Apache perde a sua vantagem.

Depois de algum tempo e esforço solucionando o problema em relação ao tempo excessivo no atendimento aos web services pelo Apache (retirando o keepalive) e encontrado o ponto mais próximo de uma boa configuração para o mod_jk e Tomcat, foi necessário configurar o Tomcat e o distribuidor criado para o atendimento das requisições. A configuração consistiu da ligação entre o web service e a política no arquivo de configuração do distribuidor e a configuração do servidor web Tomcat. As configurações do distribuidor foram feitas para serem simples, então não foram encontrados maiores problemas nesse ponto de configuração. Em relação ao Tomcat, as maiores preocupações foram com a limitação de tempo de conexões ativas entre os clientes e o front-end e a limitação de capacidade do frontend. O tempo das conexões pode ser configurado para que as conexões desocupem os sockets logo que comunicação seja concluída (connectionLinger). Isso evita que haja sockets no estado de time_wait. A configuração do servidor web do Tomcat é relativamente simples e requer poucos parâmetros para que seja estabelecida uma configuração para alta demanda. A configuração do front-end pode ser semelhante a dos nós do cluster, sendo o front-end o ponto de limitação.

O front-end ainda requer uma alteração a mais que os nós: a instalação do filtro. Este foi projetado para ser facilmente instalado. Para a sua instalação basta torná-lo acessível, 
depositando-o no diretório das bibliotecas do Tomcat. Feito isso, é necessário ativar o filtro, através de um arquivo de configuração do Tomcat (web.xml). Seguindo os modelos já presentes no arquivo de configuração, a alteração no arquivo mencionado é simplificada. Instalado o filtro e iniciado o distribuidor, a arquitetura está pronta para funcionar. A complexidade de configuração, em termos de quantidade de parâmetros e detalhes em relação a desempenho para o funcionamento da arquitetura em relação ao mod_jk são menores, baseando-se na experiência de colocar ambos em funcionamento.

Após a configuração da arquitetura e do mod_jk, os testes foram executados 15 vezes com a seguinte combinação: para a arquitetura homogênea, foram realizados testes comparando-se a política round-robin do distribuidor e do mod_jk e comparando uma política baseada em carga de processador usando média móvel exponencial $(\boldsymbol{M M E})^{10}$ do distribuidor com a política busy mencionada do mod_jk; para a arquitetura heterogênea foram executados os mesmos testes que para a homogênea com a adição de mais um teste comparando políticas round-robin ponderadas de acordo com a capacidade dos nós utilizados. Os valores para a round-robin ponderada foram determinados antes da execução, fazendo-se uma espécie de benchmarking usando a própria aplicação e medindo o tempo de resposta de cada nó.

A carga de trabalho utilizada nos testes foi variada de duas formas. Foram iniciadas várias linhas de execução em um cliente. Além das linhas de execução foram usados até 3 clientes. No final, os testes consistiram de um cliente com 1, 3, 5, 7 e 10 linhas de execução, seguindo de 2 clientes concomitantemente aumentado a carga de linhas de execução da mesma forma que para um cliente e de forma análoga para 3 clientes. Isso resultou em 5 x $3=$ 15 execuções, repetidas 15 vezes (para possibilitar os testes de hipótese). As 225 execuções foram realizadas 4 vezes para o cenário homogêneo (round-robin do distribuidor e mod_jk, busy do $\mathbf{m o d}$ jk e $\boldsymbol{M} \boldsymbol{M} \boldsymbol{E}$ para o distribuidor) e 6 vezes para o heterogêneo (o mesmo cenário anterior, porém com adição das políticas ponderadas). Todas as tabelas contendo os dados dos experimentos juntamente com os testes de hipótese podem ser observadas no Anexo III. Todos os gráficos derivados dos experimentos encontram-se no Anexo IV. O parâmetro de avaliação foi o tempo de resposta do web service, ou seja, o tempo passado desde o envio da requisição até seu retorno.

Dos resultados obtidos, em 73,3 \% deles o distribuidor obteve melhor desempenho, em 22,7\% não houve diferença estatisticamente significativa e em 3\% dos casos houve perda

10 A média móvel exponencial é utilizada em análises financeiras com o intuito de atenuar rápidas flutuações no valor atual de uma métrica. Ela considera uma janela para a média de valores, assim caso ocorra um pico no valor atual, a média obtida pelos valores anteriores fará com que esse pico não cause tanto impacto na média atual, assim a média responde de maneira mais suave a oscilações rápidas. 
em relação ao mod_jk. Devido à grande quantidade de resultados (tabelas e gráficos) são apresentados nesta seção apenas os de maior destaque. Em todas as tabelas apresentadas usouse a seguinte notação:

X: Distribuidor e Y: mod_jk

1) H0: $X=Y$ e H1: $X !=Y$

2) H0: $\mathrm{X}>=\mathrm{Y}$ e H1: $\mathrm{X}<\mathrm{Y}$

3) H0: $\mathrm{X}<=\mathrm{Y}$ e H1: $\mathrm{X}>\mathrm{Y}$

O dado H0 refere-se ao teste de hipótese, sendo H0 a hipótese nulidade, contrária a H1 (Bussab e Morettin, 1987), usados para mostrar estatisticamente que os dados comparados são iguais, menores ou maiores entre eles. Como mencionado anteriormente, os testes foram realizados com 15 repetições dos experimentos. Este valor foi escolhido devido ao tempo necessário para a execução de cada experimento. Os experimentos demostraram obedecer uma distribuição normal. Devido a quantidade de experimentos foi utilizada a distribuição TStudent, voltada para testes estatísticos nestas condições.

A Fig. 7.3 apresenta o gráfico de execução comparativo entre as políticas $\boldsymbol{R} \boldsymbol{R}$ (roundrobin) do distribuidor e do mod_jk para 3 clientes. Os dados apresentados na Fig. 7.3 podem ser encontrados na Tabela 1. Esse resultado ressalta o desempenho do distribuidor usando uma política simples, mostrando que a sobrecarga da consulta ao distribuidor e o redirecionamento da requisição usando a arquitetura não causa sobrecarga excessiva em relação ao mod_jk.

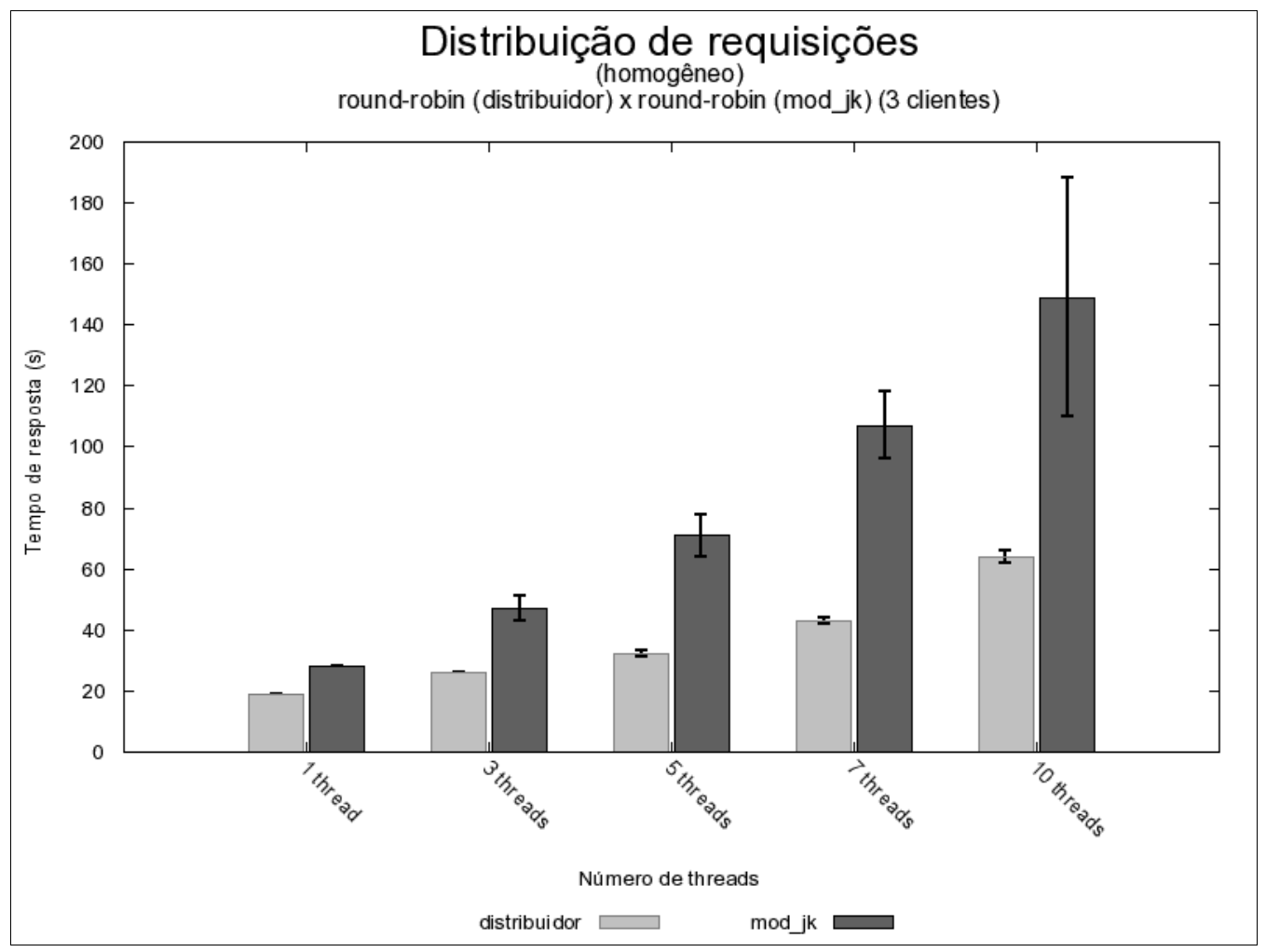

Fig. 7.3: $\boldsymbol{R} \boldsymbol{R}$ (distribuidor) x $\boldsymbol{R} \boldsymbol{R}$ (mod_jk)(3 clientes - homogêneo) 
Tab. 7.1: Valores - $\boldsymbol{R} \boldsymbol{R}$ (distribuidor) e $\boldsymbol{R} \boldsymbol{R}$ ( $\mathbf{m o d}$ jkk)(3 clientes - homogêneo)

\begin{tabular}{|c|c|c|c|c|c|c|c|c|c|c|}
\hline & \multicolumn{10}{|c|}{ Round-robin (distribuidor) x Round-robin (mod_jk) (3 cliente) (homogêneo) } \\
\hline & \multicolumn{2}{|c|}{1 thread } & \multicolumn{2}{|c|}{3 threads } & \multicolumn{2}{|c|}{5 threads } & \multicolumn{2}{|c|}{7 threads } & \multicolumn{2}{|c|}{10 threads } \\
\hline & $\mathrm{X}$ & Y & $\mathrm{X}$ & $\mathrm{Y}$ & $\mathrm{X}$ & Y & $\mathrm{X}$ & $\mathrm{Y}$ & $\mathrm{X}$ & $\mathrm{Y}$ \\
\hline Média (s) & 19,60 & 28,93 & 26,57 & 47,27 & 32,07 & 71,13 & 43,67 & 107,87 & 64,93 & 149,87 \\
\hline Desvio padrão & 1,22 & 1,91 & 2,45 & 12,16 & 3,17 & 18,84 & 4,92 & 31,28 & 6,98 & 105,61 \\
\hline $\begin{array}{r}\text { Intervalo de } \\
\text { confiança }\end{array}$ & 0,45 & 0,70 & 0,91 & 4,53 & 1,18 & 7,03 & 1,83 & 11,66 & 2,61 & 39,43 \\
\hline 1) $\mathrm{H} 0: X=Y$ & \multicolumn{2}{|c|}{ Rejeita } & \multicolumn{2}{|c|}{ Rejeita } & \multicolumn{2}{|c|}{ Rejeita } & \multicolumn{2}{|c|}{ Rejeita } & \multicolumn{2}{|c|}{ Rejeita } \\
\hline 2) $\mathrm{H} 0: \mathrm{X}>=\mathrm{Y}$ & \multicolumn{2}{|c|}{ Rejeita } & \multicolumn{2}{|c|}{ Rejeita } & \multicolumn{2}{|c|}{ Rejeita } & \multicolumn{2}{|c|}{ Rejeita } & \multicolumn{2}{|c|}{ Rejeita } \\
\hline 3) $\mathrm{H0}: \mathrm{X}<=\mathrm{Y}$ & \multicolumn{2}{|c|}{ Aceita } & \multicolumn{2}{|c|}{ Aceita } & \multicolumn{2}{|c|}{ Aceita } & \multicolumn{2}{|c|}{ Aceita } & \multicolumn{2}{|c|}{ Aceita } \\
\hline
\end{tabular}

Usando a $\boldsymbol{M M E}$ na arquitetura e comparando-se com a política busy é possível notar que houve ganho de desempenho também em relação ao mod_jk. A Fig. 7.4 expressa essa situação, acompanhada da sua tabela de valores correspondente (Tabela 7.2). Ainda, se for comparada a política round-robin (Tabela 7.1) e a $\boldsymbol{M M E}$ (Tabela 7.2) do distribuidor, é possível notar a diferença de desempenho. Isso ocorre devido à complexidade agregada na política $\boldsymbol{M M E}$, graças à lista ligada presente na mesma (com o intuito de manter a lista de nós dinâmica), a comparação do nó com menor carga $(\mathrm{O}(\mathrm{N}))$ e a coleta de tempo para verificar se há a necessidade de atualizar a situação de carga dos nós para todas as requisições atendidas. Ainda, periodicamente (graças a coleta de tempo) é realizada uma nova consulta à métrica. Essa consulta é realizada depois de um grande número de requisições, considerando que os clientes trabalham de maneira paralela e o provedor o Tomcat possui pool de threads para atender conexões.

Tab. 7.2: Valores - MME (distribuidor) x busy (mod_jk)(3 clientes - homogêneo)

\begin{tabular}{|c|c|c|c|c|c|c|c|c|c|c|}
\hline & \multicolumn{10}{|c|}{ Média móvel exponencial (distribuidor) x Política busy (mod_jk) (3 cliente) (homogêneo) } \\
\hline & \multicolumn{2}{|c|}{1 thread } & \multicolumn{2}{|c|}{3 threads } & \multicolumn{2}{|c|}{5 threads } & \multicolumn{2}{|c|}{7 threads } & \multicolumn{2}{|c|}{10 threads } \\
\hline & $\mathrm{X}$ & $\mathrm{Y}$ & $\mathrm{X}$ & $\mathrm{Y}$ & $\mathrm{X}$ & $\mathrm{Y}$ & $\mathrm{X}$ & $\mathrm{Y}$ & $\mathrm{X}$ & $\mathrm{Y}$ \\
\hline Média (s) & 22,73 & 23,80 & 35,20 & 45,13 & 51,93 & 46,47 & 76,07 & 73,73 & 115,60 & 138,73 \\
\hline Desvio padrão & 4,01 & 2,96 & 3,19 & 10,53 & 1,87 & 12,61 & 0,70 & 12,76 & 1,72 & 56,27 \\
\hline $\begin{array}{r}\text { Intervalo de } \\
\text { confiança }\end{array}$ & 2,13 & 1,57 & 1,75 & 4,75 & 1,04 & 6,98 & 0,39 & 7,07 & 0,95 & 31,16 \\
\hline 1) $\mathrm{H0}: X=Y$ & \multicolumn{2}{|c|}{ Aceita } & \multicolumn{2}{|c|}{ Rejeita } & \multicolumn{2}{|c|}{ Aceita } & \multicolumn{2}{|c|}{ Rejeita } & \multicolumn{2}{|c|}{ Aceita } \\
\hline 2) $\mathrm{H} 0: \mathrm{X}>=\mathrm{Y}$ & \multicolumn{2}{|c|}{ Aceita } & \multicolumn{2}{|c|}{ Rejeita } & \multicolumn{2}{|c|}{ Aceita } & \multicolumn{2}{|c|}{ Rejeita } & \multicolumn{2}{|c|}{ Aceita } \\
\hline 3) $\mathrm{HO}: \mathrm{X}<=\mathrm{Y}$ & \multicolumn{2}{|c|}{ Aceita } & \multicolumn{2}{|c|}{ Aceita } & \multicolumn{2}{|c|}{ Aceita } & \multicolumn{2}{|c|}{ Aceita } & \multicolumn{2}{|c|}{ Aceita } \\
\hline
\end{tabular}




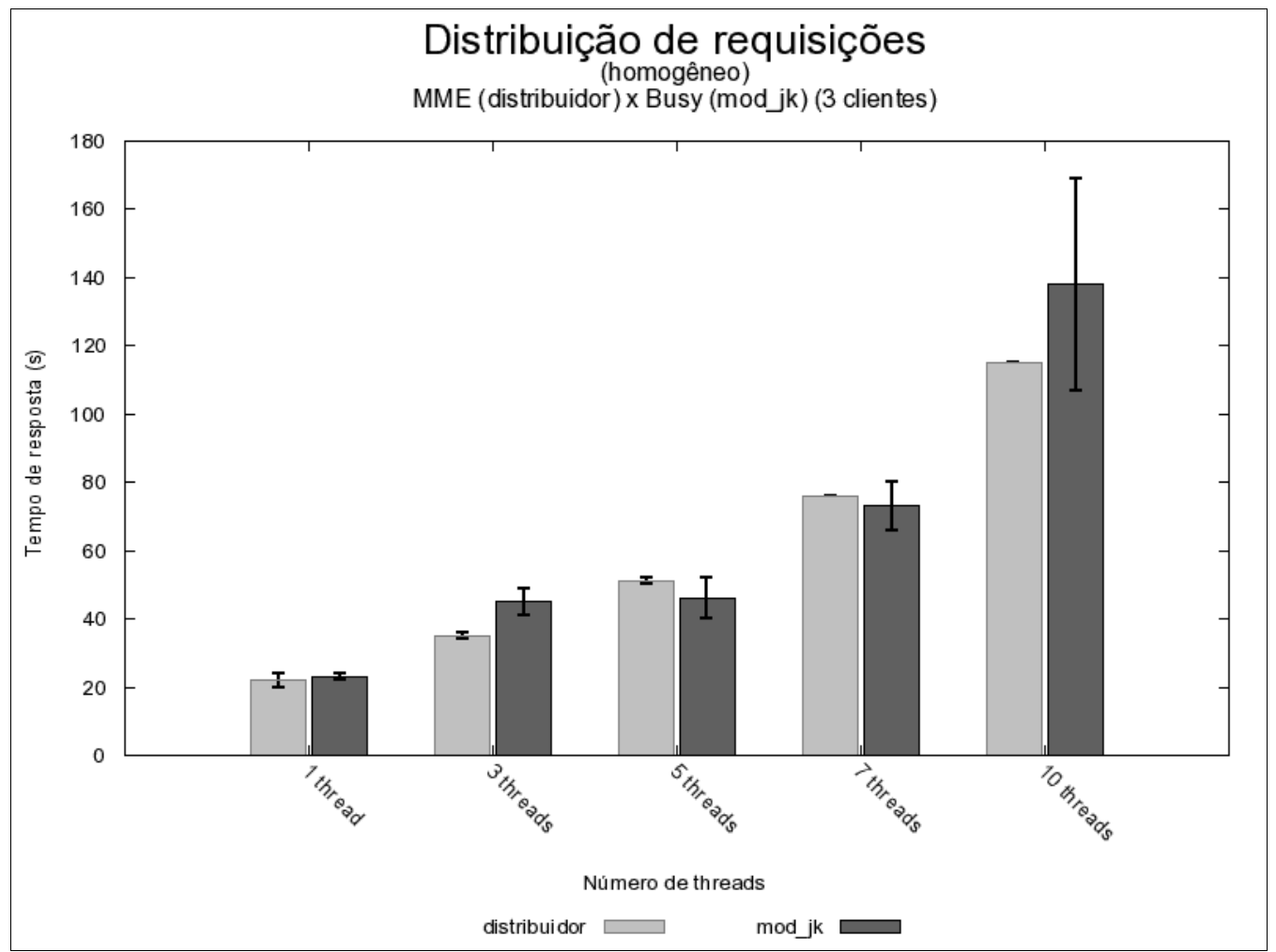

Fig. 7.4: MME (distribuidor) x busy (mod_jk)(3 clientes - homogêneo)

Na Fig. 7.4 e Tabela 7.2 é possível também observar que em comparação com a política busy, o distribuidor apresenta melhor desempenho e em outras ele se iguala, pelo teste de hipóteses. No caso, por exemplo para 10 threads, ele se torna igual estatisticamente devido ao alto desvio padrão entre os experimentos do mod_jk. Em grande parte dos experimentos, uma das características constante em relação às duas abordagens (mod_jk e o distribuidor da arquitetura proposta) é o alto desvio padrão do mod_jk e o baixo desvio padrão do distribuidor.

Tab. 7.3: Valores - $\boldsymbol{R} \boldsymbol{R}$ (distribuidor) x $\boldsymbol{R} \boldsymbol{R}$ ( $\mathbf{m o d}$ jk $)$ (2 clientes - heterogêneo)

\begin{tabular}{|c|c|c|c|c|c|c|c|c|c|c|}
\hline & \multicolumn{10}{|c|}{ Round-robin (distribuidor) x Round-robin (mod_jk) (2 cliente) (heterogêneo) } \\
\hline & \multicolumn{2}{|c|}{1 thread } & \multicolumn{2}{|c|}{3 threads } & \multicolumn{2}{|c|}{5 threads } & \multicolumn{2}{|c|}{7 threads } & \multicolumn{2}{|c|}{10 threads } \\
\hline & $\mathrm{X}$ & $\mathrm{Y}$ & $\mathrm{X}$ & $\mathrm{Y}$ & $\mathrm{X}$ & $\mathrm{Y}$ & $\mathrm{X}$ & $\mathrm{Y}$ & $\mathrm{X}$ & Y \\
\hline Média (s) & 41,27 & 50,27 & 94,13 & 127,87 & 110,40 & 160,60 & 169,67 & 481,87 & 224,13 & 409,87 \\
\hline Desvio padrão & 2,81 & 8,28 & 26,48 & 87,30 & 1,96 & 35,80 & 39,11 & 216,20 & 40,06 & 173,80 \\
\hline $\begin{array}{r}\text { Intervalo de } \\
\text { confiança }\end{array}$ & 1,53 & 4,51 & 14,50 & 47,79 & 1,08 & 19,83 & 21,66 & 119,72 & 22,05 & 95,65 \\
\hline 1) $\mathrm{H} 0: X=Y$ & \multicolumn{2}{|c|}{ Rejeita } & \multicolumn{2}{|c|}{ Aceita } & \multicolumn{2}{|c|}{ Rejeita } & \multicolumn{2}{|c|}{ Rejeita } & \multicolumn{2}{|c|}{ Rejeita } \\
\hline 2) $\mathrm{HO}: \mathrm{X}>=\mathrm{Y}$ & \multicolumn{2}{|c|}{ Rejeita } & \multicolumn{2}{|c|}{ Aceita } & \multicolumn{2}{|c|}{ Rejeita } & \multicolumn{2}{|c|}{ Rejeita } & \multicolumn{2}{|c|}{ Rejeita } \\
\hline 3) $\mathrm{H} 0: \mathrm{X}<=\mathrm{Y}$ & \multicolumn{2}{|c|}{ Aceita } & \multicolumn{2}{|c|}{ Aceita } & \multicolumn{2}{|c|}{ Aceita } & \multicolumn{2}{|c|}{ Aceita } & \multicolumn{2}{|c|}{ Aceita } \\
\hline
\end{tabular}




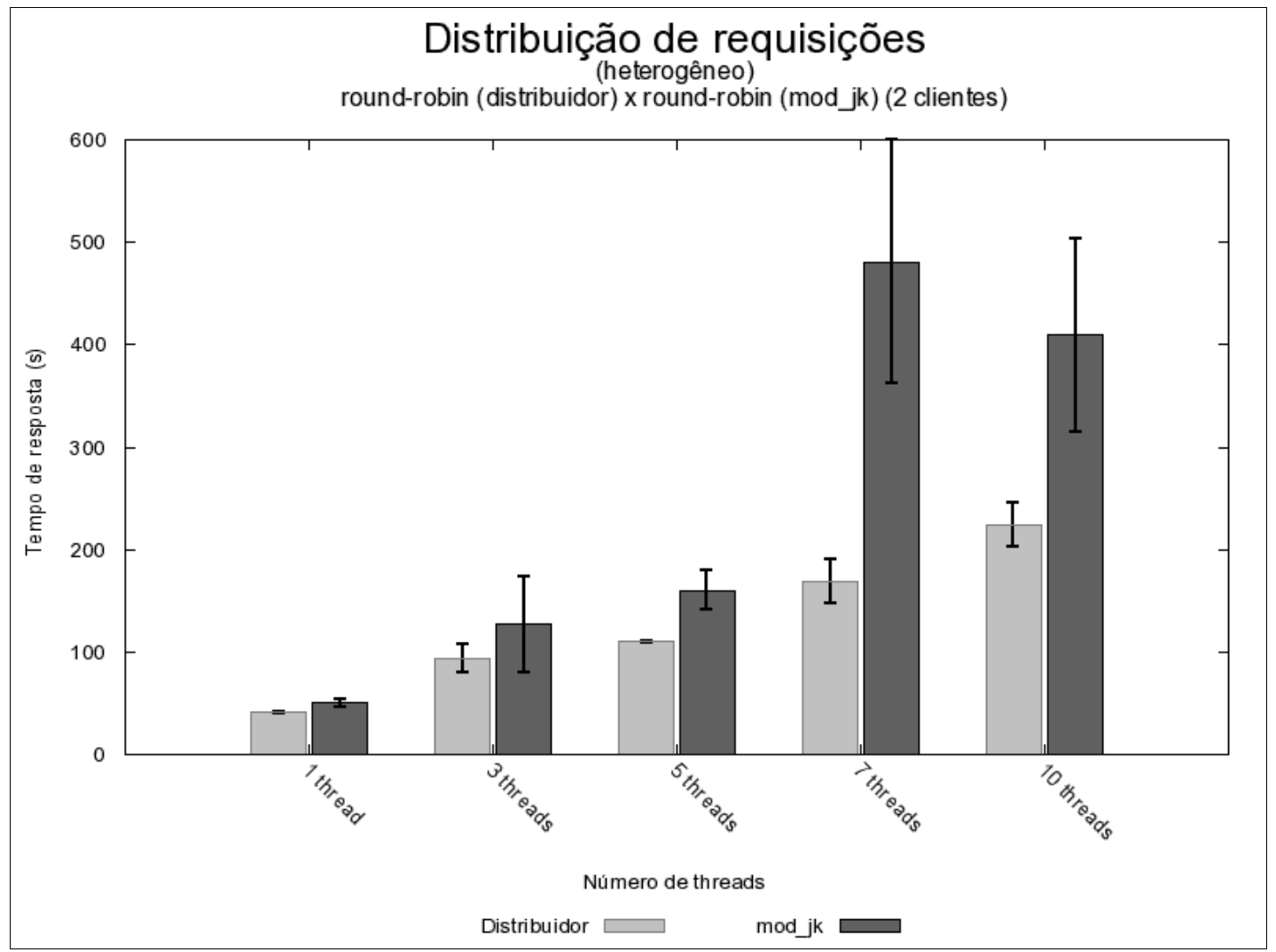

Fig. 7.5: $\boldsymbol{R} \boldsymbol{R}$ (distribuidor) x $\boldsymbol{R} \boldsymbol{R}(\mathbf{m o d}$ jk $)$ (2 clientes - heterogêneo)

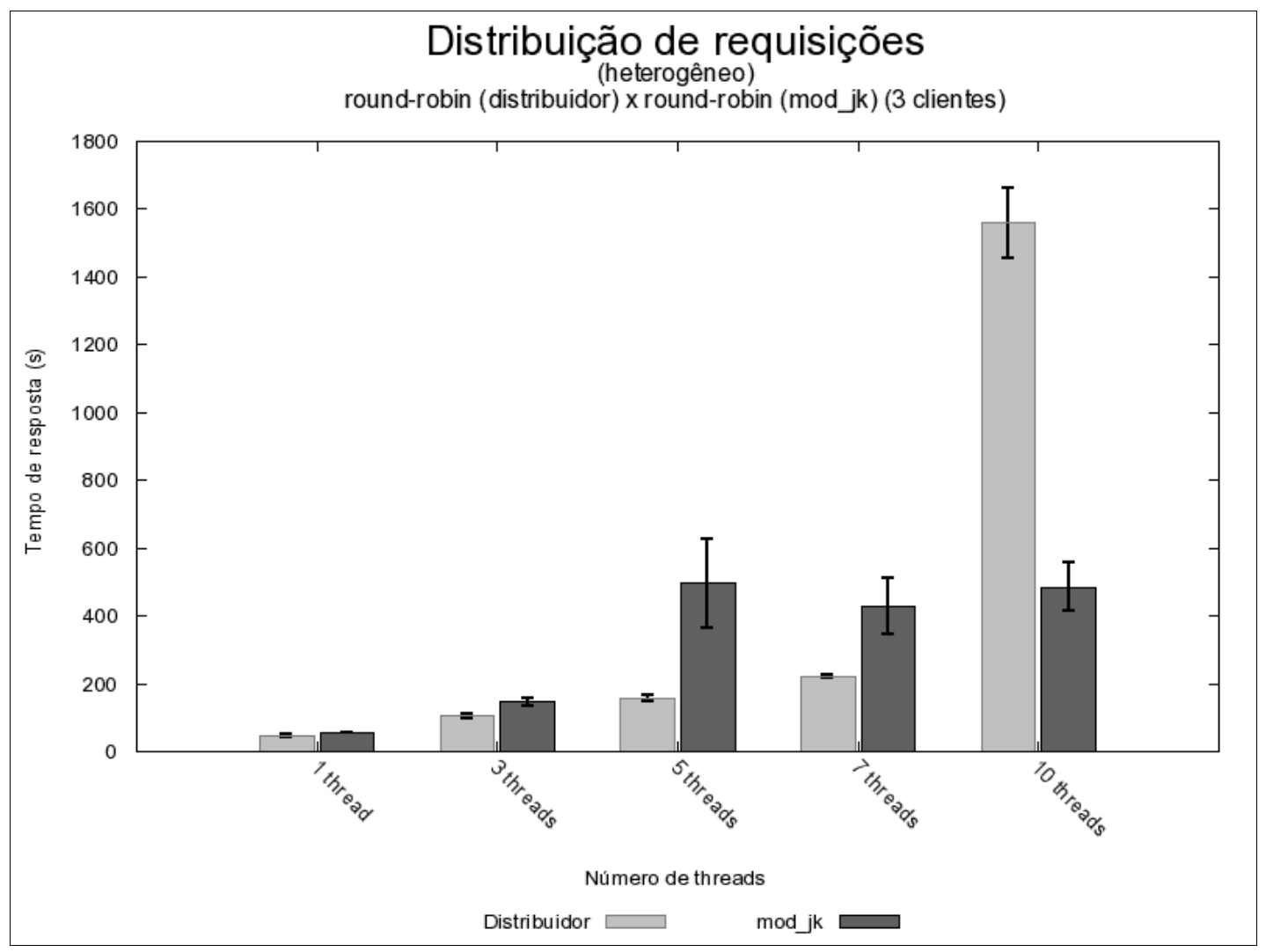

Fig. 7.6: $\boldsymbol{R} \boldsymbol{R}$ (distribuidor) x $\boldsymbol{R} \boldsymbol{R}(\mathbf{m o d}$ jkk) (3 clientes - heterogêneo) 
7.5.1. Teste utilizando serviço baseado em operação financeira

Tab. 7.4: Valores - $\boldsymbol{R} \boldsymbol{R}$ (distribuidor) x $\boldsymbol{R} \boldsymbol{R}$ ( $\mathbf{m o d}$ jk) (3 clientes - heterogêneo)

\begin{tabular}{|c|c|c|c|c|c|c|c|c|c|c|}
\hline & \multicolumn{10}{|c|}{ Round-robin (distribuidor) x Round-robin (mod_jk) (3 cliente) (heterogêneo) } \\
\hline & \multicolumn{2}{|c|}{1 thread } & \multicolumn{2}{|c|}{3 threads } & \multicolumn{2}{|c|}{5 threads } & \multicolumn{2}{|c|}{7 threads } & \multicolumn{2}{|c|}{10 threads } \\
\hline & $\mathrm{X}$ & $\mathrm{Y}$ & $\mathrm{X}$ & $\mathrm{Y}$ & $\mathrm{X}$ & $\mathrm{Y}$ & $\mathrm{X}$ & $\mathrm{Y}$ & $\mathrm{X}$ & $\mathrm{Y}$ \\
\hline Média (s) & 46,13 & 55,80 & 105,80 & 146,80 & 157,93 & 495,93 & 221,80 & 427,80 & 1559,00 & 485,67 \\
\hline Desvio padrão & 10,66 & 5,14 & 14,92 & 21,61 & 15,89 & 245,27 & 8,19 & 158,88 & 198,68 & 135,34 \\
\hline $\begin{array}{l}\text { Intervalo de } \\
\text { confiança }\end{array}$ & 5,74 & 2,77 & 7,95 & 11,52 & 8,80 & 131,00 & 4,53 & 84,67 & 105,88 & 72,12 \\
\hline 1) $\mathrm{H} 0: \mathrm{X}=\mathrm{Y}$ & \multicolumn{2}{|c|}{ Rejeita } & \multicolumn{2}{|c|}{ Rejeita } & \multicolumn{2}{|c|}{ Rejeita } & \multicolumn{2}{|c|}{ Rejeita } & \multicolumn{2}{|c|}{ Rejeita } \\
\hline 2) $\mathrm{H} 0: \mathrm{X}>=\mathrm{Y}$ & \multicolumn{2}{|c|}{ Rejeita } & \multicolumn{2}{|c|}{ Rejeita } & \multicolumn{2}{|c|}{ Rejeita } & \multicolumn{2}{|c|}{ Rejeita } & \multicolumn{2}{|c|}{ Aceita } \\
\hline 3) $\mathrm{H} 0: \mathrm{X}<=\mathrm{Y}$ & \multicolumn{2}{|c|}{ Aceita } & \multicolumn{2}{|c|}{ Aceita } & \multicolumn{2}{|c|}{ Aceita } & \multicolumn{2}{|c|}{ Aceita } & \multicolumn{2}{|c|}{ Rejeita } \\
\hline
\end{tabular}

Na plataforma heterogênea os testes da política round-robin do distribuidor e do mod_jk mostraram uma situação onde o primeiro perde e em outra é estatisticamente igual, para todas as outras há ganho de desempenho. A Fig. 7.5 apresenta a comparação para roundrobin para 2 clientes e a Fig. 7.6 para 3 clientes.

A situação onde o distribuidor perde é a de maior carga (3 clientes e 10 threads na Tabela 7.4). Nesse ponto, houve saturação das máquinas do cluster (principalmente das com menor capacidade). O ganho do mod_jk se deve ao descarte de requisições depois de um determinado tempo, diminuindo a sua média final. Como o distribuidor não descarta nenhuma requisição e nos testes atendeu a todas (mesmo que com tempo alto), a sua média subiu. Quando houve descarte, o cliente simplesmente recebeu uma mensagem de erro e a requisição não foi atendida, cenário ruim para uma aplicação que trabalha com operações financeiras. Neste caso em particular considera-se que, apesar do tempo maior, o distribuidor proposto é mais vantajoso que o mod_jk, por evitar a perda de requisições. No caso onde houve empate (2 clientes e 3 threads, Tabela 7.3), o motivo se deve ao alto desvio padrão do distribuidor, causando a "igualdade estatística”.

O método de tentativas e tempo limite de atendimento para a arquitetura não foi implementado, mas também pode ser inserido no filtro caso entenda-se que o mesmo é vantajoso para uma determinada aplicação. Sua configuração é simples, através dos próprios recursos de configuração do Tomcat.

O teste comparando a política $\mathbf{M M E}$ e busy do distribuidor e mod_jk respectivamente é apresentado na Fig. 7.7 e Tabela 7.5. Nesse resultado é possível notar que o protótipo obteve desempenho estatisticamente semelhante ao do mod_jk mesmo sem políticas mais otimizadas. Houve perda do distribuidor em relação ao mod_jk na situação de maior carga pelo fator semelhante ao ocorrido no caso anterior ( $\boldsymbol{R}$ e estrutura heterogênea). O descarte de requisições por parte do mod_jk e o método de tentativas explica os resultados. Apesar de 
estatisticamente semelhante o distribuidor obteve resultados absolutos melhores em relação o mod_jk excluindo-se a situação de maior carga a qual foi explicada.

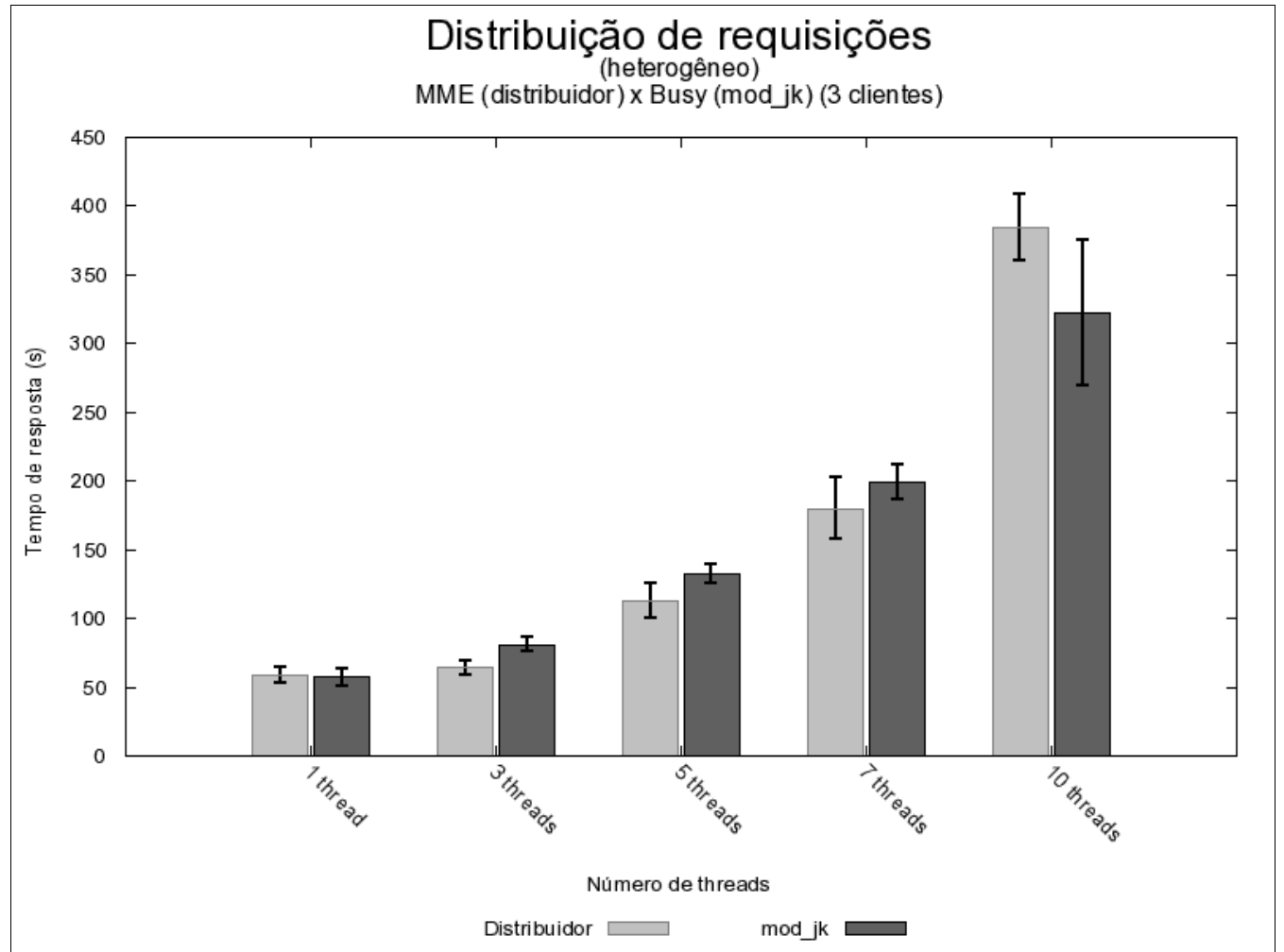

Fig. 7.7: $\mathbf{M M E}$ (distribuidor) x busy (mod_jk)(3 clientes - heterogêneo)

Tab. 7.5: Valores - MME (distribuidor) x busy (mod_jk)(3 clientes - heterogêneo)

\begin{tabular}{|c|c|c|c|c|c|c|c|c|c|c|}
\hline & \multicolumn{10}{|c|}{ Média móvel exponencial (distribuidor) x Política busy (mod_jk) (3 cliente) (heterogêneo) } \\
\hline & \multicolumn{2}{|c|}{1 thread } & \multicolumn{2}{|c|}{3 threads } & \multicolumn{2}{|c|}{5 threads } & \multicolumn{2}{|c|}{7 threads } & \multicolumn{2}{|c|}{10 threads } \\
\hline & $\mathrm{X}$ & $\mathrm{Y}$ & $\mathrm{X}$ & $\mathrm{Y}$ & $\mathrm{X}$ & $\mathrm{Y}$ & $\mathrm{X}$ & $\mathrm{Y}$ & $\mathrm{X}$ & $\mathrm{Y}$ \\
\hline Média (s) & 59,47 & 57,27 & 64,87 & 81,93 & 113,93 & 132,80 & 180,73 & 199,47 & 384,07 & 322,00 \\
\hline $\begin{array}{l}\text { Desvio } \\
\text { padrão }\end{array}$ & 11,32 & 12,54 & 10,23 & 9,51 & 25,89 & 14,00 & 42,65 & 25,90 & 45,99 & 98,24 \\
\hline $\begin{array}{r}\text { Intervalo de } \\
\text { confiança }\end{array}$ & 6,00 & 6,64 & 5,42 & 5,04 & 13,90 & 7,70 & 22,78 & 13,99 & 24,85 & 53,09 \\
\hline 1) $\mathrm{H} 0: X=Y$ & \multicolumn{2}{|c|}{ Aceita } & \multicolumn{2}{|c|}{ Rejeita } & \multicolumn{2}{|c|}{ Aceita } & \multicolumn{2}{|c|}{ Aceita } & \multicolumn{2}{|c|}{ Rejeita } \\
\hline 2) $\mathrm{HO}: \mathrm{X}>=\mathrm{Y}$ & \multicolumn{2}{|c|}{ Aceita } & \multicolumn{2}{|c|}{ Rejeita } & \multicolumn{2}{|c|}{ Aceita } & \multicolumn{2}{|c|}{ Aceita } & \multicolumn{2}{|c|}{ Aceita } \\
\hline 3) $\mathrm{HO}: \mathrm{X}<=\mathrm{Y}$ & \multicolumn{2}{|c|}{ Aceita } & \multicolumn{2}{|c|}{ Aceita } & \multicolumn{2}{|c|}{ Aceita } & \multicolumn{2}{|c|}{ Aceita } & \multicolumn{2}{|c|}{ Rejeita } \\
\hline
\end{tabular}

Os testes envolvendo a política round-robin ponderada de ambas as soluções apresentou vantagem para o distribuidor, deixando este em estatisticamente igual ao mod_jk apenas em situações de baixa carga. Na Fig. 7.8 e Tabela 7.6 é possível verificar o comportamento descrito. 


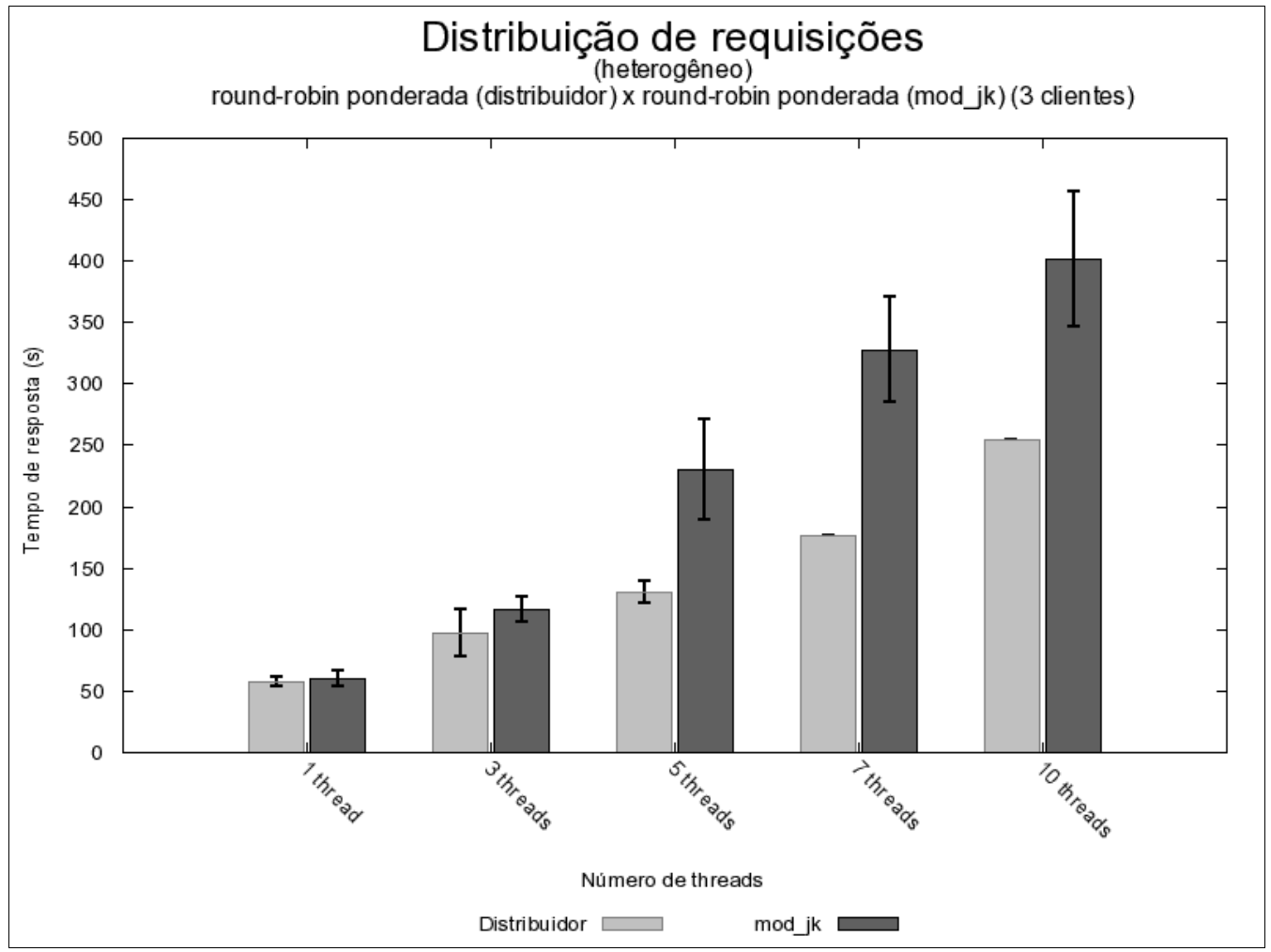

Fig. 7.8: $\boldsymbol{R} \boldsymbol{R}$ ponderada (distribuidor) x $\boldsymbol{R} \boldsymbol{R}$ ponderada ( $\mathbf{m o d}$ jjk)(3 clientes - heterogêneo)

Tab. 7.6: Valores - $\boldsymbol{R} \boldsymbol{R}$ pond. (distribuidor) x $\boldsymbol{R} \boldsymbol{R}$ pond. ( $\left.\mathbf{m o d} \_\mathbf{j k}\right)(3$ clientes - heterogêneo) Round-robin ponderada (distribuidor) (X) x Round-robin ponderada (mod_jk) (Y) (3 cliente) (heterogêneo)

\begin{tabular}{|c|c|c|c|c|c|c|c|c|c|c|}
\hline & \multicolumn{2}{|c|}{1 thread } & \multicolumn{2}{|c|}{3 threads } & \multicolumn{2}{|c|}{5 threads } & \multicolumn{2}{|c|}{7 threads } & \multicolumn{2}{|c|}{10 threads } \\
\hline & $\mathrm{X}$ & $\mathrm{Y}$ & $\mathrm{X}$ & Y & $\mathrm{X}$ & Y & $\mathrm{X}$ & Y & $\mathrm{X}$ & Y \\
\hline Média (s) & 58,87 & 60,33 & 88,73 & 116,67 & 131,73 & 230,93 & 177,40 & 328,27 & 255,20 & 401,40 \\
\hline Desvio padrão & 8,76 & 12,68 & 8,93 & 19,93 & 16,44 & 76,24 & 1,35 & 78,06 & 1,70 & 99,57 \\
\hline $\begin{array}{r}\text { Intervalo de } \\
\text { confiança }\end{array}$ & 4,67 & 6,75 & 4,83 & 10,70 & 9,05 & 41,96 & 0,75 & 43,23 & 0,94 & 55,14 \\
\hline 1) H0: $X=Y$ & \multicolumn{2}{|c|}{ Aceita } & \multicolumn{2}{|c|}{ Rejeita } & \multicolumn{2}{|c|}{ Rejeita } & \multicolumn{2}{|c|}{ Rejeita } & \multicolumn{2}{|c|}{ Rejeita } \\
\hline 2) H0: $X>=Y$ & \multicolumn{2}{|c|}{ Aceita } & \multicolumn{2}{|c|}{ Rejeita } & \multicolumn{2}{|c|}{ Rejeita } & \multicolumn{2}{|c|}{ Rejeita } & \multicolumn{2}{|c|}{ Rejeita } \\
\hline 3) $\mathrm{HO}$ : $\mathrm{X}<=\mathrm{Y}$ & \multicolumn{2}{|c|}{ Aceita } & \multicolumn{2}{|c|}{ Aceita } & \multicolumn{2}{|c|}{ Aceita } & \multicolumn{2}{|c|}{ Aceita } & \multicolumn{2}{|c|}{ Aceita } \\
\hline
\end{tabular}

Como complemento aos resultados é possível observar na Tabela 7.7 a comparação entre as políticas $\boldsymbol{M M E}$ e round-robin $(\boldsymbol{R} \boldsymbol{R})$ do distribuidor. Nela nota-se que nas situações de maior demanda há maior desempenho da política $\boldsymbol{M M E}$, mostrando que a realimentação do estado dos nós provida pela monitoração melhora a distribuição de requisições. Até mesmo é possível observar que no ponto de saturação (3 clientes e 10 threads) a $\boldsymbol{M M E}$ conseguiu diminuir a média do tempo de resposta das requisições e evitar a saturação. 
7.5.1. Teste utilizando serviço baseado em operação financeira

Tab. 7.7: Valores - $\boldsymbol{M M E}$ (distribuidor) e $\boldsymbol{R} \boldsymbol{R}$ (distribuidor)(3 clientes e heterogêneo)

\begin{tabular}{|c|c|c|c|c|c|c|c|c|c|c|}
\hline & \multicolumn{10}{|c|}{$\begin{array}{c}\text { Média móvel exponencial (X) (distribuidor) x Round-robin (Y) (distribuidor) (3 clientes) } \\
\text { (heterogêneo) }\end{array}$} \\
\hline & \multicolumn{2}{|c|}{1 thread } & \multicolumn{2}{|c|}{3 threads } & \multicolumn{2}{|c|}{5 threads } & \multicolumn{2}{|c|}{7 threads } & \multicolumn{2}{|c|}{10 threads } \\
\hline & $X$ & $\mathrm{Y}$ & $\mathrm{X}$ & $\mathrm{Y}$ & $\mathrm{X}$ & $\mathrm{Y}$ & $\mathrm{X}$ & $\mathrm{Y}$ & $\mathrm{X}$ & $\mathrm{Y}$ \\
\hline Média (s) & 59,47 & 46,13 & 64,87 & 105,80 & 113,93 & 157,93 & 180,73 & 221,80 & 384,07 & 1559,00 \\
\hline Desvio padrão & 11,32 & 10,66 & 10,23 & 14,92 & 25,89 & 15,89 & 42,65 & 8,19 & 45,99 & 198,68 \\
\hline $\begin{array}{r}\text { Intervalo de } \\
\text { confiança }\end{array}$ & 2,92 & 2,75 & 2,64 & 3,85 & 6,69 & 4,10 & 11,01 & 2,11 & 11,87 & 51,30 \\
\hline 1) $\mathrm{H} 0: X=Y$ & \multicolumn{2}{|c|}{ Rejeita } & \multicolumn{2}{|c|}{ Rejeita } & \multicolumn{2}{|c|}{ Rejeita } & \multicolumn{2}{|c|}{ Rejeita } & \multicolumn{2}{|c|}{ Rejeita } \\
\hline 2) $\mathrm{HO}: \mathrm{X}>=\mathrm{Y}$ & \multicolumn{2}{|c|}{ Aceita } & \multicolumn{2}{|c|}{ Rejeita } & \multicolumn{2}{|c|}{ Rejeita } & \multicolumn{2}{|c|}{ Rejeita } & \multicolumn{2}{|c|}{ Rejeita } \\
\hline 3) $\mathrm{HO}: \mathrm{X}<=\mathrm{Y}$ & \multicolumn{2}{|c|}{ Rejeita } & \multicolumn{2}{|c|}{ Aceita } & \multicolumn{2}{|c|}{ Aceita } & \multicolumn{2}{|c|}{ Aceita } & \multicolumn{2}{|c|}{ Aceita } \\
\hline
\end{tabular}

Os testes apresentados nesta subseção demonstram que, apesar do desenvolvimento das políticas não formarem o foco principal deste projeto de mestrado em particular e, portanto, não terem sido desenvolvidas a ponto de otimizar o seu tempo de execução e coletar as métricas mais adequadas para o serviço em questão, a arquitetura teve um desempenho satisfatório. As políticas implementadas foram simples, sem refinamentos, com o maior objetivo de mostrar a característica de flexibilidade da proposta e com baixa sobrecarga na sua execução.

\subsubsection{Teste usando web service "sintético"}

Com o objetivo de testar o funcionamento e a reação de uma política usando monitoração em relação a uma política sem a realimentação da situação atual dos nós do cluster, foi executado um experimento usando a aplicação sintética de $\boldsymbol{O C} \boldsymbol{R}$ (descrita na seção 7.3). O experimento envolveu a execução do serviço de reconhecimento de caracteres de maneira concorrente com o processamento de imagem para aplicar filtros na mesma, deixando-a apta para o reconhecimento. As aplicações, o $\boldsymbol{O C R}$ e o processamento de imagem demandam uso de processador. De maneira empírica foi constatado aumento do tempo de processamento da aplicação de $\boldsymbol{O C R}$ quando concorrente com o processamento de imagem. Esse fato foi usado para criar um ambiente onde ocorresse a concorrência e que esta pudesse ser detectada pelo monitor. $\mathrm{O}$ ambiente utilizado para o teste foi o homogêneo, deixando que apenas a concorrência fosse o único fator que influenciasse no tempo de execução. A Tabela 7.8 apresenta os resultados para a execução do serviço 10 vezes usando ambos, mod_jk e o distribuidor proposto, este último com uma política que detecta uso de processador. No mod_jk, a política mais próxima dessa métrica é a que verifica a ocupação do nó de destino (denominada busy), sendo essa a utilizada nos testes. 
Tab. 7.8: Resultados dos testes com a aplicação sintética na estrutura homogênea

\begin{tabular}{|l|r|r|}
\cline { 2 - 3 } \multicolumn{1}{c|}{} & Distribuidor $(Y)$ & mod_jk $(X)$ \\
\hline Média da execuções (seg.) & 486097,40 & 558369,70 \\
\hline Desvio padrão & 13640,08 & 7312,20 \\
\hline Variância & 186051804,93 & 53468340,23 \\
\hline$N^{\circ}$ de experimentos & 10 & 10 \\
\hline
\end{tabular}

Considerando este cenário de dados, foi utilizado o teste de hipótese baseado na distribuição T-Student, devido à quantidade de experimentos. O número de experimentos também foi assim escolhido por questões de tempo de execução para o total de execução para o total de experimentos. Foi utilizado o teste de hipótese para dados não pareados e com variância populacional diferente e desconhecida (Bussab e Morettin, 1987). Baseado no teste, foram elaboradas 3 situações com 2 hipóteses (H0 e H1), apresentadas na Tabela 7.9.

Tab. 7.9: Hipóteses para a comparação entre mod_jk e distribuidor (aplicação sintética)

\begin{tabular}{|c|c|c|c|}
\hline & 1 & 2 & 3 \\
\hline $\mathrm{HO}$ & $X=Y$ & $X \geq Y$ & $X \leq Y$ \\
\hline $\mathrm{H} 1$ & $X \neq Y$ & $X<Y$ & $X>Y$ \\
\hline
\end{tabular}

Da tabela de hipóteses (Tabela 7.9), baseado no resultado do teste de hipótese, obtevese o valor de "t" de 14,767. Considerando a região crítica para todas as 3 situações, o grau de liberdade de 13,78 e testes uni e bilaterais ( $t=1,7709$ e $t=2,1604)$ quando cabíveis, o resultado do testes é apresentado na Tabela 7.10.

Tab. 7.10: Resultado do teste de hipótese para a aplicação sintética

\begin{tabular}{|l|l|l|l|}
\cline { 2 - 4 } \multicolumn{1}{c|}{} & \multicolumn{1}{c|}{1} & \multicolumn{1}{c|}{2} & \multicolumn{1}{c|}{3} \\
\hline H0 & $\mathrm{X}=\mathrm{Y}$ : Rejeitada & $\mathrm{X} \geq \mathrm{Y}$ : Aceita & $\mathrm{X} \leq \mathrm{Y}$ : Rejeitada \\
\hline H1 & $\mathrm{X} \neq \mathrm{Y}$ : Aceita & $\mathrm{X}<\mathrm{Y}$ : Rejeitada & $\mathrm{X}>\mathrm{Y}$ : Aceita \\
\hline
\end{tabular}

Dados os resultados do teste de hipótese é possível afirmar, com 95\% de confiança no resultado, que o resultado do distribuidor (Y) é estatisticamente menor que o resultado do mod_jk (X), com uma diferença de aproximadamente 13\%. O experimento mostra que conhecida a demanda do serviço, é possível usar a monitoração disponível para as políticas para se obter índices para auxiliar no escalonamento da requisições. Essa situação assemelhase a um cluster onde os nós não são exclusivamente utilizados para o processamento do serviço em questão, mas também existem operações em batch que concorrem com a aplicação e que não são notadas pelas políticas disponíveis no mod_jk. 


\subsubsection{Versatilidade de políticas}

Uma preocupação atual mundial é pelo consumo de recursos naturais, principalmente no que diz respeito ao consumo de eletricidade. Questões como o aquecimento global e fim de reservas de combustíveis fósseis geram preocupação indiretamente para as empresas de TI. Centros de computação de empresas que demandam grande capacidade de processamento podem utilizar estruturas consideradas grandes e que costumam consumir grandes quantidades de energia, gerando gastos expressivos para as empresas. Em um cenário com escassez de recursos, pela própria lei econômica de oferta e procura, recursos energéticos se tornam caros. Entidades como a EPA (Environment Protection Agency) costumam certificar produtos em relação ao consumo de energia para informar aos compradores se os produtos estão dentro das normas de consumo. Mesmo que um produto (computador, servidor) esteja dentro de normas de consumo, sua eficiência e produtividade em relação à energia depende muito do seu uso consciente. Um pequeno servidor ligado (esperando por requisições, por exemplo) por um ano, poderá ter um consumo de 523,8 Kwh/ano ou aproximadamente R\$ 204,00 de custo (Comissão Europeia, 2009).

Estudos realizados dentro deste trabalho, obtiveram dados reais em relação à atividade de servidores para atendimento dos web services utilizados. Dentro do escopo estudado, foi possível notar que ocorrem picos de acesso (dos serviços disponibilizados para o trabalho) dentro do horário comercial. Com base nesses dados, houve a idéia de se estudar maneiras de criar políticas vinculadas aos provedores de web services para melhorar a eficiência energética de um centro de $\boldsymbol{T I}$. Considerando que uma empresa que utiliza clusters tem como um de seus objetivos diminuir custos com a estrutura através de recursos computacionais mais baratos, a eficiência energética é um ponto interessante de estudos.

Para um estudo inicial no trabalho, foi desenvolvida uma política que utiliza o recurso de wake-on-lan disponível na maioria dos computadores atuais para ligar e desligá-los através de comandos pela rede. Trabalhos semelhantes podem ser encontrados na literatura (Horvath e Skadron, 2008)(Elnozahy, Kistler e Rajamony, 2003)(Lefurgy et. al. , 2003), mas não usando tais recursos, nem relacionando web services, clusters e eficiência energética. O objetivo da política desenvolvida é fazer com que o front-end receba requisições e as redirecione para os nós do cluster disponíveis, ligando-os a medida que for necessário.

Para realizar a sua tarefa, a política desenvolvida utilizou principalmente o recurso de monitoração disponibilizado pelo distribuidor para obter informações de carga dos nós ativos. Uma vez que a carga média ultrapasse um certo limiar, mais nós são ativados. Entre a ativação de um nó e o seu total funcionamento para o atendimento há um certo intervalo de 
tempo, que pode ser notado nos resultados encontrados. Para que o front-end tenha o conhecimento que o nó já entrou em completo funcionamento e pode receber requisições e participar ativamente do cluster, foi utilizado o gmetric do Ganglia. Quando o nó entra em funcionamento, ele inicia a publicação de suas métricas de desempenho, entre elas a sua carga. Quando o nó finalmente está com o seu provedor ativado, o gmetric publica a sua atividade.

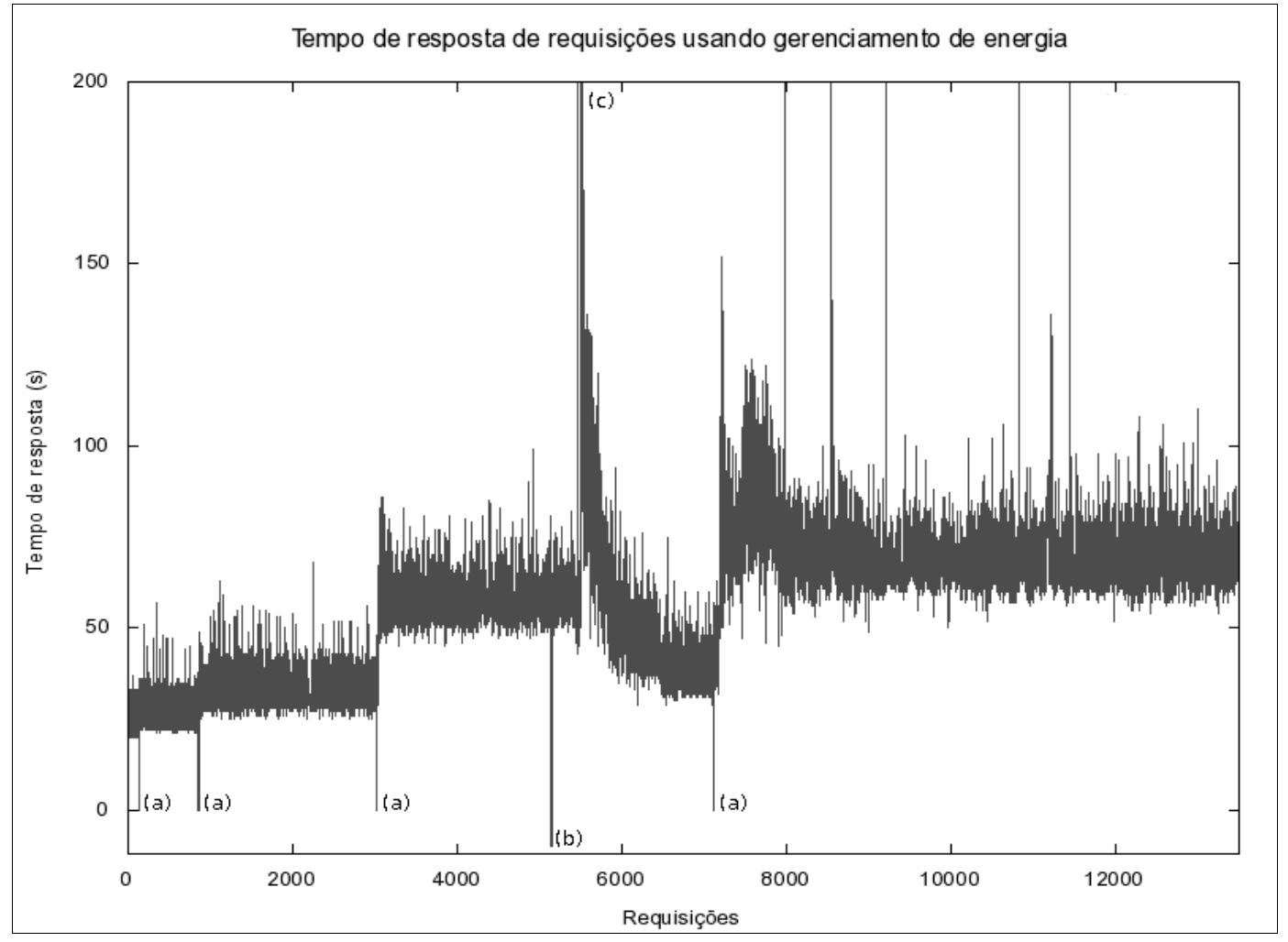

Fig. 7.9: Tempo de resposta de requisições com gerenciamento de energia

A plataforma utilizada para os testes foi o homogêneo, apresentado na Fig. 7.2a. Na Fig. 7.9 é apresentado um gráfico contendo os resultados dos testes realizados. A execução que gerou esse gráfico iniciou-se com 1 thread fazendo requisições (obtendo tempo de resposta de aproximadamente 25s). O aumento de threads deu-se de maneira exponencial, seguindo a seqüência de 3, 7, 15 e 31 threads. Cada uma das marcações “(a)” é uma sinalização colocada durante a execução para refletir no gráfico o aumento da quantidade de threads. É possível notar o aumento do tempo de resposta proporcionalmente ao aumento de threads. O ponto marcado por “(b)” é a sinalização que indica que nesse ponto foi dado o comando, por parte da política, para o segundo nó ser ligado. A indicação “(c)” no gráfico expressa o momento em que o segundo nó entrou em funcionamento finalmente, ou seja, o ponto em que ele começou a atender requisições. O aumento do tempo de resposta nesse ponto é justificado pela quantidade de faltas de cache e carregamento do provedor de web 
services na memória $\boldsymbol{R} \boldsymbol{A M}$. Com a continuação do recebimento das requisições é possível notar a redução do tempo de resposta das requisições. Nesse ponto, estão sendo executadas 15 threads, que quase passam para o tempo de execução de 7 threads (próximo das 2000 requisições) se comparado ao momento em que havia apenas um nó ativo.

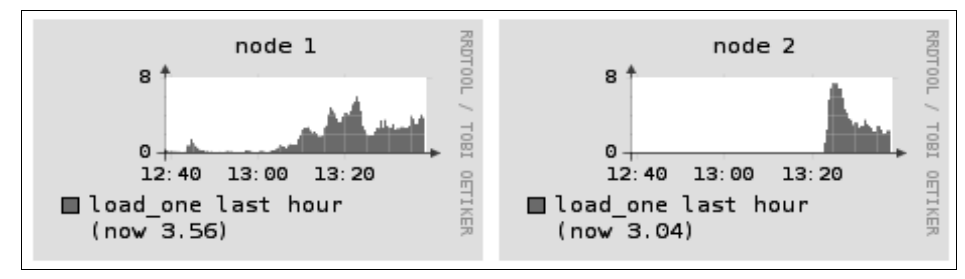

Fig. 7.10: Carga em relação ao tempo (Ganglia)

A Fig. 7.10 apresenta gráficos de carga no último minuto em um histórico com o intervalo de uma hora. Esse gráfico foi obtido da interface web do Ganglia. Nela é possível notar que o nó 1 (node 1) possui um aumento gradativo de sua carga entre 13 horas e 13 horas e 20 minutos, momento este em que estavam sendo executados o testes de gerenciamento de energia e a carga estava sendo gradativamente aumentada. Próximo às 13 horas e 25 minutos houve uma redução na carga do nó. Neste mesmo momento pode-se notar no gráfico do nó 2 (node 2) que há carga antes inexistente nesse nó. Alguns minutos antes, no nó 2, é possível observar um pico de carga, referente a carga do sistema e seus softwares intrínsecos e também do provedor de web services.

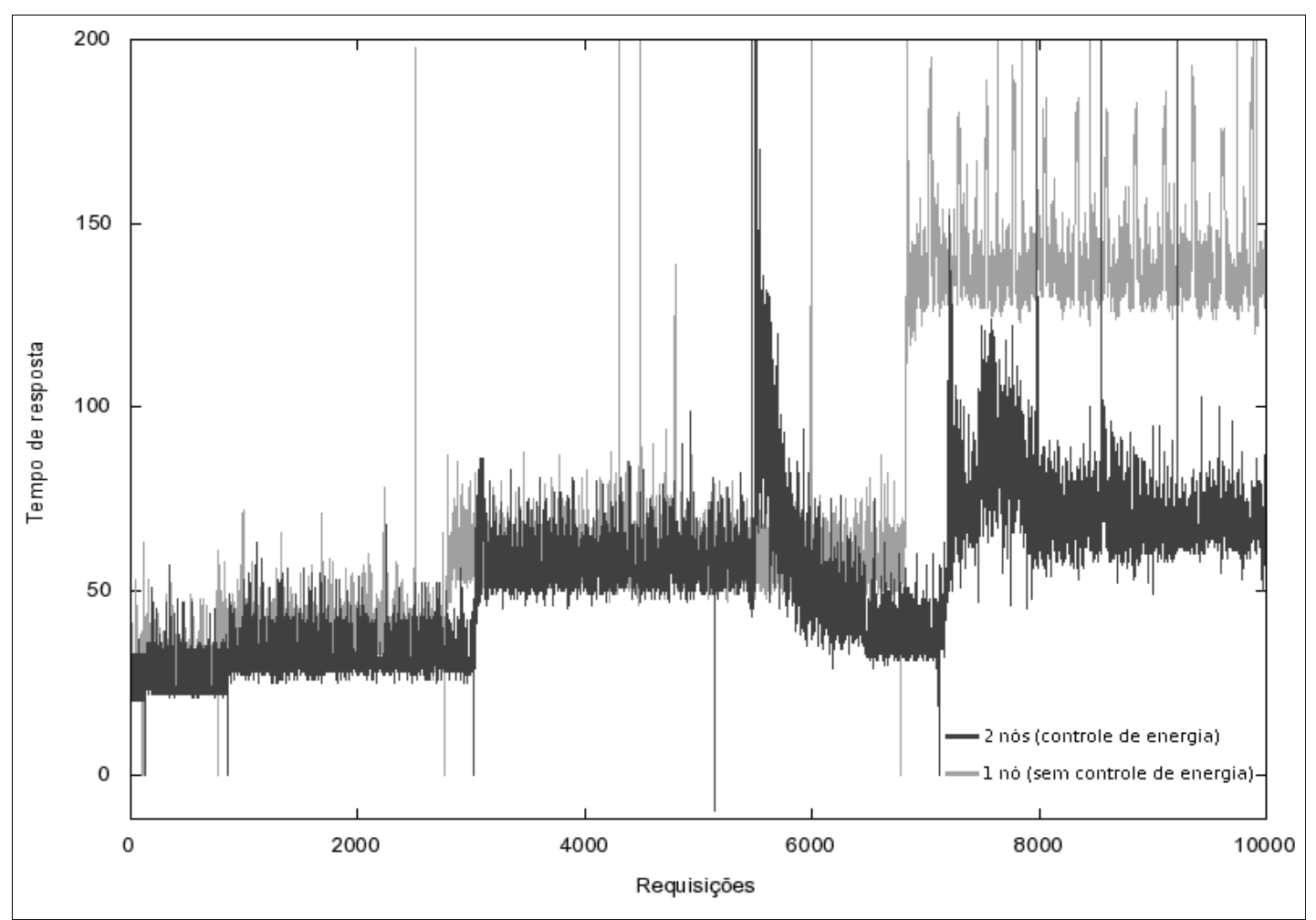

Fig. 7.11: Comparação 1 nó x 2 nós com gerenciamento de energia 
A Fig. 7.11 contém um gráfico comparativo da execução do cenário apresentado na Fig. 7.9, porém também com a execução usando apenas 1 nó, sem o gerenciamento de energia pela política. Esse gráfico (Fig. 7.11) mostra (cinza claro) o quanto o tempo de resposta é maior com apenas um nó em comparação com o cenário de 2 nós (cinza escuro).

Esse experimento foi realizado com o intuito de mostrar a versatilidade das políticas que podem ser desenvolvidas. Outro ponto interessante é que os dados para que a decisão de ativação fosse tomada foram obtidos de maneira transparente para a política. Além das aplicações citadas anteriormente em relação ao gerenciamento de energia, existe outro benefício. Em arquiteturas de TI grandes, com clusters com diversos nós ocorre um problema em relação ao ligamento dos nós. Se durante uma queda de energia todos os nós forem desligados e no retorno de energia todos forem ligados simultaneamente, o consumo de energia, conseqüentemente corrente elétrica consumida, será alto. O pico na corrente elétrica pode afetar o sistema elétrico, sobrecarregando-o e fazendo com que haja nova queda de energia. Isso se dá por dois motivos: nos computadores, o processo de boot utiliza leitura de disco e processador com maior intensidade, aumentando o consumo; outro motivo é que equipamentos elétricos apresentam uma certa “inércia elétrica/magnética” (além da própria inércia mecânica derivada de periféricos dessa origem), ocorrendo um pico de consumo durante os seus primeiros instantes de funcionamento (isso inclui desde processadores a ventoinhas). O gerenciamento de energia pode ser usando para ligar gradativamente o cluster, à medida que mais nós são necessários, mais nós são ligados, não havendo pico inicial tão grande.

\subsection{Considerações Finais}

Este capítulo apresentou os testes realizados usando a arquitetura proposta. O início do capítulo teve foco principal em ilustrar os testes realizados, abordando os softwares envolvidos (Apache HTTP Server, Apache Tomcat, JBoss, mod_jk), o hardware utilizado (estrutura homogênea e heterogênea, envolvendo clientes, front-end e servidores) e as aplicações que geraram as cargas para os testes (aplicação comercial de operação financeira e reconhecimento de caracteres). Os cenários de testes envolveram um teste em relação a desempenho e funcionalidade com 3 políticas diferentes, um teste de funcionamento da monitoração e um teste para demonstrar a versatilidade da criação das políticas. O primeiro teste mostrou que a arquitetura obteve bom desempenho mantendo as características para a qual foi proposta. O segundo teste mostrou que é possível, através das facilidades disponíveis, implementar políticas reativas ao estado dos nós. O terceiro teste apresentou um exemplo de 

uso diferente da arquitetura, com o objetivo de tornar o uso de energia do cluster mais eficiente. 



\section{Conclusão e trabalhos futuros}

\subsection{Conclusões}

Este projeto teve foco no atendimento de requisições a web services usando clusters como forma de redução de custos, aumento de escalabilidade e tolerância a falhas, em situações de alta demanda em relação a arquiteturas centralizadas. Para o atendimento foi proposta uma nova arquitetura com o intuito de possibilitar ao administrador e desenvolvedor de web services maior controle da distribuição das requisições sobre a arquitetura distribuída. A proposta deste trabalho foi testada através da implementação de um protótipo, sobre o qual foram introduzidas requisições de dois tipos, com demandas, hardware e objetivos variados.

O objetivo do trabalho foi propor uma arquitetura que fornecesse flexibilidade, através do acoplamento de políticas, e dinamicidade, podendo as políticas serem alteradas em tempo de execução e reagindo sobre a mudança do estado dos nós do cluster.

Os testes da arquitetura tomaram como referência uma solução existente de distribuição de requisições baseada no servidor web Apache HTTP Server e seu módulo chamado mod_jk. A arquitetura proposta, juntamente com o protótipo implementado, obtiveram vantagens em relação às facilidades de implementação de políticas e em alguns casos no desempenho obtido.

A arquitetura possibilitou o desacoplamento entre hardware e software, flexibilizando a maneira como os seus elementos são instalados no hardware de acordo com as demandas necessárias. Outro ponto em relação à flexibilidade foi a capacidade de criação de políticas, conectores e adaptadores para a arquitetura. As políticas são responsáveis por decidir qual o nó mais adequado para receber uma requisição em um dado momento de acordo com suas regras particulares. É possível acoplar à arquitetura uma política para cada serviço, tornando as decisões mais ajustáveis. Os conectores projetados na arquitetura fornecem a flexibilidade para que ela seja conectada a qualquer provedor de web services, funcionando como uma camada de tradução entre o provedor e o elemento de distribuição da arquitetura. Os 
adaptadores são elementos que se comunicam com monitores para fornecer ao desenvolvedor de políticas informações sobre o estado dos nós do cluster de maneira simplificada e transparente.

Dados os elementos da arquitetura, foram implementadas instâncias dos mesmos dentro de um protótipo que apresentou um bom desempenho, cumprindo os objetivos para o qual a arquitetura foi projetada.

Os testes de desempenho envolveram um cluster homogêneo e outro heterogêneo. O resultado obtido para uma política round-robin implementada no protótipo e a solução do mod_jk, ambos executados sobre o cluster homogêneo, mostrou que a arquitetura oferece menor sobrecarga para as decisões de distribuição e o encaminhamento de requisições em relação à proposta existente.

Os testes envolvendo coleta do estado dos nós mostraram que existe uma sobrecarga a mais na monitoração, porém com desempenho compatível com a proposta existente hoje. Outro ponto em relação a esta questão é a necessidade de estabelecer o perfil do web service atendido e da política utilizada, mostrando uma relação importante entre taxa de chegada de requisições e a complexidade das políticas.

Os testes sobre plataforma heterogênea usando políticas de decisão round-robin apresentaram atendimento mais confiável em relação ao mod_jk, quando em um cenário de alta demanda. A comparação entre a política round-robin e a política com decisão baseada no estado dos nós, mostrou ganho de desempenho usando a monitoração. Foi ainda obtido ganho de desempenho para a arquitetura proposta em relação à solução de referência, se comparadas políticas round-robin ponderadas em ambos os casos.

Outros testes foram realizados envolvendo web services sintéticos com demanda bem conhecida e políticas com o intuito de mostrar a sua flexibilidade usando técnicas para economia de energia. Os testes usando demandas conhecidas apresentaram ganho de desempenho para a proposta apresentada neste trabalho.

A política implementada usando técnicas de gerenciamento de energia mostrou que é possível, através da flexibilidade e monitoração fornecidas pela arquitetura, fazer um uso mais consciente de recursos computacionais. Essa política mostrou que é possível reagir à demanda de requisições e interagir com a estrutura de maneira simplificada.

O protótipo foi implementado aproveitando soluções de software existentes, como a monitoração e bibliotecas de componentes. Durante o desenvolvimento do protótipo houve preocupação em manter principalmente a flexibilidade garantindo-a de maneira a não necessitar causar paradas no atendimento às requisições para mudanças necessárias. Apesar da flexibilidade fornecida, o desempenho do núcleo da arquitetura (o distribuidor), foi 
providenciado com o uso de protocolos e estruturas de dados otimizadas.

O foco do trabalho não se concentra de maneira árdua em políticas de decisão mais eficientes. No entanto, as políticas criadas obtiveram desempenho satisfatório.

Além da contribuição na criação de uma arquitetura para o atendimento de requisições em clusters, foram conseguidas contribuições no contexto de configuração do ambiente de atendimento de requisições existente hoje, conseguindo encontrar parâmetros que influenciam no seu desempenho diretamente.

\subsection{Contribuiç̧̃es}

Este trabalho apresenta diferentes contribuições. As principais delas:

- Uma nova arquitetura de software: A arquitetura proposta tem como objetivo a distribuição de requisições a web services em clusters fornecendo subsídios para facilitar ao administrador ajustá-la da maneira mais pertinente em relação a sua estrutura e demanda gerada por seus serviços. Ainda, a nova arquitetura possibilita o fraco acoplamento na relação software/hardware da estrutura, fornecendo flexibilidade em relação à sua instalação.

- Um protótipo de ferramenta que viabiliza a distribuição flexível e dinâmica de requisições em um cluster de web services: a ferramenta que implementa a arquitetura proposta, fornecendo desempenho concomitantemente com a flexibilidade prevista pela arquitetura sem que ambos os tópicos interferissem prejudicialmente um no outro.

- Quatro políticas de distribuição de requisições a web services providos por clusters: As políticas desenvolvidas incluem uma round-robin, round-robin ponderada, uma política para ativação de nós sob demanda e uma política mais genérica facilitando o uso da monitoração e a adição e remoção de nós dinamicamente. As políticas roundrobin e round-robin ponderada desenvolvidas tem como objetivo o uso de maneira simplificada do protótipo. A política genérica usando monitoração tem como objetivo ser uma base para o estudo da influência de diferentes métricas na distribuição e também ser uma base para mostrar os recursos que podem ser explorados em novas políticas. A política de ativação de nós sob demanda atenta para uma linha de pesquisa envolvendo o uso eficiente de energia e a possibilidade de aplicação do distribuidor nesse contexto. Essa linha de pesquisa está em expansão por fatores como a preservação de recursos naturais.

- Revisão bibliográfica e levantamento de ferramentas: Para o êxito do trabalho foram coletadas informações sobre $\boldsymbol{S O A}$, um novo paradigma no desenvolvimento de 
aplicações de grande porte, e sobre web services, utilizados em SOA e que possibilitam grande interoperabilidade. Além desses dois pontos, foram levantadas informações sobre algumas formas de implementar serviços e ferramentas que auxiliam no seu desenvolvimento e no atendimento a web services. Além disso, foi realizado o estudo e a utilização de diversas técnicas de software e ferramentas que podem ser usadas no contexto de software livre. Outra contribuição desse tópico foi em relação ao uso de softwares e técnicas de distribuição de requisições de web services em clusters. A contribuição neste quesito é em relação a abertura de uma linha de pesquisa que será explorada por outros alunos, podendo estes utilizarem o levantamento realizado como passo inicial no desenvolvimentos de futuros projetos ligados ao tema deste trabalho.

- Geração de software livre: o protótipo implementado baseado na arquitetura utilizou apenas softwares distribuídos sobre licenças livres, não acarretando custos com a aquisição de novos softwares para o desenvolvimento, distribuição e utilização do software aqui proposto. Essa questão também possibilita a continuação do trabalho através de melhoramentos e contribuições da comunidade.

- Formação de recursos humanos: o projeto como um todo contribuiu para o enriquecimento em relação ao conhecimento sobre o contexto do trabalho ao aluno envolvido e do grupo de pesquisa como um todo. O assunto do trabalho é relativamente novo e com grande interesse por parte do setor comercial e científico. Os conhecimentos obtidos podem ser aplicados, inclusive pelo aluno, na contribuição para ambas as áreas (científica e comercial).

- Abertura de relação com empresas: o trabalho desenvolvido está em sincronismo com o mundo científico e também com a realidade encontrada hoje no desenvolvimento de aplicações comerciais. Durante o trabalho foram realizadas interações com uma empresa para obter informações sobre as reais carências na área de web services existentes hoje. Além dessa contribuição da empresa, foi obtido um cenário de teste real para que o protótipo desenvolvido, envolvendo tecnologias atuais e difundidas no mercado no contexto de web services.

\subsection{Trabalhos futuros}

Como trabalhos futuros podem ser citados:

- Estudo de políticas de distribuição de requisições para web services: as políticas 
desenvolvidas neste trabalho não foram otimizadas nem passaram por um estudo mais completo sobre sua efetividade em relação às demandas específicas dos serviços para que as decisões das políticas fossem tomadas. O trabalho desenvolvido possibilitou que futuramente outros projetos possam definir métricas e suas influências na distribuição. A transparência em relação à obtenção de métricas e a criação e ligação de novas políticas faz com que o tempo necessário para colocar novas idéias para a distribuição seja reduzido.

- Estudo da influência dos provedores de web services no desempenho na distribuição de requisições: a flexibilidade fornecida pelos conectores abre possibilidade para o futuro estudo do desempenho de outros provedores de web services em relação ao atendimento em plataformas distribuídas. Alguns exemplos de provedores de web services que podem ser estudados são: Jetty, Lighttpd, Axis2 (standalone), etc.

- Criação de métodos automáticos de aplicação de políticas: podem ser desenvolvidos trabalhos em relação a métodos com técnicas de inteligência artificial, por exemplo, para ajudar o criador de web services a identificar a melhor política para seu serviço ou ainda que faça a mudança automática de políticas para melhor se adaptar às demandas geradas. 



\section{Referências Bibliográficas}

ACTIVE ENDPOINTS. ActiveBPEL Open Source Engine, BPEL Standard - Active Endpoints. Disponível em: <http://www.active-endpoints.com/active-bpel-engineoverview.htm>. Acesso em: 30 jan. 2008.

ADAM, C.; STADLER, R. Implementation and Evaluation of a Middleware for SelfOrganizing Decentralized Web Services. Lecture Notes in Computer Science. Springer Berlin. Heidelberg. v. 3996/2006, p. 1-14. Junho 23, 2006.

ADAM, C. A Middleware Design for Large-scale Clusters Offering Multiple Services. IEEE electronic Transactions on Network and Service Management (IEEE eTNSM), v. 3, n. 1. Fevereiro, 2006.

ADAM, C.; STADLER, R. Adaptable server cluster with QoS objectives. Integrated Network Management. p. 149-162. Maio, 2005.

BRITTAIN, Jason; DARWIN, Ian F. Tomcat: The Definitive Guide. O'Reilly, 2003, 336p.

BROOKS, Christopher A.. An Introduction to Web Services. Disponível em: $<$ http://www.cs.usask.ca/ cab938/An\%20Introduction\%20to\%20Web\%20Services.pdf>.

Acesso em: 30 jan. 2008.

BUSSAB, Wilton O.; MORETTIN, Pedro A. Estatística básica. São Paulo: Atual, 1987. 4a. Edição.

CARDELliNI, V.; COLAJANNI, M.; YU, P.S. Dynamic load balancing on Web-server systems. Internet Computing, IEEE, vol. 3, n. 3, p. 28-39. mai./jun. 1999.

CARTER, Sandy. The new language of business: SOA \& Web 2.0. Crawfordsville: Pearson Education, Inc, 2007. 299 p.

CASAVANT, T. L.; KUHL, J. G. A Taxonomy of Scheduling in General-Purpose Distributed Computing Systems. IEEE Transactions on Software Engineering, 1988. p. 141-154.

CHESS, D. M.; PACIFICI, G.; TANTAWI, A. Experience with Collaborating Managers: Node Group Manager and Provisioning Manager. Proceedings of the Second International Conference on Automatic Computing. p. 39-50. 2005.

CHUNG, I. H.; HOLLINGSWORTH, J. K.. Automated cluster-based Web service performance tuning. In: IEEE International Symposium on High Performance Distributed Computing, 13, 2004. Proceedings of the 13th IEEE International Symposium on High performance Distributed Computing, 2004. p. 36 - 44. 


CISCO. CISCO DistributedDirector. Disponível em:

$<$ http://www.cisco.com/univercd/cc/td/doc/product/iaabu/distrdir/index.htm>. Acesso em 08 set. 2007.

CODEHAUS. Codehaus XFire. Disponível em: <http://xfire.codehaus.org/>. Acesso em: 30 jan. 2008.

COMER, Douglas. Internetworking with TCP/IP. 4. ed. Upper Saddle River: Prentice Hall, 2000. 750 p.

COMISSÃO EUROPEIA. Programa ENERGY STAR da União Europeia. Disponível em: <http://www.eu-energystar.org/pt/pt_008b.shtml>. Acesso em: 15 fev. 2009.

CONTINUENT.ORG. Sequoia: Welcome to the Sequoia Project! Disponível em: $<$ http://sequoia.continuent.org/HomePage>. Acesso em 09 set. 2007.

COSTELLO, Roger L.. Building Web Services the REST Way. Disponível em: <http://www.xfront.com/REST-Web-Services.html>. Acesso em: 30 jan. 2008.

CPN GROUP. cpntools. Disponível em: <http://wiki.daimi.au.dk/cpntools/cpntools.wiki>. Acesso em 15 fev. 2009.

THE GTK TEAM. GTK+ - About. Disponível em: <http://www.gtk.org/>. Acesso em: 15 fev. 2009.

EDDIE. What is Eddie? Disponível em: <http://eddie.sourceforge.net/what.html>. Acesso em: 10 set. 2007.

ELNOZAHY, E. N.; KISTLER, Michael; RAJAMONY, Ramakrishnan. Energy-Efficient Server Clusters. Power-Aware Computer Systems. LNCS. Springer: Berlin, 2003. vol. 2325/2003. p. 179-197.

ERL, Thomas. Service-Oriented Architecture: Concepts, Technology, and Design. Crawfordsville: Prentice Hall, 2005. 792 p.

FIELDING, Roy Thomas. Architectural Styles and the Design of Network-based Software Architectures. 2000. 162 f. Dissertação (Doutorado) - University Of California, Irvine, 2000. Disponível em: <http://www.ics.uci.edu/\%7Efielding/pubs/dissertation/top.htm>. Acesso em: 30 jan. 2008.

FIGUEIREDO, Tatiana Carvalho de. Interface AMIGO-MPI: uma abordagem flexível e dinâmica para escalonamento de processos. 2000. 97 f. Dissertação (Mestrado). Instituto de Ciências Matemáticas e de Computação - USP, São Carlos, 2000.

FLEURY, Mark; STARK, Scott; NORMAN, Richards. JBoss 4.0 The Official Guide. New York: Sams Publishin, 2005. 648 p. 
FOUNDRY NETWORK. Foundry Networks Application Switching Products. Disponível em: <http://www.foundrynet.com/products/app-switch/>.Acesso em: 10 set. 2007.

GANGLIA MONITORING SYSTEM. Ganglia Monitoring System - What is Ganglia? Disponível em: <http://ganglia.info/>. Acesso em: 16 fev. 2009.

HORVATH, Tibor; SKADRON, Kevin. Multi-mode energy management for multi-tier server clusters. Proceedings of the 17th international conference on Parallel architectures and compilation techniques. Toronto, 2008. p. 270-279.

HUNTER, Jason. Java servlet programming. Sebastopol: O’reilly \& Associates, Inc., 1998. $510 \mathrm{p}$.

IBM. IBM WebSphere Software: JBoss a divisionof Red Hat. Disponível em: <http://www-306.ibm.com/software/websphere/>. Acesso em: 30 jan. 2008.

IONA. Open.IONA. Disponível em: <http://open.iona.com/>. Acesso em: 30 jan. 2008.

JAYASINGHE , Deepal. Quickstart Apache Axis2: A practical guide to creating quality web services . Birmingham: Packt Publishing, 2008. 186 p.

JBOSS.ORG. Jboss.org: community driven. Disponível em: <http://labs.jboss.com/>. Acesso em: 30 jan. 2008.

KODALI, Raghu R.; WETHERBEE , Jonathan; ZADROZNY , Peter. Beginning EJB 3 Application Development: From Novice to Professional . Apress: Berkeley, 2006. 512 p.

LEFURGY, C.; RAJAMANI, K.; RAWSON, F.; FELTER, W.; KISTLER, M.; KELLER, T. W. Energy management for commercial servers. Computer. IEEE Computer Society: Los Alamitos, 2003. vol. 36, ed. 12, p. 39-48.

KUNTZ, Bryan; RAJAN, Karthik. MIGSOCK: Migratable TCP Socket in Linux. 2002. 87 f. Dissertação (Mestrado) - Carnegie Mellon University, Pittsburgh, PA, 2002. Disponível em: <http://www.cs.cmu.edu/ softagents/migsock/MIGSOCK.pdf>. Acesso em: 10 fev. 2009.

LEVY, R.; NAGARAJARAO, J.; PACIFICI, G.; SPREITZER, A.; TANTAWI, A. YOUSSEF, A. Performance management for cluster based Web services. IFIP/IEEE Eighth International Symposioum on Integrated Network Management. 2003. p. 247-261.

MALTZ, D. A.; BHAGWAT, P. MSOCKS: An Architecture for Transport Layer Mobility. Proceedings IEEE INFOCOM, 1998.

MARTELLO, Silvano; TOTH, Paolo. Knapsack problems: algorithms and computer implementations. New York: John Wiley \& Sons, Inc. 1990. 296p.

MASSACHUSETTS INSTITUTE OF TECHNOLOGY. MIT License. Disponível em: 
<http://www.opensource.org/licenses/mit-license.php>. Acesso em: 15 fev. 2009.

MARRS, Tom ; DAVIS, Scott. JBoss at Work: A Practical Guide . O'Reilly : Sebastopol, 2005. 306 p.

MASSIE, Matthew L.; CHUN, Brent N.; CULLER, David E. The ganglia distributed monitoring system: design, implementation, and experience. Parallel Computing, Northholland, v. 30, n. 7, p.817-840, 01 jul. 2004.

MCCOOL, R.. The Common Gateway Interface. Disponível em: <http://hoohoo.ncsa.uiuc.edu/cgi/overview.html>. Acesso em: 30 jan. 2008.

MOODIE, Matthew. Pro Apache Tomcat 6. New York: Apress, 2007. 325 p.

MYSQL AB. MySQL AB :: MySQL Cluster. Disponível em: <http://www.mysql.com/products/database/cluster/>. Acesso em 09 set. 2007.

NOKIA CORPORATION. Qt Cross-Platform Application Framework Qt - a cross-platform application and UI framework. Disponível em: <http://www.qtsoftware.com/products>. Acesso em: 15 fev. 2009.

OASIS. OASIS Technical Committees - XML Conformance Committee. Disponível em: <http://www.oasis-open.org/committees/xml-conformance/>. Acesso em: 15 fev. 2009.

OBJECT WEB. Celtix. Disponível em: <http://celtix.objectweb.org/>. Acesso em: 30 jan. 2008.

OW2. JOnAS OpenSource Java EE Application Server - Main - WebHome. Disponível em: <http://wiki.jonas.objectweb.org/xwiki/bin/view/Main/WebHome>. Acesso em: 30 jan. 2008.

PGCLUSTER. PGCluster top page. Disponível em: <http://pgcluster.projects.postgresql.org/ >. Acesso em 09 set. 2007.

RED HAT. JBoss.com: JBoss a divisionof Red Hat. Disponível em: <http://jboss.com/>. Acesso em: 30 jan. 2008.

RED HAT. Jboss.org - community driven: JBoss Web. Disponível em: <http://www.jboss.org/jbossweb/index.html>. Acesso em: 15 fev. 2009.

RED HAT. Red Hat Signs Definitive Agreement to Acquire JBoss. Disponível em: <http:// www.redhat.com/about/news/prarchive/2006/jboss.html>. Acesso em: 30 jan. 2008.

RED HAT MIDDLEWARE. hibernate.org - Hibernate. Disponível em: <http://www.hibernate.org/>. Acesso em: 15 fev. 2009. 
SANTOS, Ricardo Ribeiro dos. Escalonamento de aplicações paralelas: interface AMIGOCORBA. 139 f. Dissertação (Mestrado). Instituto de Ciências Matemáticas e de Computação - USP, São Carlos, 2001.

SICARD, Sylvain; PALMA, Noel De; HAGIMONT, Daniel. J2EE server scalability through EJB replication. In: Symposium on applied computing, 06., 2006, Dijon. Proceedings of the 2006 ACM symposium on Applied computing. New York: Acm, 2006. p. 778 - 785.

SLONY-L. SLONY-L. Disponível em: <http://slony.info/> . Acesso em 09 set. 2007.

SHIRAZI, B. A.; HURSON, A. R.; KAVI, K. M. Introduction to scheduling ad Load Balancing in Parallel and Distributed Systems, IEEE Computer Society Press, 1995. Los Alamitos, CA.

SNELL, James. Resource-oriented vs. activity-oriented Web services. Disponível em: <http://www-128.ibm.com/developerworks/webservices/library/ws-restvsoap/>. Acesso em: 30 jan. 2008.

SOUZA, Paulo Sérgio Lopes de. AMIGO: Uma contribuição para a convergência na área de escalonamento de processos. 2000. 244 f. Tese (Doutorado) Instituto de Física de São Carlos USP, São Carlos, 2000.

SOUZA, Paulo Sérgio Lopes de; SANTANA, Marcos José; SANTANA, Regina Helena Carlucci. Escalonamento de Processos: Uma contribuição para a convergência da Área. São Carlos: ICMC/USP, 2000.

SPRING SOURCE. Springframework.org. Disponível em: <http://www.springframework.org/>. Acesso em: 30 jan. 2008.

SULTAN, F.; SRINIVASAN, K.; IYER, D.; IFTODE, L. Migratory TCP: connection migration for service continuity in the Internet. Proceedings 22nd International Conference on Distributed Computing Systems, 2002. p. 469-470.

SUN MICROSYSTEMS. Why StAX? Disponível em: $<$ http://java.sun.com/webservices/docs/1.6/tutorial/doc/SJSXP2.html>. Acesso em: 30 jan. 2008.

SUN MICROSYSTEMS. Java Management Extensions (JMX). Disponível em: $<$ http://java.sun.com/javase/technologies/core/mntr-mgmt/javamanagement/>. Acesso em: 30 jan. 2008.

TANENBAUM, Andrew S.; VAN STEEN, Maarten. Distributed Systems: Principles and Paradigms. Upper Saddle River: Prentice Hall, 2002. 803 p.

TANG, C.; STEINDER, M.; SPREITZER, M.; PACIFICI, G. A Scalable Application Placement Controller for Enterprise Data Centers. Proceedings of the 16th international conference on World Wide Web. p. 331-340. 2007. 
TAVARES, T. C. ; SANTANA, Regina Helena Carlucci ; ESTRELLA, J. C. ; SANTANA, Marcos José . Caracterização dos Dados Trocados Entre Serviços Web e Provedores de Serviço. XIV Simpósio Brasileiro de Sistemas Multimídia e Web, 2008, Vila Velha - ES. Anais do XIV Simpósio Brasileiro de Sistemas Multimídia e Web, 2008. v. 2.

THE APACHE SOFTWARE FOUNDATION. Apache Tomcat. Disponível em: $<$ http://tomcat.apache.org/>. Acesso em: 30 jan. 2008.

THE APACHE SOFTWARE FOUNDATION. Apache Axis2. Disponível em: $<$ http://ws.apache.org/axis2/>. Acesso em: 30 jan. 2008.

THE APACHE SOFTWARE FOUNDATION. Index:: Apache Axis2. Disponível em: <http:// geronimo.apache.org/>. Acesso em: 30 jan. 2008.

FOUNDATION, Apache Software. WebServices - Axis. Disponível em: <http://ws.apache.org/axis/>. Acesso em: 30 jan. 2008.

TIDWELL, Doug; SNELL, James; KULCHENKO, Pavel. Programming Web Services with SOAP. O'reilly, 2001. 216 p.

VAUGHAN-NICHOLS, S. J. Web services: beyond the hype. Computer, IEEE Computer Society v. 35, n. 2, p.18-21, 1 fev. 2002. 12.

VEILLARD, Daniel. The XML C parser and toolkit of Gnome. Disponível em: <http://xmlsoft.org/>. Acesso em: 15 fev. 2009.

W3C. W3C XHTML2 Working Group Home Page. Disponível em: <http://www.w3.org/MarkUp/>. Acesso em: 10 fev. 2008.

WEBTIDE. Jetty6: Jetty WebServer. Disponível em: <http://www.mortbay.org/> . Acesso em: 30 jan. 2008.

ZUR MUEHLEN, Michael; NICKERSON, Jeffrey V.; SWENSON, Keith D.. Developing web services choreography standards: the case of REST vs. SOAP. Decision Support Systems: Web services and process management, North-holland, v. 40, n. 1, p.9-29, 1 jul. 2005. 12. 
Este anexo apresenta o modelo em $\boldsymbol{R \boldsymbol { d P C }}$ do protótipo implementado. Este modelo está em uma $\boldsymbol{R d P C}$ não hierárquica, diferentemente dos modelos apresentados na seção 5.5. O intuito do modelo aqui presente é apresentar em uma visão de nível mais baixo e completa o funcionamento do protótipo. Este modelo permite visualizar de maneira mais clara a interação entre as threads existentes no protótipo e também a seqüência de inicialização do protótipo. O significado e resultado deste modelo é o mesmo do modelo hierárquico do Capítulo 5.5. A simulação começa no lugar Iniciado (canto superior esquerdo). A seqüência inicial passa pelo carregamento do $\boldsymbol{G C}, \boldsymbol{G A}, \boldsymbol{G P}, \boldsymbol{G C n}$ e $\boldsymbol{G W}$. No fim da seqüência de inicialização o protótipo entra em seu estado normal de funcionamento, esperando por conexões nos conectores (lugar Conexoes dos provedores). Além dessas conexões, podem existir conexões vindas pelo GC (lugar Conexao externa). O fim da execução acontece no lugar Termino do distribuidor depois que as threads dos gerenciadores param e são depositadas no lugar Fim.

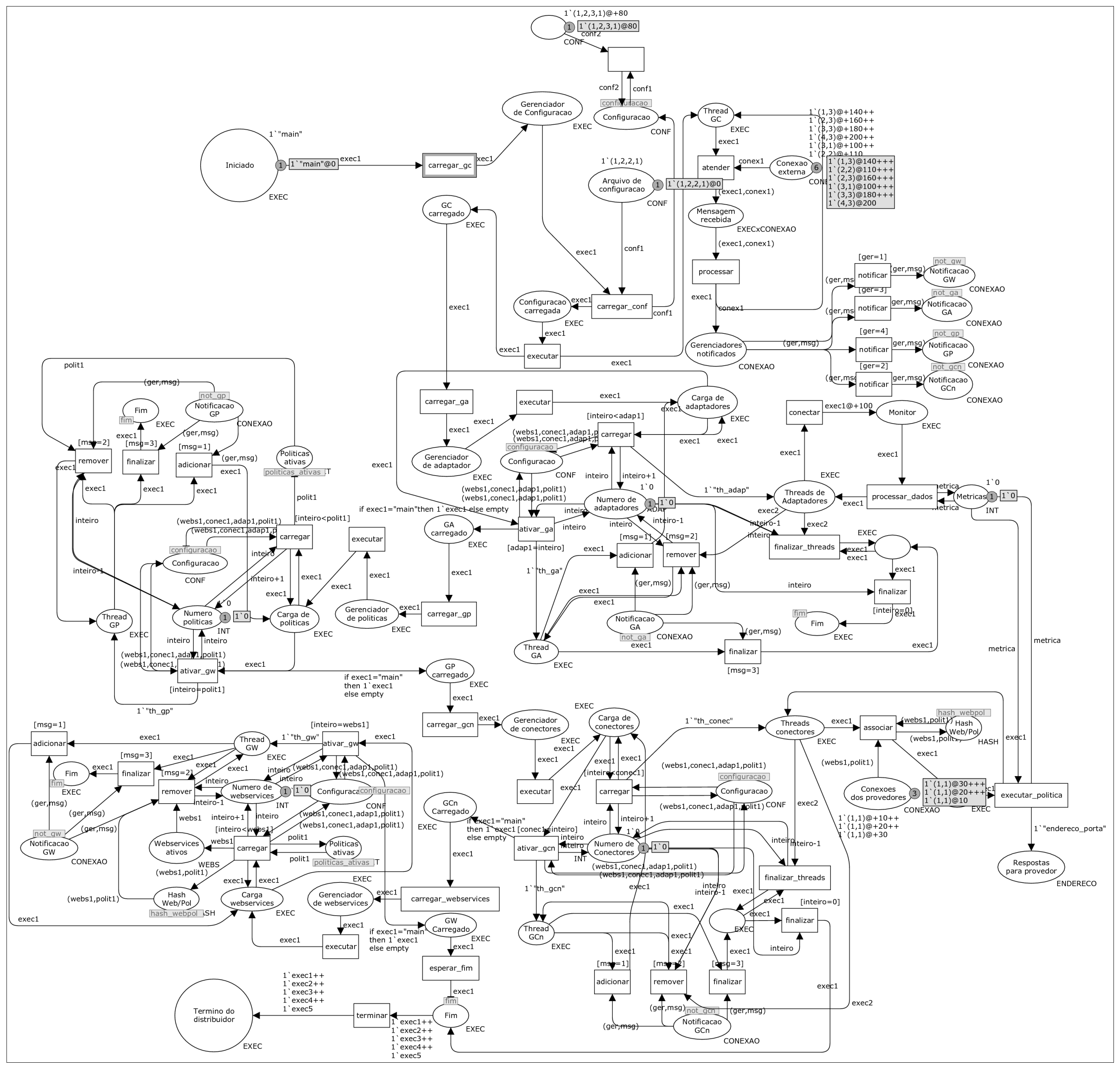

Fig. A1.1: Modelo em $\boldsymbol{R d P C}$ detalhado sem hierarquia do protótipo 

Neste anexo é apresentado um “esqueleto” básico para a implementação de uma política que analisa o nó com menor uso de $\boldsymbol{C P U}$. A assinatura básica para a função de política é a contida na linha 3, respeitando o tipo de parâmetro de entrada e o tipo de retorno. Possuindo essa assinatura, o distribuidor consegue executar a função da política toda vez que uma requisição é recebida. As políticas não executam como threads, são apenas executadas pontualmente a cada requisição. É possível persistir dados entre uma chamada e outra da função através da alocação dinâmica de memória, essa questão é apresentada das linhas 8 a 14. Nesse trecho de código é verificado se já houve alocação de memória, pois na inicialização do distribuidor (incluindo ativação de políticas dinamicamente), esse ponteiro é atribuído como nulo. Alocada a memória, devem ser carregadas as strings com os IPs das máquinas, nesse caso, apenas strings simples com caracteres que representam os endereços. Na linha 20 é possível encontrar a função de consulta à métricas vindas de algum dos monitores que podem ser ligados ao distribuidor. O resultado das métricas é retornado em uma string que para questões de comparação de valores é convertida para inteiro. Os principais cuidados na consulta são: a limpeza da string de retorno (linha 22), pois a própria função ObterMetricas a aloca e deixa livre ao utilizador liberá-la; e a formatação da string de entrada, sendo ela composta pelo endereço do nó que se necessita monitorar e a métrica.

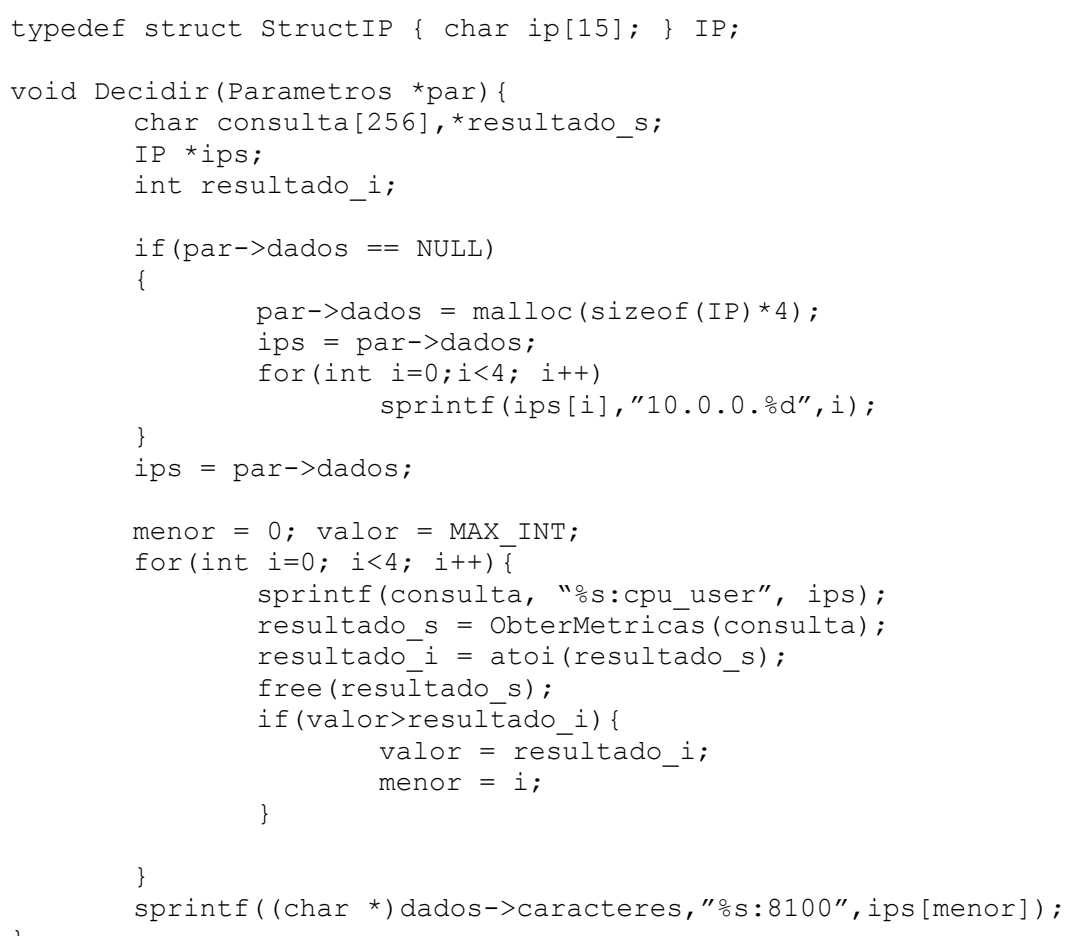

Fig. A2.1: Política baseada em uso de CPU 
Anexo II

No caso desse exemplo, a consulta e decisão pelo nó é realizada com uma simples comparação (entre as linhas 18 e 28). A comunicação, por parte da política, para o distribuidor é feita pela atribuição de uma string de caracteres contendo o nó de destino e porta para processar a requisição ao web service. É importante lembrar que não ocorre realmente comunicação entre política e distribuidor, o que ocorre é a chamada da política pelo distribuidor e o retorno do nó de destino é feito através do ponteiro passado para a função Decidir. 


\section{Anexo III}

Este anexo traz as tabelas com os resultados numéricos dos testes realizados para a aplicação comercial envolvendo a estrutura homogênea e heterogênea. As tabelas são compostas pelos valores obtidos de tempo de resposta médio entre cada requisição aos serviços. Além destes valores, são apresentados valores estatísticos que levam ao teste de hipóteses realizado para fins de comparação. As tabelas são complementares às tabelas apresentadas no Capítulo 7. Elas mostram os valores dos testes para todas as cargas testadas (1, 2 e 3 clientes). A sequiência de aparição das tabelas apresenta primeiro as tabelas para a estrutura homogênea e subseqüentemente para a heterogênea. No caso da estrutura homogênea é primeiro apresentada a comparação entre a política busy e a política $\boldsymbol{M M E}$ (Média Móvel Exponencial), usando como métrica $\boldsymbol{C P U}$ e memória, do mod_jk e distribuidor respectivamente. Em seguida estão as tabelas de comparação entre a políticas round-robin do distribuidor e do mod_jk. As tabelas referentes à estrutura heterogênea englobam os testes da política round-robin para o distribuidor e $\mathbf{m o d} \_\mathbf{j k}$, busy e $\mathbf{M} \boldsymbol{M E}$ para $\mathbf{m o d} \_\mathbf{j k}$ e distribuidor respectivamente e round-robin ponderada para ambos mod_jk. As tabelas são apresentadas nessa seqüência e de menor para maior carga (1 a 3 clientes).

Considerando para as tabelas:
$\mathrm{X}$ : Distribuidor e Y: mod_jk
1) H0: $X=Y$ e H1: $X !=Y$
2) H0: $X>=Y$ e H1: $X<Y$
3) H0: $X<=Y$ e H1: $X>Y$ 

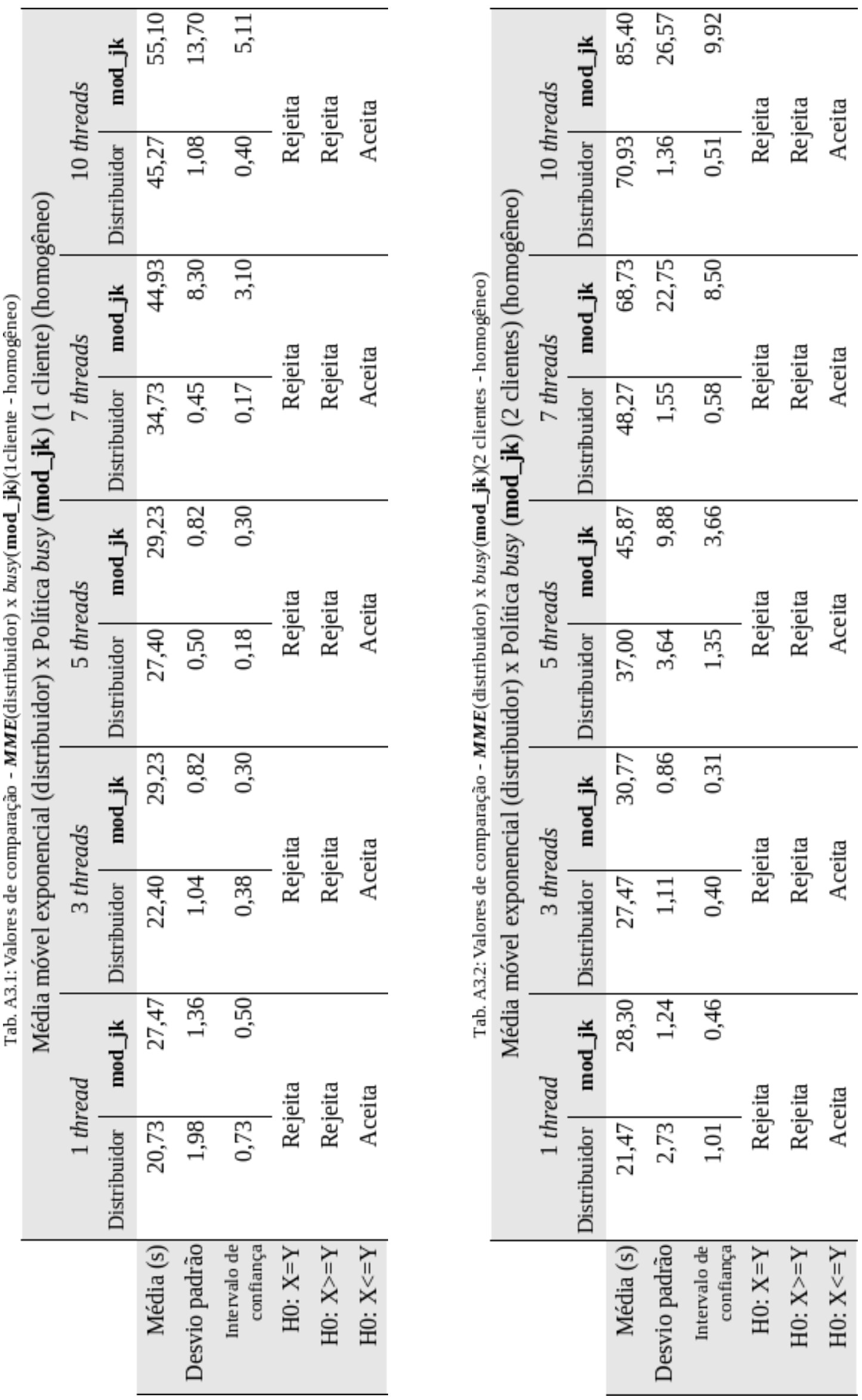

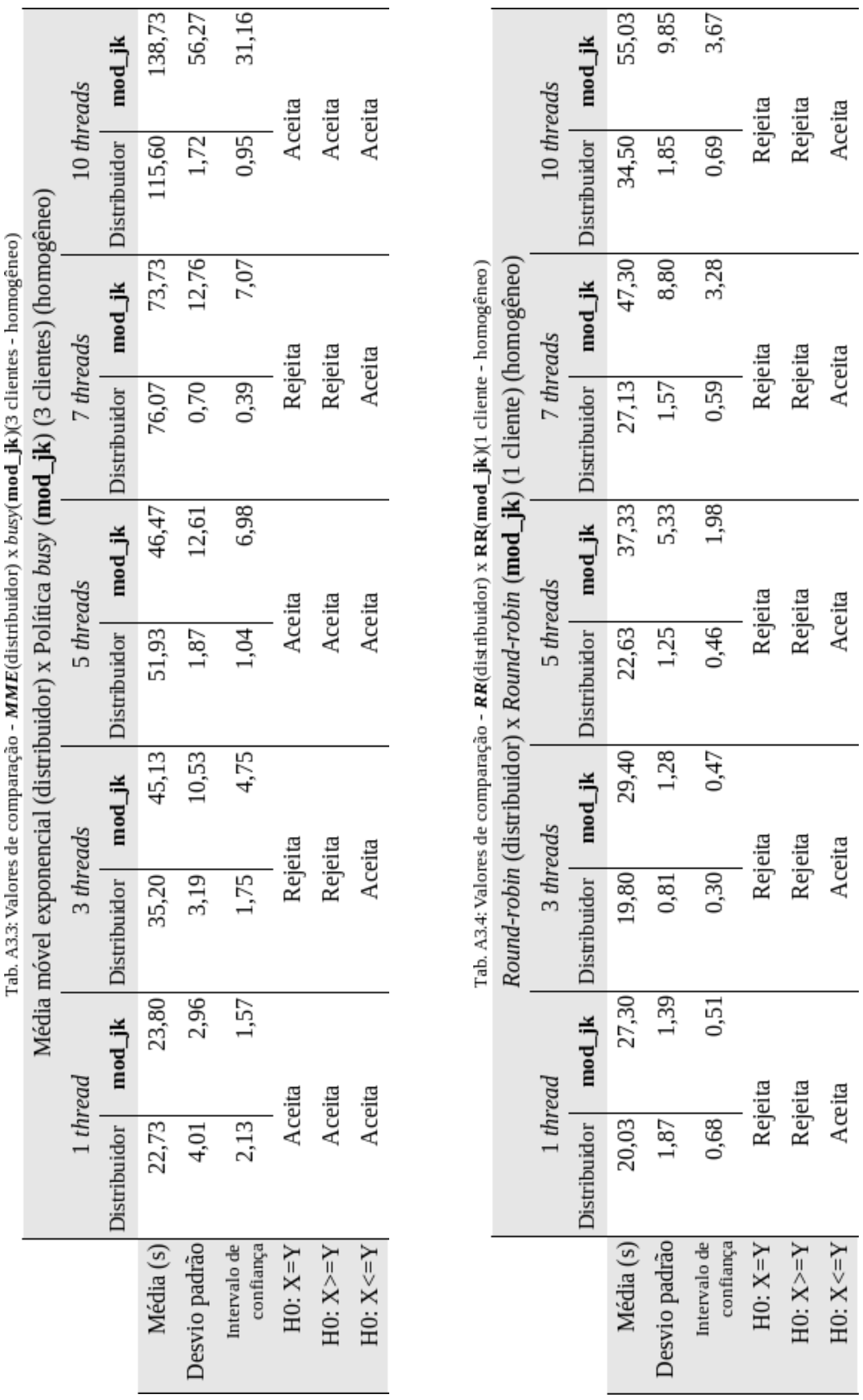
Anexo III
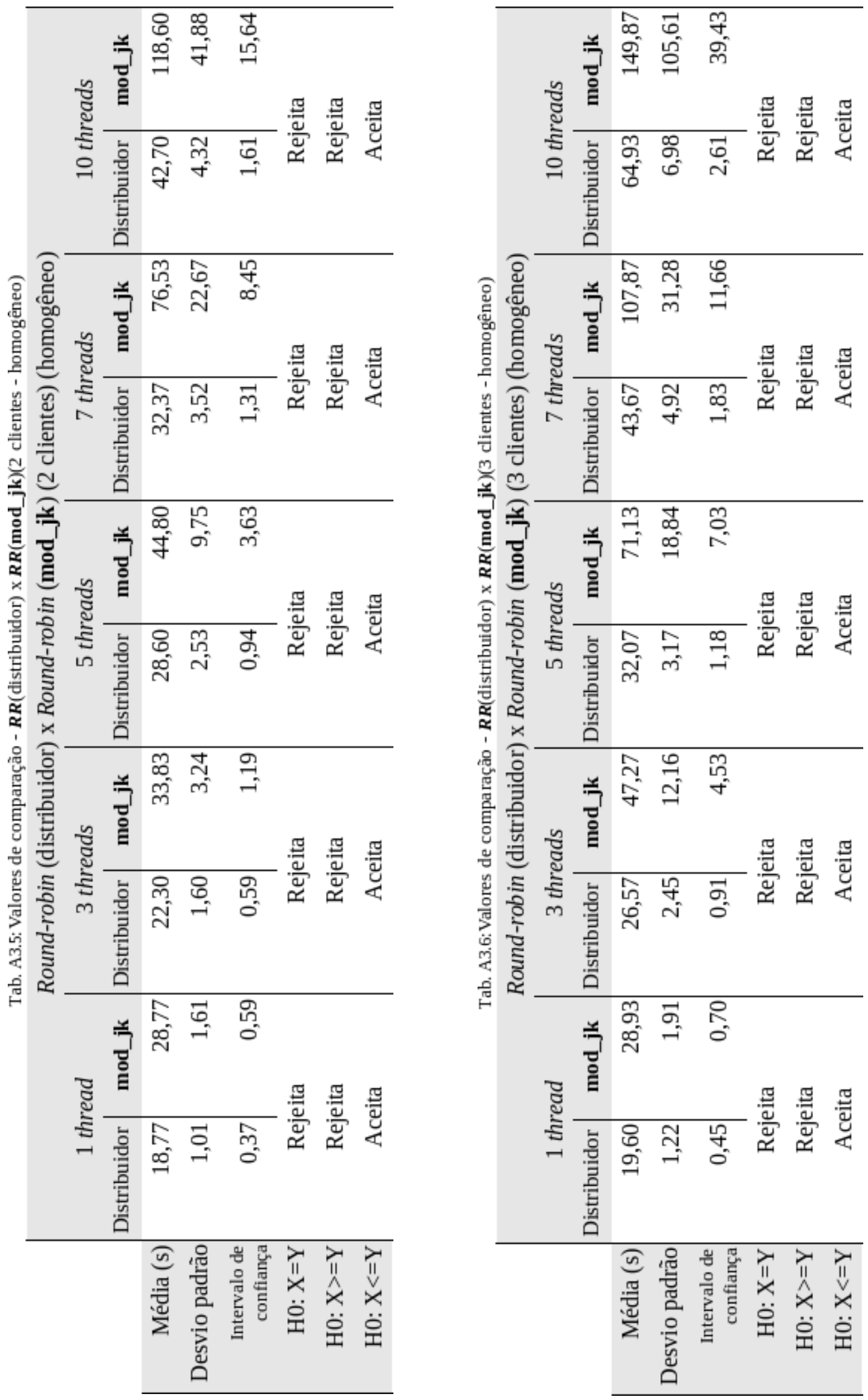

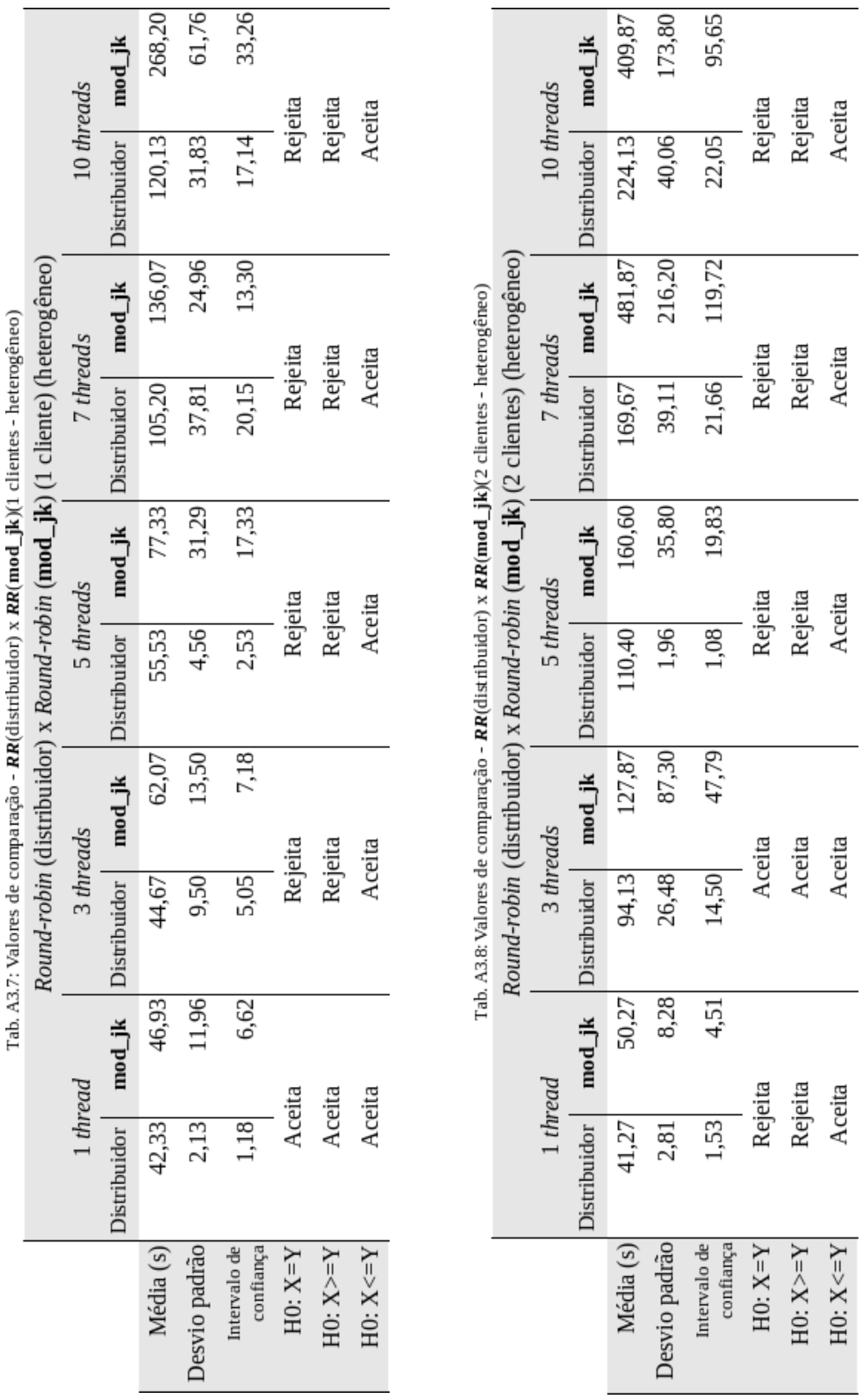
Anexo III
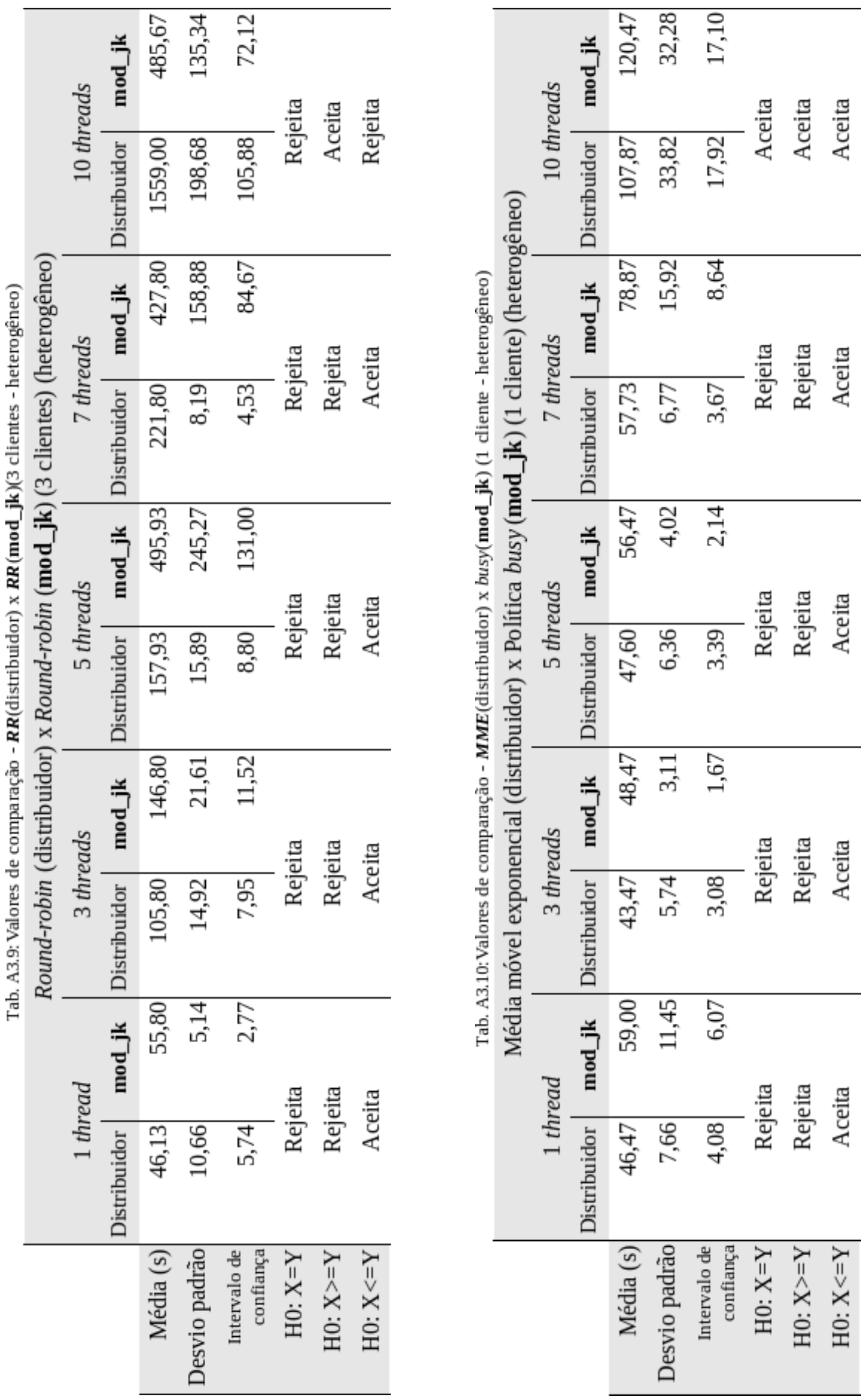
Anexo III
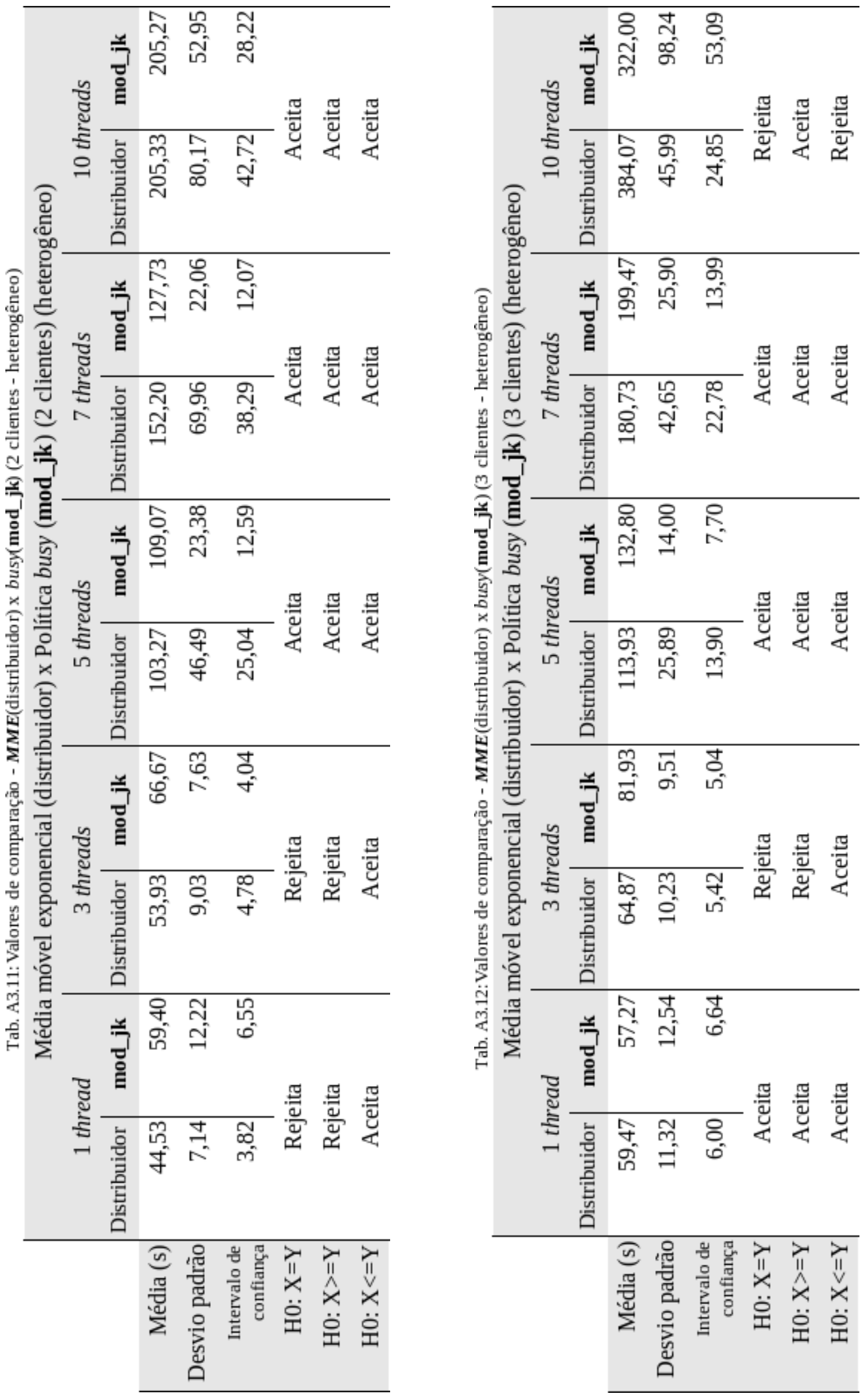
Anexo III
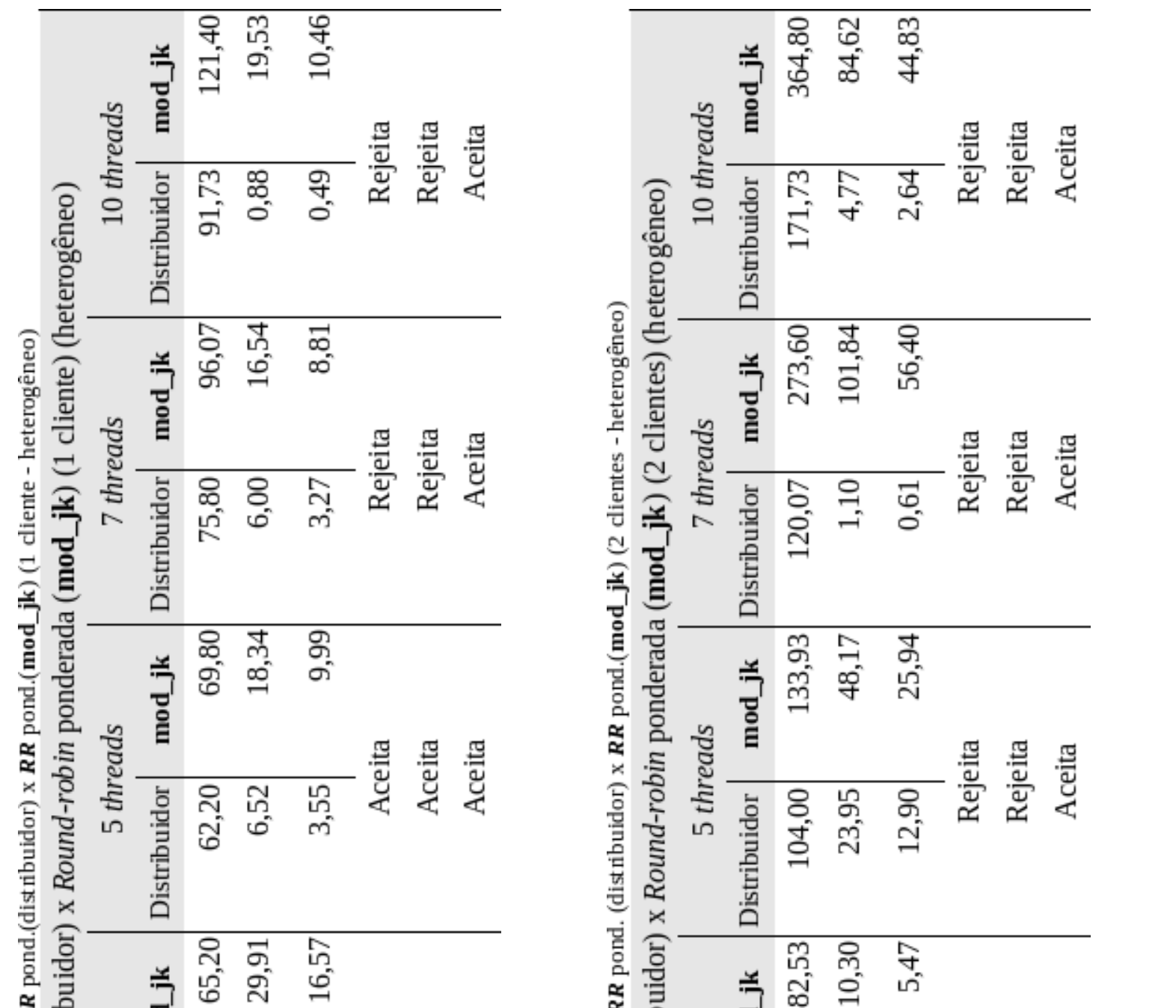

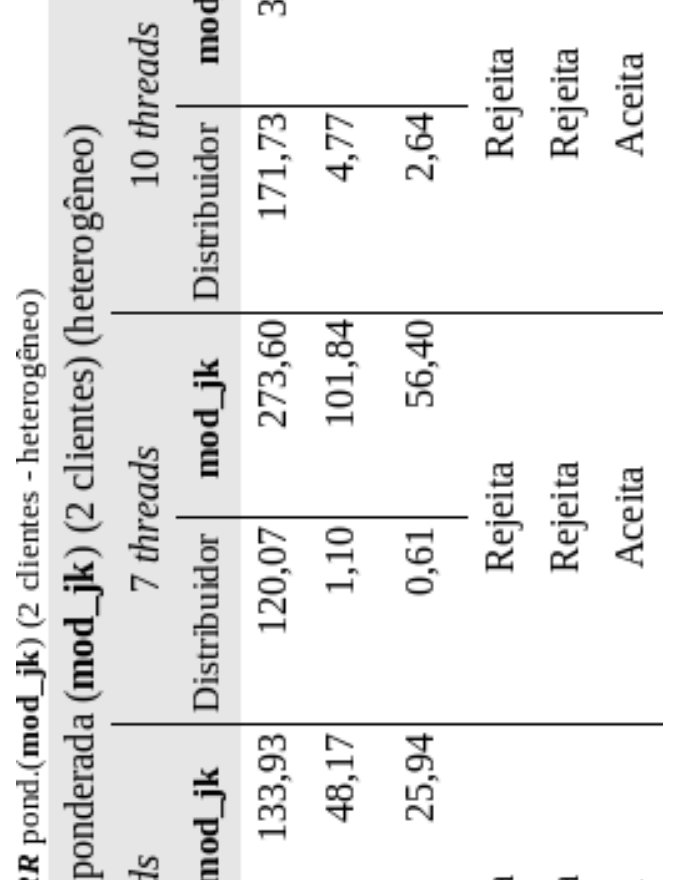

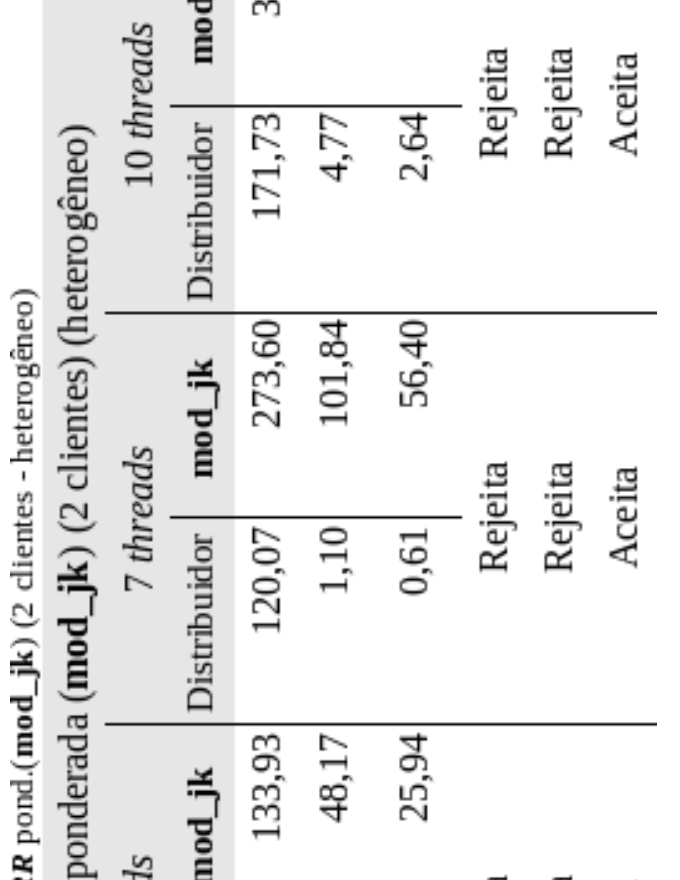

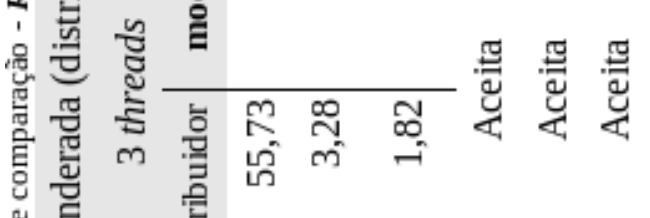

竞

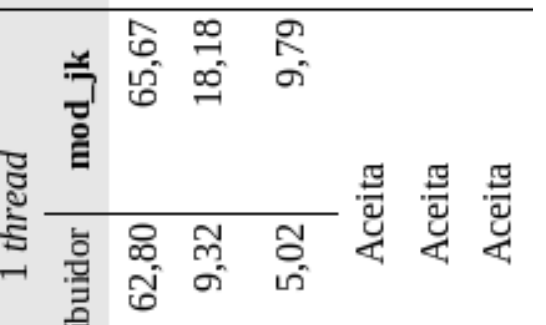

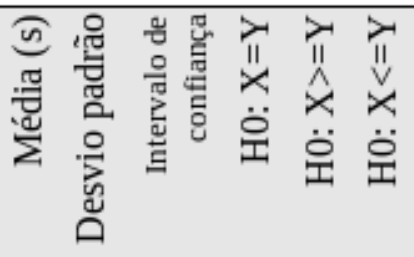

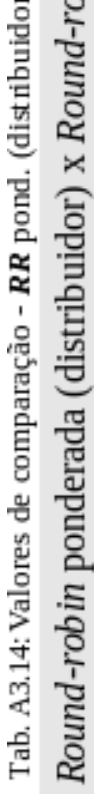

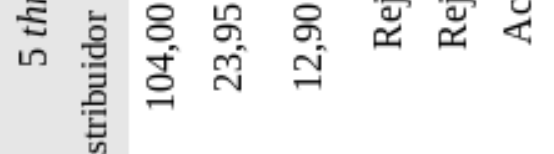

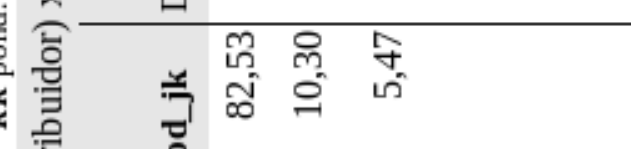

惫尊

m

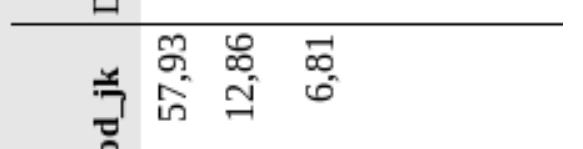

旁突

a

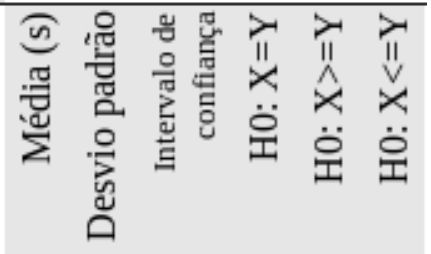


Anexo III
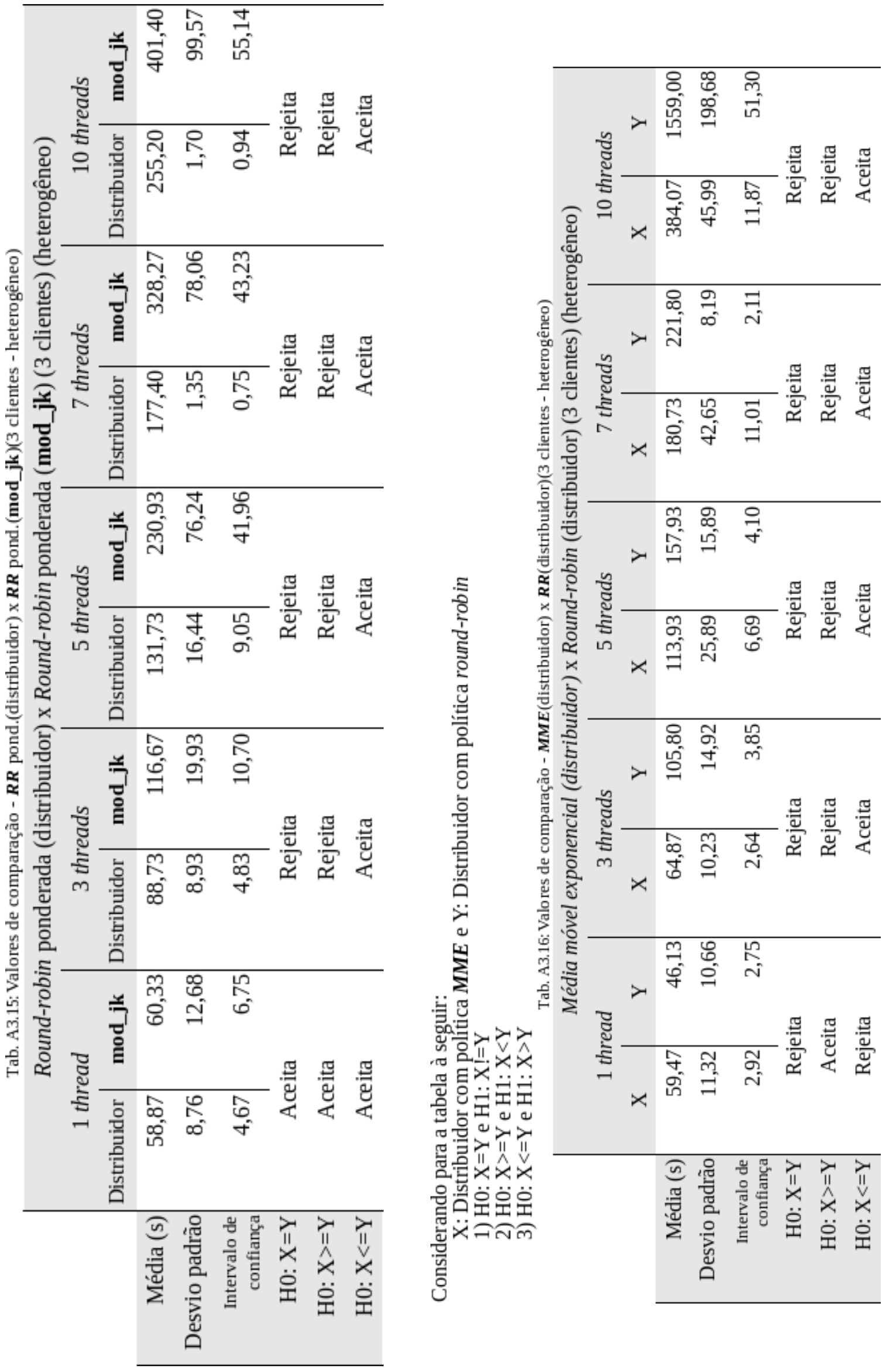



\section{Anexo IV}

Neste anexo são apresentados os gráficos para todas as execuções da aplicação comercial tanto na estrutura homogênea quanto heterogênea. Os gráficos incluem as execuções para 1, 2 e 3 clientes, não apresentadas no Capítulo 7, onde foram exibidos apenas os gráficos para a maior carga. A seqüência de aparição dos gráficos apresenta primeiro os gráficos para a estrutura homogênea e subseqüentemente para a heterogênea. No caso da estrutura homogênea é primeiro apresentada a comparação entre políticas round-robin do distribuidor e do mod_jk. Em seguida estão os gráficos da comparação entre a política busy e a política $\boldsymbol{M M E}$ (Média Móvel Exponencial), usando como métrica $\boldsymbol{C P U}$ e memória, do mod_jk e distribuidor respectivamente. Os gráficos da estrutura heterogênea englobam os testes da política round-robin para o distribuidor e mod_jk, busy e $\boldsymbol{M} \boldsymbol{M E}$ para mod_jk e distribuidor respectivamente e round-robin ponderada para ambos mod_jk e distribuidor. Os gráficos são apresentados nessa seqüência e de menor para maior carga (1 a 3 clientes).

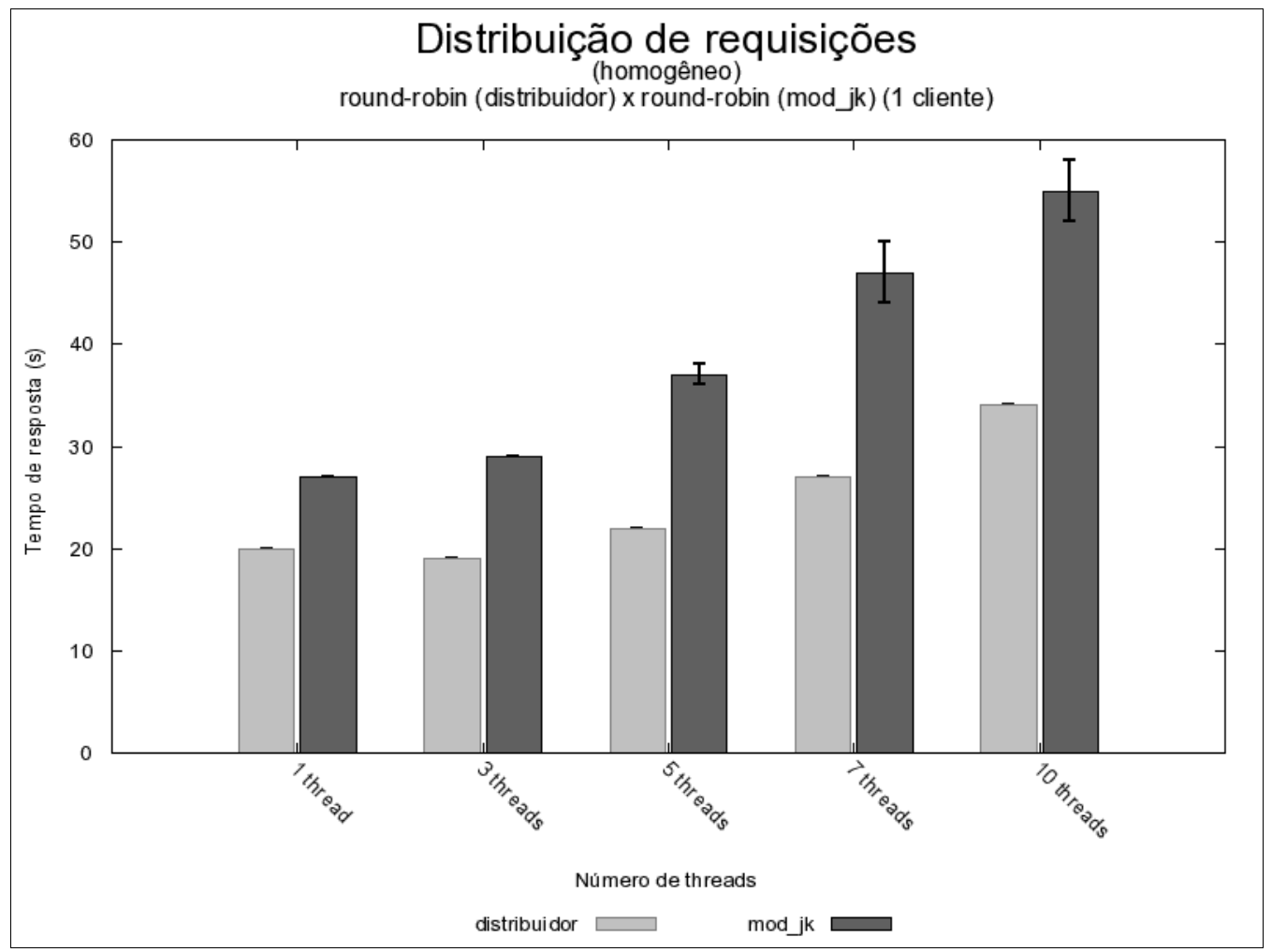

Fig. A4.1: $\boldsymbol{R} \boldsymbol{R}$ (distribuidor) x $\boldsymbol{R} \boldsymbol{R}$ (mod_jk) (1 cliente - homogêneo) 


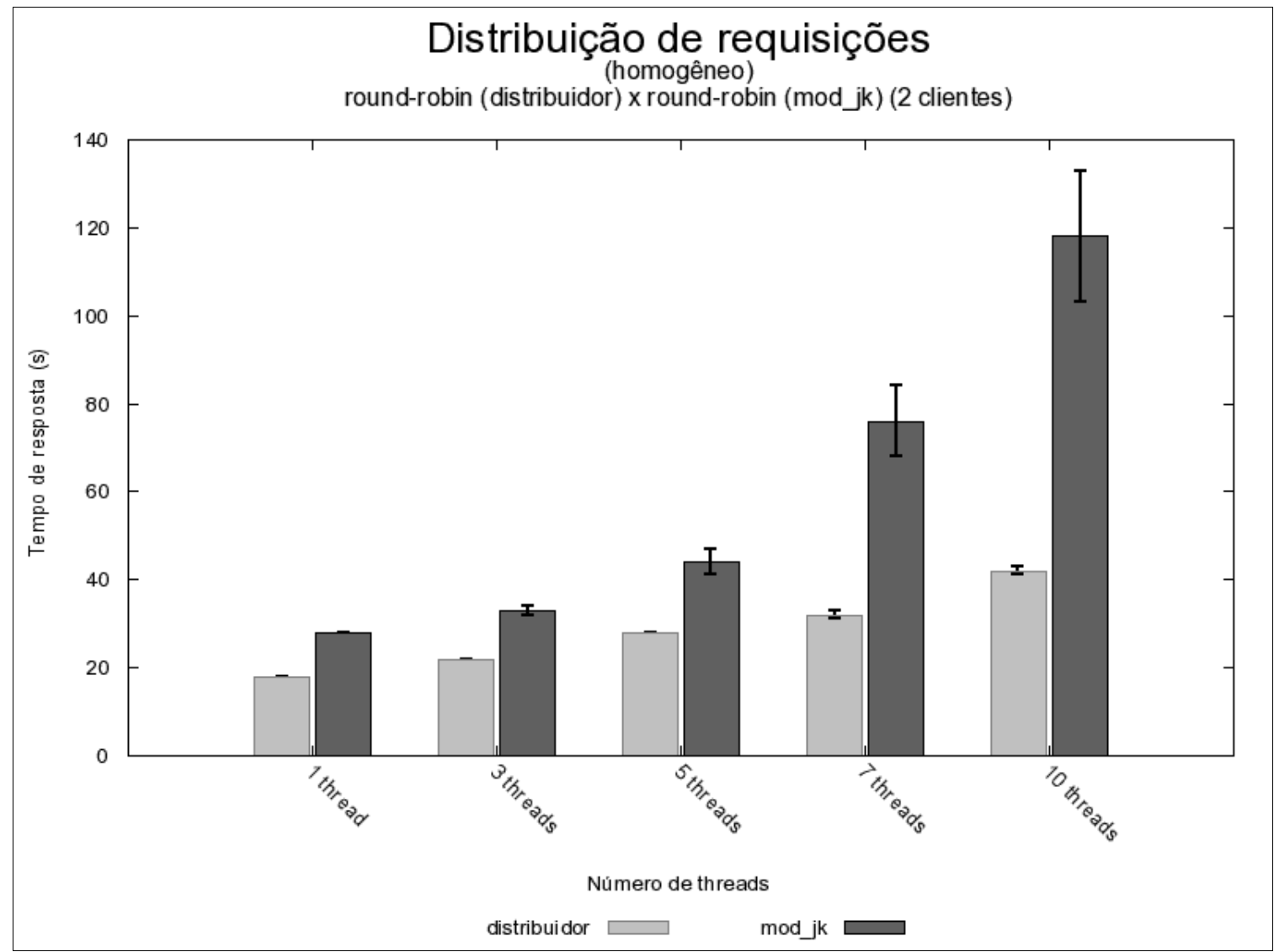

Fig. A4. 2: $\boldsymbol{R} \boldsymbol{R}$ (distribuidor) x $\boldsymbol{R} \boldsymbol{R}\left(\mathbf{m o d} \_j k\right)$ (2 clientes - homogêneo)

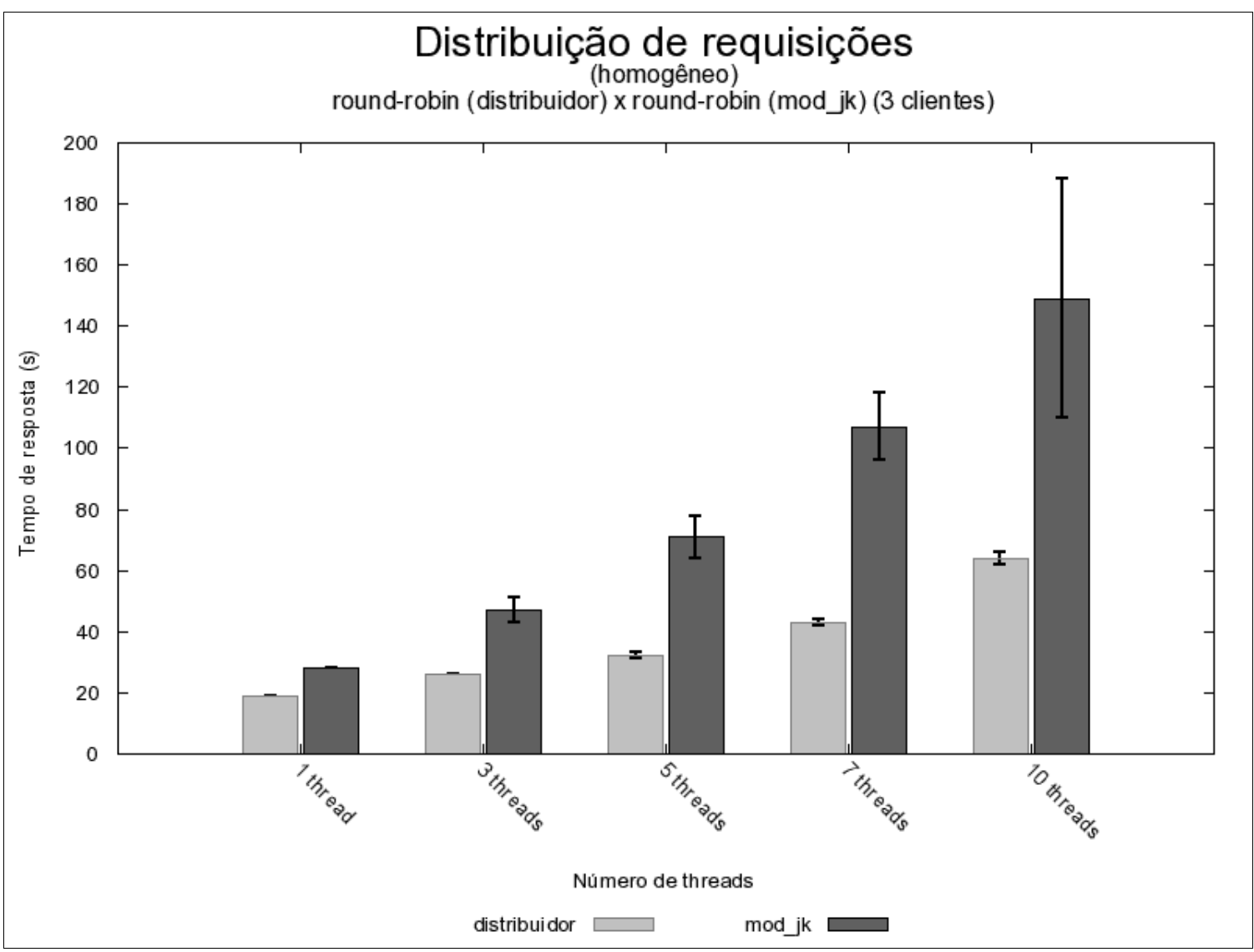

Fig. A4.3: $\boldsymbol{R} \boldsymbol{R}$ (distribuidor) x $\boldsymbol{R} \boldsymbol{R}$ ( $\left.\mathbf{m o d} \_j k\right)$ (3 clientes - homogêneo) 


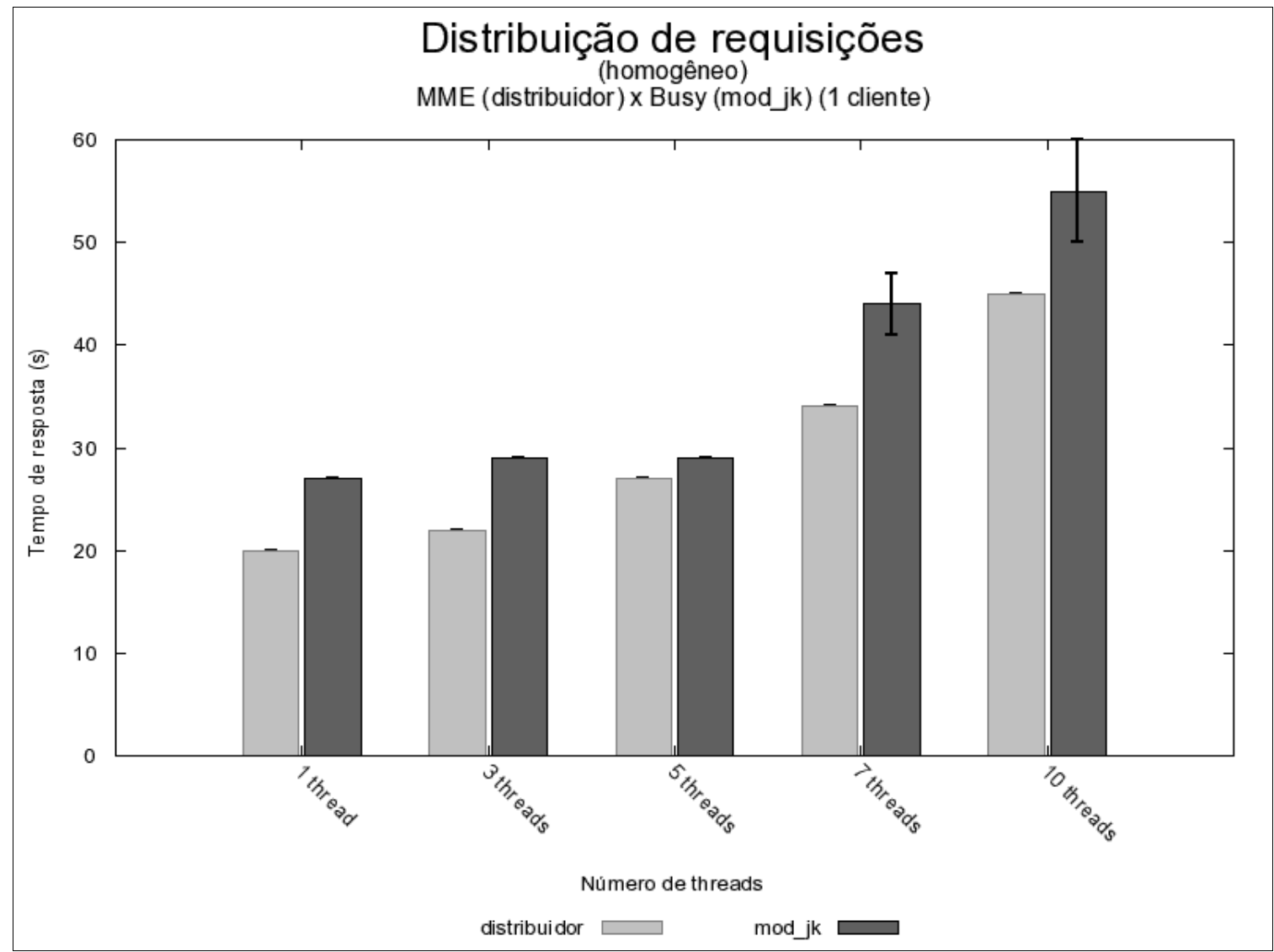

Fig. A4.4: $\boldsymbol{M} \boldsymbol{M E}$ (distribuidor) x busy (mod_jk) (1 cliente - homogêneo)

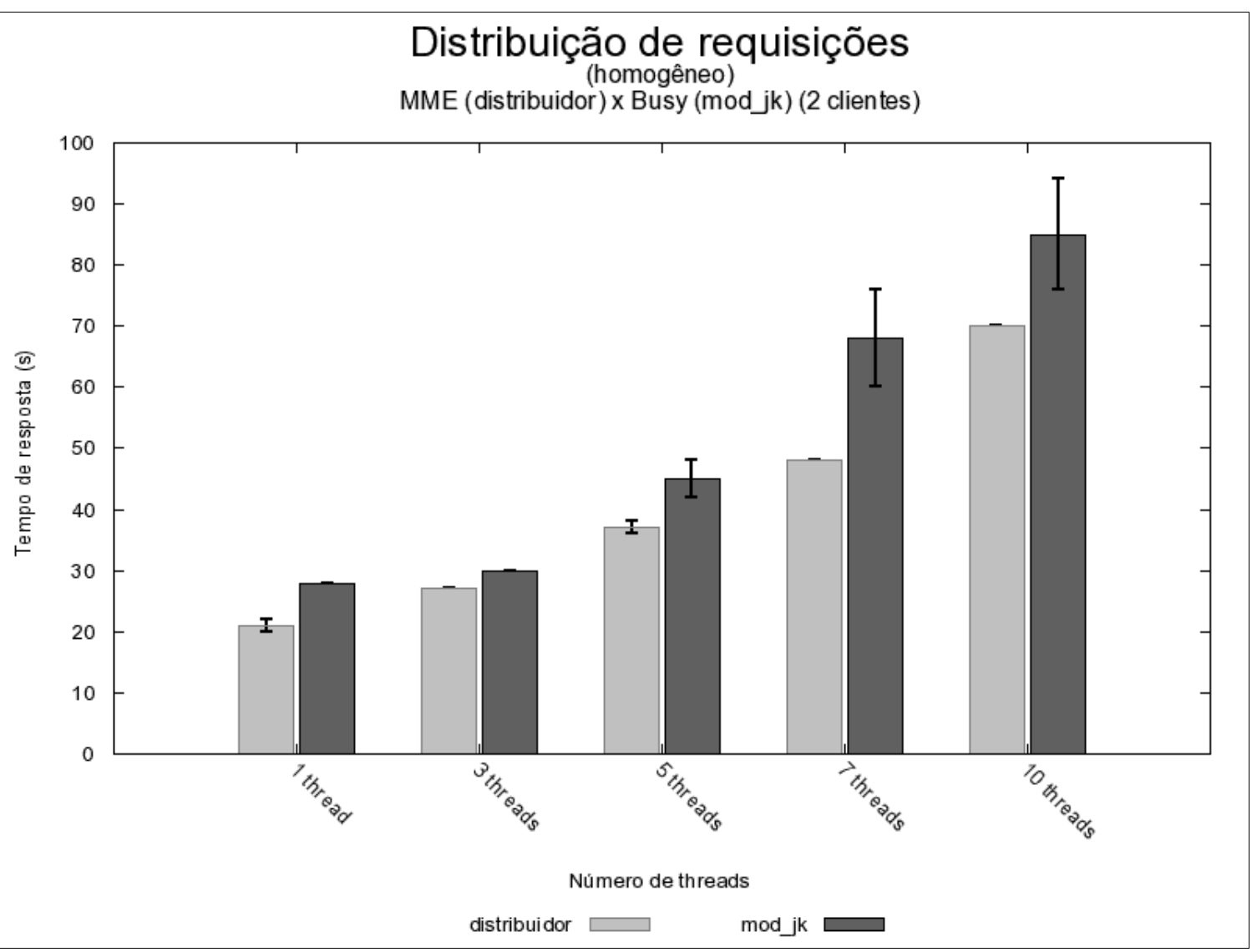

Fig. A4.5: $\boldsymbol{M} \boldsymbol{M E}$ (distribuidor) x busy (mod_jk) (2 clientes - homogêneo) 


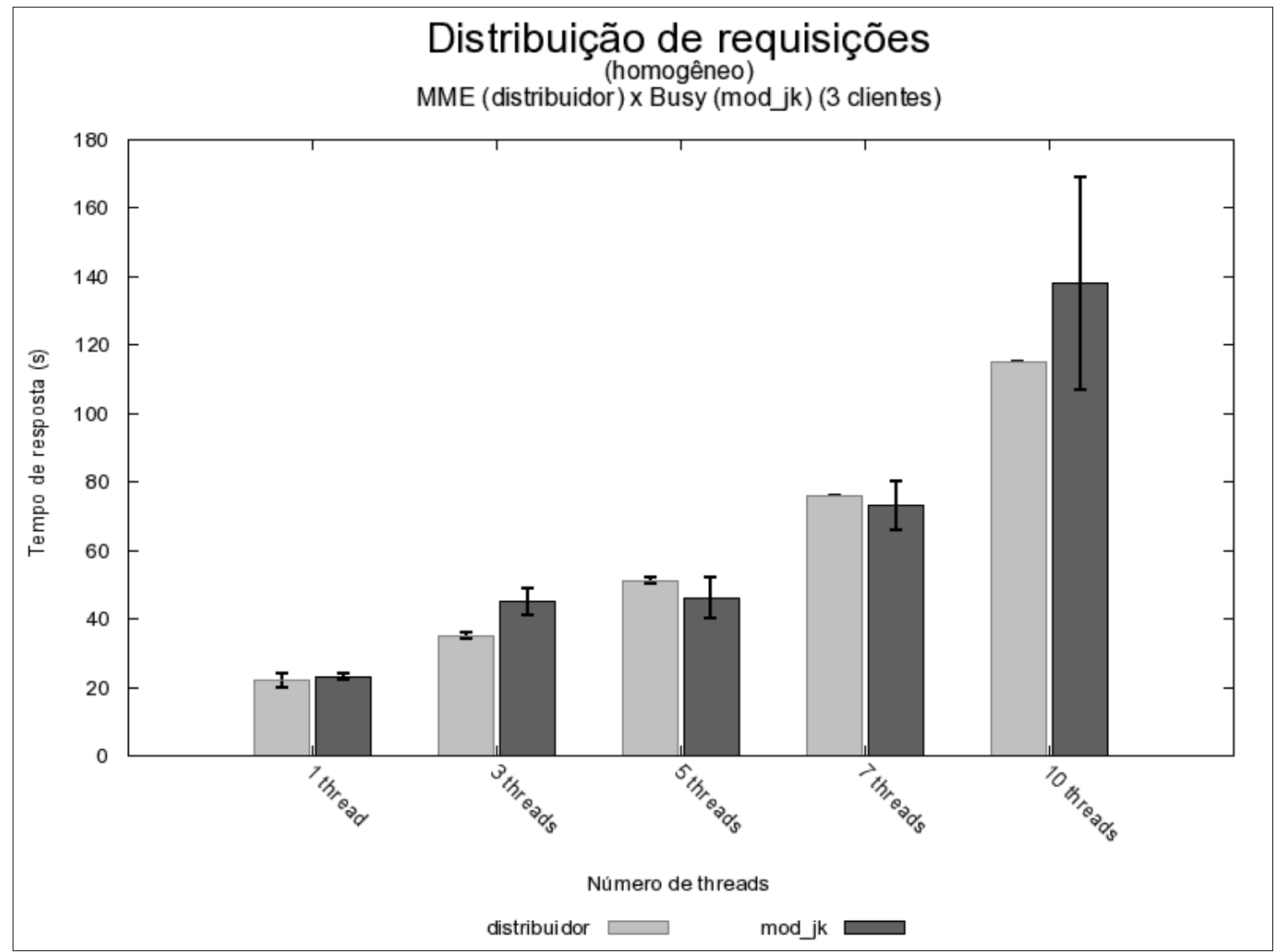

Fig. A4.6: $\boldsymbol{M M E}$ (distribuidor) x busy (mod_jk) (3 clientes - homogêneo)

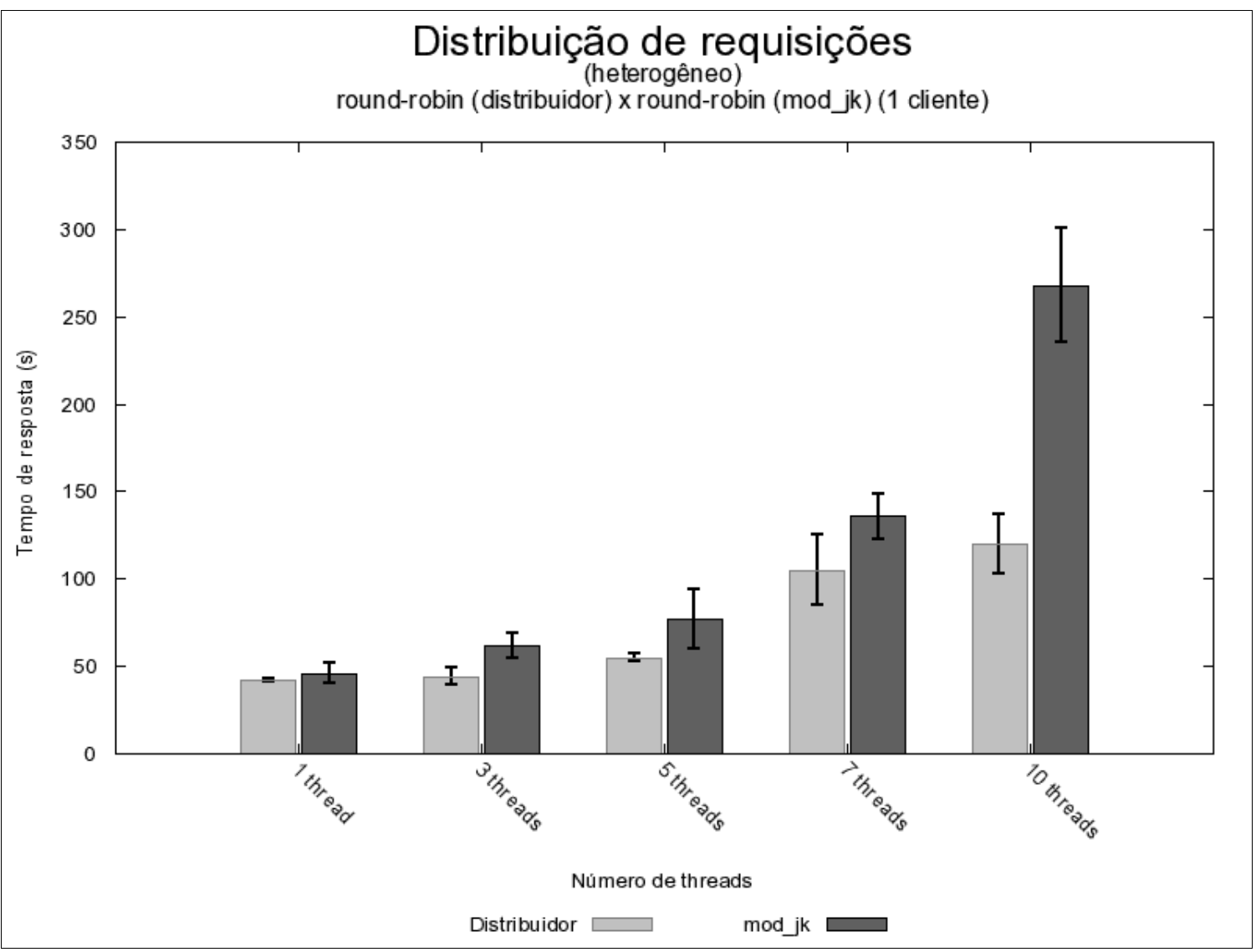

Fig. A4.7: $\boldsymbol{R} \boldsymbol{R}$ (distribuidor) x $\boldsymbol{R} \boldsymbol{R}$ (mod_jk) (1 cliente - heterogêneo) 


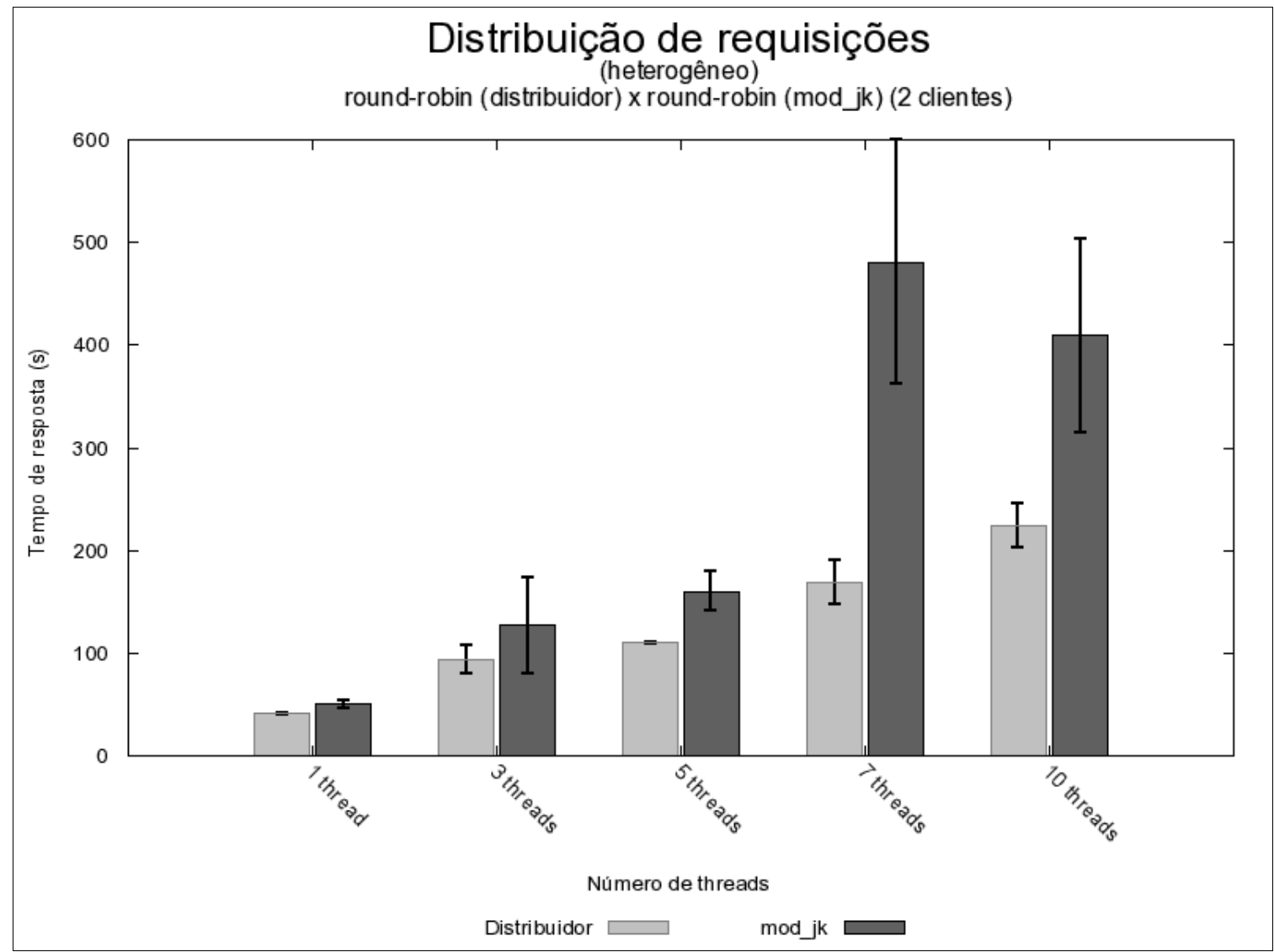

Fig. A4.8: $\boldsymbol{R} \boldsymbol{R}$ (distribuidor) x $\boldsymbol{R} \boldsymbol{R}$ ( $\left.\mathbf{m o d} \_j k\right)$ (2 clientes - heterogêneo)

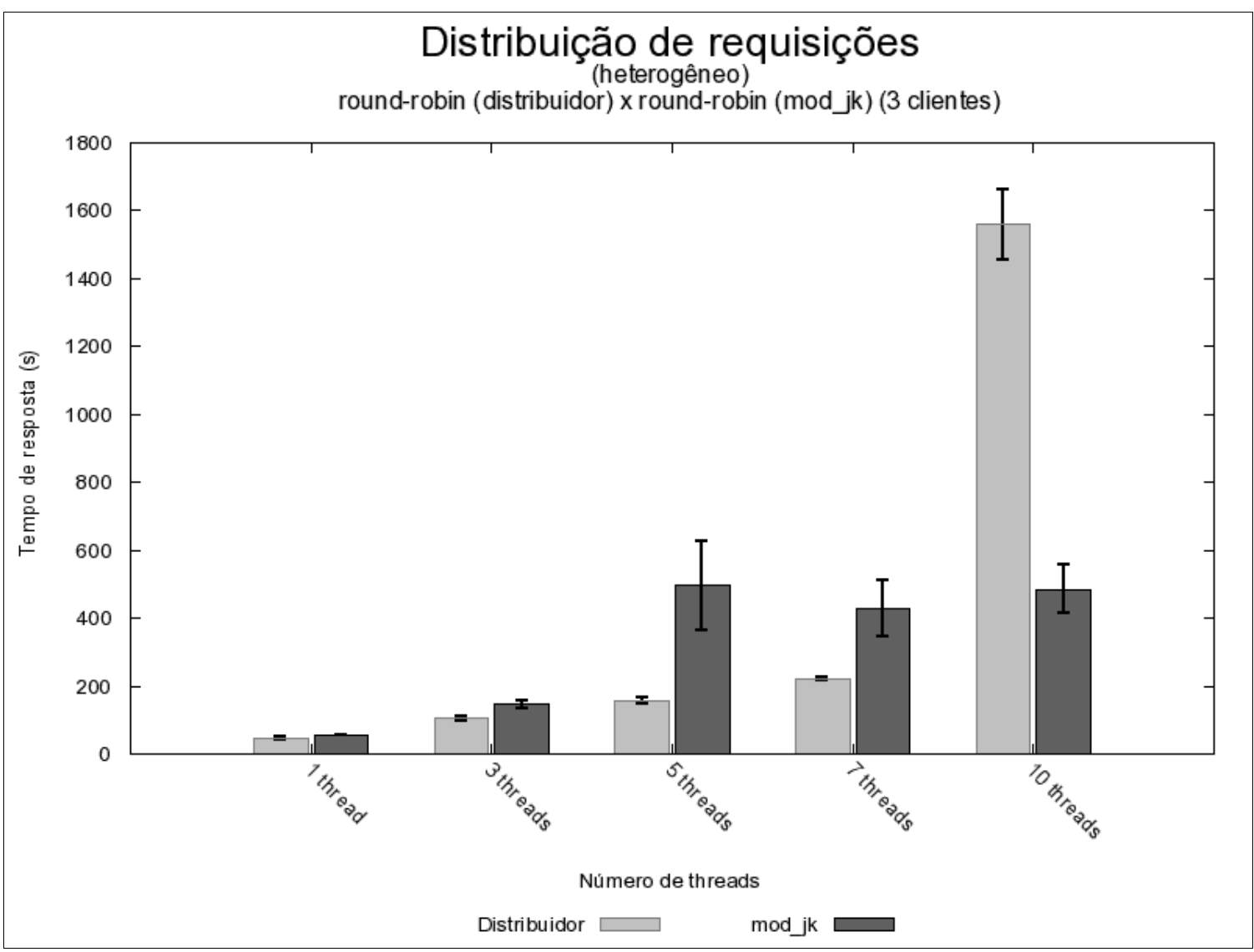

Fig. A4.9: $\boldsymbol{R} \boldsymbol{R}$ (distribuidor) x $\boldsymbol{R} \boldsymbol{R}$ ( $\mathbf{m o d}$ jjk) (3 clientes - heterogêneo) 


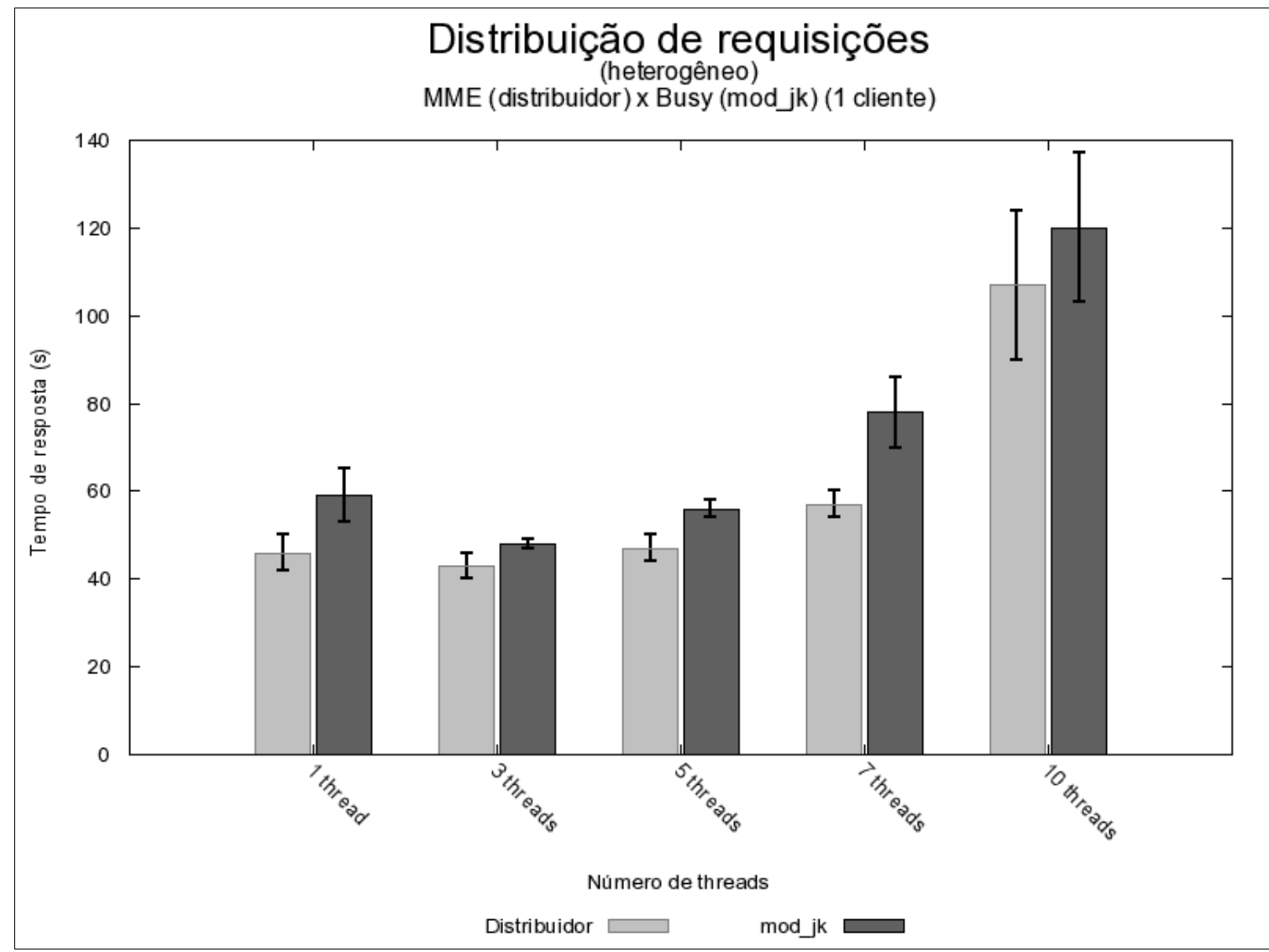

Fig. A4.10: MME (distribuidor) x busy (mod_jk) (1 cliente - heterogêneo)

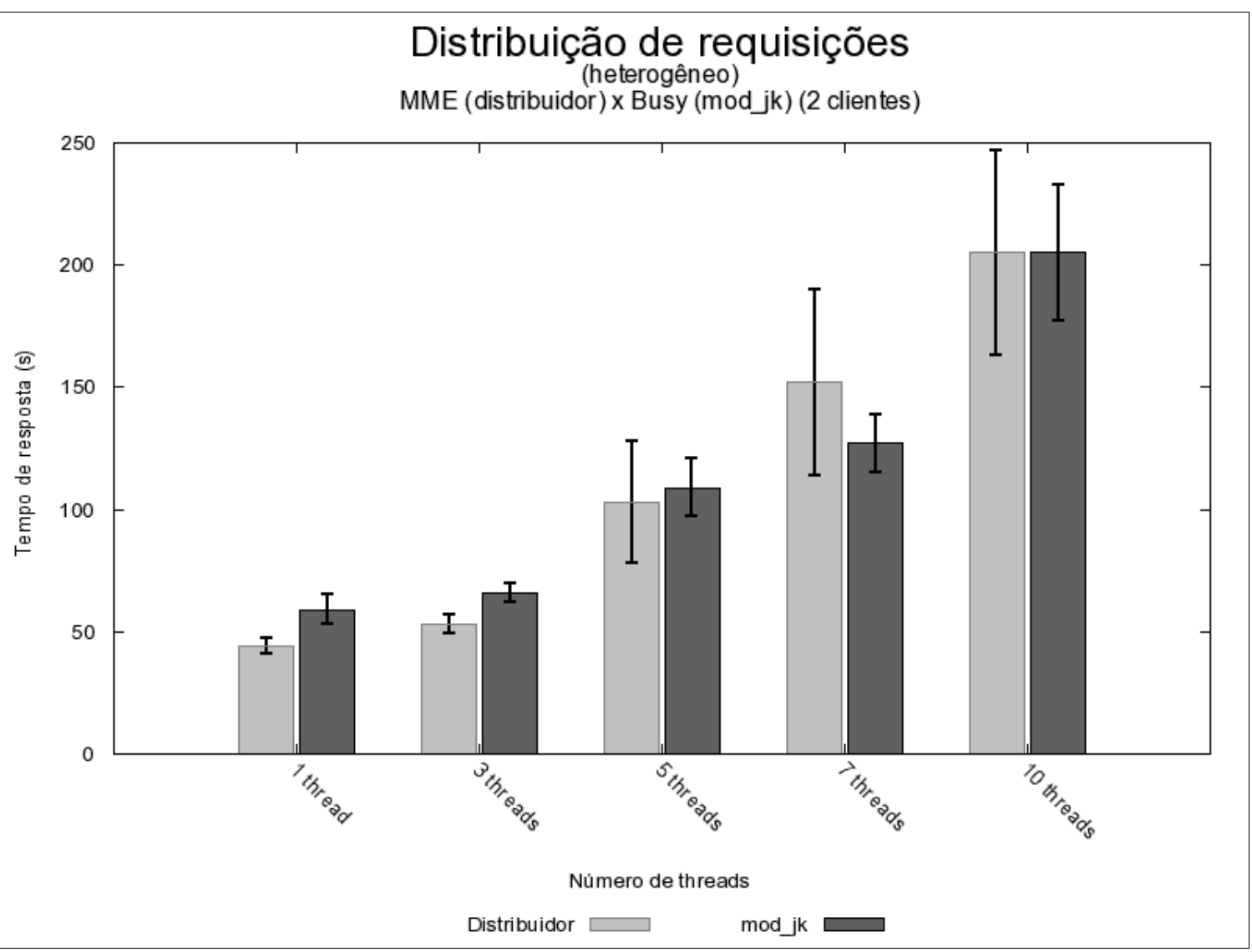

Fig. A4.11: MME (distribuidor) x busy (mod_jk) (2 clientes - heterogêneo) 


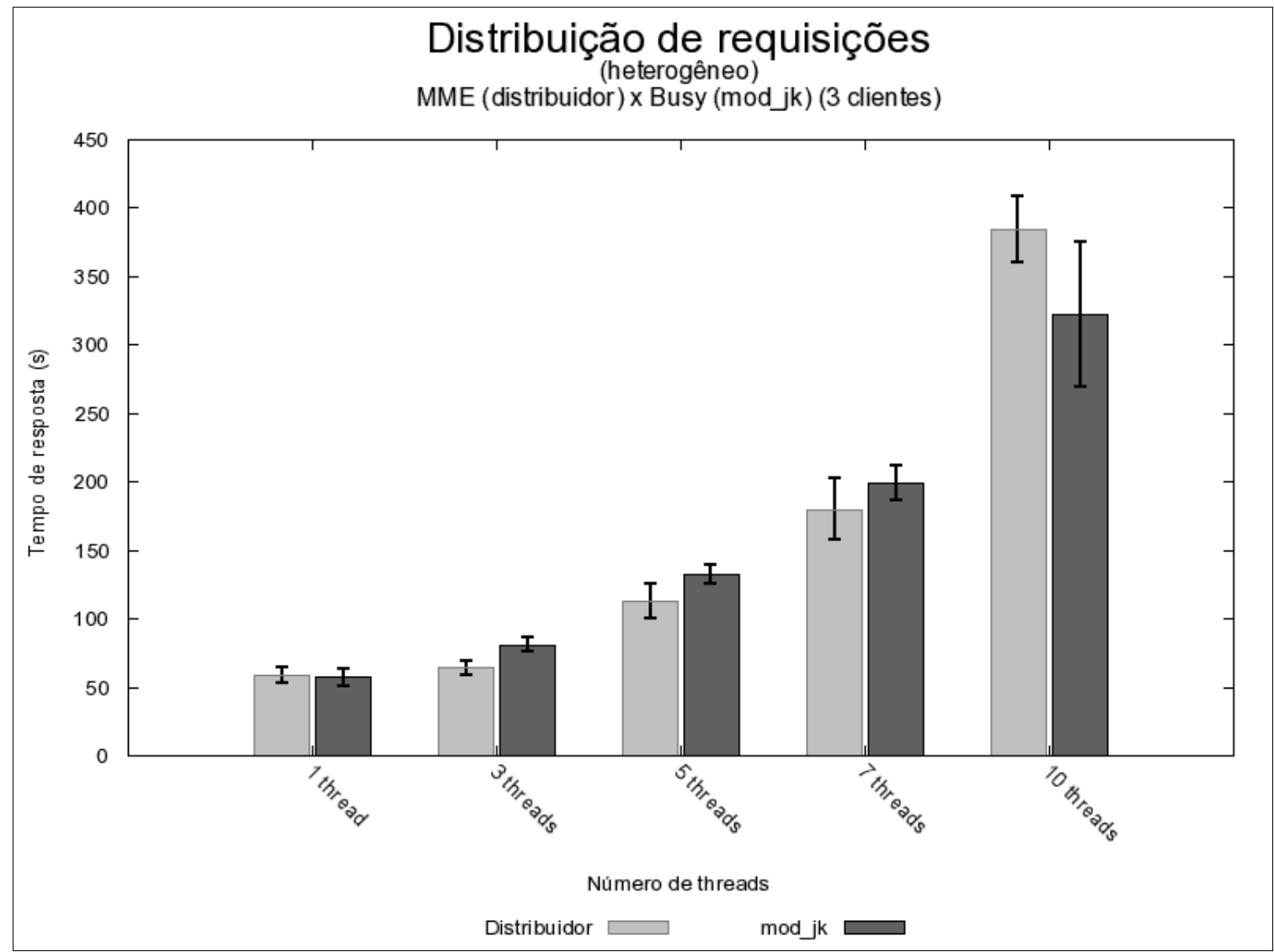

Fig. A4.12: MME (distribuidor) x busy (mod_jk) (3 clientes - heterogêneo)

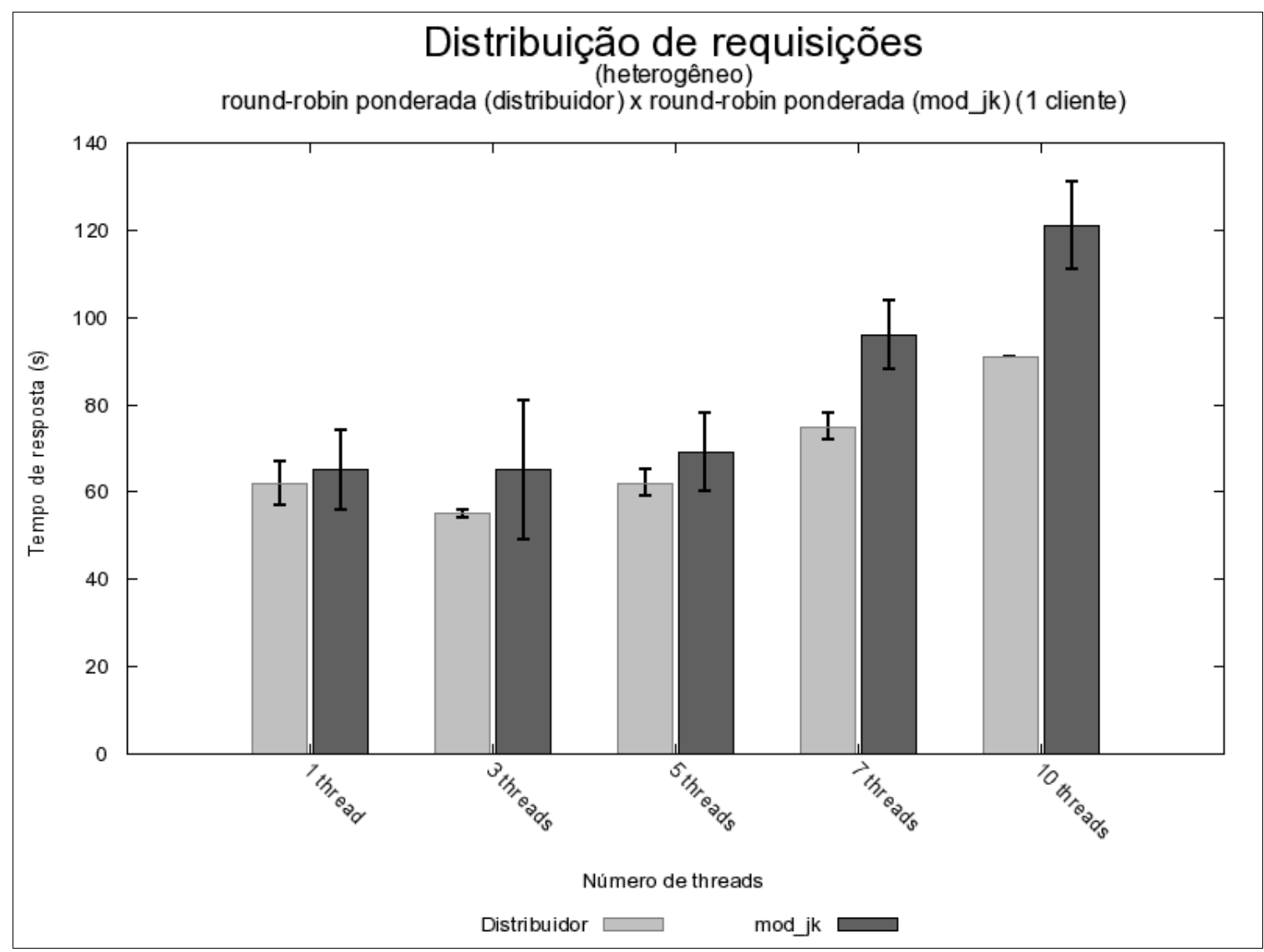

Fig. A4.13: $\boldsymbol{R} \boldsymbol{R}$ ponderada (distribuidor) x $\boldsymbol{R} \boldsymbol{R}$ ponderada (mod_jk) (1 cliente - heterogêneo) 


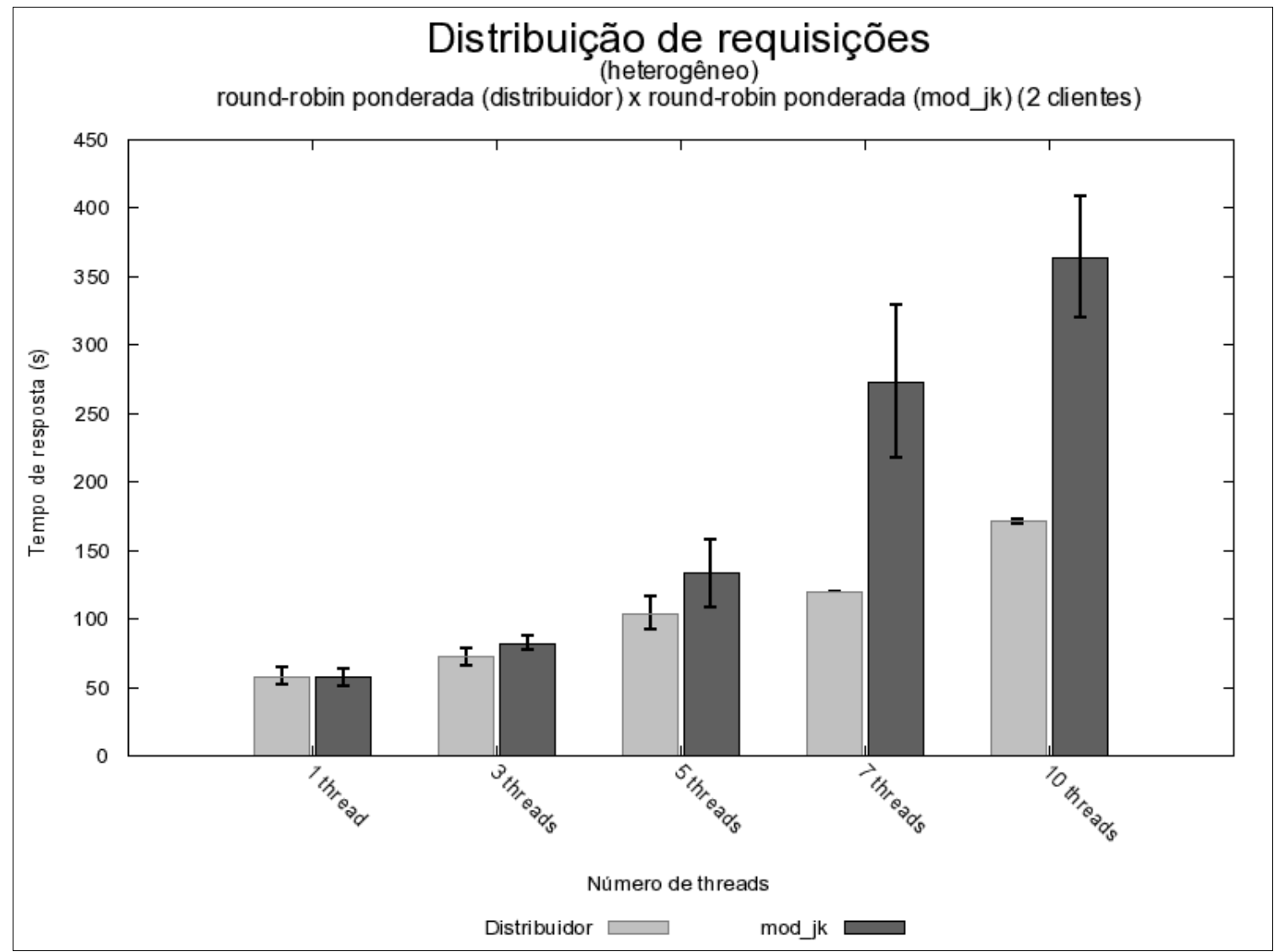

Fig. A4.14: $\boldsymbol{R} \boldsymbol{R}$ ponderada (distribuidor) x $\boldsymbol{R} \boldsymbol{R}$ ponderada ( $\mathbf{m o d} \_\mathbf{j k}$ ) (2 clientes - heterogêneo)

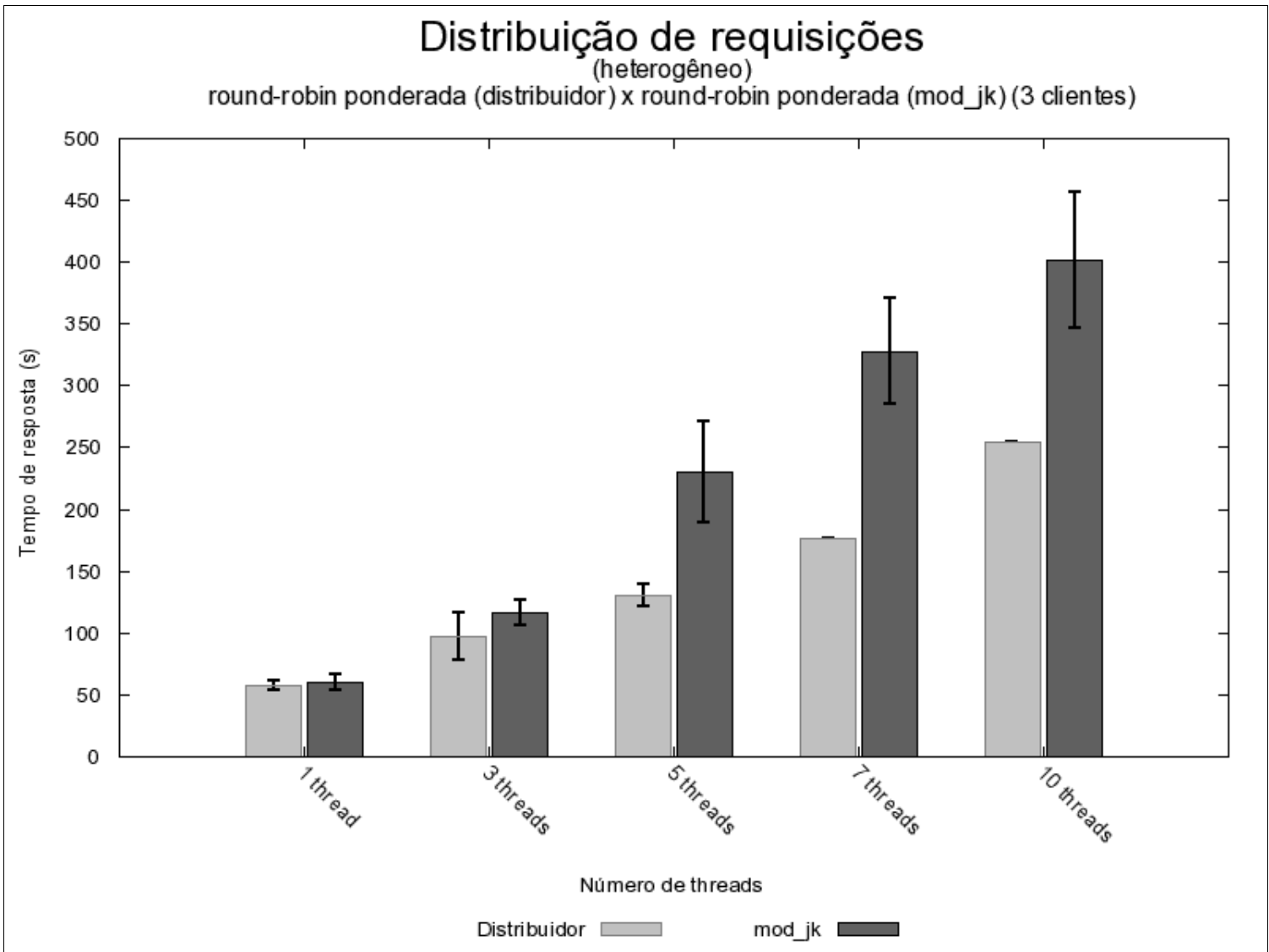

Fig. A4.15: $\boldsymbol{R} \boldsymbol{R}$ ponderada (distribuidor) x $\boldsymbol{R} \boldsymbol{R}$ ponderada ( $\mathbf{m o d} \mathbf{j} \mathbf{j k}$ ) (3 clientes - heterogêneo) 